Göttingen Series in Social and Cultural Anthropology

Gabriele Rosenthal (Ed.)

\title{
Established and Outsiders at the Same Time
}

Self-Images and We-Images of Palestinians in the West Bank and in Israel

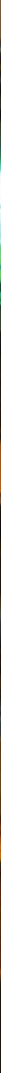



Gabriele Rosenthal (Ed.)

Established and Outsiders at the Same Time

This work is licensed under a Creative Commons Attribution-ShareAlike 4.0

International License.

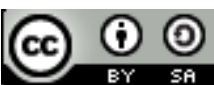


Published in 2016 by Göttingen University Press

as volume 8 in "Göttingen Series in Social and Cultural Anthropology"

This series is a continuation of "Göttinger Beiträge zur Ethnologie". 
Gabriele Rosenthal (Ed.)

Established and Outsiders at the Same Time

Self-Images and We-Images of

Palestinians in the West Bank

and in Israel

Volume 8

Göttingen Series in Social and Cultural Anthropology

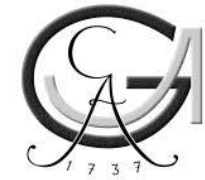

Göttingen University Press 2016 


\title{
Bibliographische Information der Deutschen Nationalbibliothek
}

Die Deutsche Nationalbibliothek verzeichnet diese Publikation in der Deutschen Nationalbibliographie; detaillierte bibliographische Daten sind im Internet über $<$ http://dnb.dnb.de $>$ abrufbar.

German edition published in 2015 by Campus, Frankfurt/M.:

Etablierte und Außenseiter zugleich. Selbst- und Fremdbilder in den palästinensischen Communities im Westjordanland und in Israel. Hg. von Gabriele Rosenthal.

\author{
"Göttingen Series in Social and Cultural Anthropology" Editors \\ Prof. Dr. Elfriede Hermann \\ Prof. Dr. Andrea Lauser \\ Prof. Dr. Roman Loimeier \\ Prof. Dr. Nikolaus Schareika \\ Institute of Social and Cultural Anthropology \\ Georg-August-Universität Göttingen \\ Theaterplatz 15 \\ D-37073 Göttingen
}

This work is protected by German Intellectual Property Right Law.

It is also available as an Open Access version through the publisher's homepage and the Göttingen University Catalogue (GUK) (http:/ / www.sub.uni-goettingen.de).

The license terms of the online version apply.

Translated by Ruth Schubert

Set and layout: Steffen Herrmann

Cover design: Friedlind Riedel

Cover picture: Johannes Becker: Old City of Jerusalem

(C) 2016 Göttingen University Press

http:/ / univerlag.uni-goettingen.de

ISBN: 978-3-86395-286-0

ISSN: $2199-5346$ 


\section{Contents}

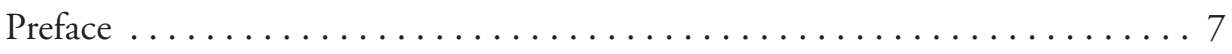

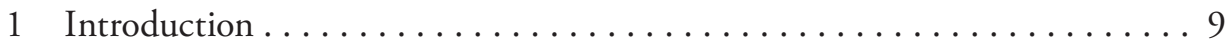

Gabriele Rosenthal

\section{Voices from the West Bank}

2 We-images and collective memories in the West Bank ........... 17 Gabriele Rosenthal

3 On the brittleness of the homogenizing we-discourse:

Christians in Bethlehem and Ramallah . . . ................ 31

Hendrik Hinrichsen, Johannes Becker, Gabriele Rosenthal

4 The homogenizing we-discourse and the social positioning of the refugee camps ........................ 45

Arne Worm, Hendrik Hinrichsen, Ahmed Albaba

5 The way outsiders speak: Counter discourses, self- and we-images of stigmatized gay men in the West Bank . . . . . . . . . . . . 67 Arne Worm, Hendrik Hinrichsen

6 Voices of former political prisoners and their families in the West Bank . 87 Gabriele Rosenthal, Ahmed Albaba 


\section{Voices from East Jerusalem}

7 Palestinians in East Jerusalem . . . . . . . . . . . . . . . . . . . 111 Johannes Becker, Arne Worm

8 Commitment to the Old City and ambivalent emplacement ....... 125 Johannes Becker

\section{Voices from Israel}

9 Palestinians in Israel . . . . . . . . . . . . . . . . . . . . . . . . . . . . . . 149 Nicole Witte

10 Palestinian voices from Haifa . . . . . . . . . . . . . . . . . . . . . 159 Nicole Witte

11 Being Palestinian in Jaffa: How Druze and Bedouin Israeli women

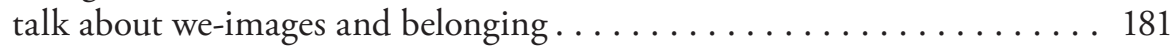
Rixta Wundrak

Glossary ...................................... 203

Transcription symbols $\ldots \ldots \ldots \ldots \ldots \ldots \ldots \ldots \ldots \ldots \ldots \ldots \ldots \ldots$

About the authors .............................. 215

Bibliography ............................... 217 


\section{Preface}

This book is the result of research and fieldwork carried out between 2010 and 2015 by a team of German, Palestinian and Jewish-Israeli social scientists. It is a study of Palestinians and Israelis in different established and outsider figurations in the West Bank and in Israel. ${ }^{1}$

We are deeply grateful to the many people in Palestine and Israel who were willing to be interviewed and to give us insights into their lives and their personal histories. Without their support our research and this book would not have been possible. We cannot mention them by name for reasons of data protection. All names and personal data of the people we interviewed, and of their relatives and friends, have been changed in order to ensure that they cannot be identified.

We would also like to express our thanks to all colleagues who, in addition to the authors of the articles in this volume, gave time to participate in our project by conducting interviews and making initial analyses of the data. These include Mariam Abdul Dayem (Tel Aviv), Eva Bahl (Göttingen), Zeina Barakat (Jerusalem), Amany Bawardy (Nazareth), Michal Beckenstein (Tel Aviv), Khansaa Diab (Jerusalem), Isabella Enzler (Göttingen), Filip Habib (Berlin), Yahya Hijazi (Jerusalem), Tal LitvakHirsch (Be'er Sheva), Adi Mana (Be'er Sheva), Serene Mjally-Knani (Be'er Sheva), Majd Qumsieh (Bethlehem), Amina Rayan (Berlin), Sveta Robermann (Jerusalem), Aida Saifi (Jerusalem), and Anan Srour (Jerusalem).

Our special thanks for their help and support go to those Palestinians from the West Bank who do not want to be named here because of the boycott of Israeli uni-

\footnotetext{
${ }^{1}$ The trilateral research project Belonging to the Outsider and Established Groupings: Palestinians and Israelis in Various Figurations was funded by the German Research Foundation (DFG) from February 2010 to October 2015. The other project leaders, in addition to the editor, were Prof. Shifra Sagy (Ben-Gurion University of the Negev, Be'er Sheva, Israel) and Prof. Mohammed S. Dajani Daoudi (East Jerusalem).
} 
versities which has been joined by all academic institutions in the West Bank, and the rejection of any kind of cooperation with Jewish-Israeli scholars and institutions which intensified during the period of our project. According to the guidelines for the boycott ${ }^{2}$ collaboration with Israeli academic institutions - but not automatically with their members as individual scholars or persons - must be rejected because academic bi- and multilateral projects are based on the false premise of symmetry "between the oppressors and the oppressed", "colonizers and colonized" and are therefore "intellectually dishonest and morally reprehensible forms of normalization".

Although each chapter of this volume appears under the name of the main author or authors, both the analysis and interpretation of empirical findings and the formulation of 'theoretical' syntheses are the result of discussions by the whole team.

\footnotetext{
${ }^{2}$ http://www.pacbi.org/etemplate.php?id=1108, 29.04.2015.
} 


\title{
$1 \quad$ Introduction $^{1}$
}

\author{
Gabriele Rosenthal
}

In Israel I have repeatedly found that, without any prompting, people will inform my colleagues and me of their opinion concerning 'the Arabs' in the country a Jewish taxi driver in West Jerusalem, for instance, on being asked to drive to East Jerusalem. Their remarks are often extremely unfriendly, highly prejudiced and indiscriminate. But sometimes they add the comment: "The Christians are a bit different."

This division of the Palestinians into 'Arabs' and 'Christians' reflects two essential features of discourses on 'the Palestinians' that are often heard in Israel, in everyday situations, in the media, or in political and academic contexts. On the one hand, a very broad, generalized and homogenized image of 'the Arabs' is created - a standardized they-image, to borrow a term from Norbert Elias. ${ }^{2}$ On the other hand, a distinction is made between Arabs and Christians, which excludes Christian Palestinians from the general category of Palestinians.

In other words the they-image of the Palestinians in the dominating discourses in Israel is homogenizing, highly generalising and divisive at the same time. Here

\footnotetext{
${ }^{1}$ A glossary is provided at the end of this volume to explain the most important concepts relating to the Palestinians' collective history up to the present day. The terms included in the glossary are indicated in the text by an arrow $(\rightarrow)$.

${ }^{2}$ The we-image always also contains an image of the other group or groupings in a figuration of human groupings. We-images and they-images are mutually dependent - they are closely intertwined. On the connection between we-image and we-ideal, and between them and an individual's selfimage, see Elias / Scotson (2008: esp. 27ff., 134ff.). For the terms "they-group" and "they-image" cf. ibid.: 28, 31).
} 
it must be remembered that one of the typical sources of power of the established is that they are in a position to divide society effectively into social groupings, and thus to define who belongs to a 'minority' and who does not, or how 'minorities' are defined in the first place. It goes without saying that they do not do this without serving their own interests, in the sense of divide et impera. The 'Arab Israelis', as they are categorized in the official language of Israel without any reference to their selfdefinition, constitute approximately 20 percent of the population and are referred to as a 'minority' in media, everyday, political and academic discourses (see Kook 2002: 66ff.). By contrast, many smaller groupings of Jewish Israelis - from very different parts of the world - belong, according to this definition, to the Jewish 'majority'.

A further decisive factor is that Jews of Arab origin are not regarded as belonging to the grouping of Arab Israelis. However, in the past few years the discourse on this has become more and more open and some Jewish Israelis whose families originate from Arab countries now position themselves in the media and in academic discourses as Arab Jews (see Shenhav 2006; Shohat 1999³), while in administrative contexts and in the hegemonial public discourses non-Jewish 'Arab' Israelis are subdivided into different ethnic and religious groupings. The ID cards of Israeli citizens issued by the Israeli government have not contained any direct indication of ethnic or religious affiliation since $2005,{ }^{4}$ yet the divisive policies towards Christians and Muslims have become intensified in recent years. Thus, in February 2014 a law was passed in the Israeli parliament, the Knesset, which for the first time defines Christian Arabs as a specific minority. In addition, and related to this, there are increasing debates within Israel on whether Christian-Israeli Palestinians should be conscripted for Israeli military service (see McGahern 2011; Newman 2014).

A further form of segregation is the status of Palestinians in East Jerusalem, who although they are issued with Jerusalem ID cards by the Israeli authorities, are 'stateless' according to the legal interpretation of Israeli courts (see ch. 7). And various forms of religious and ethnic differentiation in the policies of Israeli governments are subtly used to create a further segmentation of Palestinian society (see Lybarger 2007a; Shehadeh 1993).

\footnotetext{
${ }^{3}$ Ella Shohat (1999: 14) writes: "We Arab Jews, for example, crossed a border and ended up in Israel, but our millennial 'Arabness' did not thereby suddenly cease. Nor did it remain static in a previous historical incarnation. How could we change our language, our cuisine, our music, our ways of thinking overnight? Certainly, we have been changed. But to see Mizrahim as simply Israeli would be like seeing African Americans, despite their complex, conflictual, and miscegenated history, as simply Americans. At the same time, to expect Mizrahim to be simply Arab would be like reducing African Americans to simply Africans."

${ }^{4}$ In February 2014 the $\rightarrow$ Palestinian Authority ordered that recording religious affiliation in ID cards should be abolished in the West Bank. Hassan Alawi, a representative of the Palestinian Interior Ministry, explained that "the decision was made entirely by Palestinian authorities and ensures the equality of all Palestinians, regardless of their religion" (http://www.maannews.net/eng/ViewDetails. aspx? $\mathrm{ID}=673377,29.04 .2015)$.
} 
This instrument of 'discursive' separation into majority and minority groupings, with increasing division and fragmentation of the various minorities, is far from new; one reason why it is effective in the Israeli/ Palestinian context is because the common we-image of the Palestinians - as with many other national we-groups ${ }^{5}$ is a relatively recent phenomenon that is still undergoing change; it only began to take shape in the late 19th and early 20th centuries (see Khalidi 1997; Kimmerling/ Migdal 2003; Krämer 2008: 126f.).

Because of the political situation, the constant politically motivated and politically instrumentalized discourse on the questionableness of a Palestinian nation, and the politically motivated homogenization of 'the Arabs' as a group who 'theoretically' could just as well go and live in Jordan or some other Arab land, it is important for the Palestinians ${ }^{6}$ to see and present themselves as a we-group, both as regards the separability of their group from others and as regards their unity. Especially in the interviews we conducted in the West Bank - but also in a weaker and different form in Israel (see ch. 4) - the Palestinians painted a homogeneous and harmonious collective self-image and they-image (see ch. 2); they were always ready with arguments to cover any cracks in this image, which admitted no 'differences' between the various groupings of Palestinians. In the West Bank we observed that Palestinians strive to maintain a we-image of conflict-free unity, both in their own eyes and inside the grouping as a whole, and play down or even deny the existence of tension-laden conflict lines between different groupings. In the interviews we conducted in Israel, we found signs that Palestinian Israelis (including the Druze and the Bedouins) often also present this image, especially towards Jewish Israelis or representatives of the so-called Western world (see ch. 4). They present a homogenizing image of the Palestinians in the West Bank, but talk about differences within the group of Israeli Palestinians (see ch. 9).

The aim of the research we carried out in Israel and the West Bank between 2010 and 2015 was to reconstruct the rules applicable in different geographical contexts for discourses on the Palestinians as a we-group and for corresponding we- and selfpresentations. We were also interested in knowing who breaches these rules and why. After a relatively short time it became clear to us that especially people who are outsiders in their lifeworlds in more than one way tend not to resort to the almost universal we-image of 'we Palestinians have no internal conflicts, we only have conflicts with the Jewish Israelis', but prefer to talk about conflicts or disagreements between

\footnotetext{
${ }^{5}$ A 'national' we-group is typically a we-group - often defined on an ethnic or 'cultural' basis - with an articulated claim to its own state (see Gellner 1983: 85ff.; Gurr / Pitsch 2002: 288) or with a claim to the institutionalization of its 'culturally' based group-like structure in the form of a sub-state (such as a 'federated state' or 'province'). The demand for some kind of state institutionalization is articulated openly by a large part of this grouping, at least internally. In 'ethnic' we-groups this feature is often not present or not clearly formed.

${ }^{6}$ There is no agreement in the Palestinian discourse over whether or not, or to what extent, Bedouins and Druze 'belong' to the group of Palestinians. For this reason we always try to let ourselves be guided by the self-image of the interviewees.
} 
different groupings (see esp. chs. 8, 10,11). These interviews helped us to reconstruct the breaks in this harmonizing we-image. We were able to study the conflict lines between different groupings within Palestinian society, their collective history, and the individual histories of members of different groupings.

In the West Bank (see ch. 2) we (a team of Palestinian scholars from Israel and the West Bank, and German scholars) looked at the life stories of Palestinians, and daily interactions between Christians and Muslims and between other sociologically distinct groupings, for instance between the refugees of 1948 and 'established residents', between urban dwellers ${ }^{8}$ and newcomers from the villages, or between Palestinians from Israel and Palestinians from the West Bank. We concentrated mainly on the towns of Bethlehem and Ramallah, including the nearby $\rightarrow$ refugee camps. But we also conducted research (together with Jewish-Israeli colleagues) on different groupings of Jewish Israelis and Palestinians in the Old City of Jerusalem (see Becker 2013: ch. 8) and in Haifa (see Witte 2014: ch. 10) and Jaffa (cf. Wundrak 2012: ch. 11). Our main focus was on the perspectives and experiences of Palestinians as members of different groupings and local group constellations (Palestinian and Jewish Israelis, Muslim-Palestinian and Christian-Palestinian Israelis in the local context of a Muslim or Christian or Jewish majority).

The aim of our research project was to make a study of the social relationships and interaction dynamics between members of different social groupings whose relationship is based on mutual but unequal dependencies. Among other things, we were interested in whether and to what extent numerical majorities correspond to the constitution of an established-outsider figuration - in other words to what extent numerical minorities are outsider groupings in the sense proposed by Norbert Elias. ${ }^{9}$ Using a social-constructivist and figurational approach, ${ }^{10}$ we tried to reconstruct the web of interdependence between people, the dynamic network of relationships and dependencies, and the fluctuating unequal power balances between established and outsiders. Power is not a static object but has a relational character and is processual or dynamic. Thus not only can actors participate to different degrees in power balances in different figurations or settings, but their shares in these power balances are always subject to processes of change, except perhaps in the case of extremely short-lived social figurations.

\footnotetext{
${ }^{7}$ Approximately 29.7 percent of the population of the West Bank are refugees and their descendants from the present-day territory of Israel (see Palestinian Central Bureau of Statistics (PCBS) 2011).

${ }^{8}$ Around 70 percent of the population of the West Bank live in towns (PCBS 2012).

${ }^{9}$ An important feature of Elias's conception is that fluctuating (and as a rule asymmetrical) power balances are an integral element of relationships between people (Elias 1978). On the model of a figuration of established and outsiders (i.e. more powerful groups and less powerful groups that are interdependent with them), see esp. Elias / Scotson 2008; Bogner 2003; Mennell 1989; Treibel 1993. ${ }^{10}$ For details of a theoretical and methodological connection between social-constructivist biographical research and figurational sociology, see Bogner/Rosenthal 2012; Bogner/Rosenthal in print; Radenbach/Rosenthal 2012; Rosenthal 2010.
} 
In the given historical context of Israelis and Palestinians, single individuals may interact in very different social and local contexts. Sometimes they act as members of ethno-political or religious outsider groupings and on other occasions as members of the established grouping. This can be illustrated by the example of a Palestinian woman with Israeli citizenship who is a Christian and who lives in Israel in an 'Arab' village with a Christian majority. She interacts with Jewish Israelis in all social settings as a member of a grouping of outsiders in the state of Israel, while in her village she acts towards her Muslim neighbours as a member of the local religious majority and thus often of the established in this village. In most local contexts in the West Bank, a Christian woman will belong to the religious minority, but in certain local contexts, such as in Bethlehem, she can belong to the established grouping consisting mostly of Christians in this town. By contrast, a Palestinian man from the Old City of Jerusalem with a Jerusalem ID is in a comparatively more powerful position than a Palestinian man from a refugee camp in the West Bank, but very clearly - as our interviews showed - in the position of an outsider in respect of the grouping of Palestinians from the north of Israel who have Israeli citizenship. This list could be extended (for instance to include the Bedouins, the Druze and the different Christian denominations, or Palestinians with a good education or economic capital as against Palestinians with little education or no economic capital), and it shows the extraordinary complexity of interactions within this research field. This complexity requires a research design that takes into account the different figurations, in other words who interacts with whom and in which regional context. The most important thing is to make careful analyses that do justice to each historical individual case, paying attention to the subjective perspectives, sequences of experiences and biographies of the individual actors (see Rosenthal 2012). Besides narrative-biographical ${ }^{11}$ and thematically focused interviews, ${ }^{12}$ we therefore also used participant observations in different everyday contexts, especially contexts which enabled us to observe interactions between members of different groupings. ${ }^{13}$ In addition, the team led by Shifra Sagy used standardized questionnaires to investigate the relationship between Muslim and Christian Palestinians (see Mana et al. 2012) and between Palestinians from Israel and from the West Bank (see Mana et al. 2014). In these two quantitative studies, the fragility of the harmonizing we-image and the conflict lines between different groupings of Palestinians became visible in the way the question were answered, and there was a clear need among the respondents, especially the Christian Palestinians, to distinguish their own from other groupings.

\footnotetext{
${ }^{11}$ In narrative-biographical interviews we let the person tell the story of their family and their own life freely. This is the main narrative or biographical self-presentation. Only when it is finished do we ask questions relating to points that the person has mentioned. In a third interview phase, we ask about issues that have not been mentioned (see Rosenthal 2011: 151-173; Schütze 1983, 2014). On the methods used for analysing these interviews, see Rosenthal 1995, 2011: ch. 6.2.

${ }^{12}$ In the thematically focused interviews, we also used a narrative interview method in which the person was asked to tell us about certain events and topics, e.g. the history or story of an organization.

${ }^{13}$ On observation methods and the writing up and analysis of reports, see Rosenthal 2011: ch. 4.4.
} 
In our analysis of the data we gathered using qualitative instruments, we sought answers to the following questions: Within the interactions observed between members of different groupings of outsiders and established, what are the constitutive factors for these people's webs of relationships and interdependencies? With which concrete experiences are they bound up? And in which way have these experiences changed their life and their patterns of interpretation, including the patterns of their biographical self-interpretations?

Of course, with our desire to reconstruct the unequal power balances among different groupings of Palestinians and the potential, but also lived, conflict lines between them, we might be accused of supporting Israel's divisive policies and thus weakening the we-group of the Palestinians. However, we believe that concealing or tabooing internal conflicts in public discourses promotes, or even aggravates, collective conflicts and grievances among the Palestinians, at least in the long term, and is thus more likely to weaken their political solidarity and collective power to act than an open (but more disciplined) discourse about their different interests, conflicts, perspectives and opinions. It is our opinion that a careful analysis of underlying conflicts is an opportunity to show how such conflicts might be transformed, especially in everyday practices. Recognizing differences and conflicts and working together to find constructive ways of managing the resulting tensions could be a good resource for concerted action against attempts to divide the Palestinians and could contribute to their political solidarity. But first it is necessary to find out which kinds of conflict can be observed, which groupings are in conflict with each other in which local or regional contexts, and whether there are signs of constructive change in their patterns of interaction. In other words: do the group, family and biographical constellations and situative contexts offer opportunities for changing rigid patterns of interaction and for conflict solutions that create and nurture trust instead of eroding and undermining it? The same applies to many other cases concerning relationships within and between we-groups.

This volume can therefore be seen as an attempt to give a voice to different groupings of Palestinians who live in the West Bank and in Israel. We will show the situations in which they live today, their very diverse family histories and personal biographies, and also the various ways in which they suffer from discrimination within Palestinian society. Our aim is not to individualize. Rather, as in other research fields, by adopting a sociological perspective we want to show in what ways the differences that can be observed are due to belonging to different social groupings and their interdependencies with other groupings, and how far they are due to the resulting complex figurations they form (unintentionally or intentionally, with or without their knowledge) with Jewish Israelis or Israeli society and the Israeli state.

The structure of this book serves to achieve this aim. In different chapters we describe and discuss the various groupings we were able to reconstruct and the often conflict-laden but also mutually supportive relationships between these groupings in different local or regional contexts (West Bank, Old City of Jerusalem, Jaffa and Haifa). 
Voices from the West Bank 



\title{
2 We-images and collective memories in the West Bank
}

\author{
Gabriele Rosenthal
}

\subsection{The homogenizing we-discourse}

In the autumn of 2010, when we began our interviews and participant observations in Ramallah and Bethlehem and in the nearby $\rightarrow$ refugee camps, we quickly realized that the following we-image was vehemently defended by almost everyone: 'we Palestinians have no internal conflicts, we only have conflicts with the Israelis'. If reference was made in the course of an interview to conflicts between different Palestinian groupings or to local problems such as increasing drug use and crime, the person usually continued by arguing that the Israelis were to be blamed.

In the ethnographic interviews conducted in the context of our participant observations, we were able to elicit arguments in support of this harmonizing we-image by deliberately asking about the person's religion, a question that is considered politically 'incorrect' in this geographical context. This question, and questions concerning the relationship between refugees and long-time residents, were automatically interpreted as questions about conflicts between these groupings, which were denied, with long arguments highlighting how well they lived together. Questions about religion or about the relationships between different groupings are easily perceived as calling the Palestinian nation into question, and arouse a need to defend a harmonious and homogeneous we-image which represents all Palestinians as victims of the same painful fate, whether as a people or as individuals, in the past and in the present. Yet despite the efforts to stress the harmonious relationships between different groupings, we noticed many pointers suggesting that there were certain internal 
tensions. This put us in a dilemma: by asking about the relationships between different groupings we were bringing up a subject which on the one hand stressed the differences between groupings and called into question the common we-image that everyone tried so hard to present, but which on the other hand was of considerable relevance in everyday life in Ramallah and Bethlehem and which in the biographical interviews was usually referred to in one way or another by the interviewees without any outside prompting.

Asking openly about someone's religion is not considered permissible, even if a Palestinian asks another Palestinian in an open way. Nevertheless, through the indirect questions they asked about place of origin or family name, we could see that our interviewees felt a need to know about the collective belongings of our Palestinian colleagues, who came from the West Bank and from Israel, who included Christians and Muslims, and whose families were long-time residents and refugees. Our analysis of the interviews showed that the collective belongings of the interviewers played a significant role for the people we interviewed. I have already drawn attention to this in the case of a Muslim refugee family (Rosenthal 2012), and it can be seen in the case of the Khadirs, a Christian family presented in this volume (see ch. 3). Especially at the initial stage, this knowledge influenced the framing of the interview and thus determined the themes that were spoken about.

Another phenomenon connected with the relevance of this we-image was that in the narrative-biographical interviews, the interviewees - despite our narrative questions - only rarely produced long narrations in the sense of moving from one story to another; instead of recounting self-experienced events, they told collective transmitted stories, or they narrated their own experiences only when these corresponded to the collective memory and the collectively desirable we-image. The main theme talked about in the interviews (mainly using the text type referred to as argumentation) was the suffering of Palestinians under the Israeli occupation. The interviewees presented us with a highly stereotyped collective memory with hardly any familyhistory components and always containing more or less the same collective events, in particular the $\rightarrow$ Nakba in the context of the founding of the Israeli state in 1948, the $\rightarrow$ First Intifada and the $\rightarrow$ Second Intifada.

The Nakba is of central importance in the collective memory. During the conflicts that broke out in Palestine upon announcement of the UN Resolution in November 1947, and the $\rightarrow$ war that began in May 1948 and ended with the signing of the last cease-fire agreement in June 1949, several thousand Palestinians lost their lives, between 700,000 and 750,000 Palestinians ${ }^{1}$ fled after losing their land, and the great majority of abandoned Palestinian villages, numbering over 400 , were destroyed "through deliberate action by the Israeli army and Jewish settlers" (Krämer

\footnotetext{
${ }^{1}$ These figures vary depending on the source. In the final report of the United Nations Economic Survey Mission for the Middle East of December 1949, the figure was estimated to be 726,000 (see Morris 2004: 602).
} 
2008: 322). ${ }^{2}$ In view of the relatively small territory involved, about 8,000 square miles (21,000 sq.km.), and the much lower population density at that time, 700,000 refugees is a very large number. At the end of the First World War, before the great waves of immigration of Jews from Eastern Europe, the entire population of what became the $\rightarrow$ Mandate of Palestine was less than 700,000. ${ }^{3}$

In the interviews with refugees and their descendants - meaning their children, but usually not their grandchildren (see Rosenthal 2012) - it became clear that they felt a strong attachment to the places in which they or their families had lived up to 1948 or 1967. Besides the general importance of 'land' in political discourses and in the context of rural areas where agriculture or forestry are predominant, this has to do with the fact that the self-image of Palestinians is explicitly bound up with their land. The saying "My land is my identity" was already documented during the British Mandate period in the 1920s when identity cards were introduced (Turki 1988: 65). The Palestinian writer Fawaz Turki continues: "The foundation of Palestinian culture and inner history, as expressed in literature, poetry, rhetoric, folk tales, song, dance, and political theory, is rooted in this worldview of man and land as two components of the same system, expressing the life process." The connection between the Palestinian 'identity' and land, or the importance of lost land, is very prominent in the work of the contemporary lyricist Mahmoud Darwish, for example (see Ahmed et al. 2012).

The $\rightarrow$ war of 1967 again led to an estimated number of at least 200,000 Palestinian refugees from the West Bank, East Jerusalem and Gaza, and many people were driven out of their homes in the West Bank. ${ }^{4}$ However, in the interviews in the West Bank - unlike those conducted in the Old City of Jerusalem - the interviewees did not tell stories about this, and if they did, then usually only after being asked about it by the interviewer. Those who told stories about this time without being prompted were usually long-established residents from Christian families, and they told how they offered shelter and food to the refugees, who were mostly Muslims. Not least they mentioned this in order to demonstrate the deep and unquestioning solidarity between Christians and Muslim refugees in the West Bank. In other words, in these cases speaking about 1967 was a way of confirming the harmonizing collective memory. By contrast, we heard very little about the retreat of the Jordanian army from the West Bank - generally regarded as having been premature - and hardly anyone talked about the outcome of this war, which was very disappointing for the Palestinians. This period with its hope for a military victory by the Arab armies called $\rightarrow$ Naksa in Arabic - is seen as a turning point in the history of the Near East

\footnotetext{
${ }^{2}$ For details, see Khalidi 1992; Morris 1987, 2008.

3 "At the end of March 1919, the military authorities gave a population estimate of 648,000 people, among them 551,000 Muslims, 65,300 Jews, 62,500 Christians, and 5,050 'Others' (Druze, Armenians, Baha' is, and others)" (Krämer 2008: 156). In 1946 there were 1.94 million people living in the British Mandate and the number of Jews had risen to 600,000 (ibid.: 183).

${ }^{4}$ On various sources in respect of the number of refuges in 1967, see Tolan 2007: $507 \mathrm{f}$.
} 
conflict and we assume that its non-thematization is connected with the enormous disappointment or disillusionment of the families or individuals interviewed who saw it as the dashing of their hopes that they would be able to return to their home villages and towns.

Besides the collective history that was presented in a very stereotyped manner in the interviews, we were repeatedly told in almost all biographical and ethnographic interviews that there are no conflicts between different groupings of Palestinians, only between Palestinians and Israel, the Israelis, the Israeli soldiers or settlers, or with the Jews in general (Hinrichsen/ Worm 2012; Rosenthal 2012). People said this was so, even though it was in contradiction to various experiences they told us about, or to everyday situations that we were able to observe. Whether Christians or Muslims, established or refugees, people living in camps or in towns: they all claimed that these sub-groupings within the Palestinian we-group lived peacefully together. They argued that the relationships between the different groupings were harmonious, and although tensions were frequently alluded to, they played down their importance or explicitly denied them. The we- and self-presentations of family history and life story were full of argumentation sequences used to reproduce and defend this we-image, by naming the central historical events in the collective memory, and by exemplifying stories intended to demonstrate how much the Palestinians have suffered under Israeli rule or occupation. This framing of the interviews meant that no one gave us long chains of stories, and only by using narrative questions were we sometimes able to elicit stories from biographical spheres unrelated to this thematic field. ${ }^{5}$

A very clear and stereotyped form of this image of a harmonious, and mostly homogeneous, we-group with a common history was also presented in interviews by experts, such as representatives of Palestinian NGOs, who are used to making their difficult situation, or that of the Palestinians, clear to representatives of the 'Western' world. As Rixta Wundrak (2012) has put it in the context of Jaffa, they act as speakers, or political representatives of their communities. Thus, for example, a member of a camp committee who had referred to the lack of support received from two neighbouring towns, gave the following answer when asked about this: "We have no conflicts with town A or town B - we are one people, we have one religion." Despite the presence of Anan Srour, a Christian Palestinian member of our project team whose religious affiliation was usually clear to the interviewees - this man goes to the extent of speaking not only of one people, but also of one religion.

We at first interpreted these findings as being due to the presence of the German researchers, who represent the so-called Western world in the eyes of the Palestinian

\footnotetext{
${ }^{5}$ Following Aron Gurwitsch (1964), when analysing biographical interviews (Rosenthal 1995) we must ask how far interview sequences are arranged as a gestalt in which the different sequences form a highly interrelated network and are thus elements of one, or more than one, thematic fields. Gurwitsch discusses the dialectical relationship between the "theme" - what is of interest at a given moment - and the "thematic field" in which the themes are embedded and which forms the "background or horizon out of which the theme emerges as the center" (1964: 4).
} 
interviewees. There is no doubt that the biographical interviews and interviews in everyday contexts which we conducted in this region were influenced to a considerable degree by the Middle East conflict, and the resulting complex figurations of Palestinians, Jewish Israelis and representatives of the so-called Western (Christianinfluenced) world. When people spoke about their family history and their own life story, this was framed by their presentation of the national we-group and its collective history, and was thus embedded in and interwoven with the dominant figuration with Jewish Israelis which is connected to confrontations and power inequalities characterized by violence. In order to find out to what extent this harmonizing weimage and collective memory was determined by a framing of the interaction due to the nationality of the interviewers, we started to hold interviews and carry out participant observations at which only Palestinian members of our team were present. The findings were the same: dominance of the collective memory as reduced to a few historical dates, a focus on the suffering of the we-group under Israeli rule, and a harmonizing picture of the relationships between different parts of the we-group. This harmonizing picture is also painted by Palestinians internally, at least in public and semi-public discourses, and in interactions between Christians and Muslims, or between long-time residents and refugees, and obviously they use it to reassure and 'comfort' themselves. Promoting the idea of a conflict-free we-group as a means of collective self-reassurance is not uncommon in cases of intense or violent collective conflict, and in this case must always be seen before the backdrop of the Israeli state policy of trying to create splits in the non-Jewish population. The result is that Palestinians are very concerned to ward off attempts to divide them into different categories forming so-called minorities who are powerless against the 'culturally' and socio-politically scarcely less heterogeneous group of 'Jewish' Israelis. When talking to members of the research team, they fight against these (more or less deliberate) attempts to create splits by repeatedly stressing that they are one community in which no one is discriminated against on grounds of their religion, or their status as refugee or long-time residents, or because of their legal residence status.

However, the research team was also able to observe that this practised presentation of a harmonizing we-image sometimes faded away in the course of repeated meetings, or was not repeated at a second interview, and a different framing of the memory process was used (for instance "my suffering following the early death of my father"). In some interviews, the dominant discourse on the we-group of Palestinians was not recognizable at all. Some interviewees, for instance, used even their first interview as a kind of therapeutic session in which they could speak freely about the discrimination they had suffered - for example as homosexual men - or they presented their own discriminated we-group (for example "we homosexual Palestinians") to a 'Western' interviewer, believing that the interviewer would be more tolerant than the people they had to deal with in their own environment (see ch. 5). In the course of the research it became increasingly clear that this framing of the interview as an opportunity to talk about their personal problems or the way their we-group is discriminated against (or the group to which they are regarded as belonging) was 
chosen by outsiders in Palestinian society, such as people in a binational marriage relationship, men who are defined as 'homosexual', or people who have lived abroad for many years and who in some way do not feel at home in Palestine. In general, we can assume that interviews with outsiders who are more or less distanced from 'their' own we-group, or who do not feel they belong to it, or who feel excluded from it, discriminated or marginalized, provide an opportunity to learn about how people interpret certain parts of the collective history that are omitted from or pushed to the margins of the dominant discourses (see Bogner/ Rosenthal 2012).

Because of this empirical finding, the research team actively sought interviewees who could be regarded as outsiders in Palestinian society. The result was empirical confirmation of our assumption that especially people who are in an outsider position in their lifeworld in a plural (and thus relatively highly 'individualized') sense tend not to use the harmonizing we-image in their biographical self-thematizations. This applies for instance to those who are outsiders not only in relation to the longtime residents in their local context, in relation to the members of established families, in relation to people with citizenship and relatively unrestricted travel rights, and above all in relation to the Israelis, but who also have other ascribed features which make them social outsiders (such as belonging to a confessional, sexual or political minority, being disabled, or having a negatively valued background such as confessionally mixed parents). These people tell more stories, often a lot more, about their 'individual' experiences which do not belong to the thematic field of "suffering under the Israeli occupation"; they embark on longer chains of narrations and memories, and they tell stories about conflicts and tensions between different Palestinian groupings. They thematize how they feel discriminated against (in the local context) as Christians or Muslims, or as inhabitants of the refugee camps, and speak about local tensions between long-time residents and refugees, or between Christians and Muslims. ${ }^{6}$ Unlike those we- and self-presentations that are predominantly based on the harmonious image of the Palestinian we-group, or on relevant parts of the collective memory, and that are thus dominated by the figuration of the Palestinians and the Jewish Israelis or the state of Israel, the outsiders talk more about their own life history and tell stories that reflect their personal biographical relevances. Their presentations are dominated by the figuration of themselves as relatively 'individualized' outsiders (through their social position) and the we-group of established Palestinians - although (and this must be stressed here) the figuration of themselves and the state of Israel is also important for their self-interpretations, and in certain contexts has a massive influence on the we- and self-images presented by them, especially in the context of 'political' discourses.

\footnotetext{
${ }^{6}$ Hendrik Hinrichsen and Arne Worm (2012) conclude from the interviews they conducted that speaking about these experiences of discrimination or about violent episodes in a conflict between Christians and Muslims can provide a way of speaking indirectly about the way they feel discriminated against as homosexuals and the resulting fear of being violently attacked (see ch. 5).
} 


\subsection{Practising collective memories}

Collective memories (see Rosenthal 2010, 2016) ${ }^{7}$ are part of the cultural practice that determines which memories and constructions of the past are excluded or pushed to the side, and which become dominant in the discourse of certain groupings (whether a family, a historical generation, ${ }^{8}$ a local community, or political, religious or ethnic groupings) and in public or mass media discourses. For Maurice Halbwachs (1925/ 1992), family memory resulting from shared experiences, and the way past events are repeatedly talked about by members of the family between themselves is paradigmatic for the collective memory. This creates a framework "which, so to speak, is the traditional armor of the family" (Halbwachs 1992: 59).

The following analysis of a a three-generation family of Palestinians in the West Bank serves as an empirical example of the way collective memory is preserved and handed down within the family and how different generations are affected by it.

A central element of the collective memory of Palestinians, as mentioned above, is the Nakba, the forced displacement or flight of many Palestinians from their homes in the context of the founding of the Israeli state in 1948. The Palestinians commemorate this event every year on May 15th, Nakba Day (Yawm an-Nakba); Israeli Independence Day (Yom Ha'atzmaut) is celebrated at the same time in Israel. The demonstrations regularly held on this day result in violent clashes with the Israeli army. In 2011 some people were killed and hundreds were injured during demonstrations at checkpoints and cease-fire lines. For the grouping of those Palestinian families whose members fled from the territory of the state of Israel as defined in 1948 , the Nakba means preserving the memory of their places of origin and is associated with their political claim to $a \rightarrow$ "Right of Return". There are also various other public contexts in which memories of the destroyed Arab villages in Israel are kept alive. For example, in the Ibdaa Cultural Center in the Dheischeh Refugee Camp near Bethlehem there is a restaurant where the tables are named after the places of origin of the refugee families that live there. Many descendants of these families have constructions of belonging that are built around the memory of their family's place of origin. They have learned to present themselves as 'coming' from this place; a place which has either completely changed or no longer exists, and which in most cases they have never seen. In the spring and autumn of 2011, my colleagues and I

\footnotetext{
7 The social-constructivist and biographical approach to collective memory and memory practice followed by the author is based on Maurice Halbwachs' distinction between individual, collective and historical memories (1925/1992). While historical memory shapes the past through more or less professional historiography, collective memory in Halbwachs' terminology relates to the formation of broad cultural traditions. Halbwachs was particularly concerned with demonstrating the memory's dependency on social processes/phenomena. He made clear that individual memory is dependent upon socially given collective frames.

${ }^{8}$ We understand historical generations in the sense proposed by Karl Mannheim (1952); on the connection between historical and genealogical generations, see Rosenthal (1997, 2000).
} 
Gabriele Rosenthal

interviewed a refugee family in the Aida Refugee Camp near Bethlehem. ${ }^{9}$ We spoke to the two grandfathers, a daughter and the oldest grandson, ${ }^{10}$ and were able to witness the way the youngest grandson was trained in this important part of the family memory. In 1948 the two grandfathers, who are brothers, fled with their families to Bethlehem as small children, just like the two grandmothers, from a Muslim village near Jerusalem that is referred to here as Beit-A. Almost all the inhabitants of this village were expelled by Israeli troops in the course of Operation Ha-Har in October 1948. Today there are no Palestinians living in Beit-A; there are still a few ruined Arab houses, and some that are lived in by Jewish Israelis.

I interviewed the grandfather Ubaida together with my colleague Anan Srour. Towards the end of the interview, Ubaida called his five-year-old grandson to come and join us. The following dialogue ensued, which I quote here in a literal translation from the Arabic:

Ubaida: Where do you come from, my grandson, from which village?

Grandson: From A-district [he names the district of Bethlehem in which he lives]

Ubaida: And where does your father come from?

Grandson: From? From Bethlehem

Ubaida: And where do I come from?

Grandson: From the West Bank

Grandmother: Beit -

Grandson: Bethlehem

Grandfather: This village

The boy's grandfather pointed to a framed photograph of his home village, which he had shown us at the beginning of the interview and which could be said to frame his life story. The grandmother, who was sitting beside them, tried to help by asking:

Grandmother: This is?

Ubaida: What is this?

Grandson: A picture of Beit-A

Ubaida: And where was I born?

Grandmother: There

Grandson: In Beit-A?

\footnotetext{
${ }^{9}$ For a detailed account of this family, see Rosenthal 2012.

${ }^{10}$ All interviews were conducted in Arabic and interpreted simultaneously by a Palestinian colleague. The following quotations do not reproduce the simultaneous interpretation, but are translations of the relevant passages in the transcript.
} 
Though it was not easy, the performance came to a successful conclusion and the grandfather laughed. The knowledge demanded here that one belongs to the village from which the grandparent generation was expelled is a central component of the family memory, and of the collective memory of the grouping of Palestinian refugees as a whole. Ubaida's children also had to learn this component, as shown by the interview with his daughter Basima, which I again conducted together with Anan Srour. Basima was born in 1972 in the Aida Refugee Camp. In the 1980s she moved with her parents into a newly built house on the outskirts of Bethlehem. After marrying in 1990, she moved back to Aida. She begins her biographical narration as follows: "Firstly, I am from Beit-A, a refugee, we were expelled from there in 1967." Basima thus locates herself in her parents' place of origin and their 'history of expulsion' and employs the 'right of return' discourse. But it is noticeable that she speaks of '1967' instead of '1948'. 1967 was also a war year and the West Bank was occupied in a very few days by the Israeli army. Very few new refugees came to the Aida Camp. However, just like 1948, 1967 was an important turning point in the history of the Palestinians. Up to then the West Bank had been administered by Jordan, but now it came under Israeli rule. Even though this brought with it various changes in their way of life, the Nakba of 1948 is by far more important in the collective memory of the refugees and of all Palestinians. For Basima - in line with the political discourse - the important thing is not when her family left Israeli territory, but from where they were displaced. After this introduction, Basima then - like the other members of her family - places her life story in the thematic field 'My life as a refugee under the Israeli occupation' and says no more about her family history. By positioning herself biographically in terms of "I was displaced from Beit-A", she has satisfied the requirements of both her family memory and the collective memory of the grouping of refugees, and can now narrate her own life story within this frame of reference.

Suffering in the camp is the dominant element in the self-presentation of Basima's son Arif (born in 1991), who was interviewed by Nicole Witte and Anan Srour. Interestingly, he does not identify himself in terms of the origin of his family in BeitA, but only in terms of his life in Aida. He does mention that his grandparents fled, but in the whole of the interview he does not mention the name of their village. $\mathrm{He}$ is not concerned with the 'right of return' so much as with a demand for one state and the whole of the territory for the Palestinians. He locates himself much more clearly in the we-group of his generation which experienced the Second Intifada as children and adolescents, and makes less reference to his family history. Accordingly, he begins his life story as follows: "I was born in the camp, in the Aida Camp, and I grew up in this camp, I lived, er, in Palestine, like every child, and specially in the camps." Other interviews with members of his historical generation, which we call 'Childhood and adolescence during the Second Intifada', show that using the wegroup of one's own generation as a frame and a strong feeling of belonging to this generation is especially common in the generation unit (see Mannheim 1952) of the grandchildren of refugees. 
Gabriele Rosenthal

Practising collective memories, both cultural and communicative, involves more than just memorizing certain stocks of knowledge or historical events to ensure they are not forgotten. As has been shown by Aleida Assmann (2016), amongst others, the important thing is to learn a) what ought to be forgotten or not thematized, b) how certain events must be interpreted, and c) what components of the collective history should be rewritten or even invented. So-called false memories, meaning inventing events that didn't happen, as well as denying events that did happen, are not only biographical strategies used by individuals to reinterpret their own past, but also an important part of collective constructions of history (see Hahn 2010: 97), which in turn can significantly influence individual memories - usually unnoticed by the subjects.

\subsection{On the power of collective memories to shape present perceptions}

Orientation towards the collective memory or, in other words, the collective frame of reference, may lead those who remember to reinterpret past events that they have experienced themselves or which were passed down to them, and can also blot out or distort present perceptions. I was able to observe this, at first accidentally and later more systematically, in connection with the lion statues at al-Manara Square in Ramallah. In order to explain the empirical findings, some information about this square is necessary. Located in the centre of Ramallah, al-Manara Square is linked in the collective memory with the Christian origins of the city.

A number of myths are associated with the founding of Ramallah in the mid 16th century by the Christian family Haddad from Karak, in the south of presentday Jordan. In the collective memory, differences between Christians and Muslims are mainly made manifest in different weightings or differently accented versions of the city's history. Before the Israeli occupation authorities removed the monument in 1982 / 83, there was a pillar in the middle of the square surrounded by the heads of five lions, ${ }^{11}$ which - as we were repeatedly told in Ramallah - represented the city's founding families. Christians like to point out that these were Christian families belonging to the Haddadin clan. Today, following complete reconstruction of the square (completed in July 2000), there are four big lions at the base of a pillar. Next to one of the lions is a lioness with two cubs, giving the impression of a family of lions. In addition, there are eight fountains which - according to Shibli (2006: 58) - represent eight families. The three additional families that arrived in the 19th century included the al-Ajlouni family, which came from Hebron in the first half of the 19th century and was the first Muslim family in Ramallah. Shaheen (2005: 225),

\footnotetext{
${ }_{11}$ The pillar with the lion heads was erected in 1951 in the square known since 1935 as al-Manara (lighthouse) following the connection of Ramallah and al-Bireh to the electricity grid (see Shibli 2006).
} 
who does not discuss these fountains in his chapter on al-Manara Square, argues that the five lion heads were meaningful at a time when the majority of the population of Ramallah was descended from the five founding families. But the four statues are more appropriate today, when "the overwhelming majority of people living in Ramallah are either refugees or outsiders who have flocked to Ramallah since the 1948 and 1967 wars". The wrist watch which one of the lions is wearing on its front leg, and which was mentioned in many interviews, can be seen as symbolizing the way these statues are connected with the present.

Characteristic of the collective memory of the inhabitants of Ramallah is the fact that I spoke to several inhabitants of the city, both Muslims and Christians, who were fully convinced that today there are still five statues of lions in the square representing the five Christian founding families. I was told this not because I asked about the square but because people wanted to explain to me the Christian origins of the city. During my next visit to Ramallah in spring 2012, I began to ask how many lions there are in the square in the course of short ethnographic interviews, and in the final part of biographical interviews. The confusion increased when some interviewees said there were more than five big lions in the square. So I asked my Palestinian colleague Ahmed Albaba (who lives in Ramallah and who himself was at first convinced there were five big lions) to conduct some short interviews on this matter. ${ }^{12} \mathrm{He}$ began the interviews with the question: "Can you remember a situation in which you heard about al-Manara Square or in which you experienced something there yourself?" and ended by asking about the number of lions. In the eleven interviews conducted by him in June and September 2012, all except two of the interviewees made reference to the founding myth of the city and how the founding families are represented by the lions. The number of lions ranged from four to eight. Here it must be remembered that the 'more recent' collective memory, as described by Shibli, refers to eight Christian and Muslim families. A Christian man (born in 1964), who spoke of eight founding families, said they were all Christian and that they settled in Ramallah and al-Bireh. Thus, he includes the neighbouring Muslim town in the Christian founding myth. By contrast, a Muslim man (born in 1974) speaks of six lions which represent the six Christian and Muslim founding families of Ramallah and al-Bireh.

We can thus assume that the myth of the founding of the city by five Christian families belonging to the Haddadin clan, as well as memories of the five lion heads that formerly adorned the square, overlay people's perception of the four big lions. The frame of reference of an explicitly Christian origin of the city limits this origin to Christian families, while Muslims tend to include Muslim families from Ramallah or al-Bireh in the founding myth. Anyone who is not familiar with this founding myth - which I was not at the beginning of my research - is able to see and remember four lions. This was the case with a Muslim man (born in 1972) from a refugee

\footnotetext{
${ }^{12}$ I would like to take this opportunity to thank him warmly for his assistance and for his important contributions to this chapter.
} 
family, who knew nothing about the meaning of the lions, and who was quite certain that there were four big lions in the square. He thought that the lions symbolized strength, a strength resulting from the religious diversity of the Palestinian people.

While almost every inhabitant of Ramallah is willing to talk about the founding of the city and the lions, there is one topic that is practically never mentioned, or which, to put it more succinctly, is taboo in public discourse in the West Bank. This topic is the killing of people suspected of collaborating with the Israeli authorities, and especially the public executions in 2002 and 2003 (at the time of the Second Intifada), some of which took place at al-Manara Square. It must be noted that these executions were not carried out by the institutions of the Palestinian Authority. The three murders mentioned below that took place in al-Manara Square were ascribed to the al-Aqsa Brigades, the militant wing of $\rightarrow$ Fatah.

Of the interviewees who were asked directly about al-Manara Square, a West European (born in 1976), who had lived in Ramallah for several years, was the first to mention that during the Second Intifada "collaborators and so on were hung upside down there". This is a reference to the public executions which were reported in the media at that time with pictures taken in Ramallah and other places, like Bethlehem. As far as we were able to find out, ${ }^{13}$ one man in March $2002^{14}$ and one in April $2002^{15}$ were executed, hung up by the feet and exposed to public view at al-Manara Square, after being accused of collaboration. There was another public execution at al-Manara Square in August 2003, when a young man was shot before the eyes of a crowd of people. ${ }^{16}$ These images can surely not be easily forgotten by the witnesses; the same applies to the fears of surviving relatives and other feelings bound up with these executions, and also to debates over whether the victims were wrongly accused of collaboration. Nevertheless, this is not a subject one can talk to a German researcher about. And even Ahmed Albaba, who was not in Ramallah during the Second Intifada, was told very little, not even in the last interviews he conducted when he began to ask direct questions about the executions at al-Manara Square. ${ }^{17}$ One interviewee who works for the city administration, briefly admitted that a collaborator was hung up in the square, before quickly changing the subject. An elderly Christian - who was born around 1942 during the British Mandate period - says: "It was only once. The English executed people there." The Christian interviewee (born in 1964) mentioned above says that during the First Intifada a man suspected

\footnotetext{
${ }^{13}$ My thanks go to Johannes Becker for the relevant internet research.

${ }^{14}$ http://www.spiegel.de/politik/ausland/nahost-krise-blutbad-und-ausgangssperre-a-186683.html; http://www.middleeast.org/read.cgi?category=Magazine\&num=698\&standalone=0\&month=3\&ye ar=2002\&function=text, 24.09.2012.

$15 \mathrm{http} / /$ www.greenspun.com/bboard/q-and-a-fetch-msg.tcl?msg_id=009v1T; http://articles. baltimoresun.com/2002-04-25/news/0204250227_1_palestinian-police-force-ramallah-west-bank, 30.08.2016.

${ }^{16}$ See http://www.abc.net.au/worldtoday/content/2003/s924523.htm, 19.09.2012.

${ }^{17}$ It may be significant in this context that A. Albaba explained at the beginning of each interview that he was working with a team of German researchers.
} 
of collaboration was burnt to death in the square by "free patriotic youth". Immediately after saying this, he changed the subject by moving from this component of the communicative memory - he had heard about it from a relative - to a component of the cultural memory. He says: "al-Manara Square in Ramallah is like the Dome of the Rock in Jerusalem", referring thus to the historical importance of the square.

A general assumption can now be formulated that most interviewees, when asked about this square, feel more comfortable talking about components of the cultural memory. Perhaps talking about the way the square symbolizes the founding of the city helps to ward off other memories, whether of events experienced personally by the speaker or of events heard of from others or read about in the press. We can go further and assume that present perceptions of the four lion statues, which were set up just a few months before the beginning of the Second Intifada, or of the reconstruction of the whole square by the Palestinian Authority, were, and still are, clouded by violent events - including the invasion by the Israeli army in March 2002. This can lead to a wish to remember the square as it used to be, and the foundation myth connected with it. But it is to be presumed that this does not cause the memories of executions in the square to disappear from people's minds or from everyday discourses, any more than their memories of Israeli tanks, curfews, house searches and arrests by the Israeli army.

This component of collective history in Ramallah, which for contemporary witnesses is bound up with concrete persons and concrete political groups, cannot simply fall into oblivion. It is therefore pertinent to ask in which wider societal constellations, or in which family or biographical situations this component can be talked about, and when the conflicts and differences of opinion associated with it are likely to lead to violence. Further research is also needed to determine the extent to which the significance of this component of the city's history, communication and current memory practice differ not only according to political and national affiliation, but also according to generational affiliation. It must also be asked which grouping with which version of the history will dominate and modify the collective memory in the future. This question arises not only in connection with the history of the Second Intifada, but also in connection with the Christian origins of Ramallah and the hitherto existing emphasis on the way members of different religions live peacefully together in the city (see Rosenthal 2012).

By presenting this example of al-Manara Square in the collective memory of the inhabitants of Ramallah, I have attempted to show that the borders between cultural and communicative memory are not fixed, and that it is important to determine empirically in which contexts reference is made to which collective memories and we-images or we-concepts, and why people refer to cultural memories.

The memory practice observed in the West Bank is a cultural practice that is exposed to a high degree of social control and is bound up with a number of taboos, both in respect of which components of the cultural memory can be mentioned in the context of which version of the collective history, and in respect of which components of the orally passed down or self-experienced past may be talked about, how 
and with whom. In the following chapters we will look more closely at this social control, at those who escape it and do not use the hegemonic we-image, and at those whose life story corresponds paradigmatically to this we-image. 


\title{
3 On the brittleness of the homogenizing we-discourse: Christians in Bethlehem and Ramallah
}

\author{
Hendrik Hinrichsen, Johannes Becker, Gabriele Rosenthal
}

\subsection{Introduction}

We will begin this chapter on Christians and Muslims with a scene that was recorded by Hendrik Hinrichsen during his field work in Bethlehem in the autumn of 2014. It contains in condensed form many observations that we repeatedly made, in this or a similar form, at different places in the West Bank.

A few days after a short interview on the relationship between Christians and Muslims, a Muslim interviewee from a $\rightarrow$ refugee camp - we will call him Samad - suggested that H. Hinrichsen might like to interview two Christian acquaintances of his, in his presence. It was arranged that the interview should take place at the university. Samad, his cousin, Hendrik Hinrichsen and our Palestinian colleague Ahmed Albaba arrived on time at the agreed meeting place on the campus, but the two Christians did not turn up. Instead, by chance, Samad met some politically active Muslim students he knew. We got into a conversation with them, which was translated for H. Hinrichsen by Ahmed Albaba. Samad managed to steer the conversation towards the relationship between Christians and Muslims. One person argued that Israel and 'the West' were trying to create splits between Christians and Muslims, but that the students were working together and there were martyrs on both 
sides. Another person commented that parents on both sides taught their children to regard their own religion as superior, and that although the relationship was good in general, this played a role in delicate matters like love and marriage. To the question whether the relationship between Christians and Muslims had changed, Samad's cousin answered that this was difficult to say, for there was nothing to serve as evidence of this: in Egypt churches were burned down, but not in Palestine. When Samad noticed a Christian friend of his walking past, he called him over. They greeted each other with kisses on the cheeks; the friend sat down next to Samad, who turned to him, saying that he wanted to know whether he felt discriminated against as a Christian. The friend hesitated before saying: "To be honest, I do a bit." He explained that although they were friends, like brothers, and in his generation there was no problem (he was in his mid twenties at the most), people in the young generation would say: "Oh, he's a Christian, he must be boycotted." While he was talking, he looked at the ground, and while Ahmed Albaba was still translating what he had said, he took his leave and walked away.

On the one hand, as in so many of the interviews we conducted, the Israeli policy of 'divide and rule' as experienced by the interviewees leads here to emphasis being laid on the national unity of the Palestinians and the harmonious nature of relationships between Christians and Muslims. On the other hand, this situation also contains allusions and behaviours that disturb the need for harmonization. Before taking a closer look at these 'disturbances' or cracks in the harmonizing we-image, it is important to consider the unequal power figuration with the Israelis. It must be remembered that mutual relations between Christians and Muslims in this region cannot be seen independently from the intertwined figurations with Jewish and non-Jewish Israelis (Rosenthal 2012). What we are dealing with in this overall figuration is a highly contentious past and present. As a result of the Israeli state policy of creating splits in the non-Jewish population (see ch. 2), Christian and Muslim Palestinians fight hard against any attempt to classify and divide them into different socalled minorities. ${ }^{1}$ These would be powerless against the grouping of Jewish Israelis, which in reality is 'culturally' scarcely less heterogeneous. Stories about situations that were felt to be attempts at division - such as preferential treatment at the checkpoints around Jerusalem - can be found repeatedly in our interviews with Christian Palestinians, who tell them in order to express their unity with the Muslims. ${ }^{2}$ Thus, a Christian man told us how ashamed he feels when he stands in a queue to enter

\footnotetext{
${ }^{1}$ Accusations of a 'divide and rule' policy in respect of the West Bank and Gaza have repeatedly been made since the beginning of the occupation. These range from the claim that Israel wanted to split the Palestinian people by supporting Islamist groups in the 1970s and 1980s (see Lybarger 2007a: 778-779) to accusations of unequal treatment in the issuing of work and visitors' permits for Israel. Lybarger (ibid.: 791) comments: "Israeli agencies, parties, and politicians [...] have often proved eager and adept at exploiting inter-Palestinian disputes and differences."

${ }^{2}$ In the course of several visits between 2011 and 2014, we conducted 28 biographical narrative
} 
Jerusalem and is allowed to cross the border while other men have to stay behind. And in an interview conducted in English with Helene, a Christian woman (see ch. 6) who was arrested after being involved in bomb attacks, she describes how the attempt to split Christians and Muslims was used during her interrogation:

"You know at first they started to talk being nice you know you are Christian, why are you involved in such a thing, you have a nice family [...] you are pretty, you are young and eh, you are Christian and eh look what they are doing to you in Lebanon yaani, the Muslims, what they are doing to you in Lebanon, but this is eh, it didn't work out on me, this is not where I am living here, all the time they are trying to make a war between Muslims and Christians ((Interviewer: $\mathrm{mhm}))$ you know, they are always ((I: $\mathrm{mhm}))$ they are trying to make war, but they never really succeeded to make Muslims against Christians or Christians, eh, since they occupied us, yeah, yeah, but it didn't work, interrogation, after you said no, no, they beat you."

In their meetings with us, the Palestinians speak up against attempts to divide them by repeating that they are a community in which no one is discriminated against on grounds of religion, or status as refugee or longtime resident, or residence status. In an interview with our colleague Arne Worm, a Muslim man from a refugee family put this in a nutshell as follows: "All of us, including our Christian brothers, we all suffer together." In their eyes, we, as researchers from Germany, represented the socalled Western world. The result was that we were almost always, and in vehement terms, presented with the we-image of 'We Palestinians have no internal conflicts, we only have conflicts with the Israelis' (see ch. 2). ${ }^{3}$ This stance has also been made manifest in concrete political moves, such as the administrative decision to allow only Christian candidates in the mayoral elections in Ramallah and Bethlehem, or a decree issued in 2014 by the $\rightarrow$ Palestinian Authority henceforth not to register religious affiliation in identity cards. ${ }^{4}$

Our research has shown that this we-image is also presented by Palestinians in internal discourses, at least in public and semi-public discourses, and in interactions between Christians and Muslims, and that to a certain extent they try to assure themselves that it really is so. If we were to declare ourselves satisfied with these assurances, which we heard repeatedly throughout our ethnographic field work in discussions and in the biographical interviews we conducted, and if we were to describe them as an empirical finding in respect of everyday reality in the West Bank (i.e. not only as part of a learnt discourse), it would be relatively simple for us. By doing so we

interviews with Christian Palestinians of different denominations, as well as a large number of ethnographic interviews and participant observations.

${ }^{3}$ This framing, which led to the presentation of this we-image, was sometimes played down in the course of repeated meetings, or abandoned in favour of a different framing (see ch. 2).

${ }^{4}$ See http://www.maannews.net/eng/ViewDetails.aspx?ID=673377, 28.05.2015. 
would confirm the explicit message communicated by our interviewees and barely hear any objections. This would also mean complying with an unspoken request to focus on conflict-charged relationships with Jewish settlers, Israeli soldiers, and the Israeli occupying power in general. In particular, this would save us from the danger of giving support to the Israeli policy of creating divisions. However, the aim of our research is to reconstruct the complex relations between Christians and Muslims, to identify areas of conflict such as those alluded to in the scene described above, and to open up opportunities for a dialogue which might help to deal with the conflicts.

In the rest of this chapter, we will concentrate on the life situations as well as the 'subjective' perspectives and experiences of Christians in the two cities of Ramallah and Bethlehem and the smaller communities around them, and on the dominant discourse of a conflict-free relationship between Christians and Muslims. Because our focus is on the figuration between Christians and Muslims, we will consider the Christians as one grouping without differentiating between the various denominations and their complex interdependencies and unequal power balances. ${ }^{5}$ In order to highlight how the harmonious and homogenizing we-image becomes brittle, we will present the case of a Christian family and use this example to discuss intergenerational differences.

\subsection{On the interactive (self-)assurance: 'We have no conflicts'}

Most of the Christians in the West Bank live in Ramallah and Bethlehem and the surrounding villages. ${ }^{6}$ Up to the mid 1950s, they formed a majority in both cities, although perceptible numbers of Palestinian Christians began to emigrate from the beginning of the 20th century (see Krämer 2008: 138; Sabella 1994). The size of the Christian communities - at least in relation to the number of Muslims - shrank further following the $\rightarrow$ First Intifada and the $\rightarrow$ Second Intifada. Even in the towns of Beit Jala or Beit Sahour, which still have a Christian majority, the demographic trend suggests that this will no longer be the case in the near future. The Christians

\footnotetext{
${ }^{5}$ On the historical development of the different Christian denominations in the Arab world, and the relations between them and other religious groupings, see Tamcke 2008.

${ }^{6}$ According to the PCBS 2007 statistics, more than three quarters of the Christians in the West Bank live in the Governorates of Bethlehem and Ramallah, and about one quarter in the cities of Bethlehem and Ramallah. In Bethlehem in 2007 about 27 percent of the inhabitants of the city were Christians, while this figure was 35 percent in the census of 1997. According to the census of 2007 the Christians in Ramallah formed about 20 percent of the population (31.5 percent in PCBS 1997). For the municipality of Beit Jala, where the majority is Christian, the 2007 census gives about 55 percent Christians, and for Beit Sahour about 67 percent. These figures from the censuses of 1997 and 2007 give a rough idea, but even employees of the Bureau of Statistics in Ramallah say that they are not entirely reliable. The figures are based in part on an unpublished extract from the 2007 census. We are grateful to the staff of the Bureau in Ramallah for giving us access to these statistics.
} 
fear the loss of their political and social influence and their relatively well established economic and cultural position which can still be observed in certain contexts (see Kårtveit 2012: 98-99). When we explicitly ask about it, no attempt is made to conceal this demographic trend from us so-called Western researchers, but we are repeatedly told by both Christians and Muslims that there are no conflicts between the two groupings. The people obviously feel a need to assure us - and probably also to assure themselves - that religious affiliation plays no role in the Palestinian collective. Yet, in almost all interviews, one of the first things they try to do is to establish whether our Palestinian colleagues are Christian or Muslim. It is considered as politically incorrect to ask about someone's religion directly. For this reason, the Palestinian members of our team - regardless of whether German team members are present or not - are rarely asked directly which religion they belong to. Nevertheless, the question is there and the interviewees try to obtain the information indirectly by asking about the person's family name or place of origin (see Rosenthal 2012). During talks with our Palestinian colleagues it became obvious how confident they feel in their definition of others' religious belonging, even if they have only met them briefly in the West Bank. This labelling usually takes place in the first few minutes of a meeting, and is a clear sign of how important it is to everyone.

The sometimes clearly separate lifeworlds in which people live are visible in interviews, and especially in observations made in family contexts or in public spaces. A good example is the university campus in Bethlehem, where the spatial separation of Christian and Muslim student cliques is obvious. The dividing line is very clear when it comes to marrying someone from a different religious grouping. In our first interviews, we noticed the need for harmony, expressed in highly stereotyped references to peaceful co-existence between Christians and Muslims. We (in particular Gabriele Rosenthal) then began to take advantage of the ignorance of the cultural rules that was ascribed to us by deliberately contravening them. For example, in the last phase of some interviews ${ }^{7}$ we asked whether the interviewee could imagine a child of theirs wanting to marry a person belonging to the other religious community and whether they would accept this. Regardless of whether the person was a Christian or a Muslim, the discourse on the harmonious we-relationship between Christians and Muslims that had been carefully maintained up to this point was usually abandoned, and the interviewee expressed his or her astonishment at the question, making it clear that the very idea of such a marriage was disquieting, and describing it as impossible.

In some interviews we heard explicit accounts of how people felt they had suffered discrimination as a Christian or as a Muslim. In almost every case these were people who are outsiders in more than one way, as discussed in the previous chapter.

\footnotetext{
7 The rules for biographical narrative interviews (see Rosenthal 2011: 151-173; Schütze 1983, 2014) require that we wait until the last phase of the interview before introducing topics that have not been mentioned by the interviewee. Not least, this is necessary in order to avoid influencing and possibly blocking the flow of the interview.
} 
Our analyses show that speaking about experiences of discrimination by members of the other religious grouping, or recounting stories of conflicts between Christians and Muslims, can serve as a means of speaking indirectly about the matter of being discriminated against as a homosexual, which is experienced and perceived as being far more threatening and associated with fears of being violently attacked (see ch. 5).

An example of the kind of everyday experience that is omitted from the dominant discourse, and which usually only outsiders tell us about, is the way that people in Ramallah or Bethlehem who openly show they are Christian, for instance by wearing a cross, have to endure derisive remarks directed at them by Muslim passersby. Aware as they are of belonging to a shrinking minority which is gradually losing its social influence, our Christian interviewees feel threatened by such experiences, but seldom speak about them. Partnerships between Christians and Muslims, as mentioned above, are also generally felt to be threatening, and on the Christian side they are sometimes associated with rumours such as 'the Muslims are out to steal Christian girls'. In those cases known to us, the families, both Christian and Muslim, of the young people involved put pressure on their children to end the relationship quickly. ${ }^{8}$

On the Muslim side, people tell us about their experiences of Christian clientelism. Muslim interviewees complain, for example, that Christian students at the university in Bethlehem are given preferential treatment and have a much better chance of being admitted because of their religion. Another issue is the ownership of land and real estate in Ramallah and Bethlehem by Christians who have emigrated to 'the West'. It is said that the rent they demand is too high and hinders the use of buildings (for more details, see Kårtveit 2012).

Starting with our fieldwork in the spring of 2013, we have identified other cracks in the harmonizing and homogenizing we-image presented to us - also in interviews with established Christians. We first noticed explanations which seemed to us quite stereotyped of how private relationships were better in the past, when one invited people to a party, for instance, without thinking about whether they were Christian or Muslim. This rather glorified and nostalgic view of a past in which, as we will show, the categories 'long-time resident' versus 'refugee' were evidently more important than religious affiliation in the period between 1948 and the $\rightarrow$ war of 1967, is now contrasted with a present in which there are fewer informal contacts between Christians and Muslims. Today, as people sometimes admitted to us, it is important to know the religion of another person, or in other words religious affiliation plays a much greater role today than it used to in the past.

\footnotetext{
${ }^{8}$ We know of two cases in Jerusalem where interreligious marriages were welcomed or accepted by the Christian families. In both cases, these families had a low socio-economic status and were struggling with various conflicts. The interviews in these families showed that marrying into a functioning Muslim family may be regarded as more important than religious affiliation.
} 
We were told by Christians that today, much more than in the past, Muslims are out to achieve political dominance. Before the backdrop of the events in Egypt and Syria, Christians are clearly nervous about how the Arab world is developing, and their fears are linked to thoughts of emigration, or at least to the idea that it is safer to stay within the confines of one's own family. It is too early to say conclusively whether everyday experiences of discrimination, whether of Christians or Muslims, have really increased, or whether this topic has simply become less taboo, or whether discriminating behaviour has become more open or more unambiguous.

\subsection{The Khadir family: Brittle self-assurances}

In order to illustrate the increasingly brittle nature of assurances of peaceful co-existence, we will present an analysis of interviews held in a three-generation family. ${ }^{9}$ This is a respected, old-established Christian family in a village close to Ramallah. In contrast to other villages, the proportion of Christians here has remained stable in recent years, representing about one third of the population. For reasons of data protection we can name neither the village, whose history and present demographic and political development we have closely investigated, nor the names of the family members and their denomination. We have also altered other personal data as far as possible without changing their significance.

In the spring and autumn of 2013 we conducted interviews in the Khadir family (as we have chosen to call it) with six family members belonging to three generations. Here we will discuss the interviews held with Clara (born about 1928), her sons Majed (born in 1968), Ibrahim (born in 1961) and Tawfiq (born in 1958), and her grandson Habib (born in 1997).

For the Khadiris, emigration and travel abroad play a comparably minor role. In other Christian families we interviewed, we frequently heard that a considerable part of the extended family lives in a country in the Americas, especially in Chile and in the US, which both have a big Christian Palestinian diaspora. In addition, many of the Christians we interviewed in the West Bank had themselves spent several years there, either studying or working. By contrast, as far as we know, only one member of the immediate Khadir family lives 'in the West', and of the family members we interviewed none had stayed for any time in 'the West'. This can be understood as meaning that the family is located in Palestine, and this is supported by other biographical data: many family members have Arab names that are not immediately recognizable as Christian, some of the sons attended the state secondary school, and not the Christian private schools that are available, and they studied in Beirut or Baghdad during the Ba'ath period when Iraq was perceived as a supporter of $\rightarrow$ Arab nationalism (see for instance Freitag 2003: 139ff.). During the First Intifada some

\footnotetext{
9 The presentation includes biographical reconstructions based on interviews with individuals and the resulting reconstruction of the family history (see Rosenthal 2011: 208ff.).
} 
members of the family were imprisoned. The family attaches great importance to education, and on the basis of successful school careers they aspire to occupations that are associated with institutional or (socio-) political influence in Palestinian society (judges, teachers, doctors, etc.).

We assume that the Khadiris feel they belong to the Arab cultural area. Along with George Sabra (2006: 48), one could describe them as 'Arab Christians'. According to Sabra (2006: 44), one of the most important characteristics of this Christian position, as against those he calls 'Eastern Christians', is "openness to the larger Islamic context, motivated by the desire for acceptance and equality, and aiming at finding common grounds for coexistence and cooperation." 'Arab Christians' define themselves as members of the Arab or Palestinian nation (and not of another ethnopolitically defined we-group or formation) and tend to identify with the Middle East rather than with other world regions. ${ }^{10}$ Tawfiq, the second eldest son of the family, introduced himself accordingly at the beginning of his life story. He said: "As you know we are Palestinians for a long time." In their plans for the future, the Khadiris, like many other 'Arab Christians', place great reliance on cooperation with their Muslim neighbours and assume that they will stay in Palestine.

It is striking that representations of the village in the media (statements made by the inhabitants in the internet, reports by visiting Christians, media reports, etc.) frequently correspond exactly to the statements made by the family members in interviews and discussions: everyone underlines the really harmonious relations between Christian and Muslim inhabitants, which have existed for a long time and are expressed for example in interreligious traditions (which we cannot describe for reasons of anonymity), as well as in reciprocal visits. All say that the inhabitants, both Muslims and Christians, suffer together under the Israeli occupation, and fighting against it is their most important aim. This variant of the homogenizing and harmonizing we-discourse is put very clearly in the interview with Majed, the youngest son of the family, which was conducted in English by Ahmed Albaba and Hendrik Hinrichsen. Majed attended a public secondary school, studied mathematics at a public college, and works for an insurance firm in a neighbouring town. When the two interviewers open the biographical narrative interview in the usual way by asking him to tell the story of his family and of his own life, Majed begins with a mythical story of the founding of his village, in which various Christian and Muslim families settle in the area as a result of gifts of land to his 'great-great-grandfather' which the latter in turn gave to his Muslim 'friends'. From this time on, says Majed, the members of both religions lived together peacefully in "not co-existence, but shared existence". The picture of harmonious relations between Christians and Muslims in the village painted here dominates the whole of the interview: Majed - like all the other members of the family - later underlines that Christians and Muslims regularly visit each other and cook for each other at weddings and funerals.

\footnotetext{
${ }^{10}$ Sabra (2006: 48) continues: 'In short, the 'Arab Christian' type dislikes the West and hates Israel more than it fears the Muslims, at least publicly."
} 
Interestingly, Majed frames his account of the arrival of Palestinian refugees in the village following the $\rightarrow 1948$ / 49 war - long before he was born - by referring to the existing harmonious relations between the two religious communities. He assures us that the Muslim refugees, many of whom later settled permanently in the village, were treated by the Christians 'like brothers', because the Christians already had a "relationship" with other Muslims living in the village. Thus, as we will show below, he frames the arrival of the refugees in a very different way from his mother Clara, who distinguishes between refugees and long-time residents without mentioning any differences in religion. The period of the First Intifada is also described by Majed as a time of intensive cooperation in the village: Christian and Muslim families formed a single community, and both Christian and Muslim youths were sought by the Israeli army.

Majed's main narrative, or autonomously shaped biographical self-presentation, ends on the one hand with a long explanation of why, in his opinion, 'extremism in Islam' and the conflicts between Christians and Muslims in Syria are due to Western influence, and on the other hand with a clear rejection of Christian emigration from Palestine: even if he "were the only Christian in the Middle East", he, Majed, would not emigrate, but "live in love" with his Muslim brothers. Our supposition that the Khadir family are 'Arab Christians', who identify strongly with the local Arab context and distance themselves from the 'West', seems to be confirmed here. But there is one important difference between the formulations used by Majed and those of his mother, which are presented below: while for her, 'we' is a reference to a homogeneous village community, for Majed the village community continues to exist, but internally it is clearly divided into two religious we-groups. Thus, he is at pains to underline a unity between the two groupings which his mother simply takes for granted.

How can Majed's demonstrative insistence on the harmonious relationships between Christians and Muslims in the village be explained? On the one hand, it can be read as a reaction to Israeli attempts to create splits among the Palestinians. On the other hand, it could be interpreted as a sign that the peaceful co-existence of Christians and Muslims is perceived as being increasingly precarious. There is, after all, no need to express so explicitly and repeatedly something that is taken for granted or perceived to be self-evident.

Majed also refers to changes in neighbourly relations: for instance, today, if you go to visit someone, people think you want something ("you want to do something"). "He's probably come because of the elections", they would say. And if he grew a beard, people would think he was now $\rightarrow$ Hamas, says Majed with a laugh. $\mathrm{He}$ adds that this was not so in the past. Here, Majed describes an increasing estrangement and growing distrust between the inhabitants of the village, which he links to religious differences not directly, but indirectly, by mentioning the Islamist Hamas.

Perceived changes in relationships with the Muslim inhabitants of the village are more explicitly referred to by Majed's brother Ibrahim. After leaving school, Ibrahim 
began to help his father to cultivate his fields. Today, he is the manager of a big firm. The interview was conducted by Gabriele Rosenthal and a Palestinian colleague from Bethlehem, who wishes to remain anonymous. He is a leading psychotherapist in an academic institution which supports the boycott of joint research with Israeli scholars. ${ }^{11}$ He knew the family through professional contacts and arranged for us to meet them. During most of the interview, Ibrahim confined himself to the theme of suffering under the Israeli occupation. After it was finished, the interviewers sat for a time with him, his wife, his brother-in-law and his sister-in-law. When Gabriele Rosenthal broke the discourse rules by asking explicitly about changes in the relationships between Christians and Muslims, Ibrahim addressed our Palestinian colleague in Arabic, in words to this effect: "Excuse me, I shouldn't say this, because you are a Muslim, but I must say it: we are afraid, we are growing more and more afraid of the Muslims, and today it makes a difference whether someone is a Christian or a Muslim." The other people present also said that their relations with Muslim neighbours used to be better, that today they didn't always feel welcome, and that there were less private contacts than there used to be. Above all, they feared that the persecution of Christians in Syria, which they had heard about, could spread to Palestine. In addition to their trust in our Muslim colleague with his professional reputation, we assume that it was the news that Christians had been killed in Syria in spring 2013 that made Ibrahim and his family speak so openly of their fears, something that in our experience was unusual.

Ibrahim, like his brother Majed, claims that the majority of the people in the village are Christians. In this, the brothers paint a picture that is different from that given in the Palestinian census (PCBS 2007), and in other publications, according to which Muslims have been in the majority for some time. Their emphasis on a majority status which seems to be controversial can be read as an attempt to 'defend' the increasingly precarious position of Christians as established inhabitants of the village, especially before the backdrop of certain events in local politics, which we will not describe here in order to preserve the anonymity of the actors.

The interview with Clara, the 85 year old mother of Ibrahim and Majed, was conducted in Arabic by Gabriele Rosenthal and her colleagues. It was dominated by her memories of the $\rightarrow$ Nakba in 1948 and the war of 1967. Clara's narrations are mostly determined by her past perspectives. Married to a relative at the age of fifteen, she had just given birth to her first child when refugees from areas to the west arrived in the village. During the interview, she often describes historical experiences in terms similar to those used by her son Majed. For example, just like him, she says that after the war there was "a refugee under every tree". But there is a decisive difference: she does not frame these stories with the argument that there are harmonious relations between Christians and Muslims in the village. While both Christian and

\footnotetext{
${ }_{11}$ The interview was conducted primarily in Arabic and translated for Gabriele Rosenthal by the colleague from Bethlehem. But there were also passages in which English was used as the medium of communication, mainly because Ibrahim's wife wanted to talk to her in English.
} 
Muslim refugees came to the village, the family who moved into the house next to the Khadiris came, as we were able to find out, from a Muslim village. Clara refers several times to her family's close relationship with these neighbours, without making any mention at all of their religion. She talks for instance about the difficulty of providing food and shelter for the refugees in the village after their arrival in $1948 / 49$, and about the fear these neighbours had of a new confrontation with the Israeli army in connection with the war of 1967.

But when talking about these times, Clara displays a certain sense of superiority which can probably be attributed to her awareness of being a member of the Khadir family, which is a very old established family in the village; perhaps it can also be read as compensation for her marriage into a rather uneducated part of the family. In her self-presentation, Clara uses language that shows she is politically well informed (in the sense of older $\rightarrow$ pan-Arab ideas or ideas of secular nationalism ${ }^{12}$ ), and she underlines that her father was very well educated and politically influential in the village. For example, she talks about how her father was the one who made clear to the other villagers that they had close ties to the land and urged them to stay and not flee. She also talks about his promise to hide and protect the neighbouring family, without mentioning that they were Muslims. This is remarkable because talking about the way her father (who, incidentally, was a priest) was always willing to help others would be a good opportunity to point out how Christians and Muslims cooperated in the village. We presume that at this point of the interview Clara recounts her memories of past events from the perspective of the time, a time when religious affiliation was possibly not important as a distinctive feature, and no discourse was needed for the evocation of harmonious relations, as is the case today. Clara refers explicitly to her religion at very few points in the interview (for instance in the context of her marriage). It is mainly her account of the religious education of her father that is framed by the topic of religion. Otherwise she sticks to her past perspective, and her stories are dominated by descriptions of rural life and contacts between villages and within the village.

The fact that Clara makes almost no reference to people's religious affiliation is also remarkable in the light of an interview with her son Tawfiq on the day before, in which she participated. This interview was conducted in both Arabic and English by Gabriele Rosenthal together with her colleague from Bethlehem, and in it she made clear that she would be interested to know more about relationships between Christians and Muslims. In line with the harmonizing we-image, Tawfiq spoke at length about how the two groupings have no problems with each other. Clara, for whom parts of these sequences were translated into Arabic, then said that today there were not as many contacts as there used to be, and explained that in the past it was taken

\footnotetext{
${ }^{12}$ Pan-Arab ideas were very popular in the West Bank in the 1950s. They were succeeded by a strong movement in favour of Palestinian nationalism, but "the tension between pan-Arabism and Palestinism would not entirely disappear in the 1960s" (Kimmerling/Migdal 2003: 227 and see 225-227; see Lybarger 2007a: 784-786).
} 
for granted that families invited each other to funerals and other festive occasions, regardless of their religion.

The generational difference between Clara and her sons in respect of explicitly distinguishing between Christians and Muslims can also be conceived of as being due to different historical generations in the sense proposed by Karl Mannheim (1952). If we do not regard these differences as accidental, but as being conditioned by different experiences, we might expect that in the generation of the grandchildren an even greater distinction between Christians and Muslims would be made. This expectation was confirmed in an interview with one of the older grandsons (born about 1982), ${ }^{13}$ but not, or not to the same extent, in the interview with Tawfiq's eldest son Habib (1997), which was conducted by Gabriele Rosenthal and her colleague from Bethlehem during a visit in the autumn of 2013. In the latter case, interestingly, our assumption seemed to be correct on the level of experiences and practices, but not so on the level of how Habib talked about it. At the time of the interview, he was sixteen and due to take his final secondary-school examinations (tawjibi) in one and a half years. His very controlled self-presentation and his determination to speak English even though this wasn't easy for him, suggest that the interview can be read as a kind of demonstration of family education and career expectations and an Arab-Christian self-understanding in the presence of people from the outside. This created an interview setting which made it even more difficult to talk about the taboo issue of tensions and conflicts between Christians and Muslims in the West Bank. Habib sees himself as being in the process of becoming adult, and his self-presentation is clearly shaped by the uncertainties and self-discovery processes of mid-adolescence. He says that he used to be weak, but that now he is strong; that in the past he used to go out a lot and waste a lot of time, but that now he is concentrating on his education, without which he will be "lost". He intends to study medicine like his father and he describes the course of his future university studies in detail. Then he will begin by working in his father's practice and after two years he will be able to have patients of his own. As a member of the younger generation, he actively locates himself in Palestine and does not even mention the possibility of going abroad.

Interestingly, however, he is at a Christian private school, while his father went to the public school. And he has now (more or less voluntarily) given up the leisure activities (such as playing billiards) which he enjoyed six months ago with a mixed Christian-Muslim group of friends. In answer to our questions, he says that he no longer meets these friends outside school and that he has practically no contacts apart from his family, in other words that he spends his free time almost exclusively with his extended family and thus in a purely Christian environment.

Habib also speaks of having had "problems with other people" at school, which he does not further explain. In the interview he associates these 'problems' themati-

\footnotetext{
${ }^{13}$ This interviewee spoke very openly about what he sees as increasing conflicts between Christians and Muslims. His arguments show that he supports Arab nationalism, and above all he criticizes those Christians "who do not serve their country but emigrate like cowards".
} 
cally with, among other things, "respect for religions", and says only that Muslim youths from a nearby refugee camp, which he regularly passed on his way home from school had made scornful remarks about his father and his family name. However, when we ask what kind of remarks they made, he avoids answering directly. It is quite possible that here Habib is remembering experiences of suffering discrimination due to his religion, but that he does not want to discuss them in the interview situation, or that he has learned not to talk about them explicitly.

Habib's answers to other questions put by the interviewer also suggest that he cannot or will not talk about concrete experiences in connection with such themes. When asked what he thinks of the situation in Palestine's neighbouring countries, he says that he "feels bad": "I feel bad about Syria so bad S- Syria is a wonderful place there is the terrorist is destroying the churches and explode it, this is so bad and dangerous." But when asked whether he, as a Christian, is afraid because of the situation, he answers: "No I'm not I'm proud that I am Chr- masibi [...] Christian, so proud of this, I I do not feel ashamed or scared." Subsequently Habib tells a story that is often heard in connection with the harmonious relations between Muslims and Christians in Palestine. He relates how Umar ibn al-Khattab, who conquered Jerusalem in 637, refused to pray in the Church of the Holy Sepulchre because this would throw doubt on its status as a Christian place of worship. ${ }^{14}$ Then he accuses the Israelis of planning to destroy the $\rightarrow$ al-Aqsa Mosque, and says he believes that the Church of the Holy Sepulchre is therefore also endangered.

In this situation of having to answer direct questions, Habib remains faithful to the we-discourse in which the neighbouring countries are described as being close but different, while the relationship between Christians and Muslims in Palestine is harmonious. But in a different context, he almost casually mentions this issue again. Habib is asked what he hopes his life will be like ten years from now. He says that he hopes for success in his career, freedom to travel, and that "everybody be together [...] as Muslims and Christians to be together no, at the past qabel kanat al-'alaqat ahsan [the relationship used to be better]". It is hard to say to what degree Habib has personally experienced discrimination in his everyday life, or has noticed, even at the age of sixteen, a deterioration in relationships between Christians and Muslims. It is possible that in the interview setting his chief aim is to 'correctly' reproduce the accepted views of his family concerning changes in these relations. Habib's remarks about being 'proud' to be a Christian are reminiscent of the assurances of Christian 'steadfastness' made by his uncle Majed (see above) and seem like a kind of rehearsal of 'Arab Christianity'. These statements, like the detailed description of his career plans, are probably intended to demonstrate in the presence of his parents how well he has internalized his family's expectations and self-constructions. But on the level of experiences and practices and the level of the latent meaning of the text of the interview, there are hints that Habib has retreated into the confines of his family, has

\footnotetext{
${ }^{14}$ Cohen (2011b: 77), for example, describes an interreligious meeting of Christian and Muslim clerics, at which a Greek-Orthodox bishop told the same story.
} 
had experiences of discrimination that he cannot talk about because this is a taboo issue, and that he has noticed a deterioration in the relations between Christians and Muslims in the village.

That this interview is also a kind of practical training in the collective we-image of the Christians in Palestine becomes clear when Gabriele Rosenthal asks what would happen if he were to fall in love with a Muslima. First, a loud laugh from Habib's mother can be heard in the background, before his father, who joins us towards the end of the interview, says in a didactic tone: "I don't think that you are going to fall in love with a Muslim woman", to which Habib responds by saying: "No I don't I will not gonna allow this." After this, Habib's mother creates a kind of 'test situation' for her son by asking him how many children he wants to have and indicates her approval of his answer ("three children"). It is clear that the family has delegated a task to Habib and that he is under considerable pressure to fulfil it: he must 'establish himself successfully as a Christian in Palestine', and is currently busy renouncing anything that might hinder this, such as 'hanging out' with other young people.

\subsection{Conclusion}

With this case study we have tried to show how the harmonizing and homogenizing collective we-image of the Palestinians in the West Bank is becoming increasingly brittle, and to make assumptions in respect of generational differences. As compared to the results of the field work we carried out between 2010 and 2012, many of the ethnographic and biographical interviews we conducted in 2013 and in the spring of 2014 show a greater tendency to talk about the separate lives of Christians and Muslims, and about experiences of discrimination on both sides. It is mainly young Palestinians and - another important finding of our study - mainly people with a low socio-economic status who speak most about religious, and also political, differences. In summary, we can make the following assumption with regard to generational differences, which needs to be tested by further empirical research: while members of the older generation, who experienced the Nakba as a formative event in their youth, still distinguish today between long-time residents and refugees, members of the middle generation, who were born before or shortly after 1967, are far more concerned with the distinction between Christians and Muslims, and rely strongly on a discourse of harmonious relations. Members of the young generation on the other hand, who are usually the grandchildren of the Nakba generation, are beginning to question this discourse, and we suspect that they experience the difference between Christians and Muslims in their everyday lives. Habib, the grandson presented here, belongs to an established Christian family which emphatically regards itself as 'Arab Christian'. He represents a generation unit of young Arab Christians who are placed under enormous pressure by their families to perform and adapt, and who are expected to fulfil the family's 'mission' by staying in the country in order to strengthen the collective interests of the national we-group. 


\title{
4 The homogenizing we-discourse and the social positioning of the refugee camps
}

\author{
Arne Worm, Hendrik Hinrichsen, Abmed Albaba
}

\subsection{Introduction}

In this chapter we will discuss the results of our research into the experiences, the we- and self-images, and the social positionings of Palestinians living in the $\rightarrow$ refugee camps in and around Bethlehem and Ramallah. ${ }^{1}$ There are probably no other localities (with the exception of the Old City of Jerusalem) that are charged with such great symbolic and political significance in the Palestinian discourse as the refugee camps. Their existence to this day is a part of the collective history, a reminder of the $\rightarrow$ Nakba (1948/49) and the political claim to a $\rightarrow$ right of return for those Palestinians (and their descendants) who fled or were expelled from areas which became part of the Israeli territory in the context of the Israeli-Arab war of 1948/49.

Today, around 65 years since they were set up, the refugee camps seem to have little in common with the provisional tented camps that were first erected on these same sites. Today, the camps consist of permanent buildings and can be said to form neighbourhoods; nevertheless, they are clearly distinguishable from the surrounding localities by their narrow streets, chronic overcrowding and infrastructural deficiencies (Hanafi 2009: 500). Together with the fact that the walls of the houses are covered with graffiti and pictures in memory of the Nakba and the home villages of

\footnotetext{
${ }^{1}$ In addition to ethnographic interviews, we conducted 46 biographical narrative interviews in the refugee camps of Deheischeh, Aida, Al-Amari, Qalandia, Jalazoon and Arroub, in the regions of Ramallah and Bethlehem.
} 
the refugees, these specific local features mean that these neighbourhoods are easily recognizable as refugee camps, both for Palestinians living in the West Bank and for foreign visitors.

However, the history of the camps and their inhabitants, their present positioning in Palestinian society, and their internal structure cannot be reduced to the results of the events during al-Nakba in 1948/49 which led to their being set up in the first place, nor to their presumed significance as a political symbol. Our research shows that although there are some commonalities between the refugee camps in the West Bank, both in respect of their history and in respect of the self-images and ascribed images of the camps and their inhabitants, it is very important not to homogenize them and not to regard them in isolation from their local and regional social contexts and the conflicts that have often arisen in these contexts. Our analyses show that there are considerable differences in the biographical courses and present situations of the Palestinians living in the camps, depending on which generation they belong to, their socio-economic circumstances and their political objectives, and also big differences in the power chances of different actors within the camps.

Some basic information about the refugee camps in the West Bank and important historical events, such as the Nakba, the $\rightarrow$ First Intifada and the $\rightarrow$ Second Intifada, is given in the Glossary at the end of this book. We will not repeat this information in this chapter, but will concentrate instead on the three types of we- and self-presentation which we have been able to identify on the basis of our empirical data. The following questions are important for the discussion:

a) To what extent and how clearly do the interviewees follow the rules of the harmonizing and homogenizing we-discourse in their self-presentations? (see ch. 2)

b) How is this related to the biographical experiences and positions of the speakers in their present-day local and supralocal figurations?

In the interviews we carried out in the camps, comments about the special character of the camp as a social space and its inhabitants as a we-group with a shared collective history, as well as the present-day precarious living conditions and the experiences of violence, were a part of all self-presentations in one form or another. But when it comes to following the we-discourse, there are big differences.

On the one hand, there are people who follow the we-discourse in a practised manner all the time' (type 1). In their presentations, these people describe the flight and expulsion of the refugees and life in the camp as being representative of the experience of all Palestinians, including longtime residents in the West Bank. Differences in respect of the way the camps are disadvantaged within Palestinian society, or conflicts between those living inside and those living outside the camp, are not mentioned, nor is any reference made to inequalities within the camp. This we-presentation is the obvious way in an everyday context for people in the refugee camp to talk about themselves to people from 'outside' the camp. The fact that the interviewers are per- 
ceived as being from 'the West' certainly plays an important role in this framing. Yet this discourse is internalized, and so well 'rehearsed' that it is also used in interviews conducted only by our Palestinian colleagues. This kind of we- and self-presentation is used mainly by Palestinians who have an established position within the internal power balances in the camp, or who are accepted in the camp as authorities. They usually belong to the generation of the children of the Nakba generation, and their status in the camp is closely bound up with their political activities and the networks they formed during and after the First Intifada. As we will show below, when the grandchildren generation makes this kind of presentation they follow the powerful members of the second generation.

On the other hand, there are people who openly criticize the $\rightarrow$ Palestinian $\mathrm{Na}$ tional Authority and, in a more restrained manner, also the internal hierarchies in the camp, and who express dissatisfaction with the situation in which they are living. In our sample, the interviewees who represent this second type, which we call 'a critical approach to the we-discourse', are young men (Arabic: shabab) who are outsiders in respect of the power balances within the camp, and who belong to the grandchildren generation of the refugees. They were involved in violent clashes with the Israeli army, or with the Palestinian National Authority, during their (late) adolescence, after - or in some cases during - the Second Intifada (2000-2005). Today they see and present themselves as 'worthy but marginalized combatants'.

The third type of we- and self-presentation is characterized by a purely situative use of the we-discourse? Depending on the context, framing and conduct of the interview, these people oscillate between making a stereotyped presentation of the wediscourse and the homogenizing collective memory, into which they fit their own life story and family history, whether compatible or not (see ch. 6.3; Rosenthal 2012), and talking about their own life and the history of their family. The representatives of this type are mostly camp dwellers - but also people living outside the camp who personally experienced the Nakba and the flight in 1948/49, in other words the Nakba generation. Because they look back on their own experiences, which are sometimes very distressing and traumatic and often do not correspond to the hegemonic we-discourse and the collective memory, their memories of these experiences are revived, depending on the situation. They talk about them whenever the interview context allows it. As we will show, it is the members of the second and third generation of refugees who try to avoid talking about these memories. ${ }^{2}$

\footnotetext{
2 There is a fourth type which is not discussed here: a biographical self-presentation in which the hegemonic we-discourse is (almost) completely irrelevant, meaning that it is used neither all the time (type 1) nor situatively (type 3), nor critically (type 2). Our analyses show that the representatives of this type are all in a very strong way outsiders in the camp, and that they are undergoing a crisis which they experience as an 'individual' crisis. For instance, we conducted an interview with a Palestinian woman with a Jewish husband who sometimes also lives in the camp. She had suffered extreme domestic violence not only in her present situation, but also in the past when she lived with her parents. Her self-presentation is focused on her 'individual' suffering and her difficult family history and personal life story. In this interview the we-discourse is almost completely absent.
} 


\subsection{The we-discourse: Life in the refugee camp as representative of the whole Palestinian we-group}

These presentations are strongly focused on the camp and its history as an experiential space. They stress the collective suffering of the camp dwellers as a result of the Israeli expulsion and occupation (the Nakba; arrests and killings of camp dwellers by the Israeli army; the chronic infrastructural deficiencies and the difficult economic situation).

In their we- and self-presentations, the representatives of this type largely follow the rules of the practised we-discourse (see ch. 2): both internal differences in the camp, and differences between the camp dwellers and other Palestinian groupings, are, as we will show, either played down or barely thematized at all. Also in agreement with the we-discourse, the Nakba, which is usually the starting point of the presentation, followed by the founding of the camp, is simply equated with the year 1948 . The Nakba generation's story of displacement, including that of their own family members, parents or grandparents, consists of exemplifying stories of suffering that they experienced themselves or heard about from others, and the life of the Palestinians before 1948 is idealized; they explain that in those days everyone lived together without conflicts, everyone had free access to water and land, and life in general was freer and easier. This discourse, which is related to the hegemonic collective memory, centres around the Nakba and the present difficult living conditions which are a direct result of it. Consequently, events and phases in the collective or family history relating to the period before the Nakba or after it, up to the First Intifada, are not talked about. Our analyses of the interviews show clearly that concrete experiences of the family during the Nakba are often not preserved in the family memory.

In connection with this contrast between the hard living conditions in the camp and the idealized image of life before 1948, representatives of this type stress the right of return more strongly than other groupings; they entertain the vision of a return, and they refer to the political necessity of maintaining this perspective. This is expressed not only as the objective of the refugees, but as the objective of all Palestinians. Nevertheless, the way these presentations focus on the collective situation in the camp, relegating 'individual' experiences outside the camp (such as school or work) to a background that is hardly mentioned, transports the image of a specific group situation. Life in the camp is presented as the only axis that is relevant for the life story. However, this location of the speakers in a we-group 'in the camp' is not necessarily in contradiction to the we-discourse, because in this variant the history and the situation of the camp is painted as a representative part of the general Palestinian experience. To put it more precisely, this variant says: 'The general experience of the Palestinian we-group under the Israeli policy of expulsion and occupation is made particularly clear in the camp.' Significantly, this pattern is not used (or not as rigidly) by Palestinians from refugee families who do not live, or no longer live, in the camp. In other words, the variant of the we-discourse described here is a camp-specific variant. 
Our field work in the refugee camps shows that this we framing is the most obvious and the most practised we- and self-presentation in the everyday world, and is connected with the unequal power relations in the figuration between Israelis and Palestinians (see ch. 2). But the framing of interviews according to the rules of the we-discourse also seems to be bound up with the position of the speakers in the internal power balances in the camps. These power relations, and the relations between the camp authorities and groupings outside the camp, and with the PA, are highly complex and differ considerably depending on which camp in the West Bank (see Hanafi 2010: 9ff.). However, our findings suggest that those speakers who use the we-discourse most rigidly move in a milieu from which a part of the powerful elite in the refugee camps comes. This milieu consists of persons whose engagement and political activities in the committees ${ }^{3}$ before and during the First Intifada ended with their attaining a position in the camps that brought status and authority. As a rule they are the children of the Nakba generation. During the founding phase of the PA in the 1990s some of these people were prepared to accept integration in or cooperation with the Authority. ${ }^{4}$ Their established position in the camp also depends on being regarded as legitimate representatives of the interests of the people, both within the camp and in external figurations (including with the PA). One could say that they have to speak for the people living in the camp in particular, but also for the Palestinians in general.

This can be illustrated by our interviews with two people who are both active in organizations in their camp and in a relatively established position. We presume that for them their we- and self-presentations in the we-discourse constitute a kind of symbolic capital (Bourdieu 1998) which helps them to preserve their 'individual' and 'organizational' scope of action. They are also both used to dealing with foreign visitors, in particular from Europe (volunteers, journalists, etc.).

Abu Samer (born in the camp in the early 1950s, now about 60 years old), who was interviewed in Arabic and English by Arne Worm and Ahmed Albaba in March 2013, works in a local organization that regularly carries out political tours of the

\footnotetext{
${ }^{3}$ The First Intifada was carried out by a large number of networked local committees. These were organized by a party, by students' and worker' associations, or by neighbourhood and family networks (see Robinson 1997).

${ }^{4}$ Hanafi (2009: 509) sums up this development as follows: “(..) refugee camps no longer enjoy harmonious communitarian structures headed by local notables (mukhtars). Since the end of the 1970s, we have witnessed the emergence of a new elite whose legitimacy is based on the Palestinian national struggle. This situation was changed after the launching of the Oslo process, because participation in this struggle alone is no longer sufficient for someone to become a power broker." To this one could add that another important factor for the chances of a "power broker" in the refugee camps today is having links to the PA that were forged in the 1990s. In its development phase it was not necessary to belong to the $\rightarrow$ PLO elite or the dominant Fatah party, but only to be a recognized 'worthy combatant': "Some cadres in the left-wing fractions, especially those with a record of struggle under Israeli military rule or in exile, were given honorary posts within PNA ministries." (Taraki 2008: 69; see also Bornstein 2001: 563). However, this does not mean that most of the 'Intifada veterans' were interested in cooperating with the PA.
} 
camp for foreign groups; it is also networked with foreign NGOs that organize trips abroad for children and adolescents from the camp. The organization is financed partly by foreign partner organizations, and partly by the PA. To this day the leading members are regarded in the camp as 'worthy' Intifada combatants. We will show below (see chapter 4.3) that such organizations are not undisputed in the camp. Among other things, they are accused of cooperating too closely with the PA and of practising clientelism within the camp. The people in the camp have an ambivalent relationship with the PA: while they often reject its offers of help (for example in the provision of security services) in favour of maintaining their autonomy, in other spheres they criticize its failure to support the camp (infrastructure; political representation), or they even work closely together with the Palestinian authorities. Indeed, various organizations and committees with varying degrees of 'closeness' to the PA compete for influence and resources in the camps (see Hanafi 2010: 8).

Abu Samer is a member of the executive committee of an organization that is close to the $\rightarrow$ Fatah and to the PA. This organization provided us with accommodation for a few days during our field work. Abu Samer willingly offered to let us interview him, but announced before the interview that he did not want to talk about himself personally. ${ }^{5} \mathrm{He}$ focuses in his presentation on the Nakba, the difficult collective conditions in the camp that have resulted from it, and the way his organization is working to improve the situation in the camp, in cooperation with foreign partners. Abu Samer's interview framing serves as a correction of the image of the Palestinians as "criminal and bloodthirsty murderers", as he says, which is ascribed to them by the Israelis and which also dominates in Europe. His presentation is at first restricted to the camp as the place of action and of suffering. But to our question about differences between the camp and the town, he answers that the camp can be considered as representative of a general, collectively shared situation: "What happened here in the camp also happened elsewhere the result was the same."

Throughout the interview, Abu Samer insists that there are no differences between poor and rich, between Christians and Muslims or between the camp and the town. Everyone is affected to the same degree by the difficult situation. There is poverty, but there is no crime. The subject of 'crime', which is brought up several times by Abu Samer himself, is interesting because according to our results, in contrast to the stereotypes in respect of 'terrorists' or 'Islam', crime is not perceptible as an important element in the 'European images' of Palestinians that are circulated in the local context. So how can Abu Samer's references to crime be interpreted? It is striking that he mentions it whenever differences between the refugees and the longtime residents are in the air, in other words whenever such differences are co-present as a theme. According to our empirical findings, the idea that the refugee camps are

\footnotetext{
${ }^{5}$ Within this framing Abu Samer avoids speaking about his personal biography. To our question about the First Intifada, which happened at a time when he was away in Saudi Arabia for several years, he insists more than once that he kept himself fully informed all the time. It obviously belongs to the requirements of the discourse to stress the permanent nature of belonging to the collective.
} 
'bad areas' plagued by crime (with rumours of stolen cars, drug dealing, and so on) is common among the long-time residents of the town. Inhabitants of the refugee camps and long-time residents all refer to this ascribed image in their interviews, for instance when they talk about why many long-time residents won't allow their children to visit friends in the camp. According to our reading, Abu Samer's emphasis on national unity is a form of defence against this inner-Palestinian ascription.

There is another interview situation which also shows how unwilling Abu Samer is to speak about topics connected with the negative inner-Palestinian images of the refugee camps. During our field work in this region there was an incident in which shots were fired at a police station during the night. A local news portal reported that the culprits were people from the camp in which Abu Samer lives, and that the shots were fired in the context of a family dispute. On the following day, we asked Abu Samer about it, but he brushed the subject aside, saying it was the work of some crazy people and it didn't interest him because it was not a "national matter". When we ask him in the interview about the economic inequalities between people in the camp and people outside it, which he had referred to himself, Abu Samer relativizes his statement and underlines the fundamentally shared situation and the resulting collective aims of all Palestinians (such as the right of return): "We everybody waiting the day to go back to their land we waiting for the day making our flag saying it's a Palestinian state this is the dream of all the Palestinian around the world if he is rich if he is poor if he's old if he is young it is a Palestinian dream you'll never stop that nobody can forget it."

Here, the relativizing of differences (in this case economic differences) in accordance with the rules of the homogenizing we-discourse, goes together with the extension of political aims to include the right of return. Without breaking the rules of the we-discourse, a group-specific theme is thus inscribed in the national we-discourse. From other interviews we know that the right of return not only enters into the Israeli-Palestinian figuration as a political position, but must also be regarded as playing a role in the negotiation of power balances in Palestinian society, and in maintaining the autonomy of the camps. Thus, in the conflict with the PA over whether people living in the camps need to pay their electricity bills, ${ }^{6}$ some people claim that they are only living there on a temporary basis. They argue that any form of institutionalization must be rejected as a denial of the right of return. In Abu Samer's homogenizing presentation such themes are avoided, but there are signs that the 'refugee variant' of the we-discourse outlined here can be located not only within the figuration of conflict between Israelis and Palestinians, but also in the context of the inner-Palestinian positioning of the camps (as illustrated by Abu Samer's rejection of the crime allegation).

Similar rules for we- and self-presentations are revealed in an interview with a woman who belongs to the generation of the grandchildren of the Nakba generation. At the time of the interview, which was conducted in English by Hendrik Hinrich-

${ }^{6}$ See http://english.al-akhbar.com/node/15037 (04.05.2015). 
sen and Arne Worm in January 2011, Raja (born in 1987) is 25 years old and lives in a camp outside Bethlehem. The course of her biography shows clearly how the use of the 'we-discourse' is connected with her deep involvement in the activities of a local cultural centre, her closeness to the established activists of the second generation, and her increased possibilities of action for a self-determined life as a woman. Raja's father, whose parents had to flee in 1948, was a member of the second generation during the First Intifada. He was active in various committees in the camp, and was imprisoned several times by the Israelis. He helped to found this cultural centre during the $\rightarrow$ Oslo phase in the 1990s and at the time of the interview he is a member of the executive committee there. Mainly because of his political activities and his imprisonment, he belongs to the established in the camp. For his daughter Raja he is an important identity figure.

An outstanding feature of her biography is the dynamic way she has risen socially in a very politicized and difficult socialization context. She was born shortly before the First Intifada and grew up in the camp, where she experienced both the massive presence of the Israeli army, and a family life that was strongly focused on coping with this situation. Her involvement in the local cultural centre has opened up individual possibilities of action which are a relief for her and connected to prestige; they are closely bound up with playing a role that represents the camp and 'Palestine' (for instance as a member of a Dabke dance group 7 ). The centre has enabled her to gain access to spaces of action outside the camp. For example, she has spent several years studying in France, as a result of the cultural centre's contacts at the end of the Second Intifada. This has made Raja's life special in comparison to the lives of most other people in the camp. She still receives a grant through contacts of the cultural centre, in which her father is a member of the executive committee. After completing her studies, Raja returned to the camp and at the time of the interview she has been living with her family again for about a year.

Although Raja, in contrast to Abu Samer, agrees to take part in a family and life history interview, her presentation is also focused on the difficult conditions in the camp and the fact that she has never ceased to belong to this context. The 'red thread' that runs through all sequences is her continuous membership of a we-group all of whom without distinction are suffering from the Israeli occupation. This thematic field includes themes from the family history such as the 'expulsion of her grandparents and other family members from their home village' and life in Palestinian villages before 1948 which is depicted as idyllic.

Right from the beginning, Raja presents her own life story as typical of a group situation that is characterized by infrastructural deficiencies and the resulting hardships, and by arrests, curfews, house searches and killings of Palestinians by the Israeli army. With hardly any exceptions, she recounts her whole life story very strictly in terms of this thematic framework, and presents the experiences of her family and

\footnotetext{
${ }^{7}$ Dabke is a folk dance that is found in many Middle Eastern countries. On the role of Dabke as a national Palestinian self-presentation, see Kaschl 2003.
} 
herself in a manner that suggests that they could just as well be the experiences of any other member of the we-group in the camp. A good illustration of this is her response to our question about what happened when she visited her father in prison as a child:

Interviewer 1: Can you maybe, tell little bit more in detail what the situation was like?

Raja: I don't, okay when I was there I don't remember like I remember he was very like tiring day ((I.1: "hmm")) but now these people tell me, who they go visit their=their siblings or sons

Raja does not engage in a process of remembering, but argues instead that it was the same as for everyone in the we-group, for they have all had similar (distressing) experiences. The we-discourse in which self-experienced events are representative of the collective experience prevents Raja from presenting a (memory-based) narration made up of a string of stories in which Raja herself is the centre of the action. Instead, she uses a thematic structure that relates other people's experiences to her own experiences and vice versa.

In her biographical self-presentation, Raja hardly mentions, or passes over, conflicts and tensions between different Palestinian groupings inside and outside the camp. For example, she does not speak about, or only hints at, the disputes between secular and religious political milieus that are carried on in her immediate environment. There have been repeated conflicts within the camp over the work of the cultural centre which since its founding has been close to the secular political parties; and shortly before the outbreak of the Second Intifada there was a case of arson there which gave rise to controversial discussions. But when we asked Raja directly about this by e-mail, she denied knowing anything about it and failed to react to further attempts to contact her.

Raja speaks only cautiously about her controversial position in the camp as a woman who moves increasingly in the public sphere, which is mainly a male preserve. Within this "patriarchal society", as she herself calls it, she is relatively privileged and has opportunities to act autonomously (for example to spend long periods abroad), because she plays a prominent representational role. In her main narrative, Raja says nothing about the seven years she spent in France - the largest part of her adult life - and makes only curt responses to our subsequent questions. This systematic omission of biographically important topics contributes to creating an impression of unquestioned membership of a homogeneous camp community, in which everyone is equally affected by the consequences of the conflict with the Jewish Israelis. For Raja, this we-presentation is what she has practised during her life, it is a source of prestige for her in the present, and it gives her the privileges to act that we have referred to. 


\subsection{Critical approaches to the we-discourse: Marginalization of the shabab 'after Oslo'}

Among the interviews we conducted in the refugee camps there are several cases in which the interviewees do not follow the rules of the homogenizing we-discourse, and explicitly refer to 'inner-Palestinian' discriminations, differentiations and conflicts. Before discussing these presentations, we will first take a look at certain commonalities in the life courses of these people. They are young men aged between 18 and 25 who are grandsons of the Nakba generation and who have spent their childhood and adolescence in a refugee camp, where most of them still live today. They have in common that in their (late) adolescence, after the Second Intifada, and in some cases during it, they took part in demonstrations and violent 'confrontations' both with the Israeli army, for instance at checkpoints or during attempts to prevent nocturnal arrests in the camp, and with the security forces of the Palestinian Authority. ${ }^{8}$ Their involvement in the confrontations led to sentences of several years (one to three years) in Israeli prisons, and some of them were detained for a few days or weeks by the Palestinian Authority. Two of the men we interviewed were shot by Israeli soldiers and still suffer today from the long-term effects of their wounds, which affect their ability to work. In addition, the young men have no school leaving qualifications, or only 'poor' results, which means they have no chance of entering university. Since being released from prison, they have been unemployed or have had only precarious, illegal jobs as 'day labourers' on building sites or in restaurants in Israel. During the time we have known them, starting in spring 2013, they have barely succeeded in securing permanent employment. Their efforts to find work or plans to emigrate to Western countries have often failed. Their failure to find employment means that these young men are unable to save money to build a home of their own, or add an extension to the house of their parents, which is usually a precondition for marrying, to say nothing of the costs of a wedding and founding a family. Munir, whose case is discussed below, has married despite being unemployed and has piled up high debts to pay for his wedding and rented accommodation outside the refugee camp. ${ }^{9}$

The interviews with the young men were conducted during this phase of unemployment. An analysis of their self-presentations shows that they are used by the interviewees mainly as an opportunity to talk about their precarious biographical

\footnotetext{
${ }^{8}$ In these confrontations they threw stones and Molotov cocktails, set up barriers and occupied main roads. But they have never used firearms or attacked Israeli civilians, and they are not organized on a party basis, even if they sympathize with certain parties. Thus, they have been involved in clashes resembling those which gained enormous attention and a certain degree of fame both in mass media discourses and academic discourses on 'stone throwing youths' in the First Intifada (see Giacaman/Johnson 1989; Hudson 1994: 128ff.; Kuttab 1988). 'Confrontations' of this kind involving youths from the refugee camps have become a part of everyday life in recent decades, even outside phases of high intensity conflict like the First or the Second Intifada.

${ }_{9}^{9}$ For parallels to the concept of 'waithood', see Singermann 2011.
} 
situations, and therefore do not follow the rules of the homogenizing we-discourse. Stories about their own 'resistance actions', the way they were arrested, wounded or imprisoned, in other words their own "resistance record", to borrow a term from Loren Lybarger (2007b: 134), are not used as evidence of the suffering of a homogenized Palestinian national collective under the Israeli occupation. Rather, our interviewees present their biographies within the thematic field of 'the marginalization of worthy combatants', which can be paraphrased as follows: 'We are now disadvantaged in Palestinian society because of our struggle against Israel, which is a necessary struggle.' The following thematic components constitute both the we-image and the self-presentations of these young men:

a) The young men frame their personal resistance records by referring to the necessity and the importance of the 'struggle against Israel'. They conceive of resistance to the Israeli occupation and defending the right of return of the refugees as part of the duty of each young generation to 'liberate Palestine'. They also refer to the counter discourse which was developed in the context of the First Intifada, and which interprets imprisonment by the Israelis as a 'school' (see Rosenfeld 2004: 238). But an analysis of their self-presentations shows most importantly that when the young men go into details of their 'resistance actions', talking about how they were wounded, arrested and imprisoned, they are offsetting the way they have 'served the Palestinian cause' against their present social position, which they perceive as one of deprivation, and contrasting the two. Starting from a we-image as 'marginalized combatants', they say, in some cases explicitly, that they believe they will never find employment because they have been in prison, or that they will never be able to 'afford' anything because they have been 'wounded in action'.

b) The figuration between the people in the refugee camps and the long-time residents of the West Bank is also negotiated by these young men within the thematic field of 'marginalization as worthy combatants'. As they see it, the refugees in the camps, although harder hit by the Israeli occupation and more involved in resistance against it, are disadvantaged in comparison to other Palestinian groupings.

c) A central element of the biographical self-presentations of the young men is 'marginalization as combatants' within the refugee camp, which they attribute mainly to the milieu of established former Intifada veterans who now cooperate with the PA, as described in section 4.2. The young men accuse the veterans of failing to take into account the 'resistance records' of the recipients when distributing resources available to them, but of behaving in a clientelistic manner. They claim that in the camp these established spread gossip (Elias/Scotson 2008: 31) that they are 'unemployed youths' who 'sell drugs' in the camps. And they say that some of the established men even try to ensure they are not issued with the certificate of good conduct (Arabic: 
Shahadat Husun al-Seir wa al-Suluk) that is required for many kinds of employment (including service jobs in the private sector). Thus, they are critical of the actors and organizations in the circles to which Abu Samer and Raja belong. As we have shown above, these actors do not talk about internal tensions within the camp and try to present the refugee camps as 'homogeneous units' through systematic omissions in their we- and self-presentations. However, the young men show much more restraint in talking about these particular actors than they do in talking about the marginalization of refugees in general.

d) The young men link talking about their 'resistance record' with serious complaints about the Palestinian Authority. They claim that the PA "hates them anyway", "asks the same questions as the Israelis" in interrogations following arrests, and functions as a "second occupying power". They say it does nothing for the refugees, and only seeks to get a greater hold and more administrative authority over the relatively autonomous refugee camps in the West Bank.

e) Other biographical elements, such as experiences in the context of school, or their relationship with their parents, grandparents or siblings, and the history of their family in general, are introduced by the young men only to the extent that they are relevant to the above-mentioned thematic areas, and as a rule they do not elaborate on these issues narratively or only in a very rudimentary way. Some of the young men do not even name the home village of their grandparents.

As we see it, the self-presentations of the young men, which go against the homogenizing we-discourse, are an expression of multiply discriminated positionings, as shown in their figurations with the Israeli occupiers, with the Palestinian security agencies, with long-time residents in the West Bank, and with the internal 'power elite' in the camps described in section 4.2. Their disadvantaged position, and the stigmatizing way they are portrayed by other people, are an expression of, and an instrument of power in, the shifting of power balances in the refugee camps following the Oslo agreements. A general devaluation of the 'classic resistance record' in the present social context is connected with this shift (Worm/Hinrichsen 2014) and points to the special generational location (Mannheim 1952) of the young men. As 'worthy combatants' (from their point of view) they are thus in an aggravated or multiple outsider position, as against the activists of the First Intifada.

The following case examples will serve to illustrate these ideas. First we will present the biographical narrative interview with Munir that was conducted by Ahmed Albaba and Hendrik Hinrichsen in 2013. The we-image of the young men as 'worthy but deprived combatants' is very explicit in this interview, which also gives an insight into the way they distinguish between themselves and other actors in the camp who, as Munir claims, ignore their 'resistance record'. 
Munir (born in 1988) grew up in the same refugee camp as Abu Samer (see above) and lived there up to his marriage two years ago. During and after the Second Intifada he was involved in confrontations with the Israeli army. Especially in the first few months of the Second Intifada, he threw stones and Molotov cocktails, but he did not take part in the armed actions and attacks that were carried out by competing paramilitary groupings and which became dominant in the course of the Second Intifada (Pearlman 2011: 152; Norman 2010: 31f.). Munir was shot in the hip in 2007 during a confrontation with Israeli soldiers who were making arrests near his refugee camp. Since then he has undergone three operations and is unable to hold a regular job. Munir got married two years ago and he has a two-year-old son. The couple has run up high debts for the wedding and for a rented home outside the camp. Munir receives a small allowance from the PA because he was 'wounded by the occupiers'.

In his biographical self-presentation Munir focuses on the typical thematic areas mentioned above, namely his 'resistance record' and the way he feels disadvantaged as a 'worthy combatant'. He speaks for instance about his many clashes with Israeli soldiers, the five weeks he spent in an Israeli prison (a relatively short time in comparison to the other young men we interviewed), and the difficulty of travelling to Jordan as an ex-prisoner because of the security interviews. Munir also talks about the consequences of his bullet wound. Because internal organs were damaged, he is not able to perform normal work. At the moment he has a casual job in a hotel kitchen, but he does not earn nearly enough to pay the rent and he has heavy debts. The allowance from the PA is far too low and there is not even a national day in honour of the wounded. He evaluates that he is disadvantaged because of the Intifada: some had profited but "we, the ones who were arrested, wounded and we suffered in the camp and during the siege and so we got nothing from it we cannot even buy a home".

This passage shows clearly that Munir sees himself as belonging to a we of 'disadvantaged combatants' who have fought and suffered for 'the Palestinian cause' but now live in a deprived situation. At the same time, he includes in his 'summation' that the refugee camps were especially affected. What he perceives as the deprived position of the refugees is negotiated within his we-conception of the 'marginalized combatant', but, as shown above, the two are not identical. Thus, at a later point in the interview Munir explicitly distances himself from actors and organizations in the refugee camp who fail to take the 'resistance record' into account when deciding who deserves support. In the last sequence of his main narration ("there's one other thing"), Munir begins to speak about the organization in which Abu Samer works (see above). He makes clear that he does not approve of this organization. He explains that it regularly receives visiting groups of young people from Great Britain, who then invite young Palestinians to come and visit their country. He claims, however, that the ones who work for the organization and accompany the visitors are not the ones who are allowed to go to Great Britain; moreover, he thinks that the organization gets generous financial support from the PA which it keeps for itself. 
He goes on to say that someone he knows was once able to go abroad for three weeks and he had asked him why he was allowed to go. The person told Munir not to worry, he would talk to the people responsible and perhaps he would then be able to come too. Munir had answered: "What do you think who deserves it more when there is a group of foreigners to go abroad with them, the one who was injured, the one who was arrested and who had to stay at home for years because of his treatment or those who do nothing and go on trips abroad every year?"

Several times during the interview, Munir creates a we-conception of people who have been 'wounded and imprisoned' and argues very explicitly that they 'deserve' to go abroad far more than those who have done 'nothing'. At the beginning of this passage on the organization in which Abu Samer works, Munir asked Ahmed Albaba not to translate it for Hendrik Hinrichsen ("but you mustn't tell him"; "no, I want to tell you personally"), but agreed after Ahmed Albaba had assured him that we were "a team". This caution on the part of Munir can be explained by the fact that he knew that Arne Worm and Hendrik Hinrichsen had spent a few nights in the organization of which he was so critical. We interpret his reticence as confirming the plausibility of the hypothesis we developed during the interviews, namely that it is much more difficult for the young men to talk about internal tensions and lines of difference in the refugee camps than for instance, their experiences of marginalization as refugees. This is surely connected with the fact that their power chances are lower than those of the established in the camp.

This precarious positioning within the power balances in the refugee camp was also suggested to us by our research among a group of friends from a refugee camp close to Ramallah. Our first contact with these young men was during a field trip in the spring of 2013, and we got to know them better during subsequent trips between 2013 and 2015. We have not yet completed our analysis of the interviews and our reconstruction of the biographies of members of the young men's families. All members of the group or 'clique' were frequently involved in the past, usually together as a group, in violent confrontations with Israeli soldiers or with the security forces of the Palestinian Authority and had been detained in Israeli prisons. Our interviews with the young men consistently suggest that their 'resistance records' are decisive for the integration of the clique. For instance they say that they do have other friends but that their friendship is "much closer with those who have been in prison". One member of the clique, Mahmoud, whose case is presented below, mentions that he got to know two of the others one night, during an attempt to prevent Israeli soldiers from carrying out arrests in the camp, when Molotov cocktails were being handed out. After this they had begun to meet regularly.

Most of them try to keep their participation in these confrontations a secret from their parents and older family members. But as a rule the families suspect what is going on and try to dissuade their children from taking part. Interviews that we conducted with the parents show very clearly that they are not very proud of the ac- 
tions of their children. ${ }^{10}$ In their opinion, the demonstrations and violent confrontations are pointless and dangerous and they disapprove of their children taking part in them. By contrast, the young men in the clique, both in group interviews and in individual interviews, defend their 'resistance records' and insist that resistance to the occupation is necessary and meaningful. These claims are usually linked to a very stylized 'militant rhetoric'. For them this is a means of dealing discursively with their perceived 'marginalization as worthy combatants' and their discrimination as refugees in contrast to the long-time residents. With this framing they are able to refer - albeit very cautiously - to their opposition to actors in the camp who are 'close to the authorities', who have 'combatant histories' from the First Intifada and who they regard as having being 'bought by the PA'.

In an interview conducted by Hendrik Hinrichsen and Ahmed Albaba during a visit in the winter of 2014, the above-mentioned member of the clique, Mahmoud, speaks more openly about the 'opposition' to their clique in the camp, which up to this point had only been indirectly implied. When Mahmoud describes how he had waited one night at the camp entrance with other friends from the clique in case Israeli soldiers tried to enter the camp, he says that they were criticized by people from the camp. They are the ones who "profit" from the situation and want "everything to stay as it is". In response to a question to narrate such a situation, Mahmoud tells how he once overheard a conversation during an event in the camp: in this conversation someone from the camp described him and his friends as "unemployed youths" who "sell hashish and drugs at night at the entrance to the camp". This made him angry, so he told the person that they stood at the entrance because some of the boys were 'wanted' and they were anxious to prevent them being arrested in their families' houses. He also told this person that he should act against them, since he had a "position". Mahmoud gave this influential person his full name and the names of the other 'boys', even though the person could "make trouble" for him because he had contacts among the security agents. In response to a question from us, Mahmoud says that the person is not employed by the authorities, but that he could arrange for him to be arrested by the Palestinian security forces. He could also make it impossible for him to obtain the certificate of good conduct that is often needed when seeking employment. However, he is not willing to tell us the name of the person. Later in the interview, Mahmoud and another friend who has joined us, again make reference to their feeling that they are suffering under a 'double' occupation (by the Israeli army and by the PA). In this context, they also distance themselves from the established members of their generation in the camp. In their eyes, these are the ones "who have succeeded because their father is this or that, because they know this or that person, because they have succeeded; [...] this misery is because you love your country and when you do this, you are in conflict with two occupiers and then all the doors are closed".

${ }_{10}$ This is presumably different from the First Intifada when, as Kuttab (1988: 18) remarks, parents were "proud of their children and their accomplishments [their resistance records; authors' note]". 
In subsequent interviews, the friends of Mahmoud also make reference to the way they are stigmatized in the camp, for instance as 'drug dealers'. This stigmatizing image of the young men that is widespread in the refugee camp also appears in the remarks made by their parents when they say that their children have "the wrong friends".

We argue that the extent of the young men's outsider position contributes to their critical treatment of the homogenizing we-discourse in their self-presentations and to their willingness to talk about various inner-Palestinian experiences of inequality. They deviate from the we-discourse because their freedom to act has also been restricted by inner-Palestinian actors.

\subsection{Situative approach to the rules of the hegemonic discourse: The we- and self-presentations of members of the Nakba generation}

How do the members of the Nakba generation deal with the fact that although their experiences of 1948 are a main component of the collective memory and hegemonic discourse, their descendants show no great interest in their personal experiences, especially when these do not fit into this discourse? These people are not a historical generation in the narrow sense, because they were not all the same age when they experienced the expulsion and flight of their families, but they were all old enough to be able to remember it. It is not surprising that they find it difficult to describe their many-faceted experiences of the Nakba entirely in terms of the narrow framework of the collective discourse. But the question remains as to how they deal with the rules of the dominant discourse in their we- and self-presentations. In our interviews with them it is clear that, depending on the context and conduct of the interview, they alternate between the homogenizing we-discourse and a presentation of their own experiences and those of their family. This can lead to evident contradictions, as shown below in the case of Fatima's family (ch. 6). The members of the Nakba generation oscillate between a framing of their life story in terms of the collective history, and talking about biographical elements which are either not part of the wediscourse of collective history, or which contradict it. This can be illustrated by the case of the Salman family.

A total of seven interviews were conducted with six members of the Salman family by Ahmed Albaba, Gabriele Rosenthal, Amina Rayan and Hendrik Hinrichsen. Ahmed Albaba interviewed grandfather Sabir (born 1936) in Arabic in the autumn of 2013 and the spring of 2014. The discussion here is mainly focused on these two interviews, which are very different from each other and which show an alternation between two separate figures. In the first interview, or the first figure, Sabir sticks firmly to the homogenizing we-discourse and the corresponding collective memory, tells hardly any stories, and does not speak about anything that does not fit into the 
discourse. In the second interview, Sabir follows his own biographical relevancies rather than the discourse, and talks about those biographical experiences that were important in his life before, during and after the Nakba. Before beginning our discussion, we will first give a short account of Sabir's experienced life.

In 1947, following political unrest, many inhabitants of the rural village of Naani, including the Salman family, moved to Lod (20 kilometres east of Tel Aviv). A few months later, in 1948, Sabir experienced the exodus from Lod, during which many Palestinians were massacred by Israeli soldiers. ${ }^{11}$ At this time he was 13 or 14 . Our analysis of the interviews with him shows that before 1948 Sabir had already suffered some traumatic experiences in his nuclear family and his extended family. This phase can be described as an individual and collective trajectory of suffering, in the sense proposed by Fritz Schütze (2006, 2007; Riemann/Schütze 1991). For Sabir, this trajectory begins with the death of his father in 1940, when he was about four years old. It is unclear what he died of and Sabir cannot remember, but his father's death led to economic and social difficulties in his nuclear family, and subsequently several family disruptions. He was separated from his mother, and lived by turns with an elder brother from his father's first marriage, and with the family of his elder sister. Later, he returned to live with his mother and her second husband. This socialization in a family system that was disengaging is embedded in the collective trajectory of the Nakba and in experiencing and witnessing killings and destruction in his original village and in Lod. His family succeeded in fleeing and moved from one refugee camp to another in the West Bank and in Jordan, before finally settling in a camp near Ramallah in the 1950s.

In the first interview, which follows the rules of the we-discourse, Sabir makes scarcely any mention of all these distressing experiences. By contrast, in the second interview he begins an almost unhindered stream of recollection and narration of his life story. Here, as mentioned above, we can speak of two presentation framings or two separate figures which are structurally distinct. One figure sketches the collective memory, while the second figure paints the story of his family and himself. According to our analysis, this important difference can be put down to the fact that members of the second and third generations of the family were present during the first interview and, as we will show, they sometimes corrected him. In the presence of family members from the second and third generations, the interviewees feel obliged to follow the rules of the homogenizing we-discourse, as we have been able to observe in other interviews.

In the first interview, Sabir focuses on the Nakba and talks about only those personal experiences which correspond to collective experiences in the we-discourse - as in the case of Raja, which is discussed above. In this way, Sabir does not have to talk about his broken family and his personal suffering. Influential here is the pres-

${ }^{11}$ On the basis of $\rightarrow$ IDF archive documents, Morris (2004: 428) assumes that 250 Palestinian civilians lost their lives during the so-called Dani Operation in July 1948 in Lod. 
ence of his son (born about 1965), a member of the second generation, during the interview. After the interviewer has invited Sabir to tell the story of his family and his own life, the eldest son immediately proposes to his father to talk about "your life in your home village up to this phase in which you are living now". Thus, the son takes charge of the situation and encourages his father to speak about 'life in the village before 1948' and the Nakba. But Sabir uses only one part of this framing. He does not talk about life in his village, but uses the Nakba to frame his life story:

"In (19)48 [...] we were occupied by the Jews [...] they shot at us from their open jeeps and we ran away and looked for somewhere to hide [...] on the way we stayed twelve days from ((name of the place)) before reaching Ramallah [...] we stayed there four or five days then the Jordanian army came and transported us to ((a refugee camp))."

In the further course of this first interview, Sabir concentrates almost exclusively on the theme of the 'Nakba 1948' from a we-perspective, and makes scarcely any mention of his 'individual' experiences. His description of the Nakba as a story of flight or expulsion from the home village to the refugee camp corresponds to the homogenizing discourse of the Palestinian refugees. The places they stopped at on the way are not mentioned, or only fleetingly, even though they suffered all kinds of difficulties, including discrimination by the long-time residents - both during their flight and later in the camp. Thus there are no stories about the period under $\rightarrow$ Jordanian administration from 1948 to the Israeli occupation in 1967. Sabir jumps from 1948 to a later time, and talks about the political unrest during the First and Second Intifadas, and about his stressful experiences with Israeli soldiers during this time. By doing so, he avoids anything that might contradict the hegemonic and homogenizing discourse, and he does not speak about conflicts within his family or about experiences of discrimination by long-time residents.

In the case of Sabir's family, the biographical case reconstructions based on the interviews show that the schematic presentation of the Nakba as a collective trajectory has two functions for the family system, which go beyond the discursive covering up of cracks in the Palestinian we-image. On the one hand, it is used to cover up an individual trajectory of suffering in the context of a disengaging and broken family system. On the other hand, it is connected with intergenerational debates over the flight and expulsion of the grandparents. The younger generations are familiar with the story of their flight from their home village, but because it is told in the expected way, based on the hegemonic discourse, it contains some contradictions. Sometimes they react critically to the grandfather's story. In the following sequence of the first interview, for example, a grandson, who is about twenty, interrupts Sabir's account of his flight with the following remark: "There were only two shots, my grandfather, and then you all just ran away." He thus questions the reasons for the flight and challenges his grandfather to explain why they ran away. On the manifest level, the grandfather is not addressed by his grandson as an individual, but as a member of the 
Nakba generation ("you all”). The grandfather answers: "We only ran away when the Jews started to threaten us with their guns [...] I was only thirteen at the time."

The grandfather obviously feels obliged to justify the family's flight. He first reacts to the collective form of address ("you all") and argues that everyone's life was in danger ("we"). And then he mentions that he himself was powerless to act because of his age. With this 'individual' legitimation the grandfather is probably also defending himself against a latent accusation in the words of his grandson (why did you run away?). This extract from the interview shows that the family dialogue in respect of the Nakba obviously remains very close to the we-discourse and is characterized by collective ascriptions of responsibility and a collective denial of guilt, and that this makes it difficult to open a dialogue on the 'individual' experiences of the Nakba generation.

This reaction on the part of the grandfather, which is obviously a practised reaction that is found in similar forms in other interviews with the Nakba generation (see Rosenthal 2012: 141), can be observed at other points of the interview with Sabir. His account of the flight from his home village, produced in interaction with the younger members of his family, is not only an expression of the collective memory of the refugees, but also a reflection of the family dialogue on the family history during and before the Nakba, which narrows (it) and concentrates on thematizing the collective trajectory of the Nakba generation. As a result, the children and grandchildren of refugee families know relatively little about the history of their family and the history of the Nakba generation before and during the Nakba. These gaps in the family memory account for the way family members and family events are confused in the interviews with Sabir's children and grandchildren.

We can conclude that the taboo against talking about the personal experiences of the Nakba generation, which can also be observed in other families, is a defence mechanism against threatening perceptions of the experienced impotence of the parents and grandparents. We can also conclude that the later generations indirectly make the members of the Nakba generation responsible for their present difficult life in the refugee camp.

Unlike the first interview, Sabir's second interview with Ahmed Albaba took place without any other members of the family being present. He was able to talk about his painful experiences, which is not always compatible with the collective discourse. Given the open interviewing and the absence of other family members, he is able to concentrate in this interview on his own memories of the past and to talk about these memories. He recounts his flight in 1948, but keeps jumping to things that happened before it and after it. It becomes clear that his individual experiences of separation and constant change of attachment figure are still very painful memories for him today. This raises two questions: whether, as a result of the hegemonic discourse, the members of the Nakba generation had, and still have, insufficient opportunity to talk to their families about their personal suffering, especially suffering that is not related to the Nakba, and what transgenerational consequences this has. 


\subsection{Conclusion}

In this chapter we have presented three types of we- and self-presentation found among Palestinians who live in one of the refugee camps in the West Bank. These presentations differ considerably in respect of the degree to which they follow the rules of a harmonizing and homogenizing we-discourse. A comparison of these three types of self- and we-presentation shows that (1) the hegemonic we-image in the camps (type 1) largely corresponds to the general homogenizing we-discourse (see ch. 2), and that (2) there is a tendency to hide the variety of biographical trajectories, perspectives and positionings found among Palestinian refugees in the camps in their complex figurations with each other and with groupings outside the camp. Not least this applies to power inequities, discrimination and associated conflicts both inside and outside the camp. It appears that (3) the degree to which the we-discourse is used depends on the positioning of the speakers within the camp's internal power balances, the discourse being used by those who can be described as established in the camp, while it is treated more critically by those who can be described as outsiders. (4) Our impression is that the hegemonic we-image in the camps, which is also bound up with the negotiation of status differences, makes it difficult to open a family dialogue on the 'individual', often painful, concrete experiences of the Nakba generation.

Those speakers who strictly follow the we-discourse present the camp as a symbol of the collective suffering of Palestinians in the past and in the present, and seldom mention differences and conflicts within the camp, and between those in the camp and groupings outside it (type 1). By contrast, the self-presentations of the shabab are aimed at revealing what they perceive as discrimination, or their outsider positioning within Palestinian society (type 2). For those representatives of the first type (people who follow the we-discourse in a practised manner all the time) who belong to the established in the camp and who are usually members of the second generation, following the we-discourse is obviously important to their established positioning within changed power balances inside and outside the camp in connection with the setting up of the Palestinian Authority. In the case of the shabab, who represent the second type (people who are critical of the we-discourse) and who regard themselves as outsiders, there is such a huge difference between the we-discourse and their own present difficulties that they are prepared to openly express their opposition to the established outside the camp (for example the PA) and to cautiously criticize the established inside the camp. Their self- and we-presentations can be interpreted as a way of processing what they see as their marginalization or the failure of society to recognize them as 'worthy activists or combatants for the national collective'.

As we have shown in the context of the self-presentations of the Nakba generation, these people alternate between the requirements of the we-discourse as the familiar and predominant presentation scheme in an everyday context and a memory-based, 'individual' approach to their past experiences (type 3). They are representatives of a third type: a situative or alternating approach to the we-discourse. The changes of 
framing that are characteristic of this type show very clearly what is only suggested by the representatives of the first type: that remembering and talking about past and present personal experiences are incompatible with the dominant we-discourse, where such memories have no place. It is also apparent that the dominant we-image shapes the dialogue on the Nakba between different generations of the family, so that this dialogue remains on the level of argumentatively assigning collective guilt and collective defence, and hinders any communication of 'individual' perspectives in the past and the present. 



\section{The way outsiders speak: Counter discourses, self- and we-images of stigmatized gay men in the West Bank}

Arne Worm, Hendrik Hinrichsen

\subsection{Introduction}

In this chapter we will examine the self-presentations, social positionings and biographical courses of Palestinian men in the West Bank who are in a strong outsider position in terms of the theory of established and outsiders (Elias / Scotson 2008). On the basis of the hypothesis that the perspectives of outsiders, as 'unheard voices' that are marginalized by the hegemonic we-discourse, can be important for an understanding of the local figurations (Bogner/ Rosenthal 2012), we will discuss two cases where social position is interrelated with being stigmatized as gay. ${ }^{1}$

In the light of our interviews with Palestinians who define themselves as gay, ${ }^{2}$ it is clear that their positionings and experiences in the West Bank are extremely het-

\footnotetext{
${ }^{1}$ Besides journalistic publications and reports by NGOs (see the website of the Palestinian LGBTQ organization AlQaws: http://www.alqaws.org, 28.04.2015; Kagan/Ben-Dor 2008; Whitaker 2006; Halevi 2002), there are only a few scholarly studies (e.g. Hochberg 2010) of the social position of male homosexuality in the Palestinian areas today. In the West Bank homosexuality is not officially punishable under criminal law. A law making homosexuality punishable was enacted in the period of the $\rightarrow$ British Mandate, and was repealed in 1951 by $\rightarrow$ Jordan for the West Bank (but not in Gaza). In 1994 the laws enacted before 1967 were declared valid by the $\rightarrow$ PA.

${ }^{2}$ In our terminology and analysis we follow the self-definitions of the interviewees. In those inter-
} 
erogeneous, especially in respect of what they perceive as their outsider position. ${ }^{3}$ In this chapter we will discuss the cases of Malik and Boutros, as we will call them, because they see themselves in a marginalized and stigmatized position and from this perspective they do not follow the rules of the homogenizing we-discourse (see ch. 2). In their biographical self-presentations they mainly focus (directly or indirectly) on their position as outsiders, the stigmatizing they-images as not conforming to established masculinity ${ }^{4}$ in the West Bank, with which they see themselves confronted, and their self- and we-images which are not included in the we-discourse. However, they have very different self-presentations. These are connected to different, biographically built-up, patterns of interpretation, and different manners of working through and defending their outsider experiences: Malik, ${ }^{5}$ who comes from a Muslim refugee family, speaks from the beginning very openly about his experiences of exclusion as a gay man and opposes the established they-image of gay men with a counter image of his we-group which rejects the derogatory public labels. By contrast, Boutros, who comes from a (formerly) established Christian family, speaks much more cautiously and indirectly about his homosexuality for large parts of the interview. He feels very isolated in his local environment and, as a kind of substitute for his experiences of difference as a gay man, he speaks quite openly about differences between Christians and Muslims in his surroundings, which would not be thematized by people who follow the homogenizing we-discourse.

Our discussion of these two cases is based on the theory of established and outsiders (Elias / Scotson 2008) and Erving Goffman's stigma theory (1986), as discussed for instance by Coston and Kimmel (2012) in respect of deviant masculinities. We will show how outsider positions are created by processes of stigmatization, or as a result of unequal power chances between established and outsiders. In these processes, the stigmatized are not simply passive victims of discrimination, but resort to various kinds of "stigma management" in order to counter attempts to alienate them (Goffman 1986). Whether the outsiders absorb into their self-image the negative, stigmatizing they-images applied to them by the established, or whether they try

views and group discussions that were held in Arabic, the participants frequently used the English term 'gay' to refer to themselves.

${ }^{3}$ Altogether we conducted narrative-biographical interviews, sometimes involving more than one session, with eight Palestinians in the West Bank and with one Palestinian in the Old City of Jerusalem who defined themselves as gay. In addition to the authors, Johannes Becker and Ahmed Albaba helped to conduct these interviews.

${ }^{4}$ We use the expression 'established masculinity' in order to stay within the terminology of the theory of established and outsiders, but this is also a reference to the concept of 'hegemonic masculinity' (Connell 1995). With this concept, gender relations in a concrete society are analysed as resulting not only from hierarchizing social practices that distinguish men from women (and privilege the men), but also from competing kinds of masculinity. In this theory, the privileged positioning of men who correspond to the socially established norm, or dominant masculinity, is also produced in the process of devaluating other masculinities that are regarded as being weaker.

${ }^{5}$ All names used here are pseudonyms. Other personal data have also been slightly modified for reasons of anonymity. 
to ward off the damaging effects of the they-images by developing counter images, depends on the degree of power asymmetry between the groups and the distribution of power instruments (Elias / Scotson 2008: 6f.), as is made evident by the cases discussed below.

We will show that the different self- and we-images of these two men, who are both discriminated against because of their homosexuality, result from the nature of their outsider positions and the different ways in which they differ from the Palestinian we-discourse. In other words, the degree to which inner-Palestinian conflicts and differences, and self- and we-images that deviate from the we-discourse, are thematized in the self-presentations of the outsiders, is related to the extent of their outsider position and the strategies they have developed in the course of their lives to work through this position.

\subsection{Malik}

In this section we will discuss the self-presentation of Malik, ${ }^{6}$ a Muslim Palestinian who defines himself as gay and who comes from a refugee family. Malik lives with his family near Bethlehem in a house that is very close to one of the $\rightarrow$ refugee camps. We have chosen to discuss his case because Malik, who is about thirty years old, is the only gay Palestinian in our sample who does not actively try to hide his homosexuality in his social environment, meaning from his family, friends and neighbours, and who describes himself as 'out'. We were put in touch with Malik by one of our Palestinian field assistants who lives near him and knows him. From the beginning of the interview, Malik speaks quite openly about the stigmatizing images of gay men with which he is confronted, and his experiences of discrimination in the past and in the present. In contrast to Boutros (see below), Malik sees himself as a member of a discriminated we-group of gay men and tries to formulate a counterimage to the established discourse from this position. At Malik's request, his friend Rashid, who also defines himself as gay, is present during the second half of the first interview. Before taking a closer look at the structure of Malik's self-presentation, we will first briefly describe his biographical course and his present situation.

Malik comes from a Muslim family who fled from their home village of Zakaryya in the context of the $\rightarrow$ Nakba. After two years they moved into a house close to one of the refugee camps near Bethlehem. Only his nuclear family still lives in this area today, while most of the extended family has migrated to Jordan. Malik's family shared their outsider position as 'newcomers' with other families living close by (today two brothers still live with their families in the same house as Malik and his

${ }^{6}$ The authors interviewed Malik in English on two occasions in March 2013 (total interview time about six hours). In addition we were able to conduct interviews with Malik's father (in Arabic) and with three of his gay friends (Arabic/English). Malik's sister was interviewed in Arabic by Ahmed Albaba and Gabriele Rosenthal. 
father; a sister of Malik lives across the road). From the 1960s, Malik's father (born in 1946), as the eldest son, was responsible for providing for the family, which meant he had to leave school without any qualification and earn money as a construction worker; he is still in this precarious situation today. He married a cousin from the Jordanian branch of the family who comes from the same home village.

Malik was born in the early 1980s as the last child of the family (he has three older brothers and two older sisters). He was too young to be actively involved in the $\rightarrow$ First Intifada, but he grew up in a local environment in which political involvement and confrontations with 'the Israelis' were an important part of everyday life. During his time at a $\rightarrow$ UNRWA school in the refugee camp, Malik was confronted with experienced exclusion and ascriptions of unmanliness, which increased in the course of his adolescence. This ascription, which we will return to below, was the main stigmatization category, not only in his peer group but also in his family. Malik also locates his growing awareness of feeling sexually attracted to men in this phase.

As we will discuss below, the idea that he is rather 'feminine', both physically and in respect of character traits, as compared with established ideas of masculinity, is part of his self-image as a gay man. Even though the reactions of his (extended) family to his sexual orientation are complex and, as in other cases, are not easy to fit into the scheme of 'rejection or support by the family', in the course of Malik's adolescence his nuclear family came to accept it. This acceptance is based on the argument that he is a woman in a man's body ${ }^{7}$ and that 'that is how God made him'. His sister and his niece, for instance, put it in these terms in their interview. Thus, Malik increasingly took on household duties in the family, and for a few years he cared for his sick mother, who died in 2005.

Malik is the only one in his nuclear family to have obtained a university degree, which can be interpreted as clear upward mobility in respect of (formal) education. He describes the university as a more protected space in comparison to primary and secondary school. During this period, he decided to be 'open' about his homosexuality and a group of gay Palestinians formed itself. This circle of friends, most of whom conceal their homosexuality, still meets regularly in Malik's house today.

To this day Malik suffers from stigma and discrimination in the form of local gossip, and also violent attacks. In the most serious case of sexualized violence he told us about, he and a friend were carried off by a group men to a place outside the town and were severely beaten up. However, on this occasion Malik and his friend were able to defend themselves against attempts to rape them. ${ }^{8}$ Malik reported the perpetrators to the police and they were arrested and sentenced to jail terms, in some

\footnotetext{
${ }^{7}$ It seems likely that Malik's family regards him as transsexual and not primarily as gay. However, as will be seen, our analyses suggest that in the context of our study no clear distinction is made between transsexual and gay, either in they-images, which are concerned with deviant kinds of masculinity, or in Malik's self-image (and in the internal discourse of his clique) (see also note 9). Malik explicitly defines himself as gay.

${ }^{8}$ As will be discussed, distinguishing between 'active' and 'passive' roles in the sexual act is important within the established conception of homosexuality (as various interviewees explained to us). While
} 
cases of several years. On the other hand, Malik has also experienced support from members of his family and neighbours who have defended him in cases of verbal and physical abuse.

Malik is currently unemployed and his economic situation is very precarious. He lives with his father in one room. He has to travel on foot or by public transport when he goes anywhere, moving in public spaces where he has experienced abuse.

\section{Malik's self-thematization}

Malik's biographical self-thematization is essentially focused on his difficult situation as a gay man in Palestinian society in the West Bank and is dominated by the presentation of everyday experiences of exclusion and discrimination. On being invited to talk freely about the story of his family and of his own life, he begins with a brief account of his Palestinian refugee background. This theme is typically treated at the beginning of biographical interviews with Palestinians in the refugee camps who follow the we-discourse (see ch. 4). But Malik does not deepen this topic. After a few sentences he moves on to an open presentation of the way he suffers discrimination as a gay man which puts him in an outsider position in the West Bank:

"Um (3) about me I didn't have job until now because um, I am in se=sensitive situation, I will tell you, because I am gay, I have a lot of a troubles abou-, in my life because I am gay because you know the Palestinian society or like the Muslim and Arab society they don't accept us talk about me and the other gays um like me I don't have-, they don't give me a chance to have job because they talk about um, your shape your clothes is weird and your voice is soft, girlish [...]."

The main thematic areas for his framing of the interview are staked out here: the open thematization of his precarious situation (including his economic situation) which is due to people in the local surrounding knowing about his sexual orientation, his definition of himself as belonging to a discriminated we-group of gay men, blame-gossip about gay men ("they talk about you"), and a focus on stigmatizing references to his physical characteristics ("shape", "voice") and other external features ("clothes") which are construed as being feminine (and therefore deviant).

In the subsequent course of the interview, his frank self-thematization as a marginalized gay man can be broadly interpreted as an explicit discussion of what he perceives as society's image of gay men. Thus his self-thematization develops into a consideration of all kinds of different contexts in his lifeworld in respect of the question whether and to what extent he is stigmatized and marginalized in them as a gay man. By means of detailed exemplifying stories and argumentative figures

penetrating is not necessarily considered as unmanly or gay, being penetrated is definitely regarded as 'feminine' / gay. 
he describes how he sometimes experienced massive discrimination from classmates during his schooldays, the debates that took place in his family, and how hard it is to find a job. He also speaks at length about the way the neighbours gossip about him and about the way he is subjected to repeated violent and partially sexualized attacks by other young men in public and semi-public spaces. This framing of the interview is aimed at obtaining recognition by the interviewers of his experiences of discrimination and his patterns of biographical work. From his perspective they belong to the 'European-Western' world and he obviously ascribes to them an accepting stance on homosexuality.

As can be seen in the following extract, those parts of the they-image perceived by Malik are mainly focused on condemning 'male homosexuality' as an effeminate kind of masculinity which does not correspond to established masculinity. ${ }^{9}$ This concerns a person's external appearance and (body) habitus, and the playing of a 'passive role' during the sexual act, as well as ascriptions of 'feminine weakness' and (connected with this) promiscuity. ${ }^{10}$

"They think about gay people, they are weak, they are without honour, they are spies with the Jewish and Israelians, they are addicted on on on drugs everything bad they- they (1) concern it to us [...] they talk about the gay people they work in prostitution [...] they care about sex, they are- they just want to have fun [...] they don't know that the gay people they are creative, and they have their own personality, they can be a doctor and can be successful in everything (2) and they think that every day I have sex (1) with another- they don't know we care about relationships, we care about love, [...] we are not prostitutes, we are not bitches."

Touching on the themes of collaboration, ${ }^{11}$ sexual promiscuity, prostitution and drug use, the social they-image of gay men described here sounds like a list of the main taboo subjects in Palestinian society in the West Bank. Constructing practices and characteristics of another group as anomic can be seen as a classical form of the stigmatization of outsiders (Elias/Scotson 2008: 10f.). However, these ascriptions are obviously not directed in the first place at men who have sex with men, but at men who are 'effeminate' in comparison with established masculinity.

\footnotetext{
9 This also corresponds to the Arabic term mokhannath with which Malik is sometimes confronted. It can be translated as effeminate man, but also as transgender woman (another term is louty).

${ }^{10}$ The construction of homosexuality as a deviant kind of masculinity draws attention to the components of the image of established masculinity, which are also discussed by Peteet (1994) and Amireh (2003): Peteet (1994: 34) mentions the need to demonstrate 'brave deeds' and strength, while Amireh (2003: 760) sees being able to control one's sexual desire (a counter image to the accusation of promiscuity) as a part of established masculinity.

${ }^{11}$ The threatening connection between ascriptions of homosexuality and accusations of collaboration is also discussed by Amireh (2010: 638). Malik reckons that he is in no danger in this respect, because he is 'out' and therefore not susceptible to blackmail.
} 
Male homosexuality, as deviant masculinity, is obviously also conceptualized in this they-image as a breach of 'national honour'; this is clear at various points of the interview, for instance when Malik tells the story of how he was attacked by a group of men, and comments: "But they are so defective EVEN THOUGH I am gay what do I bother you I didn't affect you, anything even so we are gay did this thing affect you I'm not your brother I'm not from your family to shame you he told me no you shame us you are Palestinian."

This they-image that focuses on deviant masculinity is thus bound up with the denial of being a 'good' patriot; conversely, 'being a Palestinian' means fulfilling the expectations of established masculinity (see Amireh 2010: 638; Hochberg 2010: 507). In another context, Malik indicates that some people in the West Bank think that all gay men come from Israel and that homosexuality is a 'Western' phenomenon. The construction that homosexuality is a 'Western' phenomenon is also discussed by Hochberg (2010: 508) in respect of the Palestinian areas, but in Malik's experience - unlike Boutros - it is only a marginal part of the they-image and is explicitly not a part of his self-image, even though he uses 'Western' discourse elements (such as the notion of 'coming out') when describing himself. In particular Malik vehemently rejects the accusation of weakness which is contained in the they-image. An emphasis on his power to act and his 'ability to defend himself' runs through the whole of his self-presentation and is plausibilized in many exemplifying stories he tells:

"In the daylight, four guys, they are teenagers, they followed me and they bothered me a lot, they followed me and everywhere I went they bothered me, by words and they threw stones, so I stopped them, I said what do you want? [...] did I do something bad to you they kept following me but after that I'll tell you what happened, I BROKE the glass, a bottle, and I hit him in his face with the glass."

Malik's emphasis on, and defence of, his power to act can be read as a rejection of the weakness that is ascribed to 'gay men' in the discourse of the established, and which is also a part of the stereotypes in respect of collaboration and drug use. His attempt to found a political self-representation organization, together with friends, must also be seen in this context. His proposal was rejected by an official of the PA with the argument that this would only be possible after the founding of the Palestinian state and the end of the Israeli occupation.

The extracts from the interview which we have quoted show that in describing his experiences of discrimination and stigmatization, Malik regards himself as part of a we-group of gay men, and he states that his experiences and opinions are shared by this we-group. His attempts at an argumentative defence, and devaluation of the they-image as perceived by him, are aimed at establishing a counter image of gay men as a group. With this we-image Malik counters the stigmatizing they-image by stressing that gay men conform to socially established norms (for instance by having steady partnerships, the same educational and vocational aspirations, or the same 
dress preferences) and are just as capable as other men of defending themselves when they are attacked. Malik's we-image is constituted by his efforts to reject a they-image that ostracizes gay men by claiming there is a difference between established and deviant masculinity.

This particular way of dealing with stigmatization is discussed by Coston and Kimmel (2012) under the name 'normification', on the basis of Erving Goffman's stigma theory (1986). Characteristic of this variant is that dealing with stigma begins by neutralizing the differences that are said to exist between the stigmatized group and the established: "Normification involves exaggerating the similarities and downplaying the differences" (Coston/ Kimmel 2012: 100). While such an attempt to reject derogatory labels is understandable, it is also important to realize that the possibility of warding off a stigmatizing they-image is not unconditional and that it depends on the degree of power inequality between the established and the outsiders. According to Coston and Kimmel (ibid.), 'normification' as a strategy to neutralize stigma requires a minimum of social power, and it requires not being isolated, or at least not completely. In the theory of established and outsiders, the interdependency of power balances between different groupings and the possibility of stigmatizing others or of dealing with stigmatization is a central issue:

"[...] an uneven balance of power [...] is also the decisive condition of any effective stigmatisation of an outsider group by an established group. One group can effectively stigmatise another only as long as it is well established in positions of power from which the stigmatised group is excluded. As long as that is the case, the stigma of collective disgrace attached to the outsiders can be made to stick." (Elias/Scotson 2008: 6)

Following the theory of established and outsiders, we can assume that belonging to an integrated we-group and having a corresponding we-image can be regarded as instruments of power in the confrontation with the established. Both together make it possible to formulate a counter image and to deal with conflicts with the established. The significance for conflict management of the degree of integration of a we-group is expressed succinctly by Bogner (2003: 173, transl. from the German) as follows: "If a group is not integrated, it is unable to act as a group. If it is not able to act collectively, it is unable to exercise power - in other words, it is unable to successfully endure conflicts with other groups."

We can assume that Malik's stable we-image as a member of a we-group of gay Palestinian men, his social integration (an essential element of which is his friendship with a group of gay men) and experiences of solidarity, and his attempt to create a counter image in opposition to the stigmatizing they-image, are interrelated. And in his biographical self-thematization, despite all his stories of discrimination, Malik does not give the impression of complete social ostracism and isolation of his person beyond this group of friends, but presents various social spheres and actors as being 'indifferent' towards or supportive of his sexual orientation. Thus, he repeatedly 
underlines the acceptance and support he gets from most of his neighbours, who "respect and help" him. In addition, he speaks about the generally supportive, or at worst indifferent, attitude of the $\rightarrow \mathrm{PA}$ authorities. For example, the state schools would be prepared to employ him, but rejection by the pupils makes it impossible for him to work as a teacher. He also describes the Palestinian police as cooperative, and serious in their efforts to catch those guilty of sexualized violence, despite the fact that he was asked irritating questions about his sex life during an investigation. Malik explicitly underlines what he perceives as the accepting attitude of the "religious people", as he calls them. In contrast to the frequent assumption that religious conservativism is directly bound up with a rejection of homosexuality, Malik says that the attacks and the gossip do not come from the 'religious Muslims': "The Muslim religious people, they don't bother us at all, I have a friend who is religious, do you know the people who bother us they are normal people who are not religious, these people- they told me it's your nature your voice is nature, God create you like this."

As we have seen, Malik's nuclear family also largely follows this interpretation and is prepared to defend Malik - as a family member - against verbal or physical attacks from the outside. His brothers would challenge or beat anyone who attacked him.

Despite the strategy of creating a counter image as a form of defence against negative ascriptions, the ascription of 'being more feminine' (meaning more emotional, having a less muscular body, being less politically militant) is part of Malik's own self- and we-image. This can be illustrated by the following passage, in which he recounts an argument between himself and his brothers: "They were talking about the manly, about the rough things with the men, you are soft, you treat like women, I told them I will let the manhood to you to make Palestine free (1) I will let the manhood for you, because you are men, you can kick out Israeli from your land, from your manhood."

This passage also recalls the connection between the established construction of masculinity and the 'national resistance project' (see Amireh 2003, Massad 1995, Peteet 1994). It is clear here how Malik counters the accusation of deviant masculinity with an ironic denigration of the established categories of manhood (involvement in 'resistance activities' against Israel). But here, his self- and we-image does not seek to level out the differences between himself and his brothers, in the sense of 'normification' as a form of stigma management. Rather, he excludes himself from the patterns of action which constitute established masculinity. The acceptance of ascribed femininity as part of his own self- and we-image, which is implied here, can also be found in other interviews we conducted with gay men, both on the level of body habitus (clothing, make-up, posture), and on the level of rationalization. In the case of Malik, this is clear for instance when he describes himself as 'peace-loving' and less 'violent' because he is gay, and he says explicitly "they [the gay men] are woman from inside not from outside". A part of the internalization of this ascription is identifying signs of one's own homosexuality in one's own early childhood (for example using make-up or playing with 'girls' toys'). 
Malik's strategy for dealing with the stigmatizing they-image thus obviously includes accepting some parts of it, which corresponds to Norbert Elias' account of extremely asymmetrical power relations in established-outsider figurations (Elias/ Scotson 2008: 6). And not only does he accept the way his masculinity differs from established masculinity, but he even emphasizes this difference ('minstrelization' in Goffman's terminology; see Coston / Kimmel 2012: 100). Malik's stigma management strategy and his corresponding we-image can thus be located between accepting certain ascriptions and creating a counter image to defend himself against accusations of abnormal practices. In contrast to the case of Boutros (see below), Malik's we-image thus contains a minimum of "symbolic resistance" (Bogner 2003: 177, transl. from the German) to the stigmatizing they-image, which is how this "compromise between identification with the discredited they-image and an attempt [...] to save a self- or we-image that differs from it as the basis for one's own autonomous agency" (ibid.) can be interpreted.

\section{Deviations from the we-discourse}

By using the interview for a frank discussion of his repeated perceptions of restriction, tension and direct conflict with the patriarchal majority society, Malik clearly deviates from the rules of the we-discourse of national unity and 'suffering under the Israeli occupation'. His open admission of belonging to a we-group of gay men, and his attempt to counter the they-image (failure to conform to established masculinity) with an integrated self- and we-image, are important components of Malik's biographical pattern of action and are renewed or refreshed in the interview. For Malik, in contrast to Boutros (see below), the resulting deviation from the we-discourse consists mainly in exposing the stigmatizing they-image of gay men as a group (and his critique of it).

However, Malik's lack of commitment to the we-discourse also means, for example, that he readily talks about experiencing how refugees are disadvantaged, which is flatly denied in the discourse, and how economic differences in Palestinian society affect people's lives. Malik interprets his current precarious economic situation as being directly related to the fact that he belongs to a refugee family, and he thinks that he is more disadvantaged than his gay friends: "And most of the people like Rashid, he's not refugee $[\ldots]$ and also many of them they suffer, but not- they are not suffer so much because their families they are rich $[. .$.$] they make a visa for him to study in$ Europe, and also the other one, his father was (4) working in the government."

Framing the interview with the formulation of a we-image and associated biographical experiences also means that Malik does not go into any details about those areas of his family history and his own life history which he interprets as being connected with the Nakba and the Israeli occupation. We presume that such experiences (especially his refugee background), which are thematic areas within the wediscourse, are more important for his biographical course than is suggested by his self-thematization. Thus, unlike Boutros, Malik does indeed see himself as a member 
(even if a marginalized member) of a Palestinian collective. For example, when we ask about his refugee background in the second part of the interview, he presents the we-discourse in the form of a very stylized account of the attachment of his grandparents to the land and a visit to their home village a few years back that aroused strong emotions: "When I see Jerusalem when I [...] see the villages, the destroyed villages I become sad I am sad about all the Palestinian not about about my family or about myself, because I want the Palestinian not-, to be refugee in=in foreign country or Arab country I want all of them to be in their own land."

There are also other points in the interview which show that Malik has both personal experiences and argumentative patterns of interpretation which he regards as representative of his Palestinian we-group. However, he does not place these in the centre of his presentation. It seems to us that his framing of the interview with a focus on his self- and we-image as a gay Palestinian man prevents him from being able to put himself in the position of the 'Palestinian collective' and to follow the we-discourse.

\subsection{Boutros}

As a contrast to Malik, in this section we will present the case of Boutros, who comes from an established Greek-Orthodox family who are long-time residents in greater Ramallah. He was interviewed in several sessions by the authors in January 2011. ${ }^{12}$ At the time of the interview, Boutros was around 40 years old, and lived with his mother and the family of an older brother in a big house on the edge of the town. Boutros' self-presentation is essentially structured by his homosexuality and his precarious outsider status in the public space which results from this, but he talks about these things much more indirectly and cautiously than Malik does. From the beginning Boutros speaks freely about his outsider position in Ramallah, albeit in rather general and argumentative terms. But during most of the interview, when it comes to his own homosexuality and his concrete experiences of discrimination in the form of local gossip and sexualized violence, he is very cautious, resorting to veiled hints and tentative formulations. Only in the last session - at first with the tape recorder switched off, but later with it on - does he speak explicitly about his own homosexuality, and only then does he refer to himself as gay.

Boutros presents, and rationalizes, his outsider position as the result of a cultural difference between the traditional, conservative and intolerant attitudes of the local population and himself as someone who practises a 'distinguished', liberal, European-type lifestyle. He repeatedly criticizes the high degree of social control across all groups in Ramallah, which is aimed at ensuring that everyone maintains - in his own words - the "Palestinian tradition". For this reason, he prefers the company

${ }^{12}$ Boutros was interviewed by the authors in four sessions on two successive days (totalling almost 16 hours). The interviews were conducted predominantly in English. 
of foreigners and has very few social contacts in his local environment. The way we made contact with Boutros fits this pattern of action: Boutros approached us on the street near his house, was interested to know who we were, and repeatedly referred to his familiarity with European pop culture and high culture. We interpret his description of himself as "more European" as a way of working through the experiences of discrimination to which he was exposed at least from his adolescence, a biographical pattern that has become firmly entrenched during his life course.

Dealing with his outsider position as a gay man by means of 'removing' himself from the Palestinian national collective means that in the interviews Boutros readily tells stories (and thus starts memory processes) relating to tensions and conflicts between local groupings, for example between Christians and Muslims. He also gives free expression to his own stereotyped ideas about 'the Muslims'. When speaking about local (patriarchal) practices in respect of sanctioning contacts and relationships between religious groupings, Boutros takes advantage of the opportunity to speak about his own experiences of exclusion, while covering up stigmatization relating to his homosexuality. Unlike Malik, Boutros does not classify himself as a member of a we-group of gay men; for him, his outsider experiences and his lifestyle are unique and individual: "as I am only the guy ehh different than other Palestinian then you feel yourself like you are weak." As we will show, the way Boutros speaks about his homosexuality can be described as a form of stigma management through concealment. However, he conceals his stigmatization as a gay behind a highly individualized self-image that demonstrates how different he is from the established, and the high degree to which he is an outsider. Boutros' heavy emphasis on the difference between himself and the established rather refers to a stigma management which can be seen as a kind of 'minstrelization' (see above), confirming the idea that homosexuality is a 'Western' phenomenon.

This self-thematization which tends to conceal his homosexuality makes it much more fragile for Boutros than for Malik to refer to himself as gay and to talk about the self-image of his gender role; his self-image contains elements of self-blame and shame. Accordingly, he makes no attempt to discuss what he perceives as society's they-image of gay men as a group. The removal of himself from the Palestinian national collective by means of his self-construction as "more European" is a kind of assignment to a we-group, but it offers him no alternative options for action in his local environment (such as setting up a reference group), or any kind of group integration. Again unlike Malik, he ascribes to himself little or no possibility of action, or personal disposition, to offer opposition to the hostilities he experiences in concrete situations. Before going on to discuss Boutros' self-presentation in detail, we will sketch some elements of his biographical course.

We can assume that, as long-time residents, Boutros' extended family belonged to the economically and socially established ${ }^{13}$ in Ramallah. This position became eroded due, amongst other things, to the emigration of many Christian families

${ }^{13}$ For reasons of anonymity we can say little about the family, whose history in Ramallah can be 
(today, several of Boutros' older siblings and other relatives live in Europe), which resulted from the increasingly difficult political situation and a general shift in the demographic balance between Christians and Muslims in the West Bank in the second half of the 20th century (see ch. 3). This development intensified after Boutros' birth at the beginning of the 1970s. He was an 'afterthought' in the family; his siblings are all much older than him. We know relatively little about Boutros' childhood, but in the interview there are indications that he had a hard time at school. $\mathrm{He}$ went to a Christian private school which had a very good reputation and the highest fees in the area. However, his schooldays were probably a time of fear and connected with experiences of exclusion. He himself locates the beginning of his increasing experiences of exclusion in this period, and he hints at sexualized violence by other pupils. Boutros' late adolescence coincided with the First Intifada (1987-1993), but he did not become politically active. Boutros' experiences of increasing isolation were connected with the attempts he made during his adolescence to enter into same-sex partnerships within his extended family and in his social environment. The result for Boutros were experiences of rejection and exclusion. At the age of eighteen he dropped out of school before taking his tawjibi (final examination).

During the Oslo phase in the mid 1990s, Boutros increasingly sought (sexual) contact with 'Westerners' and acquired a basic knowledge of two European languages. He also began trying to emigrate to Europe, but aborted the attempt because of the lack of job prospects and his own situation of social decline. Since this time, he has regularly offered accommodation to male foreigners, sometimes for long periods, he has increasingly tried to adopt a 'Western' lifestyle, as he calls it himself, ${ }^{14}$ and he has tried to broaden his general education - all things which Boutros classifies as 'being European'. The death of Boutros' father in the early 2000s, the closing of his shop, and the emigration of some members of the family prior to this, led to a further decline in the formerly established social position of the family. In Ramallah, Boutros increasingly supported and cared for his mother.

During the interview, Boutros is generally very cautious when speaking about his precarious outsider status in Ramallah, where he is subjected to gossip, avoidance, and physical attacks. Even in the interviews with us, Boutros finds it distressing to talk about these experiences. He implies that he has been a victim of attempted rape at least twice, once during his early adolescence and once as an adult, a few years back. Today, his position in the family is ambivalent. From our experience in the family ${ }^{15}$ and in the interview, we can assume that the members of Boutros' family guess that he is homosexual, but that no one talks openly about it. Due to the estab-

\footnotetext{
traced back to the 19th century. Boutros' grandfather had a high position in the local administration during the Ottoman period and his father had a shop in the town centre.

${ }^{14}$ In order to give himself what he regards as a 'European' habitus, Boutros began to make his external appearance different from those around him by dressing 'fashionably', letting his hair grow long, wearing jewellery (such as an earring), and taking up artistic occupations (photography, design).

${ }^{15}$ For example we were present when an uncle of Boutros came to visit him with his core family.
} 
lished status of the family, we can assume that he is given a certain protection against attacks. But Boutros also reports of hostilities directed against his homosexuality and even of being beaten by his cousins who live in the same house.

\section{Boutros' self-presentation}

We will now look at three structural components of Boutros' self-presentation, and their relationship to the homogenizing we-discourse: the open thematization of his outsider positioning in connection with his self-construction as 'European', the relatively open thematization of differences between Muslims and Christians in Ramallah, and the indirect thematization of his discrimination as a homosexual. These three components are interconnected.

Even before the first interview, and at the beginning of the interview, Boutros says very openly that he is 'different' from the rest of the local population, and thematizes his feelings of constraint, great isolation and vulnerability at the present time: "all the Palestinian here they live in the West Bank they suffer from something - I suffer from something else." In large parts of the interview, Boutros makes cautious attempts to be more concrete about this "something", to explain the cause and the nature of his outsider positioning, and to get into a stream of narration about his experiences of suffering. Yet, when he speaks about his negative views and his unhappy social situation in Ramallah, Boutros largely does this hesitatingly and in very general terms, as in the following excerpt:

"Shortly speaking it's about=ahh: what I don't=I don't like it here: is that I=I don't feel that I feel comfortable with the people here and I can have friends here because I always feel=ehh there is a big different between me and between the people here and I feel there is something like gap or wall [...] if you don't have friends if you are only by yourself you feel that you are weak."

The thematic components of this sequence - his insurmountable social isolation, the restriction of his freedom and the feeling of being weak (and thus vulnerable) constitute the reference axes of Boutros' self-presentation throughout the interview. Here, he leaves open the question of what this essential difference ("wall", "gap") between him and the 'others' consists of, and which options of action he sees as curtailed. However, from the beginning it is possible to read between the lines what Boutros says more openly later in the interview: he is referring here to the way people gossip about him because he is gay, and how they try to discipline him in respect of his social and intimate contacts. In a short narration he tells about the visit of a French tourist, who lived in Boutros' house for a time, and how rumours were going round that they had sex together. At this early point in the interview, Boutros gives the impression that there were no sexual contacts between the two of them, and he evaluates the story as evidence of how his reputation is threatened by this high degree of social control, by the traditional and conservative values of the people 
all around him, and the way they try to force him to follow patterns of action and relationship which Boutros construes as "Palestinian tradition".

In this first interview with us, Boutros does not relate his outsider status directly to his homosexuality, but presents it as the result of a cultural difference between the 'traditional' majority society and his non-conformist, artistic and liberal lifestyle based on European culture. He lays emphasis on his travels and his cultural interests and knowledge, and at the same time explicitly denigrates what he sees as Palestinian society in general, of which he says: "They have no culture." On the one hand, we interpret his self-construction as a 'European' and his degradation of the local context as a biographical pattern of working through his experiences of exclusion as a gay, his isolation and the ascription of being in some way inferior, while at the same time covering up the real category of his stigma. His insistent description of himself as "Western" is confirmation of one of the ascriptions commonly present in the they-image of gay men (as seen in the case of Malik). But his heavy emphasis on his individual difference from the established, with which he tries to empower himself in respect of their negative ascriptions, leaves the powerful they-image intact, since the real stigmatization category cannot be named, nor is he able to formulate a counter image. In the case of Boutros, his emphasis on difference, which to some degree accepts the they-image, has been discussed above as a form of stigma management that can be called 'minstrelization'. It is the central pattern of his self-image and signals an extremely strong and isolated outsider position. In other words: on the level of everyday life and on the level of his self-image (or we-image), Boutros lacks integrated belonging to a we-group in respect of his homosexuality.

Boutros' self-image is interrelated with his pattern of action of making contact with foreign visitors. This not only helps him to work through his exclusion from local circles, but also allows him to really experience himself as "more European", and to find sexual partners. At first he rationalizes his welcoming of foreign guests as an opportunity for learning and cultural exchange. But his revelation of his interest in sexual contacts with foreign visitors during the course of the interview is already hinted at quite early on in our talk through his attempts to discover the sexual preferences of the two male interviewers and the nature of their relationship, and to test our willingness to have intimate sexual contacts. Thus he asks relatively early on whether we are a couple, whether we have an 'open' attitude, repeatedly makes us compliments, and suggests that we could have a "good time" if we were to stay overnight with him. We tell him that we are researchers, answer his question whether we are a couple in the negative, and explain that we both have women partners.

Because of Boutros' stigmatized local outsider position, his limited freedom of movement due to the occupation, and the high number of tourists in Ramallah, making contact with foreigners who do not belong to the local context is a pattern of action by which he tries to organize his sex life within this social space, while at the same time concealing his homosexuality as far as possible.

Thus, on the levels of patterns of action and patterns of interpretation, he deals with his outsider experiences as a gay through his self-construction as a 'European 
among Palestinians' and not in terms of belonging to a they- or we-group of gay Palestinians. In doing so, Boutros is using an Oriental topos of the superiority of 'European culture' and removing himself from the 'national collective'. As we have seen in the case of Malik, the gossip about Boutros, as he perceives it, is also directed at a denial of national belonging, as shown by his report of a conflict with a nephew: "he doesn't like me he said, I am not like acting like Palestinian."

As a result of this explicit removal of a national we-group, and in contrast to the harmonizing we-discourse, Boutros is willing to talk about tensions and conflicts, for instance between Christians and Muslims, and in the interview he gives voice to his own prejudices in respect of 'the Muslims'. Thus, there are many passages in which he speaks about inner-Palestinian differences, for instance about the patriarchal control of women in his neighbourhood or about tensions between different Christian congregations. He also speaks very directly about tensions between Christians and Muslims in Ramallah: "People here they discriminate between (2) your religion Christian Muslim they- (...) there is some serious problems." He concentrates on talking about the way both Christians and Muslims in his area actively try to prevent interreligious marriages. Because he does not follow the we-discourse, he is able to present his own stereotyped ideas about the local Muslim population very openly: for example, he says that Muslims have more children and therefore the death of a child as a result of political conflicts does not affect them in the same way as Christian families. Boutros sees the difference in the number of children as being due to different lifestyles and preferences of the religious groupings; for instance he claims Christians are more ambitious regarding their children's education, and Muslims have more children because they accept polygamy. Moreover, 'the Muslims' are much more tolerant of overcrowded and spartan living conditions:

"We like to live like good ya good condition the life has to be, a good life (P.1: $\mathrm{hmm}$ ) you have to eat good you have to have nice clothes and to have=ehh ya all everything has to be perfect but the Muslim they don't care they live all of them in one room if you visit like the=ehh refugee camp in Ramallah you see they live all together in one room."

Boutros claims that this difference in the ability to tolerate bad living conditions is also the reason why Christians emigrate and Muslims don't. He says that the reason why Muslims put up more resistance is not that they are affected to a different degree by the Israeli occupation or that they are forced to live in worse conditions due to socio-economic differences; rather, their culturally anchored living conditions, which Boutros presents as being the result of their choices, enable the Muslims, whom he equates here with refugees in the camp, to put up more resistance.

Boutros' thematization of tensions between Christians and Muslims is bound up with narrations and memory processes relating to his experiences of discrimination as a gay man. Thus, he relates in detail a situation in which a policeman insulted him in front of a group of 'Western' tourists, with whom he was going about in Ramal- 
lah. Boutros first makes the following comment: "I think because I am Christian (2) there are some people that don't like the Christian here." In response to our request to tell us again about this situation, Boutros reveals, after some hesitations in the narrative process, that it was to do with his homosexuality. The policeman had said to the group of tourists, "yeah that I like eh I like ehm men". That Boutros is hesitant to thematize his own homosexuality is certainly also grounded in the fact that he is obliged to be cautious how he talks to us, because of his stigma management based on concealment and the danger arising from local gossip. However, a fine analysis of this passage and other parts of the interview suggests that placing his experiences of discrimination and violence in the thematic field of 'tensions between Christians and Muslims' is also an attempt to work through these experiences. Thus, Boutros uses a kind of 'gradual approach' to test the degree to which he can thematize these experiences, which in some cases are highly distressing for him. For Boutros, speaking about the discrimination he has experienced as a Christian, and differences between Christians and Muslims which belong to this thematic field, is also connected to stressful and unsettling experiences, but by assigning himself to a we-group of Christians he places himself in a figurational position that is much more powerful than his position as a gay man.

Thus, when Boutros talks about conflicts in Palestinian society this can be interpreted as a move towards working through his outsider position. This becomes clearer in the course of the interview, for instance when he repeatedly begins to speak about very stressful experiences, but then stops and says that perhaps he will tell us more later. Indeed, as the interview progresses, he talks more and more openly about the way he was, and still is, exposed to discrimination due to his homosexuality, in public spaces, by the police and in his family. But Boutros remains very hesitant in thematizing these experiences. This indirect kind of biographical work is a sign that for Boutros 'being gay' is much less firmly anchored on the level of an internalized, positive self-image than it is in the case of Malik.

The habitus demonstrated by Boutros and his self-image as a liberal, artistic 'European', together with his stories of discrimination, show that he is engaged in a confrontation with the established construction of masculinity, and that he is a victim because he is seen as failing to conform to it. However, since he places his experiences of being different in the framework of a general cultural deviation, he does not address the dimension 'images of masculinity' on the manifest level. Boutros does not assign himself to a group of gay men, he has no we-image as a gay man, and he is therefore unable to negotiate the social they-images openly or to develop a counter image. He feels isolated and defenceless, and regards his situation as his own individual problem. He is thus in an extreme outsider position: "Unmitigated contempt and one-sided stigmatisation of outsiders without redress [...] signal a very uneven balance of power" (Elias / Scotson 2008: 6). 


\subsection{Conclusion}

The cases of Malik and Boutros discussed in this chapter show very clearly that persons in an extreme social outsider position are less concerned with maintaining the homogenizing we-discourse that we were confronted with in many other interviews with Palestinians in the West Bank. Their voices thus give us an insight into social processes and everyday experiences that tend to be concealed by the harmonizing and homogenizing we-image. This corresponds to Norbert Elias' theory of established and outsiders, where the exclusion of outsiders from the we-group of powerful established by stigmatization and discriminating they-images is the means and the (temporary) result of an established-outsider figuration. But a comparison of the self-presentations and biographies of two gay men in clear outsider positions also shows that there are big differences in the working-through processes to deal with stigmatization which they have developed in the course of their biographies, in their ability to defend themselves against negative labelling (for instance being 'unmanly', being a disgrace to the national collective, or acting immorally), and thus also in the degree of their outsider position. The options to defend oneself against stigma obviously depend on the "strength of the stigmatized group" (Coston / Kimmel 2012: 101): "If you're alone, minstrelizing may be a life-saving technique. If [...] you are strong, you might try and militantly turn the tables" (ibid.). Notable here is the connection between defence against stigma, belonging to a group, and the development of a we-image.

Malik's self-image as a gay man is based on internalization of some components of the they-image ('more feminine'), and rejection of others ('a less valuable member of the community'). In contrast to Boutros, he negotiates both within the framework of a we-image of gay men, and on the basis of this we-image he can speak openly about his homosexuality. Malik's firm self-understanding of being gay, and of having a we-image, is probably also a functional component of his power to act. Malik has something to oppose to the stigmatizations, both individually and as a member of a group, and from this position he can speak up against the they-image that a gay man cannot be a member of Palestinian society.

Boutros' outsider position, on the other hand, is characterized by his own explicit removal from the 'national collective', as a component and a result of his biographical work in respect of his outsider stigmatization. Thus, from a figurational point of view, he is in a much more isolated outsider position than Malik, even though at first he might seem to have an established position, since his family is economically better off and has a higher status. From his marginalized position, Boutros cannot risk speaking openly about his homosexuality, and cannot speak about the they-image of him as gay, which is a prerequisite for forming a (collective) counter image.

While Malik is integrated in a we-group of gay men and contact with his group of gay friends is part of his everyday life, the we-group construction to which Boutros feels that he belongs ('cultivated Europeans') is more abstract and fragile and prevents him from forming contacts in the local context. 
As we have been able to show in the cases of Malik and Boutros, their biographical patterns of biographical work in respect of stigmatization and the dependent selfand we-images are interrelated with the way they deviate from the homogenizing we-discourse. It is clear that their outsider positioning is not identical, and that their perspectives regarding internal differences and conflicts in Palestinian society - not only in relation to their position as gay men - are therefore also different. In the case of Boutros, in order to be able to speak about discriminating practices in his environment, he talks about differences between Christians and Muslims without being able to directly name the discrimination under which he mainly suffers (as a gay man). In other words, he tries to thematize his own difficult situation via thematizing differences between Christians and Muslims. This indirect thematization of his own outsider experiences is not important in Malik's presentation, probably because his stable we-image as gay makes it easy for him to argue against the damaging they-image.

Even if both of them deviate from the homogenizing we-discourse, the concrete gestalt of their deviation is integrally bound up with their biographically developed strategies of stigma management, their we- and self-images and their specific outsider positions. 



\title{
6 Voices of former political prisoners and their families in the West Bank
}

\author{
Gabriele Rosenthal, Abmed Albaba
}

\subsection{Introduction}

In this chapter we will focus in particular on two families in which women of the middle (genealogical) generation spent several years in Israeli prisons because of their political activities. Most of the interviews in these families were conducted in the autumn of 2013 by Gabriele Rosenthal and a Palestinian colleague from Bethlehem. This colleague wishes to remain anonymous because he works in an academic institution which strictly boycotts joint publications with Israelis.

We will start with some general remarks concerning the interviews with former prisoners that we carried out as part of the project. These include interviews with the members of two cliques of young men who were detained in Israeli prisons and in prisons of the $\rightarrow$ Palestinian Authority $^{1}(\mathrm{PA})$ in the context of the $\rightarrow$ Second Intifada (2000 to around 2005), or in the following years, because of their militant actions (such as throwing Molotov cocktails). One of these cliques consists of young

\footnotetext{
${ }^{1}$ Two of our interviewees were still in prison in the West Bank when we met them for the first time. During the day they were allowed to go out into the town. Imprisonment by the PA is based on the Oslo II agreement of 1995, under which the Palestinian security forces agreed to systematically prosecute all acts of violence against Israel committed by Palestinians and to cooperate with the Israeli security services (see Usher 1996: 21-22). But this policy was consistently implemented only after Mahmoud Abbas took up office in January 2005.
} 
men whose fathers actively fought for the $\rightarrow$ PLO before the $\rightarrow$ Oslo agreement, and remigrated to the West Bank on the founding of the PA. ${ }^{2}$ Today their fathers have high positions in the PA in one of the cities in $\rightarrow$ Zone $A$, which has been under Palestinian self-rule since 1995, and they are members of $\rightarrow$ Fatah. In other words, these young men most likely belong to established families in the West Bank. Before this backdrop and because they were political prisoners, they were promised administrative posts in the PA, for instance as a prison administrator. The other clique, which is presented in detail in chapter 4, consists of young men from less privileged families in $\mathrm{a} \rightarrow$ refugee camp. Their parents have little formal education and in most cases no vocational training. The educational careers of their sons were either ended or interrupted when they were sent to prison, and today they take odd jobs when they can find them.

But despite these clear differences in their economic and social status, the members of both groups have in common that they are totally frustrated by the present so-called 'peacetime' and the 'stagnation' of the putative peace process. They are waiting and hoping for the outbreak of a new Intifada and do not believe that the peace negotiations will make serious progress. They make only cautious plans for the future, for instance plans to marry or to emigrate. Because of their political positioning they are in conflict with their parents, especially with their fathers. The fathers, who in the past fought for a Palestinian state, currently do not want their sons to take part in militant or armed political actions. This constellation creates tense relations within the families. On the one hand, the young men see their fathers, and sometimes their mothers, as idealized models because of their political past, and they revere them as past political heroes. On the other hand, they criticize their fathers' present acceptance of the policy of the PA and of President Mahmoud Abbas - which involves not endangering the outcome of the peace talks by militant actions ${ }^{3}-$ and see this as an obstacle to effective opposition to the Israeli occupiers. However, they still let themselves be guided by their fathers, or they acknowledge their authority, and feel that this prevents them from carrying out further attacks.

Interviews were also conducted with men who were sent to prison in the context of the $\rightarrow$ First Intifada (1987 to $1993 / 95)$. In comparison to the younger men, they are far more respected in Palestinian society and most of them belong to the established in the West Bank.

In addition, the authors conducted interviews with several members of a family in which a son in the middle generation, whom we will call Salem, made a bomb during the First Intifada which exploded prematurely and injured him so seriously

\footnotetext{
${ }^{2}$ Tamari (2011: 2) estimates that about 150,000 Palestinians returned to the West Bank with the PLO in this phase.

${ }^{3}$ After the death of Arafat in November 2004, it was Mahmoud Abbas, who was elected president in January 2005, who spoke out in favour of ending violent resistance and announced the end of the Intifada. In his speech at the summit meeting in Sharm al-Sheikh, he said that the PLO and the PA "agreed with Prime Minister Ariel Sharon to stop all acts of violence against Israelis and Palestinians, wherever they are" (http://news.bbc.co.uk/2/hi/middle_east/4247327.stm, 31.08.2016).
} 
that he lost a leg as a result. Salem, who was fifteen at the time, was sentenced to a prison term, and especially during the early days of his imprisonment he was tortured to make him name the friends who helped him to plan the bomb attack. He was kept in prison in Israel for seven years. He is now over forty, and lives with his family of origin, more precisely with his brother, Abu Latif, and the latter's family. He has serious psychological problems and shows symptoms of paranoia. He suffers from the idea that the Israelis implanted a transmitter in his brain and can therefore read his thoughts. These symptoms began a few years after his release from prison. Before they started, he had completed a university degree and was working in Jordan in a good position. The incident which triggered these symptoms, including flashbacks in which he relived torture situations, was an unpleasant encounter with an Israeli soldier on the border between Jordan and the West Bank.

Salem's brother, Abu Latif, and especially his wife, Umm Latif, have also been affected by the death of Umm Latif's younger brother, who carried out a suicide attack during the Second Intifada. He was sixteen and was still at school. The interviews in the family, and the comparatively mild sanctions imposed by the Israeli army after the attack, suggest that no one in the family knew about the boy's intentions. Although it was more than ten years ago, his parents and his sister still seem to be living in a state of shock and extreme grief, and to find it difficult to accept this traumatic process and loss as real. They speak about the traumatic event as if it happened just a few months before the interview. The mother thinks of her son while she is cooking and imagines him coming through the door and sitting down at the table to join the family meal. The father sometimes see a pigeon on the window sill when he is praying and believes it is his dead son. In this family we gain the impression that the middle, and especially the younger, generation have no interest in further political activities. Instead, they concentrate on finding secure employment. In the different meetings with us, they insist that they are apolitical.

In addition, Gabriele Rosenthal and her Palestinian colleague interviewed a total of four women and one man, who have been organized in one of the militant groups in the West Bank since their youth. According to their own statements and according to our archive researches, four of them spent many years in prison because they were involved in bomb attacks and the murder of Israelis. Below, we will present in detail the story of Fatima Maaruf, as we will call her. She was and still is a member of the $\rightarrow$ Palestinian Islamic Jihad (PIJ) and is active in a sub-organization that supports the families of prisoners. Because of her membership of this organization, which is regarded as a terrorist organization, and because of her activities, she was sentenced to two prison terms totalling seven years altogether and she actually spent five years in prison.

Understandably, this man and these women spoke during the interviews only of the deeds for which they were punished or which could be proved. We cannot give many details here for reasons of data protection and to avoid creating difficulties for our interviewees. Remarkable is that they show no feelings of regret or guilt in respect of the Israelis killed by them or by other members of their organizations. 
They legitimate the killings by the pattern of interpretation that normally all Israelis, including civilians, do military service, and so are soldiers who must be fought against. Their biographical self-presentations and the presentations of their Palestinian we-group are focused on the thematic field of 'our suffering under the Israeli occupation'. For them, this is a framing of their biographical self presentations which can easily be filled with biographically relevant and momentous experiences. During their time in prison they experienced situations in which they were tortured and humiliated. They were multiply traumatized. However, this did not lead to their retirement from political activism; rather, all of them are still politically active and identify themselves with their political organizations and groups. ${ }^{4}$ The consequences of their imprisonment, of torture and mistreatment, do not stop them from renewed political activities and have not lessened the likelihood of their being rearrested, together with everything that this might involve. They still have an active political voice in the Palestinian community.

For several reasons, these interviews were challenging for Gabriele Rosenthal and her colleague from Bethlehem: the interviewees had been involved in murders and had no problem justifying this; they did not want to reveal any more than the Israeli secret service already knew, because they had to take care not to give us sensitive information about other combatants; and quite logically they could not trust us entirely - after all, no one could tell whether we were being spied on or 'bugged' by Israeli authorities. Another challenge was that they expected us to present their stories, and especially their versions of their history, in the academic discourse. In addition, we had to conduct the interviews in a way that gave them enough space to talk about their traumatizing experiences in Israeli prisons, and we had to help them to keep up the flow of the narration which meant listening attentively to their descriptions of the torture they suffered. It also meant accepting their defence and not insisting by asking further questions. There is no doubt that during the interviews, in contrast to the subsequent analysis of the texts, we were far more involved in their perspectives and feelings - and this is necessary for a good 'rapport' or trusting relationship, which requires mutual respect and taking on the role of those who narrate. Analysing the interviews, on the other hand, requires an analytical perspective and a critical evaluation of the self-presentation. This general condition for conducting and analysing interviews, finding the necessary balance between engagement and distance - as discussed by Norbert Elias (1956) - was more complicated and more emotionally demanding in these interviews than in all the other interviews we conducted in the course of the project. In many respects, this is connected with the fact that we personally found the encounters with these interviewees very pleasant, and they aroused sympathy and empathy in us. In contrast to the interviews with the

\footnotetext{
${ }^{4}$ For reasons of anonymity we cannot say here how we made contact with this group. But we wish to make clear that the interviewees know about each other and that their groups or organizations approved of us holding the interviews, after we had introduced ourselves and explained why we were interested.
} 
four women, the interview with the man was more difficult, because he asked a lot of questions about our intentions and was suspicious about how the Israeli secret service might use our knowledge. In the case of the women we were impressed by how easy it was to build up a relationship of mutual trust. We wanted to hear their stories and they wanted - as far as this was possible - to share their experiences with us. We did not want to condemn them for what they had done, we wanted to understand their actions and their suffering. And, unlike other interviewees, they told us a lot about their individual experiences. On the basis of our case reconstructions and in a contrastive comparison with other interviewees it became apparent that it was easy for these former political prisoners to embark on a narrative and memory process. Unlike other interviewees, their biographies are shaped significantly by their struggle against Israel, and their suffering under the occupation and during their imprisonment and interrogation. Thus, their history fits seamlessly into the hegemonic weimage of 'our suffering under the Israeli occupation'. Their biographies are eminent justification of this we-image, and their suffering during their time in prison appears as a central component of the we-image and the collective memory.

In this chapter we will introduce the Schahrur family and the Maaruf family not only from a critical analytical perspective, but also from an understanding perspective, and will attempt to reconstruct the processes that led to the daughters in the family becoming politically active. Following the general assumptions of biographical case reconstruction, we do not ask simple 'why' questions. For example, we do not ask why these two women became politically active in this particular way, or why they are still active. We also refrain from the question whether what they did was right or wrong (or we bracket this question). Rather, in sociological biographical research - as Norbert Elias has similarly argued (for instance 1956, 2010) - it is important to adopt a diachronic and processual perspective and to ask: which collective and individual processes have led to the political activism, the actions and the arrest of the interviewees? And: what collective and individual processes took place during and after their time in prison? This makes it possible to see these biographies "as a micro-process" within a larger "macro-process" that is experienced in a society by social formations or groupings (Elias 2010: 91).

In order to protect these families, we have changed some of the facts, or we deliberately give only vague information. We were able to use media reports on some of the interviewees, including Helene Schahrur, her role in a bomb attack and the torture she was subjected to in prison. This information has been substantially modified so that she cannot be easily identified.

We decided to describe these two families in detail because they are very different in their political and religious affiliation, in their socio-economic status, and in their socio-generational structure. In the Schahrur family, the daughter Helene was a member of Fatah and was involved in bomb attacks as long ago as the mid-1970s. This was the phase following $\rightarrow 1967$, the suffering resulting from the war and the Israeli occupation of the West Bank, the Israeli attack on one of the main bases of Fatah in Jordan (in Karameh) in March 1968, and Black September in 1970, in which 
many Palestinian activists and combatants were killed and which led to the expulsion of Palestinian organizations from Jordan, who subsequently directed their military operations against Israel from Lebanon. With reference to the first revolution of 1936, Neslen (2011: 157) calls this time the 'second thawra' (revolution), which "burned until the PLO was expelled from Lebanon in 1982" (ibid.). As he puts it, "throughout the 1970s the Palestinian revolutionary militias made propaganda and waged a violent, sometimes indiscriminate national liberation struggle" (ibid.: 158). Helene's militant activities took place at a time when the PLO and other militant organizations experienced the liquidation of many of their leaders by the Israeli army, and especially by Mossad, an Israeli secret service; civilians also lost their lives. At the same time, Palestinian groups carried out a number of attacks in Israel, such as the 'Ma'alot massacre' in 1974, in which 25 out of 115 hostages were killed, 22 of them children. Israel's government reacted by bombing camps and villages in Lebanon, in which 27 people were killed and more than 100 injured.

Helene was jailed 5 at the end of the 1970s for her part in a bomb attack, and released after eight years in the course of an exchange of prisoners.

In the other family, the Maaruf family, the daughter Fatima claims that she became politically active during the Second Intifada. However, we think that she must have been active in some way or another during the First Intifada. Fatima was jailed in 2003 and again in 2006; in 2006 she had been released shortly before she was rearrested. As already mentioned, Fatima was and still is a member of the Palestinian Islamic Jihad, or of a sub-group that supports the families of prisoners and 'martyrs'. During the time she was in prison, many houses and urban infrastructures in the Palestinian areas were destroyed during military attacks by Israel, in the course of which thousands of Palestinians were imprisoned and hundreds were killed. At the same time, a number of suicide attacks were carried out by Palestinians in Israel. The PIJ claimed responsibility for five of these, in which 46 people were killed and many seriously injured. One suicide bomber killed 21 people in a restaurant in Haifa, another killed 23 people at the bus station in Tel Aviv, and three people were killed by a female suicide bomber in Afula. ${ }^{6}$ Between 2000 and 2004, 949 Israelis and 3,523 Palestinians lost their lives in the context of such acts of collective violence (see Neslen 2011: 48), ${ }^{7}$ in which perpetrators and victims acted, or became the target of such acts, primarily as representatives of their respective we-groups.

\footnotetext{
${ }^{5}$ Antonius (1980: 29), who published a list of names of female political prisoners for the period from 1967-1979 (which includes Helene's name), estimates that there were at least 2,000 women in prison during this time.

${ }^{6}$ See http://en.wikipedia.org/wiki/List_of_Palestinian_suicide_attacks\#2003_.2823_bombings.29; Arnon Regular, Profile of the Haifa suicide bomber. October 5, 2003; www.haaretz.com; for Tel Aviv see http://news.bbc.co.uk/2/hi/middle_east/2630055.stm, 07.01.2015.

${ }^{7}$ By contrast, in the First Intifada, according to Neslen (2011: 122), 1,409 Palestinians were killed by Israeli troops and 271 Israelis were killed by Palestinians. Around 120,000 Palestinians were put in prison.
} 
The members of the Schahrur family are Christians and long-time residents of the West Bank, while the Maarufs are a Muslim refugee family that still lives in the camp. The Schahrurs can be described as economically more or less established. The two eldest grandchildren are students and a grand-daughter spent a year in England under an exchange scheme. Her father, Helene's husband, has a well-paid job in a company. By contrast, the Maaruf family is economically very insecure. The Maarufs live in a refugee camp close to Ramallah. They are religious and tend towards political Islam, but one son is a member of Fatah. Most of Fatima's siblings have been in prison several times for political reasons, in some cases when they were as young as 11 and 13 .

Fatima and Helene are still politically active. Fatima is in a sub-group of the PIJ. Helene has more left-wing ideas and therefore belongs to a different organization.

\subsection{The Schahrur family: The politically active daughter Helene}

In the autumn of 2013 Gabriele Rosenthal and her colleague from Bethlehem interviewed two members of the family: Katharina (born about 1928) and her daughter Helene (born about 1960). The grand-daughter Vivian (born in the 1990s) was interviewed around the same time by our colleague Johannes Becker. While Helene and Vivian spoke to us in English, the interview with Katharina was conducted in Arabic and translated into English by the colleague from Bethlehem. Occasionally the grand-daughter, who was present during the interview, also translated questions into Arabic for her grandmother and insisted on detailed answers. One of the most interesting sequences in this regard was a dialogue on the $\rightarrow \mathrm{Nakba}$ of 1948 , the most important historical period in the collective memory of the Palestinians (see ch. 2). The grandmother did not mention this period of her own accord. Towards the end of interview, Gabriele Rosenthal asked her to narrate the story of her experiences in the year 1948. The following passage is a translation of the dialogue which took place in Arabic between Katharina and Vivian:

Vivian: Can you tell them more about the period of the Nakba? About your life situation during the time of the Nakba?

Katharina: Which Nakba?

Vivian: ((the one of 19)) 48

Katharina: I know nothing about it, I've forgotten

Vivian: Can't you remember it?

Katharina: What happened in the Nakba?

Vivian: When the Jews came and forced everyone out of their houses and the right of return

Katharina: I’ve forgotten ((laughs)) forgotten ((laughs)) 
In 1948 Katharina was about 20 years old and we may wonder what it is that she experienced as a young woman and now does not want to speak about, or is trying to forget. Even the political claim to the $\rightarrow$ 'right of return', which her grand-daughter refers to, obviously does not move her to speak. It seems she does not want to talk about the events or facts associated with the Nakba or to be reminded of them, or she does not want them to emerge into her consciousness. Our analysis of the interviews shows that there is a general tendency in this family not to speak about experiences that are bound up with their own impotence, as will be discussed below.

As we have already pointed out, the present situation of this family is characterized by a relatively stable economic position, notable educational careers, especially in the third generation, and a transnational family network. Of the middle generation, four children live abroad ('in the West') and only two daughters still live in the West Bank, in Bethlehem. The maternal grandfather, Helene's father, died following a long illness, shortly after Helene was released from prison in Israel. A few months after his death, Helene's mother, Katharina, was beaten by Israeli soldiers and sustained serious leg injuries. Since then she has only been able to walk with difficulty and suffers from chronic pain. Characteristic of Katharina's behaviour towards $\rightarrow$ IDF soldiers is that she first hit a soldier because he had beaten a Palestinian youth: "I took hold of the soldier and hit him." Helene took her mother to live with her and her family; she had married a man who was initially in an insecure position, but who later got a good job that led to an economically established situation.

In the early 1960s, when Helene was born as the third daughter of the Schahrur family, her parents had only a very modest income. Her father did occasional jobs and money was often scarce. However, the parents, who had had a good school education during the period of the $\rightarrow$ British Mandate, made sure that their children went to secondary school, even if for some of them they could only afford the (Jordanian) state schools. All their children successfully completed their secondary education. At the time she was arrested, Helene had just passed her final exams.

Helene experienced the 1967 war and Israeli occupation as a child. Interestingly, and in contrast to our question about 1948, her mother told us many details of how she acted towards the IDF in the 1967 war and during the subsequent Israeli occupation of the West Bank. She did not allow her children to leave the house. When she saw from her balcony how a group of soldiers beat a neighbour's child in front of her house, she reacted as follows:

"I went in ((into the house)) and fetched a pot of water ((hot water)) and poured it on them, they yelled at me, but they couldn't find my door and didn't know how they could come up to me, they made us suffer a lot, I began to see them as monsters to this day, I pray every day to God for peace."

"I began to see them as monsters", says Katharina and in the interview she hints at how strongly she still retains this image today. She compares "the Jews" with the Syrian dictator Bashar al-Assad and says: "I curse Assad and the Jews, who began 
the war [...] there are devils at work out there." We can only speculate about the impression that Katharina's attitude and her fearless opposition to the Israeli soldiers in 1967 made on her children. By contrast, Helene describes her father as apolitical, as someone who spent a lot of time praying in those days. In answer to Gabriele Rosenthal's question whether her father was political, Helene answers:

"No, my father he's special, my father if he watched a movie, Arabic movie or any, and he finds some things he cries, no, my father he was so sweet and sensitive person [...] I never met a person, especially an Arabic person who is so much sensitive from anything, no, he couldn't be engaged in such a thing."

Nevertheless, her father appears to have sympathized with communism and perhaps also with one of the communist organizations of the Palestinians. He named his only son after a communist freedom fighter, as Helene points out. But Helene says that she is the only one in the family who became politically active, and that she kept this fact secret from her family. She began to take part in political activities in the mid 1970s, when she was thirteen, and she explains that among the pupils at her school it was quite normal to take part in demonstrations, go to political meetings and distribute leaflets: "I was one of million or thousands of my school doing such a thing." At fifteen she joined Fatah, and a sub-group which carried out attacks in Israel. She regularly transported bombs to Jerusalem, during the time she was supposed to be at school:

"I used to go immediately on the time of schools and come back immediately, while school was out so I was exactly on time, so no one in my family was suspicious that I was such a thing, so that was a shock for them."

When we ask what led her to take part in bomb attacks, she speaks about the Israeli army's invasion of Lebanon in 1978 and their assassination of several leading members of the PLO. She does not mention that this military action was preceded by a massacre of Israeli citizens, including many children, by members of Fatah. She also does not directly mention the fact that the Israeli attacks on PLO leaders led to the death of Lebanese civilians; she takes for granted that the two interviewers know what she means by her reference to 1978 . At any rate, it was these events that triggered in her the desire to do more than just joining demonstrations: "I wanted revenge."

One of Helene's relatives, who was a few years older than her, also transported bombs and died, "because the bomb exploded prematurely". She says that the family regarded him as a martyr and at that time "the martyr had his value" - unlike today; and that today there are many more martyrs. She explains that despite his death, she was not afraid of carrying explosives, and was much more afraid of being arrested and of what would then happen to her. Then, at the end of the 1970s, she was arrested in connection with a bomb attack. Because she was under age, she was not 
sentenced to life imprisonment, as was first intended, but to a term of over ten years in prison; however, she was released after eight years under the terms of a prisoner exchange.

In the interview, unlike other former political prisoners, Helene does not talk about how she was tortured, but only mentions it briefly or implies it between the lines. She speaks chiefly about the intolerable hygiene conditions, especially in the early days of her imprisonment: that she couldn't wash, that she couldn't change her clothes, that she had nothing she could use when her period came. She also describes the gas bombs that the guards threw into the cells, and their terrible effects that lasted for days.

She informs the Palestinian interviewer several times very firmly in Arabic that he should not ask her about the torture she suffered and its physical consequences, and not to read aloud the relevant passages from the newspaper articles she showed us during the interview. It becomes apparent that she never talks to her family about it. While she was still in prison, she tried to ensure that her parents would not see signs of torture on her body when they came to visit her. Once, when her parents asked her during a visit whether she had been raped, she said no. But her choice of words in the interview - "I did not tell them about" - suggests that this was in fact the case. To this day she doesn't talk to her family about what happened to her in prison. Her daughter Vivian first heard about some of her experiences, like gas in the cells, in connection with a school project about Palestinian prisoners. Vivian speaks in a very reflective way about her mother's disinclination to speak about these things:

"She didn't really share very much about her time in prison, um just not secretive but like it's something only her, only she would understand [...] I heard more about her was when I did a school project on Palestinian prisoners and I chose my mum to interview [...] the most the shocking thing that I discovered was that when I was reading about the history of Palestinian prisoners in prison and all the major days there was a day where, uhm, they put all prisoners in a room and they had like, ahm tear gas thrown in and uhm, and also my mum told me that yeah she was among those prisoners that were in that room it was just weird I am reading history and then my mum was part of making that history she was present that day in that room and she was affected by the gas like all the prisoners [...] mum didn't share very much, she didn't just come and share, say things or if I asked for something you would like, you would have to take the information from her ((laughter)) it took her and yeah I guess like uhm, like sometimes people just choose to block those memories, because sometimes-, you know my mum-, that she was going through because after she left she was ready to live her life."

Vivian, who speaks admiringly about her mother's past, implies that she has learnt more about it from her mother's friends than from her mother directly. 
What Helene says in the interview about her time in prison is mostly related to her worries about her family. These are the most dense and most emotional parts of the whole interview and we can assume that they are an expression of her feelings of guilt, especially towards her father, who was diagnosed with cancer while she was in prison and died shortly after her release. She repeatedly tries to assure us that "I was scared believe me, believe, believe me, nothing about myself", but she was terribly worried about her parents, and also about her brother, who was about fourteen years old at the time. He was a witness of his sister's arrest in their parents' house, and after that he was so scared that he hardly dared leave the house. As soon as he was old enough, he emigrated to the US.

After the death of her father, Helene got married; she told us that finding a husband was not easy for a Christian who had been in prison, because Christians are not proud of marrying an ex-prisoner. When we asked if she could tell us how she met him, she said:

"You know, Christianity here is really difficult of getting married, especially with one that she's political, now, we don't have that like the Muslims, the Muslims have this attitude that is really good, you know, they are, they are getting they are proud to get married prisoner, with one who is a prisoners as a Christian we don't have such a thing, you know, Christians, that she is a prisoner, they are scared, you know, if their son married her, you know, she will be arrested, and eh, she will have a problem for their child, they don't have such a thing."

It is surprising that Helene insists here so clearly on the difference between Christians and Muslims. In other parts of the interview, she argues vehemently against this differentiation, and accuses the Israelis of trying to sow divisions. She is surely aware of the fact that female Muslim ex-prisoners she knows from the organization, such as Fatima, also have problems with finding a partner. ${ }^{8}$ We assume that Helene would have liked to be given more respect by her Christian family and friends. Perhaps she uses this explanation to avoid having to admit to herself and to others that she is afraid of getting close to other people.

Helene's husband, Thomas, had proposed to her before her father's death and she had refused. But when she realized how difficult it would be to found a family, and that she wanted a partner who would give her a degree of freedom ("my space"), she agreed:

\footnotetext{
8 These difficulties are also revealed in our interviews with female prisoners, and have been discussed in the academic literature (see for instance Lybarger 2005: 39).
} 
"So after my dad died, I recognized that, you know, that he is the only, ya'ani person that asked for about my hand, but he is so sweet and he, yaani, I saw, I saw him at her house so many times, he is really, eh organized and he is a helpful person."

Even though Helene is sorry that her family had to suffer because of her imprisonment, she is quite firm about the fact that she does not regret what she did: "[...] my father was sick, I could see how he was struggling, he could not stand on his legs, you know, so, but you know, I will never regret it, I built my personality." She goes on to say that she feels strengthened by her experiences; without them she would only be "superficial". But she also admits that she will never recover from her traumatic experiences. Apart from her work in a bank, she does not leave her family and feels comfortable only in the company of her female friends, who have also been detained in Israeli prisons. The following passage shows how much she still suffers today as a result of her time in prison, and how fearful she is of entering into relationships with people outside her family:

"When I came out ((from prison)) till now I don't have any relation or any friends, I do not go out with people, till now I am suffering this [...] I do not like to talk with normal people, I feel myself only with the girls from jail [...] people from outside, maybe, you know, I don't feel it's me, I feel I have to pretend [...] I feel all the conversations are really silly [...] even I spoke with a psychologist doctor, that still I am suffering this, that I cannot communicate with people."

Her life is thus centred around the family, her children, her elderly mother who is in need of care, and her husband, who - according to Helene - is also happy to have a life that is concentrated on the family.

Vivian, the grand-daughter in this family, is proud of her mother, whom she describes as strong and courageous, and of her grandmother. She says that the strong people in her family are the women, and she describes her father, Thomas, in the same terms as those used by her mother to describe the grandfather: that he is apolitical and that his response to conflicts is to pray, as on the occasion when the neighbours' flat was searched by Israeli soldiers. By contrast, for Vivian's own self-presentation a political framing is central. She introduces herself as a student who is very interested in political matters, then asks whether she should also talk about the history of her family, and continues:

"A big part of me and my childhood growing up was me- um influenced by the 2001 events [...] and it was a weird time ((laughing)) because we had curfew most of the time, we got to learn a lot about each other, like, living in a hard situations (3) and you know first exposure to guns, political violence uhm (2) and for me I guess because my mum was in prison for seven 
years uhm just like seeing the effects not really going away uhm you know my mum went to prison and it still was the same political violence the same problems my mum had experienced."

Vivian, who associates the beginning of the Second Intifada with her mother's time in prison, was about twelve at the time, and experienced some dramatic situations. There was a phase during which for weeks she could not leave the house, the schools were closed, there was no electricity for long periods, armed clashes took place in front of her house, they could not go shopping and had to bake their own bread. Sometimes they hid Palestinian combatants in their house, and from the balcony Vivian saw how one of them was shot dead in front of the house. She speaks at length about this time and repeatedly connects it with the fact that her mother had been in prison. She then emphasizes how, unlike her mother, she has been very privileged in her later life, able to go to university and to do a semester abroad. Her greatest difficulty at present, especially since returning from England, is the way other young people behave towards her as a Christian. She describes how she has experienced discriminatory behaviour, and speaks of persecutions of Christians in Syria and Egypt. She explains that her bond with Palestine is not a bond with the country so much as with her family.

\subsection{The Maaruf family: "One of my children was always in prison"}

Fatima Maaruf was interviewed in the autumn of 2013 by Gabriele Rosenthal and her colleague from Bethlehem, who acted as interpreter because Fatima mostly spoke in Arabic. As Fatima can also speak a little English, she repeatedly tried to communicate with Gabriele Rosenthal directly in English. Her mother, Sara Maaruf, was interviewed by Johannes Becker and Mariam Abdul Dayem in Arabic in the course of two meetings. Fatima's elder brother Mutab (born in 1971), who will be presented only briefly in this chapter, was interviewed by Ahmed Albaba in Arabic in spring 2015.

The interviews with the mother, Sara, who was born at the end of 1947 or the beginning of 1948 in a Muslim family in the village of Dawayima near Hebron, and with her daughter Fatima, who was born in the early 1970s in a refugee camp near Ramallah, differ in many respects from the interviews with members of the Schahrur family. Helene Schahrur was friendly, but was always in control of the topics she was prepared to talk about or not. Helene told our Palestinian colleague very directly which questions he must not ask. It was obvious that she was anxious to maintain control over the interview. Fatima Maaruf entered much more easily into an emotional and trusting relationship with us during the interview, despite her practised control in terms of what she could thematize and what information she had to hold back because it might put her political comrades, her family or herself at risk. She 
had no problem embarking on a flow of narrations and memories relating to topics that had nothing to do with illegal activities. The interview with Fatima lasted more than three hours and we only brought it to an end because of our own time planning, as we wanted to get back to Ramallah before dark. The interviews with the mothers of Fatima and Helene also differ. While Helene's mother answered our questions in short sentences and only occasionally told a story, our colleagues Johannes Becker and Mariam Abdul Dayam held two interviews with Sara lasting for a total of over nine hours altogether. In response to their questions, Sara narrated her experiences at length and in detail. Fatima was also present during the interviews with her mother, and frequently added narrations of her own relating to events in the history of the family.

The present conditions under which the family is living in the refugee camp are also very different from those of the other family, which lives in a spacious, privately owned flat. Fatima, who is now over forty, still lives with her mother and her younger sisters in a small house in the refugee camp. A few years ago, her planned marriage fell through because she could not travel to Gaza where her fiancé lived and he could not come to the West Bank.

Our knowledge of the history of the Maaruf family - especially of the time before 1967 - is based almost entirely on the interview with Sara. In her initial selfpresentation, Sara says that in 1948, when she was a small child, her parents had to flee from their home village with her and her siblings. But from the detailed stories she told in the questioning part of the interview, it is clear that at that time she lived with her parents in Egypt, which is where her mother came from. In agreement with Sara's family history which is initially framed as a story of expulsion and flight, her daughter Fatima, in the stereotyped manner of her generation, also presents only the collective data of the Nakba, the central components of the collective memory, and especially the massacre that took place in 1948 in her parents' village, during which, according to Fatima, five hundred people were killed. ${ }^{9}$ She also says that her mother was driven out of this village. By contrast, she says nothing about the specific circumstances of her family's history, including their Egyptian background. This does not fit into the collective we-image and the collective memory of expulsion and flight, so that it is not surprising that Fatima presents herself with the identity tag, 'I am the daughter of a refugee family and I was born in the camp'. Moreover, by leaving aside her individual family history and thematizing only the homogenizing collective history, reduced to the Nakba, Fatima is able to use the discourse of the following generations which is critical of the failure of the members of the Nakba generation to defend themselves in 1948, and of their unheroic flight. Both Fatima and her brother Mutab tell us in the interview that the inhabitants of Dawayima and other villages should have made much more effort to defend themselves and their

\footnotetext{
${ }^{9}$ The number of people shot by the 89th Batalion of the Israeli army on 29th October 1948 in Dawayima (a village with 4,000 inhabitants in 1948) differs depending on the source and ranges from 100 to 1,000 victims (Morris 2008: 333; Morris 2004: 469).
} 
land. Both of them argue that the decision to run away in 1948 was wrong and was due to the ignorance of the members of the Nakba generation, who were also very gullible because they had believed the Arab propaganda and thought they would be supported by the armies of the Arab countries involved in the war. We can assume that the accusations levelled against their grandparents and parents, which serve as a form of defence against the idea of their powerlessness under the Israeli occupation, as well as Sara's and Mutab's own powerlessness, are important motives for their own political activity against the Israeli occupiers.

Sara and her husband Yusuf both come from the same 'family' or hamula. Sara is the second daughter from the second marriage of her father Ali, and from the second marriage of her mother, who comes from Egypt. During the $\rightarrow$ war months of 1948, when Sara was still a baby, she was in Egypt with her parents and her older sister (born in 1945), on a visit to her maternal grandparents. Since about 1942 her father had frequently commuted between Egypt and Palestine for business reasons, and met his wife there. In 1948 Sara's three step-brothers from the first marriage of her father stayed in the home village with the family of Ali's brother, her uncle. Her father Ali had decided to travel to Egypt shortly before the beginning of the war in 1948 - probably at the end of 1947 - because he saw that the political situation was very unstable. When fighting broke out in the British Mandate of Palestine with the announcement of UN Resolution 181 in November 1947 (see Morris 1987: ch. 2), and the war began in May 1948, he stayed in Egypt with his family and opened a grocery shop there. The members of his family who had stayed in Dawayima, including his three sons, witnessed the traumatic events in the village in October 1948. It was a terrible massacre. The IDF entered the village, killed several hundred men, women and children, destroyed houses and caused the inhabitants to flee (see Morris 2004: 469-471; Morris 2008: 333). Sara's parents were tormented with worry about their relatives, because at first they did not know where they were or what had happened to them. Sara tells us:

"They ((my parents)) only knew about it from people, as you ((the interviewer)) know, at that time there was no telephone and no radio, there was nothing, they heard from people that the war had begun and that the village ((Dawayima)) and all the area around Hebron was occupied, so they stayed there, the four of us stayed with my mother's family in Egypt for a year and a half."

We do not know exactly when Sara's parents heard that the family of her paternal uncle and his children had all been able to flee from the village and to find accommodation in A Camp near Ramallah, which was founded in 1949. At the end of 1949 or in 1950, Sara's parents decided to go back to Palestine and to join their relatives in A Camp. In the interview we repeatedly heard about the registration as refugees with the $\rightarrow$ UNRWA. Because of their specific situation - an Egyptian mother, a long stay in Egypt - it probably was not easy for this family to gain rec- 
ognition as refugees, a status which, at least later on, gave them the right to medical care, schooling for their children and other services; possibly this was when they began to rewrite the family history.

However, the attempt to reunite the family in the camp failed. There were disputes between Ali and his brother, and Ali again decided to go his own way. Together with his family, including all his children, he moved to a refugee camp near Jericho and opened a grocery shop there.

In 1955, when Sara was seven, the family suffered a tragic loss. An older brother of Sara's, who was eighteen at the time, was shot dead by a Jordanian soldier during a demonstration. In the family dialogue, which is clearly shaped by the collective memory, this very distressing event remains completely in the background. The fact that her brother was killed by a Jordanian is also at odds with the rules of the hegemonic discourse in respect of the national we-group. Sara solves this problem by repeatedly referring to a "British" soldier.

Sara's own path took her back to A Camp, back to the family of her father's brother, and to an economically more precarious and dangerous situation. At the age of 13 or 14 she was betrothed against her wish to her cousin Yusuf in A Camp. In 1963/1964 she was married to him and moved in with her husband, who was already 31 years old. She tells us that she had always been at the top of her class, but that she had to leave school when she got married. Her husband was an unskilled worker. In the interview it became clear that this life course was not her will, and that it was hard for her to have to give up her educational career:

"In Jericho with my family I was used to luxury, we went to school and I learnt a lot, we had a good life better than my life after my marriage, because my father had a kiosk [...] earned a lot of money, my husband had no money, he sold lupins ((she means lupin seeds boiled by her)) ((laugh)) he earned half a dinar or forty qurush ((pennies)) per day in the winter he sold lupins and in the summer ice cream and things like that."

Two of her siblings were also married to relatives from A Camp. Although marriage between cousins is very common in Palestine, ${ }^{10}$ we presume that this was the price that her father had to, or chose to, pay for leaving the hamula in a socially inacceptable way. We found the same pattern, which is connected with questions of loyalty, in other refugee families where a part of the family had moved out and risen socially in comparison to the members of the family who stayed in the refugee camp, and whose daughters (!) were then married to cousins who had remained in the camp (Rosenthal 2012).

The first child of Sara and Yusuf, a daughter, was born in 1966, and they went on to have seven more children at almost yearly intervals. Fatima, born in 1974, was the fifth child. The family had very little money. The father suffered from diabetes

${ }^{10}$ Johnson (2006) estimates that 30 percent of marriages are between first cousins. 
and an eye condition. The sister born before Fatima was disabled as the result of an illness in her early childhood. Fatima's two older brothers had to start helping their father in his work at a young age.

Both Sara and Fatima tell us stories about the political activities (including smuggling weapons) carried out by members of the family, especially after the war of 1967 and the beginning of the Israeli occupation. During the 1967 war, Sara's parents decided not to stay in the West Bank and fled to Jordan, taking Sara's younger siblings with them. Their relationship with the branch of the family living in Jordan - Sara's siblings who founded their families there - is stable to this day and they visit each other regularly. The relatives in Jordan are also politically active in the struggle against the Israeli occupiers, and one of Fatima's brothers-in-law was killed during an action. Her relatives in Jordan and in the West Bank have been repeatedly arrested and sentenced to jail terms.

Fatima's childhood was marked by political unrest even before the First Intifada, which began in 1987 . This was largely due to the existence of a $\rightarrow$ Jewish settlement near the camp. On their way to and from school, which took them past the settlement, Fatima and the other Palestinian children and youths used to throw stones, and this regularly led to confrontations with the Israeli soldiers stationed at the entrance to the camp. In the spring of 2015, during a visit to the Maaruf family, the co-author of this chapter became witness to such a situation, in which youths threw stones and the Israeli soldiers responded with rubber bullets, tear gas, and also live ammunition. He experienced the actions of the soldiers, who were armed with machine guns and pointed them at the youths, as extremely menacing.

Fatima and her family's first experience of a severe crisis was around 1981. IDF soldiers stormed their house in the camp and Fatima's two older brothers - aged seven and ten - were arrested and detained overnight, together with other children. Fatima's brother Mutab narrates this situation and says that the IDF had heard that a child from the camp had thrown stones. Fatima says that this kind of thing more or less belonged to everyday life, soldiers were permanently storming their house. In the interview, looking at her mother, she says:

"Yesterday I talked a lot about this I told them ((the interviewers)) how we lived in those days and how we experienced the army coming into our houses, how they beat us how they fired with gas, rubber and real bullets, so our childhood was a childhood well we had no childhood, the only thing we wanted was to throw stones at the army and they fire at us, and invade our houses, that was our whole childhood [...] we were driven out in 48, we left our land and came here, they followed us here, they didn't leave us in peace after we were driven out, they even followed us here, to storm our houses, they are always here, always, keeping us down, beating us, often they come here at night at 2 or 3 in the morning, and we all the time we are smelling gas, so much gas." 
According to Fatima, a further frightening situation was in 1983, after her eldest brother Said had thrown a Molotov cocktail at a bus. Aged fifteen, he was sent to prison for two years, and one room in his parents' house in the camp - they only had two rooms at the time - was "closed" by the IDF. ${ }^{11}$ Neither Sara nor Fatima nor Mutab - who all spoke about this part of the family's history and about the dramatic situation of Said's arrest in the house - told us whether anyone in the bus was injured. Since Said was only sent to prison for two years, we can assume that no one was killed.

The year 1983, when Fatima was nine, marked the beginning of a course of events during which again and again one or the other of her five brothers was arrested and sentenced to long prison terms because of militant actions he had committed, or was accused of committing, against the Israeli occupation. One could describe them as 'revolving door' prisoners. As a result, their schooling was constantly interrupted, until they dropped out of school completely and landed in very precarious economic situations. When their father died in 1992, the financial situation of the family became even more difficult. Fatima had just turned eighteen, had successfully completed her secondary school exams and had been at university for a few months. She is the only person in her family who completed secondary school. It can be assumed that it was her position in the family system as youngest daughter that moved the family to send her to a good secondary school outside the camp. This, together with the fact that her school career was not interrupted by terms in prison, meant that she had a much better chance than her siblings. At the time when her father died, both her eldest brother and her eldest sister were married, and the second eldest sister was in a boarding school because of her disablement. Following the death of her father, Fatima more or less took over responsibility for the household and especially for earning enough money to support the family. She dropped out of university and took on a job. When the PA was founded in 1994, she was given employment in one of its departments. In the same year, her elder brother Mutab, who was a member of Fatah, also found a secure job: he trained as a soldier for one of the secret services of the PA. But as he was already married, Fatima was the main breadwinner in her family of origin.

The family constellation at the time her father died in 1992 is probably the reason why Fatima did not marry before her failed attempt in 2011. She was already 29 at the time of her first imprisonment in 2003. Her mother told the interviewers, in the presence of her daughter, that Fatima "would have been married long since" had she not been sent to prison, but then corrected herself by saying that even before she was in prison several men had asked for her hand but that Fatima had refused them.

\footnotetext{
${ }^{11}$ In the period up to 1957 , the UNRWA replaced all tents in the camp by rooms with roofs made of concrete. Families with more than five members were given two rooms (see www.unrwa.org/ where-we-work/west-bank/camp-profiles?field=12\&qt-view__camps__camp_profiles_block=17, 23.04.2015).
} 
Fatima mentions as a sideline that she became politically active after the death of her father, but then explicitly says it was at the time of the Second Intifada as from 2000, which was when she joined the PIJ. She talks about her activities in this sub-organization which gives financial and moral support to the families of prisoners. Some of the party members she worked with have since been killed or sentenced to very long prison terms. Around 2002, for the first time, Fatima herself was detained for a day and interrogated by the secret service of the Palestinian Authority. She does not give the reason for this, but it is clear that her arrest was connected with the detention of one of her younger brothers, who had been charged with planning a suicide attack and belonging to the PIJ. He spent several months in a Palestinian prison, before it was occupied by the Israeli army and the political prisoners were transferred to Israeli prisons, where her brother spent five years. Fatima's mother, on the other hand, speaks very openly about the arrest and prison experiences of both her children, and also about her son's planned suicide attack. She tells the interviewer, "if you want to write this down, please feel free, the matter is long past", and then explains bluntly that he had been wanted by the Palestinian Authority, "because together with someone else he made an explosives belt for a suicide attack".

In 2003 Fatima herself was placed in $\rightarrow$ administrative detention, initially for a period of six months, and was charged with belonging to the PIJ shortly before she was due to be released. She says that when she was interrogated before the trial she denied belonging to this organization. For reasons of data protection we cannot give details of the trial and the exact terms of the judgement. But Fatima was kept in prison until 2009, with one short break of a few months, and was released under the terms of a prisoner exchange. In her account she gives the impression that she served those two periods in prison because she was a member of the sub-organization of the PIJ. However, we can assume that she deliberately does not tell us everything about the circumstances of her arrest and exactly what she was charged with. We must remember that speaking about illegal activities that were not proved in court, or which she denied, could constitute a risk for herself, other party members and her family. This probably explains why she does not mention any connection between her arrest and that of her younger brother, although we assume there must be some connection. In the interview, Fatima repeatedly emphasizes that she was imprisoned only because of statements made by fellow prisoners and not because of her own admissions. She argues vehemently that any active Palestinian must expect a hard fate, meaning imprisonment or dangerous injuries, and this is the way she has chosen: "On the path we have chosen there are all kinds of dangers. You can be killed or imprisoned [...] anything is possible." When we ask whether she has talked to the people who betrayed her, Fatima says that she has discussed everything openly with them. She says she can understand why other party members named her, because they were tortured during the interrogations and couldn't bear it any longer, and that collaborators had already supplied some information about her, which was already known during the interrogations. According to Fatima, she herself steadfastly refused to say anything, and we can only speculate about the suffering she must have 
endured during the interrogations. She speaks only about being kept in solitary confinement for weeks during the time of the interrogations, about her hunger strikes as a protest against this, about the degrading examinations during which she had to remove all her clothes, and situations in which she was kept in a painful position for hours with her arms and legs tied to a chair. Her mother Sara also tells us about "shabeh", a kind of torture, in which the person is prevented from falling asleep; it has been documented by Amnesty International and is often used in Israeli prisons. When Fatima tells us about this and about the whole period of the interrogations, she presents herself as someone who had been well prepared for it by the party. It needs to be kept in mind that members of the PIJ are warned not to reveal any information when they are interrogated.

When Gabriele Rosenthal asks Fatima about the killing of Palestinians whose collaboration with the IDF regularly leads to people being arrested, including in her camp, she answers as follows:

"So those who become big collaborators and are responsible for the murder of many people of our nation, that is not good work [...] I am against killing, even little animals, I don't like to see them being killed, but with these people, they have to be killed, for the Islamic Jihad-, and in our fight against the Jews, only the soldiers should be killed, but then later we were informed that many Israelis are being trained as soldiers, and this means there are more people we have to fight, look at the operations of the Islamic Jihad, they are always military- or soldiers are killed in these operations, then he has to be killed, even though I am against killing, but he deserves to be killed."

It is clear that this is not the first time that Fatima has thought about whether killing collaborators is justified, and that here - as with the killing of Israelis - she is using the discourse of her organization, according to which Israeli civilians are also soldiers. This is reminiscent of Helene, who uses the Fatah discourse. Fatima then narrates a story about a collaborator, which we heard in other interviews in a very similar form. A masked collaborator had entered a house in the camp together with the IDF, and went straight to the hiding place where the younger son of the family kept a store of weapons. The mother went up to the masked man, tore off his mask and discovered that it was her own son. This collaborator was then publicly hanged in the camp. The reader, like the interviewer, will probably wonder how the mother reacted. Fatima says: "The mother was very sad and said, this boy is not my son because he has done this."

Following her release in 2009, Fatima began studying history at the university. She left around 2011, after three semesters, but plans to go back again some time. She does not say why she left, but we assume that the reason was because she was planning to get married, although this plan failed to materialize. After her release from prison, she became engaged to a man who lives in Gaza and is also a member of the PIJ. Fatima got to know him through her political activities. For a time they 
communicated via the internet and in 2011 they agreed to marry. They chose the furniture for their bedroom in the internet, a date was fixed for the wedding, Fatima had bought her wedding dress, and after the bride's customary party with other women on the previous evening, she set out for Gaza. But because of her political record the IDF did not allow her to cross the border. Her fiancé was also not allowed to travel to the West Bank. The engagement was called off and her ex-fiancé married someone else. In the interview, three years after these events, Fatima shows that the memory makes her sad and she still speaks of her ex-fiancé in very positive terms.

So how does her mother Sara cope with her children being repeatedly arrested and with living in a refugee camp where raids by the Israeli army are part of everyday life? She is full of anger when she speaks about the Jews, calls them vermin, and says that they mistreat people in their prisons. But she also talks about how her younger son - who was probably involved in political actions together with Fatima - suffered in a Palestinian prison run by the PA:

"Once he was arrested by the Palestinian security forces, that was in 2001 ((it was probably 2002)), he had been wanted for about four months, they put him in B prison, after five months, when the Israelis marched into B prison, they ((the Israelis)) took him to an Israeli prison, the Palestinians tortured him, excuse me ((looking at the interviewer)) but they used shabeh with him harder than the Jews, hawqala ${ }^{12}$ ((there is no might nor power except in Allah)) [...] they ((the Israelis)) sentenced him to five years in prison without a trial, the Jews referred to the documents they were given by the PA, the people from the PA don't want the young people to defend Palestine, it's not allowed, it's forbidden, they want to make peace with them ((with the Israelis)), but the Jews agonize us, they invade our houses and beat us, they beat our children and women, I, I was attacked twice when they entered our house to arrest my children, I wanted to defend my children but they beat me."

\subsection{Conclusion}

As we have seen, the Maarufs represent a family in which it is mainly the second (genealogical) generation that is active in the struggle against the Israeli occupation, and, as shown by the interviews with Sara, Fatima and Mutab, mistreatment and torture suffered in the prisons is spoken about very openly in the family, unlike in the case of the Schahrurs. Everyday life and the biographical courses of the children in the Maaruf family are decisively shaped, and in many ways also obstructed, by this struggle and the repeated arrests. At the present time, however, they are in a process of reorientation. Two of Fatima's brothers have succeeded in emigrating to

\footnotetext{
${ }^{12}$ This short form of the Arabic expression is spoken by Muslims when they are in a hopeless situation.
} 
an Asian (non-Arab) country. Mutab, who is now in his mid thirties and married with children, is trying to consolidate his economic and professional situation, while Fatima is planning to resume her studies. In the Schahrur family it is the grandchildren generation that is making comparable attempts to establish themselves professionally. But in this family the 'children' (the middle genealogical generation) had already become established in a comfortable economic and professional situation many years ago. While the Nakba in 1948 marked the beginning of an economic and social downswing for the Maaruf family, which accelerated following the marriage of the mother in 1963 / 64 to a cousin living in the camp, the Schahrur family, who are long-time Christian residents of the town, experienced a process of social and economic improvement after 1948. The grandchildren of the Schahrur family, who are the same age as Fatima's younger siblings, have had an excellent school and university education; in the Maaruf family, Fatima is the only child in the family who began to study at university. While in the Maaruf family, the members of the younger generation, who still live in the camp, are engaged in an on-going struggle against the Israeli occupiers, those in the Schahrur family are concentrating on their education and their future careers.

We do not believe that these different trajectories in the two families can be explained by their religious affiliation alone. Even if we accept that children in Christian families have better educational opportunities, and that Christian grandparents or parents attach greater importance to education, it is the conditions under which the refugees live in the camps, and their repeated clashes with the Israeli occupiers, that are crucial for their failure to achieve economic and social success. As shown by the example of the Maaruf family, young Palestinians in the camps are increasingly willing to take part in militant actions against Israel, which results in violent clashes with the Israeli army almost every day, especially since the Second Intifada. The Schahrur family, on the other hand, is representative of families in which one member joined the armed struggle against the Israeli occupation in the phase after the war of 1967 due to the experiences of various members of the family during the war, and is thus among those who are still regarded as a political model by younger generations of Palestinians and who enjoy the respect even of people who reject, or have given up, the armed struggle against Israel. 
Voices from East Jerusalem 



\title{
$7 \quad$ Palestinians in East Jerusalem
}

\author{
Johannes Becker, Arne Worm
}

\subsection{Introduction}

As the religious centre of three book religions, and as a national symbol for both Israelis and Palestinians, Jerusalem is equally important to both parties. For our research project, however, our interest was focused on reconstructing the position of the Palestinian residents in their complex figurations, both with various groupings within the city, and with the Palestinians in Israel and the West Bank. The political scientist Hillel Cohen (2011b: 18) has argued that there is a "unique Jerusalem Palestinian identity". This formulation is a reminder that in this conflict-charged environment and as a result of various social, politico-administrative and physicogeographical borders, the Palestinians in East Jerusalem occupy a position between the Palestinians in the West Bank and the Palestinians living in Israel. Despite this important observation, however, our intention is to show that the inhabitants of present-day East Jerusalem constitute an urban society with its own internal differentiations, besides political and religious differentiations, just as in the other urban spaces presented in this volume. In Jerusalem this applies for instance to different generational belongings or social classes, but also to differences between long-time residents and newcomers.

In this and the following chapter we will introduce the particular situation of East Jerusalem from the perspective of the Palestinian residents, with a focus on different social, political and spatial figurations within the city. The other introductory sections of this chapter contain a general account of the city's historical, political and social embeddedness, and a short presentation of its structure. After this we will 
focus on the Kufr Aqab district. Within the complex life realities of Palestinians in Jerusalem, this district is particularly relevant to our discussion because although it is located within the city limits of Jerusalem, it is excluded from the city by the $\rightarrow$ Israeli barrier, which has serious effects on the everyday life of its inhabitants. In the next chapter we will take a closer look at the social fabric of the Old City of Jerusalem with a focus on neighbourhoods and historical generations.

\subsection{On the history and everyday realities of Palestinians in East Jerusalem}

\section{Historical sketch up to 1967}

The first settlements outside the Old City of Jerusalem were founded only in the second half of the 19th century. They led to increasing ethno-religious differentiation, because most of them were built for, or dominated by, Jews and/or members of a religious community. They also resulted in socio-economic differentiation, because the wealthier families tended to move away from the Old City. According to one of several rather different estimates, on the eve of the $\rightarrow$ war of 1948 the city of Jerusalem had about 164,000 inhabitants: 69,000 Palestinians and 97,000 Jews. ${ }^{1}$ It must be remembered, however, that the area enclosed by the city boundaries was smaller at that time; for example, up to the 1950s it did not include the whole district of Silwan (at that time a rural village), which is situated next to the Old City. After the war of 1948 Jerusalem was divided into two: the western part became a part of the state of Israel, while the eastern part was controlled by $\rightarrow$ Jordan and formally annexed in 1950. As a result of the fighting, there were refugee movements, involving mainly Palestinians who migrated to areas outside the Israeli national territory from what after 1948 was called West Jerusalem, and to a lesser degree Jews who fled to Israel from eastern parts of the city and the Old City. ${ }^{2}$ After the war the two parts of Jerusalem were separated, partly by a wall, for nineteen years, up to the Israeli occupation in 1967.

\section{Political and legal situation after 1967}

Today, East Jerusalem means those areas which together with the West Bank came under Jordanian rule when the city was divided, and were then occupied by Israel in the $\rightarrow$ war of 1967 , as well as villages and areas which were declared to be part of Jerusalem after the war, when the boundary of the city was successively extended

\footnotetext{
${ }^{1}$ Figures for 1946, see Dumper 2014: 42.

${ }^{2}$ While a right to the return of Jewish property in East Jerusalem is frequently claimed by representatives of the former owners, it is not possible for Palestinians to demand the return of their property because of the legal situation.
} 
(by about $70 \mathrm{~km}^{2}$ ). In 1967 it was de facto annexed. ${ }^{3}$ In 1980, with the 'Basic Law: Jerusalem, Capital of Israel', Jerusalem was declared by the Knesset to be the united and indivisible capital of Israel, a position which is not recognized by the international community.

The Israeli occupation in 1967 had legal consequences for the Palestinians living in East Jerusalem and impacted their everyday lives. This led to an increasing difference between their situation and that of the Palestinians in the West Bank and in Israel. In 1967, on the basis of a census which did not take into account the high number of Palestinians who had fled during the war, or who had taken up residence abroad (see UN 2011: 10), the inhabitants of East Jerusalem were given a special residence status, opportunities for limited political participation, and later also access to social benefits.

First it must be noted that Palestinians residing in East Jerusalem are affected by the same institutional discrimination as Palestinians with Israeli citizenship: they are hindered in buying land, or building or renting houses, they are disadvantaged in respect of many welfare benefits because they do not do military service, their political participation is subject to control, and it is difficult for married couples and families to live together if one of the spouses does not possess Israeli citizenship or a Jerusalem ID (see Rouhana/Sultany 2003).

The so-called Jerusalem ID, which was issued to the inhabitants of East Jerusalem in 1967, does not confer citizenship status on the holder, but is a residence permit; the holder has the legal status of a 'permanent resident' in Israel, a status which citizens of other countries can also have in Israel in certain circumstances. In other words, most of the inhabitants of East Jerusalem are not Israeli citizens; the majority have a Jordanian passport in addition to their Jerusalem ID. Theoretically they have the right to apply for Israeli citizenship. However, this is a long process with no guarantee of success (see Dumper 2002) and many inhabitants refuse to apply for political reasons. The number of applications is connected with the growing threat of losing the Jerusalem ID. But this development is accompanied by a debate among Palestinians in Jerusalem over the question of whether applying for citizenship is equivalent to recognizing the Israeli occupation and thus weakening the 'Palestinian cause'. ${ }^{4}$

Holders of a Jerusalem ID or residence permit are always in danger of losing it: the status of permanent resident cannot automatically be inherited, and evidence must regularly be produced of a permanent domicile in Jerusalem. Residency can be revoked in the case of persons who live outside Jerusalem, for example for those living in the West Bank. The way the laws are enforced has changed many times over the years. Since the mid 1990s the authorities have increasingly checked whether ID holders really do live in Jerusalem. Under the 'centre of life' policy, Palestinians

\footnotetext{
${ }^{3}$ On the complicated legal construction of the de facto annexation, see Lustick 1997.

${ }^{4}$ http://972 mag.com/quietly-east-jerusalem-palestinians-are-becoming-israeli-citizens/46298/ (06.06.2015).
} 
have to provide evidence of their address in Jerusalem, for example in the form of telephone bills, electricity bills or rent agreements. This is important because more and more people from Jerusalem have moved to the West Bank, where land is more available and cheaper, and building permits are much easier to get than in Jerusalem. In order to avoid the danger of losing their ID, many people have since moved back inside the city limits or maintain their primary residence there, at least symbolically. ${ }^{5}$ Residency can also be revoked for political reasons, for example in the case of so-called terrorist activities. At the time of writing, there are discussions going on in Israel about whether withdrawal of the Jerusalem ID should be extended to the families of 'Palestinian attackers' and to 'stone throwers' ${ }^{6}$ The maintenance or threatened loss of this ambivalent status is a major concern for Palestinians in East Jerusalem which they have to work through and which affects important biographical decisions (concerning for instance political commitment, mobility or marital and educational patterns), and the structure of their relationships.

But limited political rights were also granted to the inhabitants of East Jerusalem, for example the right to take part in local elections (but not in national elections). And Israeli civil law applies in East Jerusalem, not military occupation law as in the West Bank, which - at least formally - results in greater legal certainty. The people of East Jerusalem enjoy social benefits, health insurance and retirement benefits, as well as (labour) mobility in and outside Israel. These 'privileges' distinguish them from those who live in the West Bank. While the latter frequently express their 'envy' of the East Jerusalem Palestinians because of the social security they enjoy, the East Jerusalem Palestinians themselves complain that they are sitting on a 'powder keg' and are permanently in fear of losing their Jerusalem ID.

This specific status of East Jerusalem was aggravated further by the fact that the East Jerusalem Palestinians were increasingly cut off from their 'hinterland' (Ramallah, Bethlehem, etc.). Since the beginning of the 1990s, Palestinians who possess neither a Jerusalem ID nor Israeli citizenship must obtain official permission before entering the city. For the inhabitants of the West Bank, in particular, this has significantly reduced their job opportunities and their access to social and family networks. It has also made access to many services and to the important religious sites in the Old City much more difficult for them. This separation has become even more institutionalized and entrenched as a result of the Israeli barrier, which has separated large parts of Jerusalem from the West Bank with a high wall since 2002 (Dumper 2014 and see below).

\footnotetext{
${ }^{5}$ According to the Israeli Information Center for Human Rights, about 14,000 IDs were annulled between 1967 and 2011; see http://www.btselem.org/jerusalem/revocation_of_residency (06.06.2015).

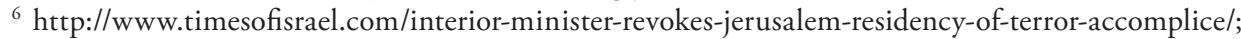
http://www.timesofisrael.com/pm-to-forward-bill-allowing-state-to-revoke-residency-of-terrorists/ (06.06.2015).
} 


\section{Spatial segregation in East Jerusalem}

Jerusalem has around 900,000 inhabitants, although this figure is only an estimate. About 62 to 66 percent of this total are identified as Jewish and between 34 and 38 percent as Palestinian, which corresponds approximately to the ratio politically desired by the Israeli decision makers (Dumper 2008: 4). About 270,000 Palestinians live in East Jerusalem (UN 2011); however, the many neighbourhoods differ considerably with regard to the composition of their population, their economic status and infrastructure, and their social integration in the city. They also change over time due to changes in social and physical boundaries. Among the most heavily populated Palestinian districts in East Jerusalem are Shuafat (including the refugee camp of the same name), the Old City and Beit Hanina.

When the city was extended in 1967, it included areas that were not yet built up. Since then, about one third of the new areas have been expropriated from their Palestinian owners and approved for the construction of new Jewish $\rightarrow$ settlements/neighbourhoods (Dumper 2008: 10). Especially since the late 1970s and early 1980s, an increasing number of settlements in East Jerusalem were being built which are almost entirely inhabited by Jewish Israelis. These include the present-day districts of Givat Shapira (French Hill), Pisgat Ze'ev, Ramot and Har Homa. But there are many other parts of East Jerusalem that are still regarded as Palestinian (such as Sheikh Jarrah or Silwan), even if Jewish settlements were founded within them. This corresponds to the 'mosaic principle' defended during his term of office by Teddy Kollek, a former mayor of Jerusalem, according to which the different population groups should live side by side and not be 'mixed up' (see for instance Tamari 2000). Nevertheless, due to spatial proximity and opportunities (even if very unequal opportunities) for exchange, for instance in the realm of business, there are more spaces in which contacts between Jewish Israelis and Palestinians can take place in comparison to the West Bank. In the West Bank, the presence of Jewish Israelis is almost entirely restricted to members of the army or settlers.

The processes of displacement that occur when Jewish Israelis move into largely Palestinian districts repeatedly lead to violent interactions between Palestinians, settlers and Israeli authorities (see UN 2011: I). This is bound up with discourses and practices such as non-recognition of Palestinian land ownership titles, or rejection of applications for building permission, which illegalize the occupancy of land by Palestinians and make the legal purchase and construction of houses in East Jerusalem extremely difficult for many Palestinians (see Braverman 2007). Moreover, in areas predominantly inhabited by Palestinians, the public infrastructures are generally of a much poorer quality than those in Jewish-Israeli areas, for example in the sphere of education (Eitan et al. 2013). ${ }^{7}$ Many scholarly publications have pointed out that

\footnotetext{
${ }^{7}$ An investment package for East Jerusalem has been approved by the city council, but at the time of writing it is unclear whether and how quickly it will be implemented, and whether it will have any positive effects on the tense situation. As an example of a debate on inequality, suffice it to men-
} 
the processes of displacement in East Jerusalem are encouraged by the administrative authorities, which amounts to official discrimination against Palestinians. This is often justified by the political aim of establishing a stable Jewish majority in the 'indivisible capital of Israel' (see Cheshin / Hutman / Melamed 1999).

The present-day reality of Palestinians living in East Jerusalem is framed by their precarious legal situation, the historical developments and present dynamics outlined above, and the symbolic importance of Jerusalem in the religious and political discourse. New practices have grown up in the face of legal, political and social challenges: the shortage of housing has led to Palestinians moving into Jewish districts - when this is permitted by the Jewish-Israeli owners. Formerly, such a move was unthinkable (Dumper 2014: 30). Others solve the problem of the shortage of housing by moving to areas (such as Kufr Aqab) which belong to Jerusalem administratively, but which are located on the 'Palestinian' side of the wall. As we will show below through voices from these areas, and as discussed in detail in chapter 8 on the Old City of Jerusalem, the lived reality and the practices of Palestinians in East Jerusalem are framed by the processes described here. However, the way these processes are experienced and interpreted by Palestinians, and the patterns of action, biographical decisions and we-images they lead to, are closely tied up with specific local histories and webs of relationships in the different districts (or social spaces). The following accounts relating to Kufr Aqab and the Old City show that we must speak of locally anchored realities - in the plural - in order to render the experiences and we-images of Palestinians in Jerusalem tangible.

\subsection{East Jerusalem 'behind the wall'}

Development and situation of an administrative no man's land

The successive construction of Israeli barriers from 2002 separated the city not only from the 'hinterland' in the West Bank, but also from parts of Jerusalem which belong to the city according to Israeli law and are under Israeli administration. This applies for example to areas such as Kufr Aqab, Samiramis or Hai al-Matar, which were integrated into the Jerusalem administrative area only after the city boundary was extended in 1967 and they were de facto annexed. These areas, which are located along a major road that connects the urban conglomerate of Ramallah and al-Bireh with Jerusalem, were described to us by Palestinians as "no man's land". This expression reflects the fact that these areas 'behind the wall' have been in a paradoxical administrative situation for over ten years: officially the Israeli or Jerusalem authorities

tion the proceedings before the High Court concerning 'postal inequality': while mail is delivered to people's homes in Jewish districts, the Palestinian inhabitants of East Jerusalem have to collect theirs from the nearest post office. See http://www.timesofisrael.com/high-court-raps-jerusalem-overpostal-inequality-for-arabs/ (06.06.2015). 
are responsible for infrastructure (roads, waste collection, etc.), public services (such as education and health), police and security, and administration of legal matters (such as issuing building permits). But de facto the authorities do nearly nothing, so that in Kufr Aqab the provision of local infrastructures and services is not only worse than in West Jerusalem but also worse than in other Palestinian neighbourhoods in East Jerusalem. This precarious situation is aggravated by the fact that the $\rightarrow$ Palestinian Authority has no formal rights there and is therefore officially unable to do anything to solve the problem. The PA has no legislative or executive powers in these areas, and is therefore not responsible for police and security services, or for issuing building and business licences. This is all the more absurd because, as a result of the barrier, these districts are increasingly connected to Ramallah and al-Bireh in the everyday world, in other words to places which do not belong to Jerusalem and which are administered partly by the PA and partly by the Israeli military authorities. This applies, for instance, to the 'old' village of Kufr Aqab ${ }^{8}$ and Qalandia $\rightarrow$ refugee camp. ${ }^{9}$ Without local knowledge it is hard to identify the exact location here of the border between houses that belong to Jerusalem and others that belong to the West Bank. There are streets in which some houses belong to Jerusalem, while others in the same street belong to the PA's $\rightarrow$ Zone A. Only the large number of high-rise buildings is a clear indication of which part belongs to Jerusalem.

How do the inhabitants of these districts speak about the places where they live? In our interviews with them we repeatedly heard rumours and stories of drug dealing, violence and crime in this 'no man's land'. Although the associations of a completely lawless area which these stories evoke are exaggerated, the discussions and interviews we held there were dominated by these topics, and by a subjective perspective of neglect, vulnerability and uncertainty. Despite the political and administrative vacuum and its 'sandwich' position between Israel and the West Bank, large numbers of Palestinians with a Jerusalem ID have moved into the Kufr Aqab region in the past ten years. As a result, Kufr Aqab, which is located on the periphery and behind the wall, is certainly the fastest growing district in Jerusalem, in terms of both the number of inhabitants and the number of buildings (see IPCC 2013: 8). According to the official statistics of the Jerusalem city administration, there were 14,366 Palestinians living in Kufr Aqab in 2011 (ibid.: 20). ${ }^{10}$ According to estimates by a Palestinian member of a local committee, which (semi-officially) cooperates with the PA for the improvement of infrastructures in Kufr Aqab (such as waste collection), the present number of inhabitants is probably two or three times higher than this. This influx of Palestinians from Jerusalem, and probably also from the West Bank, is mainly due

\footnotetext{
${ }^{8}$ The history of the 'old' village of Kufr Aqab can be traced back to Ottoman times.

${ }^{9}$ Qalandia refugee camp was built in 1949 in the context of the $\rightarrow$ Nakba and since then has been under the administration of the $\rightarrow$ UNRWA.

${ }^{10}$ Like any other information offered by the government regarding the demographic situation in Jerusalem, these official figures must be treated with caution in view of the highly politicized nature of this issue.
} 
to the fact that building is unregulated, and unlike in other parts of Jerusalem it has been largely tolerated by the Israelis, although strictly speaking it is illegal. This has led to a high building density and a very large number of high-rise buildings. In view of the displacement pressure in other neighbourhoods, and the difficulty Palestinians have in finding rented accommodation, to say nothing of buying, the tower blocks in Kufr Aqab offer relatively good and reasonably priced housing. Moreover, Palestinians from East Jerusalem can keep their ID and associated rights, since according to Israeli law their permanent place of residence is still in Jerusalem. One of the many curious features of Kufr Aqab is that evidence of living there suffices as a rule to allow the inhabitants to keep their Jerusalem ID - and obliges them to pay a local property $\operatorname{tax}$ (Arnona), even though they live in a building which from the Israeli point of view is not approved and thus illegal.

For many Palestinians living in Kufr Aqab, its separation from the rest of Jerusalem means that, in their everyday life, they spend a long time waiting at the checkpoints in order to access the Israeli labour market, social and health services and social and family networks. The Israeli 'centre of life' policy which has applied since the middle of the 1990s means that seeking these things in the regions controlled by the PA would put their Jerusalem ID at risk, even though Ramallah is more accessible and it would be much easier for them to use the employment opportunities, schools and hospitals there.

We can thus assume that for people in Jerusalem the decision to move to Kufr Aqab is probably a very ambivalent one: on the one hand, there are better living conditions and a reduction of the displacement pressure felt by the inhabitants of many other Palestinian neighbourhoods. On the other hand, they are moving into an environment where there are many restrictions and great uncertainty concerning the future status of the region, which depends on whether these districts are placed under the control of the PA within the framework of negotiations over land exchange. ${ }^{11}$ Moving from a more central district to an area 'behind the wall' is probably also bound up with a need to justify such a move, since in the Palestinian discourse (for example in newspapers and blogs) the developments in Kufr Aqab are seen as part of the Israeli policy of 'Judaizing' Jerusalem and displacing Palestinians (see also ch. 8). ${ }^{12}$ But, as we were told in interviews in two families, Kufr Aqab is also a place where 'mixed' couples (one person having a Jerusalem ID, while the other doesn't) can live without the person with a Jerusalem ID having to give it up; for them this is an important factor in choosing where they will live.

\footnotetext{
${ }^{11}$ See for example the suggestion made in 2011 by Nir Barkat, the mayor of Jerusalem (see http:// www.jpost.com/National-News/Barkat-proposes-changing-Jerusalems-borders, 28.04.2015).

${ }^{12}$ In view of the direct and indirect impediments placed in the way of Palestinians seeking adequate housing in Jerusalem, the building of houses by Palestinians in the Kufr Aqab region 'on the other side of the wall' can be regarded as a development that is partly planned, and certainly accepted, by the Israelis.
} 
Newcomers and long-time residents: Palestinian perspectives of and from Kufr Aqab

Our interviews show that there are clear differences in the perspectives of members of different groupings, or between newcomers and people who have lived in Kufr Aqab for a long time (both old-established residents and refugees). It must be remembered that as a result of the number of newcomers and the social problems arising from the 'administrative vacuum', new local figurations have been created between the different groupings. On the basis of our analyses, we will take a closer look at the perspectives of newcomers from Jerusalem, long-time residents of the old village of Kufr Aqab and refugees in Qalandia refugee camp. Our interviews and discussions $^{13}$ show that Palestinians with a Jerusalem ID and other people who live in the region have very different views in respect of the precarious status of the Kufr Aqab-region and the arrival of newcomers from Jerusalem.

1. The people who have recently arrived from Jerusalem, most of whom have not lived here for more than ten years, very clearly present their present situation and the problems associated with living here as individual challenges and only to a small degree as being due to the political context of the Middle East conflict. We were at first surprised that these interviews were framed relatively unpolitically and that the interviewees neither localize themselves in a Palestinian we-group nor interpret their own position as the consequence of Israeli policies of repression and expulsion. This is surprising because such a we-group framing could be expected in the light of the highly charged political nature of the Jerusalem question. Generally, the Jerusalemites embark on biographical self-presentations which are more strongly couched in terms of an 'individual' biographical course and barely in terms of 'we'.

Our interviewees, who in some cases have moved house within Jerusalem several times in the last ten years, live today with their (nuclear) families in Kufr Aqab. Due to the move, they have very few close social contacts in their immediate neighbourhood, where none of their relatives live, unlike in other parts of Jerusalem. However, in the interviews this is not presented as a problem; rather, in at least two families there is a suggestion that the move to Kufr Aqab is connected with conflicts within the extended family and that these are less present in Kufr Aqab (for example disapproval of marrying a man from the West Bank). They talk much more about fears of losing their Jerusalem ID and the daily irritations and stresses arising from the special situation of Kufr Aqab.

\footnotetext{
${ }^{13}$ In the course of two periods of fieldwork in September 2013 and April 2014 we conducted seven narrative biographical interviews with newcomers from Jerusalem, three interviews with long-time residents of the old village of Kufr Aqab, and two narrative biographical interviews and one group discussion with refugees from Qalandia camp. In addition, we held some ethnographic interviews with residents and shopkeepers in Kufr Aqab. The interviews were conducted by Arne Worm and by Ahmed Albaba, Mariam Abdul Dayem, Eva Bahl, Hendrik Hinrichsen and Aida Saifi.
} 
The narrative biographical interview conducted with Asma ${ }^{14}$ is a good example of this individual framing. Asma is 46 years and has lived for several years in a middle-class flat in Kufr Aqab with her husband, who does not have a Jerusalem ID, and three children. She begins her presentation by saying: "If you asked me about identity I don't know what to tell you, I have a Jerusalem ID, my identity in Israel is Jerusa=East Jerusalem not Palestinian or any other, I'm Palestinian of course, but not Palestinian in Jerusalem, I'm East Jerusalem in Israel.'

Asma is obviously referring here to her status as holder of a Jerusalem ID, with which she associates lack of recognition as a Palestinian in Israel. By referring to the hegemonic Israeli discourse in which Jerusalem is regarded as an Israeli (and not a Palestinian) city, she gives her statement a political framing. But the decisive point here is that she presents herself as having an uncertain status. Later on in the interview she speaks mainly about the personal problems connected with restricted mobility, the difficulty of finding a job, the perceived uncertainty of life in Kufr Aqab (for example worries about her children in a violent environment), and her efforts to organize family and work in this situation. She frames her own difficult circumstances not as being representative of a Palestinian group - as one would expect in the we-discourse - but as a personal challenge to herself, as an inhabitant of Jerusalem, which needs to be solved individually. Asma, whose grandfather was a refugee in 1948, and who was politically active in student committees during the $\rightarrow$ First Intifada (this is where she met her husband), places neither her refugee background nor the fact that she belongs to the 'Intifada generation' (see chapter 8) in the centre of her biographical self-presentation, but mentions them only incidentally. The presentation of her biographical course remains more or less focused on the precarious nature of her family's present situation.

An important point of orientation in her self-presentation, as seen in the above quotation, is her insistence on belonging to Jerusalem. Thus, in her initial presentation she mentions that her family has lived in Jerusalem for many years ("we have always been Jerusalemites"). In the questioning period of the interview, on the other hand, she says that her grandmother first moved to Jerusalem in 1967, in order to be registered there in the census which led to the issuing of Jerusalem IDs. Presenting the continuity of her family history in Jerusalem, and striving to preserve this continuity in the present, are much more important for Asma than fitting her biography into the hegemonic Palestinian we-discourse which is dominant in the West Bank.

2. By contrast, the 'non-Jerusalemites' interpret the arrival of the newcomers and the local problems this brings for them from the perspective of their locally anchored we-group, and in terms of the we-discourse (whether as refugees in Qalandia camp or as long-time residents of the old village of Kufr Aqab). They present the situation in Kufr Aqab more clearly as part of an Israeli strategy to drive out Palestinians. However, connected with this, the non-Jerusalemites are critical of the newcomers,

${ }_{14}$ The interview was conducted in English and Arabic by Arne Worm and Aida Saifi in September 2013. 
regarding them as a foreign group to which they ascribe various negative characteristics. One argument they use is that the 'Jerusalemites' benefit economically by moving here but do not feel responsible for the local problems. They say that they are involved in drug dealing because they need not fear being caught and charged by the police; and that they do not bring up their children properly. In this connection, cautious criticism of the PA was also expressed, because, as they say, it silently accepts the current developments in Jerusalem in general and the precarious situation in Kufr Aqab in particular, or even works actively together with 'the' Israelis. On the other hand, there is a tendency to emphasize the good relations between village and camp both among the long-time residents of the old village of Kufr Aqab and among the Qalandia refugees with whom we spoke.

In the interviews and discussions we held with Palestinians in the nearby Qalandia refugee camp, the developments in Kufr Aqab are attributed very clearly to the Israeli policy of expulsion or displacement. For example, in a group discussion, Hamada, born in 1983, tells us with a certain group pride about the camp's history of resistance against the occupiers and the well-functioning social organization among the refugees. He says for instance that, in view of the lack of police in Kufr Aqab, they deal independently with problems such as drug dealing. He describes in detail how political groupings in the camp had successfully (and with the use of force) driven drug dealers out of Kufr Aqab who were mainly Palestinians with a Jerusalem ID. However, as he says, it was a short-lived success: they had handed the drug dealers over to the PA, which did not charge them because it has no authority in Kufr Aqab, but handed them over to 'the Israelis', who had set them free.

Abu Jussuf ${ }^{15}$ (born in the early 1960s and therefore in his mid fifties) from the 'old village' of Kufr Aqab criticizes the newcomers from Jerusalem in much sharper terms. Abu Jussuf belongs to a family of long-time residents, living in the third generation in the village, which up to the 1970s was an agricultural village. He experienced the war of 1967 as a child, and following the early death of his father in the 1970s, he had to go out to work on building sites in order to support his family when he was about fifteen. He has a crucial biographical theme: his struggle to maintain an intact family life in Kufr Aqab, not only in the context of the early loss of his father, but also in the context of perceived uncertainty in respect of both the village and his means of livelihood, due to the transition from Jordanian control to Israeli ocupation. He interprets the present situation in similar terms: he believes that the decision of Palestinians with a Jerusalem ID to move to Kufr Aqab is the result of a systematic Israeli strategy of driving Palestinians out of the 'Israeli' part of Jerusalem, in order to create a demographic advantage for the Jewish population. But, as he says, in the Palestinian discourse the decisive questions are taboo: how far the 'Jerusalemites' profit from this process, and how far the PA silently tolerates it. For

\footnotetext{
${ }^{15}$ Abu Jussuf was interviewed in Arabic on two occasions by Arne Worm and Ahmed Albaba in March 2014. In addition Eva Bahl and Aida Saifi conducted an interview with Abu Jussuf's wife and one daughter.
} 
him it is clear that many 'Jerusalemites' sell their houses and flats and move to lower priced accommodation in Kufr Aqab, while at the same time keeping the privileges of their Jerusalem ID. Overall Abu Jussuf has a firmly entrenched they-image of the 'Jerusalemites': they do not observe 'traditional' educational values and do not set a good example to their children; as a result there are many problems in Kufr Aqab (drugs, crime, etc.). But he admits that one cannot express this view openly:

"But these matters, about (1) Jerusalem IDs and these things, you can't talk about them to people with a Jerusalem ID because then you will have problems, because they will then claim that they are honourable and noble [...] I am careful not to talk about them in front of Jerusalem-IDs but I have heard a lot, accusations, and warnings not to say anything, because it will cause problems for you and your family if you (laughs) they will force you to attend a village meeting; that is, if the PA has not already arrested you."

The perceived taboo in the Palestinian discourse on speaking openly about these matters is described by Abu Jussuf as frustrating, and as a hindrance in the search for solutions to local problems. He clearly sees himself as being in a weaker position in the public discourse compared to the people who have moved here from Jerusalem and the PA, and as being under threat of sanctions if he should be so courageous as to talk about the problems in Kufr Aqab. While Abu Jussuf is critical of the theygroup of newcomers from Jerusalem and of what he perceives as a taboo on this issue in the Palestinian discourse, he insists that relations with the refugees in the nearby camp are good:

"Even if he is from the refugee camp, he's a Palestinian and I'm a Palestinian, we are forced to live the facts of this life together and after all we are both refugees, they have taken his land from inside and they have taken my land from here so we are both in the same position (2) have both lost."

In view of the conflicts which have occurred in the West Bank between refugees in the camps and long-time residents (see chapter 4), this clear emphasis by a longtime resident on sharing the same history as the refugees ("we are both in the same position") is remarkable. It is true that this corresponds to the homogenizing wediscourse (see chapter 2), and when Abu Jussuf speaks of the others ("they") he is probable referring mainly to the Israeli occupation. But it is striking that in the whole interview there is no comparable use of a "we" that includes the newcomers from Jerusalem.

If we compare the different self- and we-presentations of 'Jerusalemites' and 'long-time residents' in Kufr Aqab, we find a 'classical' figurational effect in terms of the theory of established and outsiders developed by Elias and Scotson (2008): the newcomers are described in terms of negative stereotypes and accused of causing problems in the area by people who are established (through their long-time pres- 
ence) in the local space, who have a firmly entrenched we-image and who form an integrated group. However, many of the newcomers from Jerusalem can be regarded as socio-economically 'privileged' because of their better financial situation and the additional options open to them through possession of a Jerusalem ID. As we see it, this creates a field of tension in Kufr Aqab which could lead to a local split - relatively independently of any political intentions in connection with developments in this 'no man's land'. 



\section{Commitment to the Old City and ambivalent emplacement}

Johannes Becker

\subsection{Introduction}

Jerusalem is often regarded as a 'special case' - a city with a past and a present that are different from those of other cities in the West Bank or Israel. Yet its figurations of different groupings and its unique legal situation make it a place with a great variety of possible interactions within the already complex regional situation in Palestine and Israel. Discussions on Jerusalem often focus on the national struggle between Palestinians and Israelis, who both consider Jerusalem as their capital, or on conflicts over the religious power of interpretation in a 'holy city', and these two aspects are often related to each other. This paper shifts the focus to the complexity of figurations in Jerusalem, taking the Palestinian inhabitants of the Old City as an example. I will show that not only religion and politics are important, but also sociospatial, generational and class-specific belongings. Our empirical findings highlight that processes of identification and disidentification, and the forming of collective we- and they-images, are based on more than just political and religious constructions of belonging, as shown in this book for Haifa (chapter 10), Jaffa (chapter 11) and Ramallah and Bethlehem (chapter 2).

I will begin (section 8.2) by showing that although the Old City of Jerusalem is an important religious and national symbol in the inner-Palestinian discourse (the centre of three book religions, occupied by Israel), as a place to live in it is described discursively as conservative and afflicted by crime. Socio-economically, the Old City 
is counted as one of the three poorest districts of Jerusalem (see Glass/Khamaisi 2005; IPCC 2009). In terms of its national significance and simultaneous discursive denigration, the Old City is comparable to the $\rightarrow$ refugee camps in the West Bank (see chapter 4). The Palestinian inhabitants of the Old City can thus be described as one of the outsider groupings in Jerusalem.

I conducted a total of 37 narrative-biographical interviews in the Old City, mostly with Palestinians, and carried out intensive participant observation. This is the empirical basis on which, with a focus on the life stories and self-images of the actors, I will show in a later section (8.3) how they experience and how they interpret and negotiate being in the denigrated Old City. A study of their relevancies reveals that both their spatial belonging to the Old City and their belongings within the Old City are important themes both in discourses on the Old City and in the experiences and self-definitions of its inhabitants. Their spatial belonging is part of a we-image that includes residing at the religious and national centre-point. This belonging is therefore bound up with a mission to preserve and save the Old City in the face of the Israeli occupation whose presence affects their everyday life. Yet discursive denigration and poverty are also repeatedly thematized. In section 8.4 I will show that the voices of two historical generations (in the sense proposed by Karl Mannheim 1952) dominate in the Old City itself: on the one hand there is the 'Jordanian generation', for whose members the experience of poverty during the $\rightarrow$ Jordanian administration of Jerusalem (1948-1967) was constitutive. They perceived the first period of the Israeli occupation as an economic improvement, and they complain that the younger generations have placed everything they gained in jeopardy. On the other hand, there is the 'First Intifada generation', for whose members the time of the $\rightarrow$ First Intifada, which started in 1987, was the formative phase in their life. In the Old City, the most prominent voices are those members of the Intifada generation who were formerly politically active and who make the Israeli occupying power responsible for all perceived problems in the Old City.

The dominant representatives of these two generations have in common that they consider a communal, family-based, socio-conservative life in the Old City as desirable. But, as I will show in the case of Hafez (section 8.5), belonging to, and emplacement in, the Old City become ambivalent for inhabitants who share the same formative phase of life, but not the constitutive biographical experiences of the dominant representatives of these generations. This can lead to alienation from Old City space. In his self-presentation, Hafez professes his belonging to the Old City; but a reconstruction of his biographical experiences shows clearly that he has tried in various ways to get out of the Old City, either temporarily or permanently. 


\subsection{The Old City: Symbolic importance, complex figurations, discursive denigration}

The Old City belongs to that part of Jerusalem which was captured by Jordan during the $\rightarrow$ war of 1948; for 19 years the wall of the Old City lay directly behind the border separating the two parts of Jerusalem. Up to the middle of the 19th century, Jerusalem consisted only of the area that today is called the Old City. This is a walled area about one square kilometre in size, inhabited today by only about five percent of the population of Jerusalem, approximately 40,000 people. Since many of the buildings in the Old City are used only for religious purposes, this means there is an extremely high population density. In addition it is visited by about two million tourists and pilgrims every year (IPCC 2009). The sites in the Old City declared as sacred places are of central significance for the three book religions, for example the Western Wall, $\rightarrow$ the al-Aqsa Mosque and the Church of the Holy Sepulchre. In addition, the Old City serves as an important myth in the political context of different national belongings. Thus, the Old City is an ideologically highly charged place with a very high population density. Through discourses on the Old City and its position in the Middle East conflict, the figurations of Jews and Palestinians in Jerusalem discussed in chapter 7 become even sharper in the Old City.

The residential areas of the Old City are inhabited by Christians, Jews and Muslims. Although there are no neighbourhoods inhabited exclusively by members of one religious community, there are different majorities in different neighbourhoods. Members of other religions are de facto not allowed to take up residence in what is defined administratively as the Jewish quarter (see Glass/Khamaisi 2005: 36, note 4). Numerically, Palestinians form the majority in the Old City and 75 percent of the inhabitants are Muslim. Jews represent only five to ten percent. In the Old City, as in the West Bank, the presence of Jewish settlers is an important issue. Although they form only a small minority in the neighbourhoods predominantly inhabited by Palestinians, their $\rightarrow$ settlements are easily recognizable because of the strong security measures. The settlers go to court to try and regain possession of buildings which were owned or rented by Jews at any time before the war of 1948, and to buy other houses in the Old City through Palestinian contacts. This leads to suspicions of collaboration and creates distrust among Palestinians. While Jews may legitimately reclaim property under Israeli law, Palestinians may not reclaim their former property in West Jerusalem. Moreover, many buildings are acquired by methods that are illegal, or at least in a grey area, which can include physical and psychological violence against the Palestinian residents. Jewish settlements in neighbourhoods with a Palestinian majority frequently have an extremely fortified and defensive character (Dumper 2002; Glass / Khamaisi 2005; IPCC 2009).

Of the problems mentioned in chapter 7 , the huge population growth is especially acute in the Old City. It is a result of Israel's ID policy and the construction of the $\rightarrow$ Israeli barrier, which have led to the withdrawal of many Jerusalemites from the West Bank. According to estimates, the population has increased by 10,000 since 
2003 (Dumper 2014: 30). The living conditions are bad for many Palestinian residents: many houses are hopelessly overcrowded, the sanitary facilities are inadequate, the houses are extremely damp, and the municipal services limited. As in many other parts of East Jerusalem, there is a high rate of unemployment, and young people suffer from a lack of future perspectives. They stand for a 'generation in waiting' in the Middle East (Dhillon / Yousef 2009; cf. Glass / Khamaisi 2005; IPCC 2009).

Despite the politically and religiously charged situation of the Old City, the first things associated with its inhabitants in the inner-Palestinian discourse are not connected with its political importance or sanctity. Hafez, a resident of the Old City with whom I conducted an interview ${ }^{1}$ which is discussed in detail below, puts it this way:

"If you tried to to hear what other people from outside the Old City say about the residents or or eh about people in from the Old City, mainly they talk about drugs, that are spreading there, bad habits e:h, something like mafias almost, sometimes, so the the image is so dark, what I see now I see it's a place like any other place, has its advantages and disadvantages and good people and bad people, eh poverty is spread of course and it has its own eh casualties let's say, but in general I know the Palestinian camps outside Jerusalem have some worse effects than the the environment inside the Old City."

In this passage, the Old City appears as an enclosed space because Hafez talks of an outside and an inside. On the one hand this is a reference to the city walls. On the other hand, there is a suggestion that a certain lifestyle is associated with the Old City which others disapprove of, and that this is a reason for maintaining its separation. Negative qualities are ascribed to the inhabitants of the Old City, but these are relativized by $\mathrm{Hafez}$ - not by denying the existence of problems, but by speaking of the diversity of the inhabitants in order to differentiate the uniform and homogenizing ascriptions, and by comparing the Old City to other places in the West Bank, with the refugee camps, whose structural similarities have been mentioned above.

A comparison can be made in this respect with the Israeli coastal city of Jaffa, which today is a part of Tel Aviv (see chapter 11). Although Jaffa does not have the same religious and political reputation as the Old City of Jerusalem, it is also the subject of negative discourses with regard to its socio-economic situation and the alleged criminal activities of its inhabitants. Monterescu (2007) speaks of its "double exclusion", because Jaffa is denigrated both as a Palestinian city and by Palestinians as a crime-ridden city. At the same time Jaffa is undergoing a process of gentrification by Jewish Israelis. However, Jaffa's history is very different from that of Jerusalem: in contrast to the Old City, Jaffa was an independent city up to 1948. But before and

\footnotetext{
${ }^{1}$ In the course of three meetings in March and April 2011, I conducted an interview with Hafez in English lasting a total of about five hours. Also present during the interview was an acquaintance of mine who was a friend of Hafez when they were young.
} 
during the war and the founding of the state of Israel, nearly all its inhabitants fled, making a complete break in the city's history. Only later did some families return, or internally displaced persons settled there (see LeVine 2007).

By contrast, to this day, in addition to political developments, the inner-Palestinian population exchange in the Old City of Jerusalem is important, and is associated with a deterioration in socio-economic conditions there. This process, which began in the second half of the 19th century, still continues today and is linked to general socio-economic and cultural developments in the region. A knowledge of these historical processes is helpful for understanding the discursive denigration of the Old City. But they can also be considered in comparison to other historical neighbourhoods and walled cities in the Levant and North Africa, such as Damascus (Salamanca 2004) or Istanbul (Mills 2007), or old cities in Morocco (Escher 2009). During the 19th and early 20th centuries (thus in many cases during the colonial period or the period of prescribed modernization), many members of the middle and upper social classes left the old houses owned by their families and moved to bigger properties inspired by Western planning principles. This process was especially noticeable in walled old cities, because before, as in the case of Jerusalem, these densely built-up areas often constituted the entire city. The poorer families remained behind. They were joined by migrant labourers who rented the houses of the more wealthy families and later were able to buy them (see for instance Salamanca 2004). In Jerusalem the migrant labourers came mainly from Hebron and the rural areas around it. They began to settle in Jerusalem from the end of the 19th century and are known there as khalili (from the Arabic al-khalil for Hebron). Today, they form the majority among the inhabitants of the Old City: "Most of the Palestinian inhabitants are Muslims who have a Hebronite origin, which includes a clear orientation toward a strong patriarchal, traditional society" (IPCC 2009: 16). As shown by the above quotation, and as we will see below, the inhabitants are still looked down on because of their rural origin: "Longtime Jerusalem residents had a disdainful and arrogant attitude toward the Khalyleh, as Hebronites are called" (Benvenisti 1996: 8). ${ }^{2}$

However, there is a clear difference between Jerusalem and other old cities: in other cities there has been a process of gentrification in recent decades, whether of a national or international character. This has led to a rise in the market value of historical houses (for example in Marrakech and Fez in Morocco, or Istanbul in Turkey). In other cases, the everyday worlds of the old cities have been culturally reappropriated (for example by showing them in popular television series, or through restaurants and clubs in Damascus or Istanbul). This is much less the case in Jerusalem. ${ }^{3}$ There are some restoration programmes and cultural initiatives, but the interest

\footnotetext{
${ }^{2}$ Qleibo (2011) is one of the few authors who discuss the role of migrants from Hebron in the urban society of Jerusalem, but he does so on a very popular level; he praises their entrepreneurial power and their 'puritan' vein.

${ }^{3}$ The fortified Jewish settlements in those parts of the Old City with a Palestinian majority have sometimes been referred to as gentrification, because they represent an attempt "to displace the origi-
} 
of Palestinians in the residential areas of the Old City of Jerusalem, which not least are evidence of the continuity of Arab settlement, is low in comparison to interest in the 'holy sites' ${ }^{4}$ Despite the symbolic significance of the Old City as a whole, the residential areas are a discursively neglected space, and the inhabitants frequently belong to the lower socio-economic classes.

The local community study The established and the outsiders (2008) by Norbert Elias and John L. Scotson examines a community in which there are newcomers and long-time residents, as an example of an established-outsider figuration. In this empirical study the authors describe how the long-time residents of a town stigmatize and reject the people living in a newly developed area, and join together in their criticism of them. The difference between this case and Jerusalem is that in the Old City of Jerusalem the newcomers have moved into a place that is regarded as 'cultural heritage'. 5 This also distinguishes the Old City from other parts of Jerusalem where people whose families came from Hebron form the majority (such as Wadi Juz, for example), or areas with a similarly low socio-economic status. The 'blame gossip', as Elias calls it (Elias / Scotson 2008: 31), in respect of the Old City stands in contrast to its 'holy' image and its political importance. But because of the homogenizing and harmonizing Palestinian we-image (see chapters 1 and 2), the blame gossip is not distributed via official media formats, and is not very often repeated in front of people who are not familiar with the local conditions. The daily newspapers (such as the Arabic-language al-Quds) seldom contain reports of inner-Palestinian differences. Such blame gossip is mainly spread by members of the middle and upper social classes. This makes it difficult to reconstruct en détail. It collectivizes and essentializes the inhabitants of the Old City, and consists of various elements which ascribe to all inhabitants the worst qualities of the worst component groups (Elias / Scotson 2008: 5). As mentioned above, the Old City is described as a crime-ridden place. I was told that it has a high level of drug use and drug dealing, as well as prostitution, physical violence and mafia-style structures. A Palestinian colleague who lives in East Jerusalem $^{6}$ often talked angrily about the inhabitants of the Old City. He only goes there to eat lunch at one of the traditional snack bars. Otherwise, he tries to avoid entering

nal, indigenous inhabitants as a whole" (IPCC 2009: 42). But it is doubtful whether this term is adequate because the settlements are ideologically motivated, do not raise the general residential value of the neighbourhoods, and rents are increasing mainly because of the housing shortage in Jerusalem.

${ }^{4}$ For example, there is an 'Old City Revitalization Programme'. In the past two years, there have also been attempts to establish a Ramadan television series set in the Old City, in imitation of 'Bab al-Hara', the extremely popular Syrian series. This series is called 'Bab al-Amoud'. However, it does not seem to have been successful.

${ }^{5}$ Ruhne (2010: 134) has pointed out that although Elias and Scotson mention that the different urban groupings in Winston Parva are spatially separate, they do not analyse the significance of this in depth. Instead, they focus on the higher 'social age' of the long-time residents as a reason for their closing ranks against the newcomers.

${ }^{6}$ To preserve the anonymity of this colleague, who is well-known in East Jerusalem because of his work, his name is not mentioned here. 
the Old City. He told me that there are "drugs on every corner" and that the inhabitants are not as poor as they are said to be, because of the mafia-style structures; but that they prefer to maintain their traditional structures. Other ascriptions refer to the fact that the majority of the population comes from Hebron and its environs: these people are said to be uneducated, and lacking in culture because of their rural origins. But above all they are supposedly very conservative and religious. Thus it is assumed that in the Old City it is difficult to escape from the influence of the family or the hamail (extended families, plural form of hamula), and that especially for women it is difficult or impossible to lead a 'modern', self-determined life. An acquaintance of mine in Jerusalem, from the middle-class neighbourhood of Shuafat, told me he was sure that the inhabitants of the Old City themselves longed to break free of tradition and to leave this "bad place". He said he had heard that those who succeeded in doing so liked to go back there wearing the latest and most provocative fashions, in order to make clear that they had chosen a different way of life. The ascription of traditionalism is bound up with the idea of overcrowding: it is the high population density that makes strict social control necessary. ${ }^{7}$

These two different ascriptions both contribute to spreading the idea that the Old City is not a desirable place to live and that it is best avoided - that it is a place which 'modern' and educated Palestinians leave as soon as they can. These ascriptions are linked to the processes of population exchange described above: the influx of migrant labourers, who frequently come from a lower socio-economic background and from families which are not considered as significant. Although in part they are living in Jerusalem in the fourth generation, these families are still seen in terms of their real or assumed origin, and accordingly as newcomers and not as Jerusalemites: they are all khalayla. That this is not necessarily a matter of historical accuracy, but of ascriptions in respect of their life, customs and practices, can be seen in the fact that a Palestinian publication containing statistics for the Old City describes a family which considers itself as having been a 'Jerusalemite family' for centuries as 'Hebronite' (IPCC 2009), although members of the family who know about their own history told me that they did not come from there. In the same publication, another Old City family is described as migrants, but with the remark that they came to Jerusalem several hundred years ago (ibid.: 20). Thus, the essentialist character of Palestinian family ascriptions serves to confirm negative discourses on the Old City.

\footnotetext{
${ }^{7}$ Chapter 11 shows that in the case of Jaffa the Old City is a space where women can escape from the traditional structures in their village or their family.
} 


\subsection{The self-images of Jerusalemites living in the Old City}

There is a complex interrelationship between the discourses discussed in the previous section and the self- and we-images of the people who live in the Old City. In this section I will describe how they respond to and shape these discourses. First, a few remarks on the structure of the interview sample: on the basis of results obtained during a first fieldwork phase, I defined three heuristic research spaces in the Old City, in which I then set about collecting further empirical data. At first glance, these three heuristic research spaces may appear to have different spatial configurations: the first, and the one that I will mainly focus on below, is a 'traditional', largely Muslim neighbourhood; the second is the extended Jewish quarter, treated by the authorities today as a separate administrative unit, where I spoke mainly to members of the remaining Palestinian minority; and the third heuristic research space is that of the international monks who live in the Old City. The aim of this construction is twofold: to avoid defining social space in purely territorial terms, and to divide the Old City into parts that correspond as far as possible to the selfand they-images of the inhabitants; in other words it is bound up with the question whether these research spaces also constitute social spaces. Another reason for it is that the common division (and in part administrative division) of the Old City into four ethno-religious quarters, which is reproduced in Israel and 'in the West', has been quite rightly denounced as a colonial construction that has little to do with the realities of life in the Old City. The inhabitants feel that they belong to smaller neighbourhoods, with boundaries that have changed in recent times depending on the everyday life of the residents, and that were not always associated with any particular grouping (see for instance Arnon 1992; Tamari 2000).

Below, I will concentrate mainly on the fieldwork carried out in a small, largely Muslim neighbourhood within what is frequently referred to today as the Muslim Quarter. I carried out long-term participant observation in this neighbourhood, ${ }^{8}$ and conducted twelve narrative-biographical interviews there. I found suitable interviewees using the snowball method, both through people I had met during my participant observation and through colleagues and acquaintances. This multi-track approach was important: on the one hand I met people in (semi-)public spaces who reacted positively to me as a young German researcher and were willing to help me. On the other hand, it was difficult for me to organize interview meetings, and there were always discussions (presumably also 'behind the scenes') as to who should be interviewed. By asking people from outside the neighbourhood to help me to get in touch with their relatives or friends there, I was also able to contact people who are not normally present in (semi-)public spaces.

\footnotetext{
${ }^{8}$ I wrote over 70 reports of my observations in this neighbourhood during the following periods of field work: from the beginning of March to the end of April 2011, the end of January to mid April 2012, mid March to April 2013, and short visits in the autumn of 2013 and early summer 2014.
} 
A first important observation in this neighbourhood is that the inhabitants of the Old City themselves frequently thematize their spatial environment and living conditions in the Old City. This is always an important subject in the interviews and in my observation notes - in interactions with me, but also in everyday interactions between those who live there. They talk about the negative discursive ascriptions (which they are aware of), and about their everyday social life: the overcrowded conditions, the neighbourly community, difficulties within the community, the political conditions, and the symbolic character of the Old City. In interactions with me, but also with each other, the exaggerated political importance and discursive denigration of the Old City leads the inhabitants of the Old City to emphasize the positive aspects of life there. Throughout the interviews, it can be seen that the existence of social problems is either denied, or, if they are admitted, they are blamed on the Israeli occupiers. This is a variant of the hegemonic we-discourse, which says that there are 'no problems' between Palestinians. But, as I will show below, this we- and self-image is fragile and is not shared by everyone in this neighbourhood. In the interviews, people repeatedly say that a conservative lifestyle is desirable and they emphasize the advantages of close family ties and social relationships in the Old City. The interviewees react to discursive denigrations of the Old City by referring to life in their community as the "true" or "natural" way of life, while the individualized and isolated existence of small families living in new middle-class houses is presented as being inconceivable. The interviewees also give prominence to the religious and national importance of the Old City. They derive from it the mandate to protect the 'holy places', such as the al-Aqsa Mosque or the Church of the Holy Sepulchre, from 'attacks' by Jewish Israelis. And the suggestion that they are not real Jerusalemites but migrant labourers is often angrily rejected by Old City residents: How can people say that when we have lived in the Old City for generations? Those whose families came from Hebron ask whether it is not possible to have a Hebronite origin and be a 'real' Jerusalemite at the same time. This is bound up with the fear that the being branded as a migrant might be used by the Israeli authorities in the future as a way of challenging their right to reside in Jerusalem (see chapter 7). Social problems are blamed either on a small number of "bad people" (see the comments by Hafez quoted above) or on the Israeli policies. The latter, for instance, are made responsible for the fact that drug dealers get regular replenishment deliveries. But the residents quickly insist that everyone lives peacefully together, despite some small problems, and that only a few people have been corrupted by the occupiers. 


\subsection{Self-presentations of members of different generations in a small neighbourhood}

An analysis of the narrative-biographical interviews conducted in this small neighbourhood shows that typical self-presentations can be identified that are based on the generation-specific experiencing of collective history. The interviews with members of two historical generations stand out, which I have empirically reconstructed in accordance with the ideas of Karl Mannheim (1952). These are the 'Jordanian generation' (Becker 2013) and the 'First Intifada generation'. In the overall context of the Palestinian population in the West Bank and East Jerusalem, the Jordanian generation (which roughly covers those born between 1940 and 1955) can be regarded as a generation unit in the sense proposed by Mannheim, because it is typical of the Jerusalem Old City context, and we can assume that there are other generation units in other geographical spaces.' As for the 'First Intifada generation', we have been able to reconstruct similar generation-specific components in the West Bank. The constitutive experiences of these two generations are so dominant in discourses in the (semi-)public spaces of the Old City that those who nominally belong to them but, for example, did not take part in the Intifada are in a disadvantaged position. This can be illustrated by the case of Hafez. The time of the First Intifada was the formative phase of his life, but he does not share the constitutive experiences of the activists, which creates problems for him. ${ }^{10}$ As in other local contexts described in this book, it can be seen that interviewees who occupy an outsider position talk in a way that is different from what the dominant discourse demands, which explains why the interview with Hafez is not structured in the same way as other narrated life stories and experienced lives. I will come back to this point after discussing the two generations.

\section{The 'First Intifada generation'}

In the literature, Palestinians born between 1963 and the early 1970s are often referred to as the First Intifada generation. ${ }^{11}$ The discourse in the Old City is determined by the generation unit of those who participated actively in the Intifada and consequently were often imprisoned and tortured. This shapes their view of their childhood and youth. At the same time, their commitment to the national cause brought them social prestige, and sometimes even resulted in an inversion of age roles: when they returned from prison, some of them were given responsibility for

\footnotetext{
${ }^{9}$ Karl Mannheim (1952: 304) defines a generation unit as follows: "Youth experiencing the same concrete historical problems may be said to be part of the same actual generation; while those groups within the same actual generation which work up the material of their common experiences in different specific ways, constitute separate generation units."

${ }^{10}$ The type that Hafez belongs to could thus be called the generation unit of those who were not active in the First Intifada.

${ }^{11}$ Lybarger (2005) also distinguishes generation units.
} 
family or neighbourhood early on by their elders (see also chapter 6). Their typical self-presentation is focused on the experience of occupation and oppression by the Israelis, which has marked their whole life. Interviewees who belong to this generation unit speak in a stereotype and impersonal manner about suffering under, and resistance against, the Israeli occupation, and they present generalizing political and ideological arguments. Thus, they make clear use of the hegemonic we-discourse. For example, Umar ${ }^{12}$ begins his self-presentation, or we-presentation, as follows:

"We live here (2) in an occupied country, we are controlled by the occupiers in our whole life $((\mathrm{I}: \mathrm{hm}))$, we can do nothing without accepting the occupation=whether at work when: learning at=even when practising our religion (2) ((I: hm)) ah: our life is very difficult, because of the occupation, $((\mathrm{I}: \mathrm{hm}))$ the occupation makes our life more difficult $(\quad)$ based on the principle that it is a purely Jewish country $((\mathrm{I}: \mathrm{hm}))$, and so they want to drive all non-Jews out of this country."13

This beginning makes the Israeli occupation responsible for all problems, including those which Umar only talked about at a later point in the interview. Social inequalities or inner-Palestinian conflicts in the Old City are always attributed to this external generator. In this passage, the occupation is set against a 'we' and that extends the arguments of the First Intifada generation to include all Palestinians.

\section{The 'Jordanian generation'}

However, the above type of self-presentation also implies a critique of the older generation, for the First Intifada is often regarded as the project of a specific generation (Giacaman / Johnson 1989: 160). And our interviews with elderly people in the Old City, whose constitutive experiences are not the same as those of the First Intifada generation, show clearly that talking about their memories among themselves and with younger people ${ }^{14}$ has created a feeling of belonging to another historical generation, which produces a different type of self-presentation. I refer to these elderly people in the Old City, who were born roughly between 1940 and 1955, as the Jordanian generation. The members of this generation come originally from poor backgrounds in the Old City and grew up in the period when Jerusalem was under Jordanian control (1948-1967). They criticize current conditions in the Old City, which they see as being the result not only of Israeli policies, but also of the First and $\rightarrow$ Second Intifadas, which threatened their hard-earned prosperity. The pov-

\footnotetext{
${ }^{12}$ In the course of two meetings at the end of March 2013, I conducted an interview with Umar in Arabic, lasting for a total of three and a half hours.

13 The quotations from this interview have been translated from the original Arabic.

${ }^{14}$ On the formation of generations through intergenerational dialogue, see Rosenthal 2000.
} 
erty they experienced as children was their formative experience. ${ }^{15}$ They associate the Israeli occupation mainly with a perceived improvement in their financial situation in the 1970s and early 1980s, and a better state social security system. ${ }^{16}$ Thus, they doubt the hegemonic argument that the Israeli occupation is responsible for all social problems in the Old City, and make intergenerational accusations within the Palestinian grouping in the Old City. This distinguishes them from people of the same age in the refugee camps, whose experiences and self-presentations centre around their status as refugees (see chapter 4). But because of differences in their legal situation since the $\rightarrow$ war of 1967, the poorer inhabitants of the Old City also differ from the inhabitants of other cities in the West Bank. When they speak about their past, the members of the Jordanian generation argue about the economy rather than about occupation and resistance. ${ }^{17}$ At the beginning of his self-presentation, Hassan $^{18}$, a shoemaker, says: "The situation the city here it was, under Jordanian rule [...] the people were very simple ((I: hm)), ja'ani their life situation (2) was low, ((I: $\mathrm{hm})$ ) everyone worked on a very simple level, simple life." ${ }^{19}$ Hassan presents the time before 1967 as a time of poverty, and the time after the war as a period of economic upswing:

"I tell you honestly ja'ani ah, two three years after [after the 1967 war] ah: the situation opened up, tourism opened up improved ((I: hm)) (2) ah well, trade became more open $((\mathrm{I}: \mathrm{hm}))$ and there was exchange the people had money [...], economic life flourished and developed [...] the golden age of Jerusalem began in 1969 and lasted until 1985, yes."

The words "I tell you honestly" at the beginning of this passage are an indication that this argument does not correspond to the accepted consensus in Palestinian society, which says that life is hard and difficult because of the occupation. This shows how important it was for Hassan and others to explain to me their view of things. Hassan places the end of the "golden age" in the mid 1980s, and names the begin-

\footnotetext{
${ }^{15}$ For people who lived in the Old City before 1948, the experience of $\rightarrow$ al-Nakba is less constitutive than their experience of poverty. But refugees who had formerly lived in what is today the Israeli national territory also settled in the Old City.

${ }^{16}$ Even though the economic situation in Jerusalem improved during the 1960s, many of the people I interviewed associated this improvement with the Israeli occupation. But much of the more perceivable upswing in the 1970s was connected with exploitation of the Palestinian market (see for instance Romann/Weingrod 1991; Migdal 1980: 46).

${ }^{17}$ Members of the lower social classes have often been neglected by researchers (with the exception of refugees), who tend to focus on the Nakba and Intifada generations, being the people who experienced, or helped to shape, the events most firmly anchored in the discourse relating to the collective history of the Israel-Palestine conflict.

${ }^{18}$ During three meetings with Hassan in March 2012, I conducted an interview in Arabic lasting for a total of three hours.

${ }_{19}$ The quotations from this interview have been translated from the original Arabic.
} 
ning of the First Intifada, in addition to a more extreme Israeli government, as the reason for the ensuing economic, social and political decline:

"From then on, we returned=to zero, ((I: hm)) ja'ani at the beginning of the First Intifada we had no work for three months ((I: hm)), ok but not only me ((I: hm)), generally everything everywhere was stagnation [...] and this was long-lasting jaiani um, it was ah and it had very negative effects ((I: hm)), on social life, for everybody [...] the economic situation got worse, you know the rest, areas were closed off prohibitions here and you weren't allowed to go there the wall came and and."

The First Intifada is a negative counterpoint that delegitimizes the younger generations: the traditional way of life with its sense of community and mutual respect is seen as disrupted by materialism, drugs and disobedience. It is said that there is no more respect and neighbours do not visit each other like they used to do. By constantly comparing their own past experiences with the precarious situation in the Old City today, the we-group of the Jordanian generation distinguishes itself from the First Intifada generation. The members of the Jordanian generation also find here a rational explanation for the negative discourses in respect of life in the Old City.

In both generations, the interviewees concentrate on presenting the collective experiences of their we-group as a generation to such a degree that personal experiences or stories about their families are almost completely excluded. Instead, they argue in terms of historical events and processes, and by using expressions like "we belong to a generation...", "all of us...", "generally...", "we..." they raise this perception to a collective level that is framed by their generational belonging. These collective we- and self-presentations are also exchanged in (semi-)public spaces, in the streets, inner courtyards and shops. But the collective memory of the Jordanian generation is less powerful there - the members of the First Intifada generation, who are more influential in the neighbourhood, do not prevent the older people from speaking, but they are either publicly criticized for their views, or are not taken seriously and simply laughed at. This intergenerational dynamic is comparable to that between the $\rightarrow$ Nakba generation and their children (see chapter 4). 


\subsection{Hafez' position in the neighbourhood: A delegate of his family and not of his generation}

We have shown how different the we-images of the inhabitants of the Old City can be, depending on which historical generation they belong to, and have thus dismissed the discursive they-image of a homogeneous Old City collective where everyone shares similar experiences and life stories. This section is devoted to a case which doesn't fit into the framework of these generational we- and self-presentations. Hafez, who has been referred to above, is a product designer who was 45 at the time of the interview in 2011. Although Hafez' age makes him a member of the First Intifada generation, he does not share the constitutive biographical experiences of the politically active members of this generation: he is one of those who did not take part in the First Intifada, but devoted himself instead to pursuing his career and founding a family. Thus, while his education was not interrupted by spells in prison, he was not rewarded with representative positions in the neighbourhood or with high esteem. His self-presentation is therefore focused on his present situation and his commitment to the Old City. The image he presents of the Old City is differentiated; he describes the bad situation in a carefully considered way and attributes it to various factors. Later on in the interview, he talks about his personal memories much more than other members of the two historical generations do, and in doing so relativizes the nature of his professed belonging to the neighbourhood community.

\section{Hafez' self-presentation: "I still say that I love inside"}

The shape of the interview with Hafez was clearly determined by two factors. The first is related to the 'gatekeeper' of the interviews and the interview situation: I was introduced to Hafez by Younis, an acquaintance of mine who had been a friend of Hafez in his youth, although they now have hardly any contact. At Hafez' request, Younis was present during the interview sessions. This means that Hafez' self-presentation was addressed not only to me, but also to Younis. Both of them come from educated families that live in the neighbourhood. But while Younis, who comes from an old Jerusalemite family, left home before he had finished his schooling and now leads a secular life in one of the better parts of East Jerusalem, living in a block of flats with his wife and children, Hafez never left his parents' house in the Old City. While Younis looks down on the Old City, disparages it and doesn't like going back there, Hafez still lives there today.

The second determining factor is the death of Hafez' father, an imam and teacher of religion, which occurred a few months before the interview took place. Hafez had always lived with him in the family house, and his father had greatly influenced his life. Hafez' present perspective is framed by this loss and the interview is permeated with reflections on his father and his relationship with him. 
I asked Hafez to tell me about his life and his family. In his self-presentation, or his presentation of the we-group of Palestinians in the Old City, he first tries to focus on a general and argumentative account of life in the Old City. Apart from a few biographical facts and short interjections, Hafez does not say anything about his own life or about the death of his father. He even expressly refuses to talk about his own life: "so, as you see, I'm not talking about myself a lot, I'm talking about the environment inside, I guess this is better." Instead, Hafez consistently presents himself as an expert in respect of political and social processes in the Old City. It is remarkable that, in contrast to the interviews with other members of the First Intifada generation, he does not begin his presentation with the political or religious conflict lines (he discusses the political issues at length later on), but with the above-mentioned discursively charged topic of the presence of 'immigrants' in the Old City, by presenting himself as a 'true' Jerusalemite despite his family's story:

"I can start from eh, let's say I can start from Tulkarem, my family's roots are from Tulkarem, not from Jerusalem, ah maybe like eh more than eighty percent of the current residents of the Old City of Jerusalem that come from the cities around Jerusalem, the people who we whom we call Jerusalemians I don't know if this is, expression can be added are rare today, um but eh since, let's say about if if we came back ten years ago, if I go to Tulkarem, I get lost, I don't know the the city even though it it's my, the place where my grandpas came from."

After this sequence he describes life in the Old City and its challenges. Here, he insists that he, unlike Younis, has never lived outside the Old City: "I've never, lived, outside the Old City so I don't know if the if I can give the the whole image." But at the same time he presents himself as being intimately acquainted with all aspects of life in the Old City, and as an expert in respect of the social and political processes. Among other things, he puts this down to the fact that he was a political activist for his neighbourhood and - as becomes clear in the course of the interview - he sees himself (and Younis) as coming from an educated family and therefore as being better educated than other people in the Old City. This distinction between himself and the others is repeatedly implied, and also mentioned explicitly. In respect of Younis and his youth, for instance, he says: "We were the that eh some of that few people who were educated at that time in that [youth] club so we had [...] responsibility [...]."

Although Hafez belongs to a migrant family, his was not a family of poor peasants but a very influential and large family in Tulkarem (and our research showed that the family had always been influential ${ }^{20}$ ). Moreover, he can distinguish himself from others through his father, the imam, and he presents himself as having the same educational status and belonging to the same social class as Younis, whose father was

${ }^{20}$ For reasons of anonymity the sources cannot be named here. 
a teacher of religion. Hafez thus positions himself as a kind of primus inter pares in the neighbourhood. This enables him to speak disparagingly about the immigrants from Hebron (and other places). He accuses them indirectly of having let themselves be instrumentalized by Israel, encouraged to move into the Old City:

"We these days have some difficulties dealing with some people who came from the southern suburbs like Sawahera, some people are encouraged by Israel to come and have their own eh part in this cake, they've never came as owners, they've never came here, but they are now they are encouraged, they have a lot of things, ah this role was given to people from Hebron in the, at the beginning of the occupation, the number of people who came from Hebron, they came as workers, as very very simple workers, now they own a lot of ah houses and shops and even monuments in Jerusalem; that was encouraged also by the Israelians and the as I told you, the people whose roots are from Jerusalem, are very ah rare, a lot of them live outside the Palestine."

In his self-presentation he then discusses the advantages and disadvantages of living in the Old City. He repeatedly addresses Younis and compares the Old City with the newly developed area where Younis lives. As positive features he mentions the fact that markets, schools and mosques (Hafez refers to the connection to the al-Aqsa Mosque as being ideologically very important) are all very close; as a negative feature he mentions the overcrowding, which means a lack of privacy and often a loss of sleep. After this, he gives a detailed account of the political processes, as he perceives them, which put the inhabitants of the Old City under pressure: the large number of Palestinians moving back to the Old City because of the Israeli policies, Jewish settlements, the neglect of Arab neighbourhoods. He is obviously worried that he might at some time be "thrown out" of the Old City. He then describes and emphasizes how he has helped to strengthen his neighbourhood community. For thirteen years he was the leader of the local branch of a community NGO in his neighbourhood. But he resigned from this post after the death of his father (see below). Almost at the end of his main narration, Hafez sums up his discussion of the place where he lives and emplaces himself actively in the neighbourhood and in the Old City. He seems to fully identify himself with his local environment: "Ah, but if you ask me for for the last line, if I prefer to go outside or inside, I still say that I love inside."

However, not only the latent content of his self-presentation suggests that while he wants Younis and me to believe this, his conviction has lost its firmness. In fact, our reconstruction of his biographical course shows that he feels the urge to be able to leave the Old City, temporarily or permanently. 
Hafez' experienced life: "Ambition to have our own house outside the walls"

During the first interview meeting with Younis and me, Hafez places emphasis on his neighbourhood activism and says little about other aspects of his life story, but at subsequent meetings he increasingly opens up and talks about more personal matters. It becomes clear that Hafez protestations of love for the Old City are due to the obligation delegated to him by his family to show solidarity and commitment in the neighbourhood which is in opposition to his desire to leave the Old City permanently.

Hafez was born in 1966. He is the eldest of seven siblings and all his life he has negotiated his role as first born, which involves assuming responsibility for the family. He implicitly reproduced this role early on in that he was always a year or two older than the others in his circles of friends, and struggled to measure up to his father's expectations in respect of maintaining the family status. This meant, and still means, emplacement in, identifying himself with, and assuming responsibility in, the neighbourhood. His earliest friends lived in a different neighbourhood of the Old City. He describes how he "returned" to his neighbourhood around the time he entered middle school: "I came back as a as a kid, we've always been living here, but I didn't ah they didn't see me a lot [...] some some kids said we don't believe you're eh a member of the B. family we don't see you here, so I I I came back and started my let's see- let's say local activities here." Hafez (and Younis) became active in the local youth club. As with his previous friends, Hafez was the eldest in the group. They prepared publications and planned ways of helping poor families. Thus, Hafez assumed social responsibility early on, doing justice to the status of the family in the neighbourhood and to his perceived intellectual abilities. In his late adolescence, as a result of these activities, Hafez was given the opportunity several times a year to go to a Christian guest house in Israel. There, Younis and Hafez had close contact with international volunteers. Thus, Hafez' activism in the Old City enabled him to get away from it on a 'part-time' basis. This opened up new perspectives for him, different from those relating to his family and social conditions in the neighbourhood - but in a way that did not expose him to accusations of disloyalty. In addition, he regularly visited places outside Jerusalem with a group of friends from school (in which he was again the eldest). These memories of 'escaping' are presented by Hafez from his present-day point of view; he says practically nothing about his memories of life in his family and in the neighbourhood, or about his life at school.

Hafez's educational career became a difficult issue in his family when the grades he obtained in his final school examinations (tawjihi) were not good enough to allow him to go to university. His father took this very badly: "He said that he was upset more than the the news that he lost eh that he lost his son before." As a child, Hafez had seen one of his younger brothers die (though he mentions this harrowing event only briefly in the interview); so his father's words must have pained him, and possibly he perceived them as meaning that he, Hafez, had now also 'died' for his father. It is also possible that this memory was revived following his father's death shortly 
before the interview. To this day, as became very evident during the interview, Hafez still feels challenged by his father's expectations, even though he went on to do a product design course at a Community College, where he obtained excellent results and quickly rose up the ladder. However, it is unclear whether this was enough to satisfy the high expectations of his father. Immediately after the end of his studies, Hafez was offered a job as a teacher at the college, one year after his father's retirement. Thus, he had reproduced the social status of his father up to a certain degree, at least in a formal sense. "I had to to prove myself since I didn't pay enough attention at high school and that still affects me I mean the words of my father (2) so I started to to study there and I was I had really excellent eh marks and eh I tried you know to compensate or so for my father."

In the same year, at the end of 1987, the First Intifada began in East Jerusalem. Many adolescents and young adults from the neighbourhood participated in this 'popular uprising' (see above). However, Hafez did not take part; perhaps he did not want to endanger his new position in the family which he owed to his educational and professional achievements, or he did not want to upset his father, or his father had warned him to keep out of politics. The result was that he was left behind by the politically active forces in the neighbourhood. It is unclear what Hafez thought about the Intifada, and whether he felt excluded at the time by the influential forces in his neighbourhood. But he speaks at length about the fact that when the Intifada was at its height his father told him it was time he should marry - which Hafez did in 1989 at the age of 23. This is comparatively early, but Hafez had 'put his house in order' early, in the sense of earning enough to finance a wedding and to support a wife. Hafez says that he chose his wife on the basis of rational considerations rather than romantic love. He thus calls it a "traditional" marriage. His wife comes from a nearby house, and her father was a good friend of Hafez' father. Hafez took over a part of the family house, and became the father of three children in the years following 1992. Finally, he set up his own business as a product designer. Thus, Hafez helped early on to maintain the status of the family in Jerusalem and to consolidate its presence in the neighbourhood, even if this was perhaps not what he would have wished for himself. Indeed, the first thing he did after marrying was to obtain a driving licence, and he continued to visit the Christian guest house regularly - his part-time escape from the Old City.

This ambivalence between maintaining a presence and seeking escape increased: from 1998 onwards, Hafez became more and more active in neighbourhood NGOs. He became a member of the executive committee of the local neighbourhood organization, and he represented the local youth club on the national level. But certain family and political events occurred during this time which greatly increased the pressure on the 33 year old Hafez: in 1999 and 2000 further children were born, and his mother died in 1999, after which his father began to suffer from depression. As a result, Hafez became responsible for all family matters and he felt the burden of his responsibility. It made his presence in the neighbourhood even more necessary: as the eldest son he had to perform the symbolic duties of his father, and organize 
family matters such as the marriage of his siblings. On the political level, the Second Intifada began in September 2000, which led to violent clashes in Jerusalem.

These events, which required that he devote much time to family matters, occurred in the same period in which Hafez invested in a housing project in Bethlehem. The project failed, which Hafez mainly blames on the Second Intifada. But perhaps his concern for the family in the Old City at that time also influenced the failure of this plan. Hafez speaks about the housing project and his plans to move only at the end of our third meeting; not even Younis had known of his plans. As pointed out above, Hafez gradually lost his reserve as the interview progressed, and at this meeting he referred explicitly to his dream of moving out of the Old City permanently:

"Well frankly speaking I=I'm thinking of a eh several times encouraged by my wife, you know to: to buy a piece of land or to buy a house in the West Bank of course why is that since we can't afford something here in Jerusalem [...] so: eh we had that ambition to have our own house, outside the the walls of this little house we're living in in the Old City, we eager to see some some trees some birds around, which we we don't see in the Old City of course especially these days, so we we planned several times to and we started really steps on on land as they say but we once we decided to buy an apartment in some buildings that eh a foundation started to to build in Bethlehem I remember a very nice area in Bethlehem [...] then the (4) the Israelis started something against the: Palestinian authority there (2) and eh it was converted into something like war which started eh the second Palestinian uprising, you know it was military: very dangerous [...] and that what was the excuse for Israel to use all their tanks all thei:r you know, aircrafts and so [...] me- myself and other five who bought at that area, started bu- you know paying for that project other five from Jerusalem we withdrew and eh we had to cancel this eh dream."

At the beginning of this passage Hafez ascribes to his wife the idea of buying a house, as if he cannot admit to this day that it was also his wish, and, as he says himself at the end of the passage, his dream, to live somewhere else. And so he interprets the failure of the construction project as a sign that he should stay in the Old City. This report, which is full of argumentative sequences, stands alone in the interview, unrelated to other biographical events. This suggests that he might try to drive this course of events out of his memory. In general he evaluates the time after 1999 as the most difficult in his life. This is certainly due in part to the family situation at that time, but also to the fact that he failed to escape from the Old City and thus perceives himself as imprisoned in it. In answer to my subsequent question whether there is anything that makes him think it would be better to live in Bethlehem instead of in Jerusalem, he answers: "Now frankly speaking this is the feeling that we all feel every day, every day." 
After the failure of his plan to buy an apartment in Bethlehem, and the long illness of his father (who did not "wake up" from his depression until 2005, as Hafez puts it), Hafez became even more active in neighbourhood and welfare work and took on various leading roles. His narration of his failure to buy an apartment is distinctly different from his narrations about his community work, in which he stylizes himself as as part of the neighbourhood. How directly these activities are connected with his family becomes evident when he talks in detail about a successful campaign for the neighbourhood carried out in 2008. This narration is a response to a question from me about how he and his siblings spent their childhood.

"We used to play ya- together and ah that's the atmosphere of the quarter you know the quarter here ((I: $\mathrm{mhm}))$ ah that this is the natural ah eh, thing; these days the this atmosphere came back since a lot of people came back and ah a lot of kids are, existing, I love that; there is a touch that I myself would like to talk about it eh since my a position in the foundation I told you about ((I: ja)) we used to struggle against the municipality for several rights of of us and and one of the things that we achieved and it's a good thing for myself but I don- I dislike to talk about myself but this is was a real thing [...]."

This passage shows how strongly Hafez' community work in the neighbourhood is associated with his family of origin, for in response to my question about his and his siblings' childhood, he immediately places his childhood in the neighbourhood context, which then leads him to tell the story. Typical of the neighbourhood discourse, he uses the collective 'we' to speak about the community with its big families as the "natural life", and says that he does not want to talk about himself. It is therefore possible to interpret Hafez' commitment to the neighbourhood not as a desire for self-fulfilment or power, but as a way of meeting the expectations the neighbourhood and his family have of him as the first born, consolidating the social emplacement of his family in Jerusalem. And possibly Hafez perceives a need to prove his patriotism because he did not play an active part in the Intifada, and because he had come close to leaving the Old City.

Although Hafez sent his children to Old City schools, and although his daughter teaches in the same youth club as himself, only a few months after the death of his father in 2011 (when Hafez was 45) he has begun to radically reduce his activities in the neighbourhood: he has resigned his post as chairman of the neigbourhood association and he has left the executive council of the youth organization. Perhaps he feels relieved of the pressure exerted by his father, or he needs time to mourn. During a break in the interview, Hafez asked Younis whether I knew the neighbourhood that he was talking about. Younis said jokingly that I was learning Arabic there from his brother, a shopkeeper, and - Younis imitated a market crier - that I shouted the prices of the goods in the street. But Hafez did not respond to Younis' little joke, and 
only remarked that he, Hafez, was no longer very visible in the neighbourhood. ${ }^{21}$ This statement can be read as an indication of a further change in his emplacement - in the sense of retiring into his family. Although he was not always to be seen in the (semi-)public spaces of the neighbourhood even before this, it is clear that he is aware of having begun to reduce his commitment to the neighbourhood community. Physically, on the other hand, he will not be able to leave the Old City permanently because of his family situation and because of the social and political pressure he feels.

\subsection{Processual emplacements in the Old City}

The above examples of members of the Jordanian and the First Intifada generations, and the analysis of the interview with Hafez, who does not share the constitutive experiences of his generation and is thus under a certain pressure to justify himself, show that, besides religion and politics, socio-spatial, generational and class-specific belongings are also very important for the patterns of action and interpretation of the inhabitants of the Old City in Jerusalem. In the case of Hafez, it is clear that biographical experiences which differ from the dominant experiences of the members of the generation in the neighbourhood he belongs to can lead to an ambivalent emplacement, or even a sense of alienation.

The question of how people live together in cities and how living together may be organized in cultural and political terms is not new. Emplacement in a narrow territorial sense was proposed early on as one of the possible ways of building a community, for example by Ferdinand Tönnies. This concept was used by the members of the Chicago School and others as a research parameter, and in Germany it has been given concrete shape as the study of social spaces (Kessl/ Reutlinger 2007) or neighbourhood studies (Schnur 2008). In urban studies in the Middle East, the social effects of emplacement in a particular neighbourhood have frequently been discussed in respect of old cities: in this context, neighbours are said to be considered as members of the family; they are confided in but there is also a high degree of social control (see for instance Eickelman 1998: 104). These are ascriptions that are applied from outside to the inhabitants of the Old City of Jerusalem. Because social life in the Old City is described discursively as traditional, it is easy to assume that active emplacement in a neighbourhood is the only possible kind of emplacement in this territorial space: all inhabitants of old cities are constantly in contact with each other and are subject to the social control of the neighbourhood, from which there is no escape. These homogenizing discourses do not do justice to the complex social realities in the Old City, where people have different biographical experiences which are not always compatible with the dominant form of emplacement in the neighbourhood.

${ }^{21}$ Instead, since the death of his father, he has started seeing his relatives in Tulkarem, with whom he had no contact for a long time. 
Nevertheless, these they-images are important as components of a discourse to which the inhabitants must react.

The results of my research show that life in the (semi-) public spaces (streets, shops, etc.) is indeed shaped by an interactionally created neighbourhood community. In this overcrowded space, there is a good measure of social control. It is characterized by face-to-face interactions and perceived biographical and generational similarities between the inhabitants, and is a source of security. In the (semi-)public spaces of the neighbourhood, the dominant representatives of the two historical generations presented above are most visible. They counter the negative they-image with a selfimage of the Old City community. On the other hand, there are inhabitants whose biographical experiences do not correspond to those of the dominant representatives of the neighbourhood. These people are not so commonly to be seen in the (semi-) public spaces of the neighbourhood. They are expected to observe the religious and social customs (forms of greeting, fasting during Ramadan, appropriate clothing), but not to participate in the communal life of the neighbourhood.

Due to the fact that declarations of belief in the well-functioning life of the neighbourhood are socially desired and frequently to be heard in the (semi-)public spaces, it proved useful to conduct long biographical interviews involving several meetings, because in the course of such interviews it may be seen how this definition of neighbourhood can be criticized or rejected in private space. It was also important to find people for interviews who do not participate in the life of the (semi-)public spaces of the neighbourhood and whose views are therefore not represented there. Hafez, for example, at first oscillated between commitment to and part-time escape from the neighbourhood, failed in his attempt to get away completely, and is currently retiring from the neighbourhood and into his family. But those who decide to leave the Old City and move to middle-class areas, like Younis, are accused of despising the way of life in the Old City and of wanting to integrate themselves in the individualized society.

Thus, all inhabitants of the Old City have to decide whether they will emplace themselves in this spatial neighbourhood environment or only in their house and family, and also whether to stay in the Old City or move out of it - should this be possible. We can sum up by saying that a person's emplacement in the neighbourhood must be regarded as changeable and processual. 
Voices from Israel 



\title{
9 Palestinians in Israel
}

\author{
Nicole Witte
}

\subsection{Preliminary note}

"His Majesty's government view with favour the establishment in Palestine of a national home for the Jewish people, and will use their best endeavours to facilitate the achievement of this object, it being clearly understood that nothing shall be done which may prejudice the civil and religious rights of existing nonJewish communities in Palestine, or the rights and political status enjoyed by Jews in any other country." (Balfour Declaration 2.11.1917; emphasis added by N.W.)

The Balfour Declaration was a milestone in the establishment of a Jewish state in Palestine. But while the goal of establishing such a state was eventually achieved, it cannot be said that the civil rights of the non-Jewish communities remained unaffected.

This applies to the Palestinians in the occupied areas of the West Bank and East Jerusalem, of whom only some in East Jerusalem have Israeli citizenship, and who are the subject of the previous chapters in this book; and it applies to Palestinians with Israeli citizenship living in the Israeli national territory, who are the subject of this chapter. However, before proceeding to a discussion of the experiences of Palestinians in the settlement areas of Haifa and Jaffa, their constructions of belonging and the different power (im)balances between them, we will first take a look at the 
socio-historical development of the conditions in which Palestinians live as Israeli citizens today.

The division of this book into sections is not based only on formal criteria such as ID or place of residence of the Palestinians we portray, but mainly on our research results. One general finding is that there are considerable differences in the living conditions, the experiential spaces and the constructions of belonging of Palestinians in Israel and in the West Bank (cf. the quantitative studies carried out by our project partners, for instance Sagy et al. 2011; Mana et al. 2014). Although they all speak of themselves as Palestinians, our interviewees clearly have different conceptions of the supposedly common 'we', and these conceptions are sometimes irritatingly 'empty', in the sense of being unrelated to the speaker's own experience. This also applies to Palestinians in the West Bank, although for them it is easier not to let this 'emptiness' become too obvious because they have been socialized into the homogenizing we-discourse (see chapter 4).

The development of different we-images and constructions of belonging among Palestinians in Israel and in the West Bank is certainly due in part to Israel's policy of division, and in particular to the fact that opportunities for contact between Palestinians in Israel and those in the West Bank and Gaza were severely restricted a few years before the beginning of the $\rightarrow$ Second Intifada in $2000 .{ }^{1}$ With our decision to focus our research on particular social spaces, we could be accused of supporting this divisive policy, but the increasing differences are an empirical fact and are therefore important for reconstructing (and understanding) the people's structures of experience and action. Palestinians living in Israel lead different lives and have different experiences from those living in the West Bank or in Gaza. For this reason we will now take a look at the development and status of the contexts in which they live.

\subsection{The Palestinians and Israel: Terminology}

It is not possible to talk about the 'history' of the Palestinians without also considering the history of the state of Israel (understood broadly as beginning with the first wave of Zionist immigration [Alija] in the 1880s and 1890s). The interdependency between the history of the (Arab) Palestinians and that of the Jewish (Zionist) population of this region (not only in the last 150 years) is central to the conflict (see Khalidi 1987). ${ }^{2}$ The historical 'facts' taught by each side reflect different perspectives of the past, serve to legitimize these perspectives, and are part of, and an indica-

\footnotetext{
${ }^{1}$ Sporadic checks were introduced in 1991. In the course of the 1990s, the border regime of the Israeli security forces became increasingly strict, culminating in closure of the Green Line for Palestinians wanting to travel out of the West Bank or Gaza (see Gordon 2008: 39f.; for an overview, see http:// www.btselem.org/freedom_of_movement/closure, 25.05.2015).

2 "Two nations warring in the bosom of a single state" (Palestine Royal Commission Report [Peel Commission] 1937: 2).
} 
tion of, different discursive positions. In other words, the conception and especially the use of the term 'Palestinian' always has political overtones (see below). I will nevertheless venture to give a short history of the term. Up to the 1930 s, the term 'Palestinian' was used to refer all the inhabitants of Palestine; thus, for instance, the 1937 Peel Commission Report (Palestine Royal Commission) spoke of "Palestinians - Arab and Jew" (43). ${ }^{3}$ This practice was based on the idea that the inhabitants are related to (or belong to) the land, also in the sense of 'the land belongs to those who live there (have lived there for a long time)'. This is the reason why use of the term Palestinian is such a sensitive and controversial issue, quite apart from the fact that a 'common' name strengthens the cohesion of a grouping, or contributes to its outward and inward creation in the first place, and helps to distinguish it from an 'other'.

A Palestinian we- and self-image (and the custom of referring to oneself as Palestinian) first appeared, at least among the middle classes of Jaffa, in the second half of the 19th century (see Kimmerling/Migdal 2003), and spread beyond these circles in the first half of the 20th century. This we- and self-image, which was neither institutionalized nor rooted in everyday reality (and was not shared by everybody and everywhere), was opposed to the stronger (also ideologically stronger) Yishuv, a better defined and better organized grouping which increased in size in the early 20th century. Although the formation of a Palestinian we- and self-image is not only a reaction to the immigration of Jewish Zionists, its development (with regard not only to the speed of the process, but also to its direction) was directly influenced by the migration of Jews to Palestine (see Krämer 2008).

The form which is set and customary today has existed only since the announcement of the Palestinian National Charter in $1964 .{ }^{4}$ This Charter is equivalent to a manifesto of the $\rightarrow$ Palestine Liberation Organization (PLO), which was founded in 1964 as a representation of the Arab people in Palestine, in the context of the $\rightarrow$ pan-Arab ambitions of Nasser, the former Egyptian president. The PLO was the first organisation to profess a genuine Palestinian nationalism, and was subsequently recognized by the international community as representing the 'Palestinian people'.

\footnotetext{
${ }^{3}$ The Peel Commission was appointed in 1936 by the British government to investigate the causes of unrest in the Mandate of Palestine. The quotation from the Peel Commission Report in context: "From the first the junior posts were filled by Palestinians, Arab and Jew. The police were Palestinian with British officers, but a special British gendarmerie, numbering originally 762 , were enlisted in 1922, mostly from Ireland. [...] The rest of the judges and magistrates were Palestinians. Cases of religious law and personal status were determined by Moslem and Jewish tribunals" (Palestine Royal Commission Report [Peel Commission] 1937: 43).

${ }^{4}$ Palestinian National Charter, Article 6: "The Palestinians are those Arab citizens who were living normally in Palestine up to 1947, whether they remained or were expelled. Every child who was born to a Palestinian parent after this date whether in Palestine or outside is a Palestinian" (emphasis added by N.W.; see https://www.jewishvirtuallibrary.org/jsource/Peace/cove1.html, 17.05.2015). This restriction to 'Arab' citizens excluded in particular Palestinian Jews who had been living permanently in Palestine.
} 
The use of the name 'Palestine' to designate this region is equally controversial. It goes back to a Greek word meaning the 'Land of the Philistines', was Latinized by the Romans, and often used as a name for small administrative units of the empires which ruled the area. It was taken up again in the 20th century by the $\rightarrow$ British, but was first used in 1922 as the name for a geographical area, independent from the surrounding territories, which resulted from a division of the British Mandate territory. The "national home for the Jewish people" favoured in the Balfour Declaration was to be created in this area. Today, the way in which the term is used is always an indication of the speaker's (political) self- and they-location. Although it is an historical fact, a statement like 'Israel is in Palestine' cannot be uttered without locating oneself politically, in the sense, for instance, that this does not question Israel's right to exist.

Officially, the Israelis rarely use the term Palestine but prefer to speak of the territories, meaning the occupied territories, in other words the West Bank and Gaza. The Palestinians are the people who live there (including the refugees), or who come from there (but have emigrated to other countries). For this reason the Israeli state does not refer to Israeli Palestinians but to 'Arab Israelis' (see below). For the leaders of the Palestinian Authority, on the other hand, the Israeli national territory is in Palestine, but this does not (automatically) mean questioning Israel's right to existence (Süddeutsche Zeitung 2010). ${ }^{6}$ As researchers we refer to the people in our research field by the names they use to refer to themselves, or we investigate which names are used in which contexts, or how usage changes depending on different figurations with other groupings. Palestinians in the West Bank have no doubts about calling themselves Palestinians, but while Palestinians in Israel may call themselves Palestinians, they often also refer to themselves as Arab Israelis (see chapters 10 and 11).

\subsection{The Palestinians and Israel: Some historical facts}

After the end of the First World War and the defeat of the Ottoman Empire, to which Cis- and Transjordan belonged, the League of Nations gave the British government a mandate for the region. After the division of the Mandate territory in 1922, the League of Nations order to allow the immigration of Jews was restricted to Palestine. For the 'nationally-minded Arab side', which had hoped for autonomy after the Ottoman retreat, and had negotiated corresponding agreements with the opponents of the Ottoman Empire, the granting of the mandate meant a disappointing replacement of one colonial power by another (see Krämer 2008: 151ff.). There were various uprisings and attacks on the British authorities, and also against

\footnotetext{
${ }^{5}$ Up to 1922 the $\rightarrow$ League of Nations mandate granted to Great Britain covered present-day Jordan (Transjordan) and present-day Israel, as well as the West Bank and the Gaza Strip (Cisjordan). In 1922 the British divided the Mandate territory and Cisjordan was then called 'Palestine'.

${ }^{6}$ Israel is, however, still not recognized as a 'Jewish state' (Die Welt online 2014).
} 
Jews, whether long-time residents or immigrants (see for instance Segev 2000; Morris 2008). This led to the founding of 'Haganah', a paramilitary Zionist organization, because the Jewish settlers did not want to rely on the protection of the British authorities. $^{7}$

The immigration of Zionist-motivated Jews, particularly from Europe, which had begun during the Ottoman period in the 1880s, increased in the 1920s and 1930s. This Zionist immigration was in part a flight from anti-Semitic attacks, especially in eastern Europe, but it was also bound up with the goal, or at least the idea, of founding a state in Palestine. ${ }^{8}$ The rate of immigration was further increased by the Nazi regime in Germany with its explicitly anti-Semitic ideology. In 1918, 90 percent of the population in Palestine were 'Arabs', but the percentage of Jews rose continuously (Krämer 2008: 183f.). In 1949, after the war, over 800,000 people lived in the new State of Israel, of which 250,000 were Palestinians, less than one third of the total population. Here, it must be remembered that approximately 700,000 to 750,000 Palestinians fled or were expelled from the territory of the new state in the period between the rejection of the UN Partition Plan for Palestine in November 1947 and the end of the $\rightarrow$ first Arab-Israeli war in mid 1949. ' The Arab states of Egypt, Iraq, Lebanon, Saudi Arabia and Syria declared war on Israel on May 14, 1948, the day of the declaration of the founding of the new state. This war ended with ceasefire agreements and considerable territorial gains for Israel. The Gaza Strip stayed under Egyptian control and the West Bank under the control of Jordan. Through its newly won territory beyond the area that was earmarked for a Jewish state in the UN Participation Plan, Israel reached its present-day size.

Only a very small number of the Palestinians who had fled returned after the end of the war. ${ }^{10}$ They were considered illegal and their return was against the political and military will of the Jewish-Israeli leadership (see Morris 2004). ${ }^{11}$ More than 400 Palestinian villages had been destroyed, and in 1949 the Israelis began to confiscate 'abandoned land' on the basis of Israeli laws (the most important being the Absentee Property Law of 1950 and the Land Acquisition Law of 1953). While in 1945 about half of the properties in Mandatory Palestine were owned by Arabs (and almost 85

\footnotetext{
7 Haganah was founded as a militia in the 1920s; its structure became more organized following the pogrom in Hebron in 1929. Haganah also played an important role in organizing the illegal immigration of Jews into Palestine during the blockade at the end of the Second World War (see Krämer 2008).

8 "Were I to sum up the Basel Congress in a word ... it would be this: At Basel I founded the Jewish State. If I said this out loud today, I would be answered by universal laughter. Perhaps in five years, certainly in fifty, everyone will recognize this" (written by Theodor Herzl in his diary after the First Zionist Congress held in Basel in 1897, quoted by Michael Brenner (2010: 271)).

${ }^{9}$ Of the over 9 million Palestinians living today in different parts of the world, 3.7 million are officially recognized as refugees or their descendants by the United Nations.

${ }^{10}$ Estimates vary between 25,000 and 100,000 persons (see Al Jazeera 2007: Online).

${ }^{11}$ Because the returnees were considered illegal, they were never officially counted, so that it is extremely difficult to give concrete numbers.
} 
percent of the arable land), in 1949 Israel controlled ${ }^{12}$ nearly 80 percent of the territory. ${ }^{13}$

Those Palestinians who had stayed or returned were given Israeli citizenship, but they were subject to martial law up to 1966. This meant considerable restrictions of their civil rights, and so-called $\rightarrow$ administrative detention meant they could be put in prison without trial by the law-enforcement authorities: $;{ }^{14}$ travel restrictions, curfews and expulsions were widespread. In 1966 the martial law was lifted, and various laws were altered in order to provide equal rights for the Jewish and Palestinian populations (Minority Rights Group International 2009).

In the $\rightarrow$ war of June 1967 ( $\rightarrow$ 'Six-Day War'), Israel occupied the Sinai Peninsula and Gaza (captured from Egypt), the Golan Heights (captured from Syria) and the West Bank and East Jerusalem (captured from Jordan). ${ }^{15}$ As a result, and in connection with the lifting of martial law, there was an increase in political activity among Palestinians inside Israel in the medium term. For the first time they were able to contact residents of the West Bank and the Gaza Strip, as well as the refugees of 1948. This was the beginning of a kind of 'Palestinization' of the Palestinians in Israel - a process of 'reflection' (Šenkyr 1998) on their Palestinian belonging. They also became increasingly politicized. ${ }^{16}$ At the same time, due to an upswing of the Israeli economy, which not least depended on the high number of (cheap) labourers from the occupied territories, the standard of living also improved considerably for the Palestinian population in Israel. Nevertheless, the 'Arabs' in Israel show lower key performance indicators in almost all economically important areas to this day (industrialization, housing, education, employment, communal infrastructure, etc.); in other words, they suffer from difficult conditions.

In the 1970s, growing politicization, and disappointment over what was perceived as neglect by the Israeli government, led to a number of violent protests within Israel, such as the Palestinian protests against Israeli land seizures in Galilee in March 1976. Ever since then, 'Land Day' is held annually to commemorate these

\footnotetext{
${ }^{12}$ Here we can note that: "An estimated 93 percent of the country's total land area (excluding the occupied areas of the West Bank and Gaza) is owned by the state or by quasi-state agencies" (Jewish Virtual Library n.d.). There is thus no doubt that we may speak of 'Israeli control' over the area.

${ }^{13}$ It is very difficult to calculate the amount of confiscated land in Israel territory, and this issue is thus highly controversial. According to estimates it may be up to 70 percent.

${ }_{14}$ This still exists, but is restricted inside Israel to 48 hours, within which reasons for the detention must be shown in a court hearing (exception: imprisonment for six months is possible if ordered by the minister of defence). Administrative detention is not a phenomenon specific to Israel, but goes back to British law and is used for instance by the US authorities (e.g. the prison camp in Guantanamo).

15 This war led once again to the flight and expulsion of Palestinians from the newly occupied areas; according to estimates, this involved up to 250,000 people (see Tolan 2007: 507f.).

16 The growing international awareness of the 'Palestinian question' certainly contributed to this, and in particular the political successes of the PLO, such as the speech made by Yasser Arafat at the UN General Assembly in 1974.
} 
protests. Yet in these years the Israeli Palestinians gained more possibilities to express themselves politically (in parties and trade unions).

The $\rightarrow$ First Intifada which began in 1987, and which has been discussed in the chapters on the West Bank and East Jerusalem, affected the Israeli Palestinians in various ways. It highlighted the importance of non-traditional types of collective political action - a significant development in view of their lack of influence in traditional (parliamentary) Israeli politics. It resulted in broad agreement regarding a two-state solution $^{17}$ (with the West Bank and Gaza under PLO leadership). And - perhaps the most important effect for the Israeli Palestinians - the issue of their life as Israeli citizens became a subject of discussion (see Rouhana 1991; Tessler/ Grant 1998).

The election of Yitzhak Rabin as Israeli prime minister in $1992^{18}$ and the $\rightarrow$ 'Oslo peace process' allowed the Palestinians, including those in Israel, to hope for a twostate solution. At the same time, the Israeli government increased transfer payments to 'Arab communities', which led to a great improvement of the infrastructure in these areas.

After the assassination of Rabin in 1996, the active interest of Palestinian Israelis in Israeli politics (probably bound up with the hope of gaining influence) continued to be very high, and three quarters of the Palestinians took part in the elections ${ }^{19}$ which resulted in Benjamin Netanyahu becoming Prime Minister for the first time. Subsequently, Netanyahu reversed many of the decisions made by Rabin (he reintroduced a Ministry of 'Arab Affairs', for example), which led to a renewed deterioration of the living conditions of Palestinians in Israel (see Rouhana/Sultany 2003).

In October 2000, shortly after the beginning of the Second Intifada, thirteen people, of whom twelve were Palestinian Israeli citizens, were killed by security forces in northern Israel during clashes between the police and Palestinian demonstrators. In November 2000 the so-called Or Commission was appointed to investigate these incidents.

"Israel's Arab citizens have the right to equality because of the essence of the State of Israel as a democracy, and because it is a basic right of every citizen. The state must work to wipe out the stain of discrimination against its Arab citizens, in its various forms and expressions" (Or Commission report (2003), quoted from Jewish Virtual Library 2003). This text is confirmation that there was discrimination against the 'Arabs' in Israel at the time of its publication in September 2003. Since then, however, the civil rights of the Palestinians have been even further restricted, for instance with the 'regulation' of family reunification (2003) and the entry of spouses into Israel. Here, a distinction is made depending on the country of origin

\footnotetext{
${ }_{17}$ The opinions of Israelis and Palestinians regarding a two-state solution in the period from 2000 to the present day are shown in the joint surveys carried out by the Harry S. Truman Research Institute for the Advancement of Peace at the Hebrew University of Jerusalem and the Palestinian Center for Policy and Survey Research in Ramallah with support of the Konrad Adenauer Foundation (KonradAdenauer-Stiftung 2014: Online).

${ }^{18}$ Rabin's minority government relied on the support of Arab members of the Knesset.

${ }^{19}$ Over 90 percent of 'Arabs' voted for the opposing candidate, Shimon Peres (see Šenkyr 1998).
} 
of spouses in spe. However, since only Palestinians take spouses from the countries from which immigration is regulated by this law, the law is a de facto discrimination of one grouping of Israeli citizens (Palestinians) against another (Jews), while de jure it upholds equal rights (see Peled 2007). This clearly reveals the tension in the (official and public) self-image of Israel as 'democratic' and 'Jewish'. ${ }^{20}$ Even if one does not completely agree with Oren Yiftachel's argument that Israel is an ethnocracy, it cannot be denied that 'Arab Israelis' do not have the same civil rights as Jews, and that the differences are always to the disadvantage of the Arabs. This development has become intensified in recent years (see Yiftachel 2011).

\subsection{Israel and the Palestinians in Israel: Some statistics}

Israel covers an area, bounded by the 1949 ceasefire line (without the Golan Heights and East Jerusalem, which were annexed contrary to international law), of about $20,500 \mathrm{sq} \mathrm{km},{ }^{21}$ and is thus roughly the same size as Slovenia. ${ }^{22}$ Its population is about 8.35 million which makes Israel one of the most densely populated countries in the world. The population is very unequally distributed: most of the people live in urban centres along the Mediterranean coast, while only just over one million ${ }^{23}$ live in the Southern District ${ }^{24}$, which includes the Negev desert and covers more than half of the national territory.

In Israeli statistics ${ }^{25}$ the people are divided into 'Jews', 'Arabs' and 'Others'. About 75 percent of the population are listed as 'Jews', and just over 20 percent as 'Arabs'.

In addition to the Palestinians, in the narrow sense of this we- and self-definition, the category 'Arabs' includes the Druze and the Bedouins. ${ }^{26}$ These groupings each constitute about ten percent of the Arab population of Israel. The Druze live mainly

\footnotetext{
${ }^{20}$ This tension, or the political and academic discussions on it, find expression in the debate on Israel as an 'ethnic democracy' (see for instance Smooha 1998) or 'ethnocracy' (see for instance Yiftachel 2006).

${ }^{21}$ Plus coastal territorial waters of just under $450 \mathrm{sq} \mathrm{km}$.

${ }^{22}$ It is $470 \mathrm{~km}$ long, with a width of $135 \mathrm{~km}$ at the widest point and $15 \mathrm{~km}$ at the narrowest point.

${ }^{23}$ The West Bank has an area of about 5,600 sq km and about 2.6 million inhabitants (incl. East Jerusalem and Jewish settlements), so that it is even more densely populated than Israel. However, estimates of the population differ considerably (see also ch. 7 in this volume).

${ }^{24}$ Israel is divided into six administrative districts: North, Haifa, Tel Aviv, Centre, Jerusalem and South, plus the Jewish settlements in the West Bank, which are officially referred to as Judea and Samaria and are under Israeli military administration.

${ }^{25}$ These can be found on the website of the Israeli Central Bureau of Statistics at http://www1.cbs.gov. il/reader/?MIval=cw_usr_view_Folder\&ID=141, 08.06.2015.

${ }^{26}$ For purposes of clarity, the Bedouins and the Druze are not counted here as Palestinians. This does not mean that we define individuals as belonging to one (and only one) group; in our research we always employ the terms used by our informants to refer to themselves (see for instance ch. 11).
} 
on Mount Carmel, in Galilee, ${ }^{27}$ and on the Golan Heights, the Bedouins mainly in the Negev desert, and also in Galilee. Besides the Baha'i, the category 'Others' includes other small religious communities, European Christians, and people who are religiously unaffiliated (mostly spouses of Jewish immigrants from the countries of the former Soviet Union). Nearly 90 percent of the Palestinians in Israel ${ }^{28}$ are Sunni Muslims, and just over 10 percent belong to different Christian communities, such as the Melkite Greek Catholic Church, the Roman Catholic Church, the Greek Orthodox Church, the Armenian Apostolic Church or the Evangelical Lutheran Church. The so-called Melkites form the biggest group.

The Jewish population is divided according to region of origin into immigrants from Europe and North America (Ashkenazim), immigrants from North Africa and the Middle East (Mizrahim) and immigrants whose ancestors came from the Iberian Peninsula (Sephardim). The Palestinian population in Israel lives mainly in the Northern District (Galilee), where they constitute the majority. In this district is the biggest 'Palestinian city' in Israel, Nazareth ${ }^{29}$ with over 65,000 inhabitants. Just under 15 percent of the Arab population (Palestinians and Druze) live in Haifa District, about 10 percent live in the Central District and also about 10 percent (mainly Bedouins) in the Southern District. Altogether, there are more than 120 towns or villages in Israel with an 'Arab' majority. ${ }^{30}$ Only seven of these were created after the founding of the State of Israel in 1948, as projects of the Israeli government for 'sedentarizing' the Bedouins in the Negev desert. One of them, Rahat, is today one of the biggest Arab settlements in Israel, with over 40,000 inhabitants.

It is evident that the great majority of people in Israel live in ethnically separated settlements. Exceptions here are the big urban conglomerates of Tel Aviv-Jaffa and Haifa (and Jerusalem) and some smaller towns in the Central District (in particular Lod and Ramla). However, even here there are usually separate 'Jewish' and 'Palestinian' neighbourhoods (see note 31). Thus, in Haifa the Palestinians mainly live 'downtown' in the area called Wadi Nisnas (see chapter 10), and in Tel Aviv-Jaffa in Ajami, ${ }^{31}$ which is a district of Jaffa (see chapter 11). As our research has shown, it is not possible in these cases to speak of 'mixed cities'. ${ }^{32}$ In the course of our research

\footnotetext{
${ }^{27}$ Galilee is the area in the north of Israel. The name Galilee is a short form of the Hebrew galil hagojim ('heathen circle'), which goes back to the expulsion of the Jewish upper classes by the Assyrians (8th century BC) and settlement of the area by non-Jews. This led to a strengthening of the Jewish kingdom with Jerusalem as its centre.

${ }^{28}$ Excluding the Muslim Bedouins and the Druze.

${ }^{29}$ In accordance with the United Nations resolutions, Jerusalem, which has nearly 300,000 Palestinian inhabitants, is not considered here as an 'Israeli city'.

${ }^{30}$ Thus, there are fewer Palestinian 'villages' today as compared to the number that were 'abandoned' and/or destroyed during the first Arab-Jewish war in 1947-49 (see Krämer 2008; Khalidi 1992; Morris 1987).

${ }^{31}$ It must not be forgotten that in the first Arab-Jewish war those Palestinians who had not been expelled (almost 6 percent) were 'moved' from Jaffa to Ajami by the Israeli fighters (see Bolliger 2015).

${ }^{32}$ This also applies to Jerusalem, which cannot be called 'one' city: it is made up of West Jerusalem
} 
we therefore decided to concentrate on small neighbourhoods, such as parts of the district of Hadar in Haifa, and on 'mixed places' there.

Since the founding of the State of Israel in 1948, the population has risen continuously. The current rate of growth is about 1.8 percent, which is higher than in most Western industrial countries. The Jewish-Israeli discourse is dominated by 'worries' concerning the high birth rate among the Arabs, which allegedly means that the Jewish citizens of Israel will lose their quantitative majority position in the medium term. This is not only bound up with the 'fear' that Israel will lose its 'Jewish character', but it is also seen as a threat to the existence of the State of Israel (see for example Independent Media Review Analysis 2001). However, a study published in 2011 (see Faitelson 2011) shows that the Jewish population in Israel rose continuously between 1999 and 2010, and that the percentage of Arab citizens has fallen in relation to it. This is not only due to 'Jewish immigration', but also to opposite trends in the birth rate: while the rate is rising among the Jewish citizens, it is falling among the Arab population. However, these demographic facts have little effect on the discourse, for the political will (and political necessity) obviously require that the threatening scenario (loss of the 'Jewish character' of the state) be maintained: it serves as justification for legal requirements and administrative decisions that distinguish between citizens in terms of their ethnic belonging, always to the disadvantage of the Arab Israeli citizens (see above). The 'argument' of a demographic threat also allows the development of extreme positions. Thus, the suggestion of an 'exchange' of territories and populations between Israel and the West Bank was prominently put forward by Avigdor Lieberman when he was the Israeli Foreign Minister, and he brought it up again during the election campaign in the autumn of $2014^{33}$ (Middle East Monitor 2014). It is not hard to imagine the uncertainty caused by discussions relating to this proposal, at least among the Palestinians who would be immediately affected by Lieberman's plan. Although it is certainly a very controversial position in the Israeli discourse, the mere fact that it is possible for such an opinion to be expressed by an Israeli minister says something about the nature of the 'Jewish-Israeli' discourse on the Palestinian population (see Rouhana/Sultany 2003) - for de facto it is a proposal to expatriate 300,000 Israeli citizens.

Such an official proposal by a member of the Israeli government is tantamount to making the Palestinians 'second-class citizens', to seeing them as the 'enemy inside', as a threat to the State of Israel, and as a potential object of manoeuvres and negotiations in the Middle East conflict. The co-existence of Israel's different population groupings and their mutual ascriptions certainly will not benefit from this discursive position.

and East Jerusalem, quite apart from the various villages and settlements which are part of the urban conglomeration (see chapter 7).

${ }^{33}$ His Yisrael Beitenu party won 5.1 percent of the votes in the 2015 parliamentary elections. 


\title{
10 Palestinian voices from Haifa
}

\author{
Nicole Witte
}

\subsection{Why listen to voices from Haifa?}

In the preceding chapters, multiply challenged - and defended - constructions of belonging have been presented on the basis of our empirical research. We have thematized unequal power balances in figurations, experiences (often traumatic) of suffering and helplessness, which are not easy to fit into coherent biographical overall constructions. Life under occupation, life in economic poverty, life in overcrowded spaces, life under social control, life as a permanent struggle for belonging and differentiation - the life of many Palestinians in the West Bank and in Jerusalem.

Moving into the comparatively 'intact world' that exists (even for Palestinians) in the State of Israel, as we will do in this chapter, requires some rethinking. Perhaps one may even ask: why is this important here? Jaffa is a world-famous cultural and political symbol, not only because of the film 'Ajami' which was nominated for an Oscar $^{1}$, and it is clear that it must be included in a study of this kind. But Haifa why Haifa?

This chapter is an attempt to answer this question. By analysing the stories of two young biographers, it will show how Palestinians in Haifa are involved in different figurations and relations of inequality, and the categorically definable relations and constructions of belonging that are important for them. Some things will not be surprising to the attentive reader, but especially the discourse on Haifa as an 'oasis of peaceful co-existence' (of all population groups) adds a new component to the overall

\footnotetext{
${ }^{1}$ Ajami (Israel, Germany 2009), directed by Scandar Copti and Yaron Shani.
} 
picture of Palestinians in their different figurations. Even if the discursive positions of Jewish-Israelis and Palestinians (in a generalized sense) are certainly very different, 'both sides' are called upon to position themselves in respect of this discourse, both in the way they 'talk about' it and in their everyday actions.

As a result of its historical development, for the 'Jewish side' Haifa is a city in which not 'where you come from' but only 'what you are capable of achieving' counts, how 'well' and how 'hard' you study and work. The degree of freedom and the opportunities for advancement which are ascribed to (a life in) Haifa by many Palestinians are a consequence of this. Studying, working or 'doing things' in general are often interpreted by them as creative or artistic activities. Thus, Haifa is a centre of Palestinian cultural life in Israel.

The city of Haifa will be briefly presented in the following section, in order to contextualize the interdependencies of different figurations in which the biographers are involved.

\section{2 'Haifa works'}

In comparison to other cities in the region, Haifa has almost no history. What this means is clear if one considers the three biggest cities in Israel. Jerusalem can look back on several thousand years of (extraordinarily eventful) history. Jaffa is almost as old, and Tel Aviv, as a former suburb of Jaffa, not only has almost mythical links with Jewish (Zionist) immigration into the region, but is also of architectural importance as a typical 'Bauhaus city' and UNESCO World Heritage site. Haifa has none of these attributes. At least for Jewish Israelis, the city of Haifa is connected almost exclusively with education and work, but this is also the case for many Palestinians because of its historical development as an industrial city. The Technion, a university for STEM disciplines ${ }^{3}$, has a very good international reputation, and Haifa is the centre of Israel's global high-tech industry. Life in the city, and its image, are dominated by big industrial companies, and an important deep-water port with a high volume of freight traffic. In recent years, tourism (especially cruise ship tourism) has constantly increased and is becoming an important economic factor. ${ }^{4}$ However, the cruise ships only dock in Haifa, and the tourists go from here to visit Jerusalem, Tel Aviv, the Sea of Galilee or Nazareth. Despite its outstanding geographical position between Mount Carmel and the Mediterranean, Haifa obviously has less of interest to offer than those places. This low estimation of Haifa's attractivity is

\footnotetext{
2 "Jerusalem prays, Tel Aviv plays, Haifa works." This is a popular saying in Israel used jokingly to characterize the three cities. The order in which they are named depends on the focus of the speaker.

${ }^{3}$ STEM (Science, Technology, Engineering and Mathematics). Besides the Technion with currently around 13,000 students, there is also the University of Haifa (currently around 18,000 students).

${ }^{4}$ The second port for cruise ships is Ashdod south of Tel Aviv.
} 
also to be found in the (Jewish) Israeli discourse, in which Haifa is marked as provincial, or as historically, culturally and politically boring. This can also be said to be the view of most Palestinians, although there is a young and academic grouping which extends the idea of work to include creative artistic activities. But nevertheless: 'Haifa works'.

"It is so quiet." This remark is often made by interviewees in the positive sense of being able to get on with one's life without being disturbed by 'background noises', but the expression may also be used, although more rarely, by young people, in the sense of: 'Nothing ever happens here!' This notion of quietness is connected with an idea that is common all over Israel - and thus also in Haifa itself, especially among the Jewish residents - that Haifa is a good example of successful 'co-existence' between Jews and Palestinians. Our Jewish interviewees often mention this with pride; but on closer analysis, it is clear that they are very often only patting themselves on the back because 'we let them live in our city'. Personal contact is restricted to seeing each other on the street, at university, or at work. One of the biographers presented below puts it this way: "We in Haifa we live in co-existence but that means everybody alone in the same city."

It is easy for the Jews to 'ignore' the Palestinians (who make up about 10 percent of the 270,000 inhabitants) because they live in clearly segregated areas. Originally this was justified by the local topography, but consciously or unconsciously it is still maintained today. The Palestinians live almost exclusively 'downtown' or on the lower southern slopes of Mount Carmel and its hinterland, while the Jews live 'uphill' or in the northern foothills of Mount Carmel. The comment made by a Jewish interviewee that "down there is where Asia begins", may sound disparaging, but it is remarkable for the fact that the 'other' is implicitly mentioned without any concrete prompt. In the great majority of interviews with Jewish residents, the Palestinians are not mentioned voluntarily at all. On being explicitly asked about contacts, the stories they tell nearly always follow the same pattern. Thus, an elderly woman tells me that her grandson has a Palestinian classmate at the Conservatory, whom she once met. The story is told in such a way that I get the impression she was surprised that the boy was capable of speaking at all. But she ended by saying that he "played the piano very well". Another Jewish interviewee told me that he had once had a Palestinian colleague at work, in a manner that was meant to show how tolerant he was to 'put up' with this, and ending with the comment that the colleague had actually been a very good worker. 'Haifa works.'

This importance attached to work sounds like an expression of the 'Protestant Ethic' (to borrow Max Weber's term). This may seem far-fetched in the regional and cultural context of Israel, ${ }^{6}$ but if one considers the history of Haifa, Protestant-

\footnotetext{
${ }^{5}$ In such contexts Haifa is always compared to Tel Aviv, including by Palestinians, even though it would seem more logical for them to compare Haifa with Jaffa; but 'Tel Aviv plays'.

${ }^{6}$ The emphasis on 'work' also applies to socialist Zionism, as shown by the programme of the First Zionist Congress held in Basel in 1897: "Zionism seeks to establish a home for the Jewish people in
} 
ism has played a decisive role in the city's development: the Temple Society from Württemberg founded a colony in Haifa in the late 1860s (the houses built by the Templers are known today as the 'German Colony' and are one of the city's tourist attractions). This settlement - at that time outside the small fishing village of Haifa led to important developments, especially in the areas of infrastructure, agriculture and industrial activities. Thus, on the initiative of the settlers, the first pier was built, the first regular transport services to Acre were established, a first power station was set up to produce electricity, and farming and manufacturing methods were modernized. Subsequently, due in part to the political connections of the Templers, who represented many European countries as vice-consuls in Palestine, the link was deepened between the Ottoman Empire, of which Palestine was a part, and the German Empire. This led to the German Kaiser Wilhelm II visiting Haifa in 1898. For this visit, the port was expanded and, after consulting the Ottoman authorities, Wilhelm proposed that Haifa should be connected to the Hejaz Railway. This was realized in 1905 and the construction of a railway repair workshop in Haifa became the starting point of the city's industrialization, after which Haifa rose to become the most important industrial city in Palestine. The influx of labourers led to a considerable increase in the size of its population. Haifa's growth is thus directly connected with its economic development. Ever since that time, people have moved to Haifa in order to find work there. This led to the development and establishment of the idea that 'a good person is someone who works well', which, as we were able to show, is also found in our interviews.

The focus on education and work is matched by a relatively high degree of secularity. The Haredim ${ }^{7}$ make up about 3 percent of the city's overall population, much lower than the 8 percent or so which is the general average in Israel. On the other hand, well over 60 percent of the population of Haifa describe themselves as secular, which is almost 20 percent more than the average in Israel.

With its focus on education and work and its relative secularity, its 'quietness' and its geographical proximity to the areas in the north of Israel where Palestinians form the majority, the city also attracts young Palestinians seeking opportunities for education and employment. This enables young people who move to Haifa, for instance to attend the university, to 'gently' emancipate themselves from the frequently more conservative structures of their milieu of origin. For many young Palestinians from the north, moving to Haifa is not a political statement, nor a cultural one, but a 'natural' decision in their educational and professional biography. 'Haifa works'.

EretzIsrael [sic!] secured under public law. The Congress contemplates the following means to the attainment of this end: 1 . The promotion by appropriate means of the settlement in Eretz-Israel of Jewish farmers, artisans, and manufacturers [emphasis added by N.W.]" (See http://www.jewishvirtuallibrary.org/jsource/Zionism/First_Cong_\&_Basel_Program.html, 19.07.2016).

7 This is the term used to refer to themselves by those Jews who are often called 'ultra-Orthodox' in 'Western' media. 
In sum we can say that, in respect of the ethno-political conflict, Haifa is one of the 'quietest' cities in Israel inhabited by both Jews and Palestinians. ${ }^{8}$ Nevertheless, experiences of racism are common in Haifa, as shown by the cases presented below (Samira: "I faced a lot of racism at the University of Haifa"; "It is the city I love although it's so fucking racist"; Amber: "I met racism, but it's not what he [her husband; N.W.] met"). The problem seems to be that the 'co-existence' discourse means no one challenges racist ascriptions (why, when everything is supposed to be alright), and that people who experience racism see it as their personal misfortune, rather than as a form of collective suffering. As will be seen at least in the case of Samira, despite her 'understanding' of the situation on a cognitive level, this kind of personal experience increases her 'bad conscience' about the much greater suffering of Palestinians in the PA. This also means that a sense of belonging to a Palestinian collective, of whatever kind, is much more difficult to construct for the Palestinians in Haifa than it is, for instance, for Palestinians in Jaffa (as a political meeting place on the one hand, and a place that is undergoing gentrification processes at the cost of the Palestinian population on the other), or in any other place 'inside '48'.

So what do the lifeworlds of Palestinians in Haifa look like? This can be illustrated by the cases of two young women.

\subsection{Samira: "I try to concentrate on myself but I have essential problems with collective issues"}

Samira - as I will call her - came to Haifa in order to attend the university. She was one of our first interviewees in the context of this project. We made contact with her in the autumn of 2010 through our Palestinian colleague Filip Habib, who was slightly acquainted with her. She was the first person he thought of when I asked him if he could suggest anyone we could interview in Haifa. As a political activist and used to speaking in public, she would appear to be what Rixta Wundrak (2012) calls a 'megaphone' of her grouping. Someone who is a good 'spokesperson'; someone who steps forward and speaks up for herself and for others; who presents the collective history and thus shapes it discursively and gives it 'veracity'. Someone whose biographical experiences are typical of this collective history, whose biographical experiences re-present the collective history.

However, both in the interview with $\mathrm{me}^{9}$ and in the subsequent analysis it is clear that she is not functioning here as a 'megaphone' - as my colleague may have hoped - but is telling her life story. There is a strong suggestion that Samira agreed to be interviewed because of her multiple outsider position, not only as a Palestinian in Israel, but also in relation to the grouping to which she would like to belong

\footnotetext{
${ }^{8}$ One of the most frequently quoted indicators for this is the fact that there were 'only' three bomb attacks in Haifa at the beginning of the 2000s.

9 The interview was conducted in English by me alone, and was spread over three meetings.
} 
(see chapter 2). This outsider position probably results from a lesbian relationship in which she was involved at the time of the interview. I reproduced the taboo practised by Samira because I never once asked her directly about this relationship, although we met three times and the interview lasted a total of seven hours. This is a sign not only of my lack of 'courage' as interviewer, but also of the exclusionary potential, the discriminatory effect in this context of sexual preference for a 'wrong' object. Especially if one considers what other - highly problematic - topics were discussed in detail in the interview. Even if there has been a great improvement in the situation for 'LGBTs' ${ }^{10}$ in Israel in recent decades, the attitude of much of the Palestinian population is still shaped by resentments, which makes talking about it difficult even for a young graduate in a politicized, activist environment. Furthermore, it can plausibly be assumed that Samira is in the middle of her coming-out process, and sees this as a challenge and a threat to what she has always experienced as a trustful relationship with her parents, as will be shown below.

In speaking of a multiple outsider position, I am referring not only to Samira's presumed lesbianism, but also to her artistic activity. Especially in the third interview with her, it becomes clear that she sees herself 'alone' as an artist, in the sense of 'solitary'. She does not mark this as negative, but nevertheless she is isolated; for at least in Haifa there is no grouping to which she could establish belonging in this context. She speaks of other (Arab, but also European) artists as being in the same artistic tradition as herself, and thus places herself in an abstract context, which underlines her wish for location. (For reasons of anonymity it is not possible to give more specific details here of her artistic style, or quotations in connection with her artistic activities.) In the light of these readings, the meaning and urgency of the quotation used in the section heading becomes more understandable: "I try to concentrate on myself but I have essential problems with collective issues."

Samira was born as the eldest daughter of her parents in the mid 1980s (making her about 25 at the time of the interview), in a village close to Haifa inhabited almost exclusively by Muslims. My research on this village shows that during the $\rightarrow$ Nakba in 1948 nobody was driven out and no property was destroyed. Even if one can assume that the village was of little strategic importance for the Jewish side, it seems likely that the local elites cooperated, if not collaborated, with the Jewish fighters. ${ }^{11}$ Before this backdrop, there is nothing surprising about Samira's statement that "there were no political activities in [name of the village] compared to other villages." Whether, and to what extent, her father's family (her mother comes from a different village) was involved in the happenings of 1948, is not known, but, as mentioned above, Samira finds herself today in a dilemma between collective needs and personal wishes.

\footnotetext{
${ }^{10}$ Lesbian, Gay, Bisexual and Transgender.

${ }^{11}$ On the way Palestinians supported or collaborated/cooperated with the Jewish side, see Cohen (2009, 2011a).
} 
Samira says that her family of origin was "socially a little bit separated" within the ("Muslim conservative") village. She attributes this to the politically enlightened and liberal attitude of her parents, especially her mother, which was clearly in opposition to the narrow-minded, conservative atmosphere in the village or neighbourhood. Here there was "no freedom". Her presentation of her parents paints a picture of a politically interested and educated mother who came from an "artistic family", and a patient, loving father "who was accepting things". After Samira, her parents had another daughter, but no other children, so the family was comparatively small. The atmosphere in the home was "warm and caring". It seems that in the village, outside her family and her own home, Samira did not really feel she belonged - the others were 'different'. But she talks about her great attachment to nature, to the land. Even though she doubtless really did experience this in her childhood, by going beyond social relationships and talking about the 'land' in her presentation, she is able to establish a link with the Palestinian collective that is rooted - almost literally - in the land, in the soil, and which is of great importance in giving her a sense of belonging.

"We had a very special childhood, we really knew how to exploit it (4) I can't really easily talk about it, but I remember what I remember from my childhood what is really stucked in my mind in my childhood [...] we had real world to deal with in our child- childhood [...] and I think that was part of my now my attachment to the ground to the soil, we spent very big part of our time in na- nature, you know and I I have really a special relationship with nature and with animals and with insects I can really say it affects my inner world you know, although I'm living now in a city a very quick world a very fast life people, high, buildings, but nature is still like it lives inside of me $[\ldots] "$

In her biographical self-presentation, Samira does not explicitly say that she is a Muslim. She mentions her religious affiliation only to explain that her home village is a "Muslim village" and that the people are rather narrow-minded: "The village is a conservative village, Muslim conservative (2) well not conservative in specific sense [...] but (2) conservative, you can consider it conservative."

This presentation corresponds to a 'Western' stereotype of life in a Muslim village in the 'Orient'. Not many words are needed to conjure up this picture. With it, Samira is able to convey her experience of confinement and restriction, without having to go into details of (perhaps painful) concrete memories which may be unconnected with her religion. At the same time, she does not need to say anything more about life within her own family, which was the exact opposite of the 'Muslim village' in terms of freedom, tolerance and openness. Samira thus succeeds in lauding her own family and denigrating the world of the village she has left, without having to spell this out. But she only succeeds because I accept this in the interview situa- 
tion, which not only shows how powerful the stereotype is, but also helps to establish a relationship between Samira and myself based on sharing 'the same knowledge'.

After leaving school, Samira registered at the university in Haifa. "Everything I'm working in now everything that is interesting to me or everything that I do now in my life, it began it began there in the university even my artistic expressions [...]." Samira does not explain why she decided to go to Haifa, thus making it appear as the 'natural' choice. After about a year there, she became politically active (in an Arab party), working in the sphere of press and public relations. She started her main artistic activity, and earned money by doing odd jobs. She was also active in the performing and visual arts, and became increasingly well known in Haifa's alternative arts scene. At the time of the interview she had completed her degree, and in addition to continuing all these activities she had two jobs in the field of public relations and had become a kind of local 'celebrity' in Haifa. During the interview, I began to wonder how one person could have not only the time, but also the physical and mental capacities, to do all these things. And yet her active life, which may seem to border on hypomania, was in contrast to the calm and concentration she showed during the interview. Her smartphone rang but she didn't answer it, switched it to silent mode, and picked it up again only to look up some English word. Our meetings took place before a bar, and people she knew often passed by. She only called out brief greetings, and sometimes sent people away because she wanted to go on talking to me; the interview seemed to be important to her. Although her time was precious, she agreed to meet me a second, and even a third time, although the interview could have been regarded as finished after the second meeting. Why?

She wanted to tell me something, to talk about something, which, despite the big circle of people she knows, her "human network" as she calls it, she could perhaps only talk about to me, as someone from outside, someone from the West who would leave the city again. And here I come back to the subject of her sexual preference for a 'wrong' object: "I can't have a free relationship with a, living for example living with my gir- my boyfriend of course I can't, now I do I did, I did it in secret, now many people knew, knows know, but my friends, my environment here in Haifa, but of course in [name of her village] it's not, it's not."

Of course it is possible that she simply makes mistakes - after all, she is speaking in a foreign language - but there are several reasons to think this is not the case. First, Samira speaks English well and has a large vocabulary. In the above passage, she hesitates not only in respect of girl- or boyfriend, but also in her use of the present or past tense. She told me about an earlier boyfriend, whom her parents knew about, and who once went with her to her village. But at the time of the interview she was sharing a flat with a woman ("living with my gir-"). In the second interview, Samira describes her 'friendship' with this woman and the woman herself in a few words, with many pauses and yet very powerfully, almost excessively so: "[name of the woman] (3) I share with her everything (2) everything."

The powerfulness of this description comes not from the number of stories about things they have done together, or from praise of the human qualities of Samira's 
flat-mate / girlfriend, but from the omissions, the pauses, the gaps, which lend weight to her words and give the person of this woman a special position. It is a kind of description which is otherwise found only (and only in some ways) in her presentation of her mother, but Samira tells many more 'stories' about her mother. Their close relationship is described in very concrete terms. But Samira's relationship with her flat-mate is remarkably vague. She answers my questions about this woman, or the things that they share, by saying that they can understand each other "without words", for they have the same perspective on, the same understanding of, situations. Without wanting to insist unduly, it does seem as if Samira had an intimate relationship with this woman.

The question remains unanswered; she speaks about her friend, but does not specify their relationship. Yet she could easily have just told me she had a flat-mate. It seems she wants to talk about her relationship with this woman (whatever its nature may be) but that something prevents her from doing so. This ambivalence between 'wanting to speak' and 'not wanting to speak' was not clear to me during the interview; I was only aware of being irritated by something that I did not actively pursue. Unlike in the case of the Muslim village, I did not actively contribute to reproducing the stereotype in this case. I could have given Samira more 'help' to 'overcome' her ambivalence. But it remains 'her' ambivalence.

The last sentence on the recording of the interview with Samira is a question about "where we can continue the interview". It was Yom Kippur and the bar where we met had to close in the afternoon. We had already chatted for several hours; in particular we had talked for a long time about her art, and had wandered far away from the interview itself. But nevertheless, she was keen to continue the interview. She was probably still hoping to find the right moment to speak about an important topic, this important topic - but we didn't manage to find the right moment. The question is why Samira finds it so difficult to speak about being lesbian - beyond her coming-out process - and who she feels she must hide 'it' from. The answer to this seems to be her parents.

Samira describes her relationship with her mother ("my mother, I can talk years about her") as a close friendship. She says she tells her everything, but often connects this with "collective issues". She says her mother is a model for her because despite her poor education she has achieved emancipation and (emotional) independence. Although she has a more distant relationship with her father than with her mother, Samira describes him as someone who does everything he can for his daughters, and who always tries to understand things that are important for his daughters, even things he does not approve of at first. Samira tells the story of how he once heard of one of her intimate relationships with a man, and after a while talked to her about it and had with her what Samira calls a friendly and good talk. It seems that Samira has come up against limits in respect of her (assumed) homosexuality. She is probably afraid of exceeding the patience of her parents, and of damaging her friendship with her mother, in whom she dare not confide. Quite apart from the undoubted public 
or collective challenges bound up with coming out, this seem to be a very serious problem for Samira.

At the same time Samira seems to condemn her own ambivalence, her failure to speak. During the interview she repeatedly compares her own position with that of other people. In doing so, she always speaks from the position of those for whom everything is 'easier', 'not so difficult', who have had more opportunities than others, but who nevertheless do not come off well in the comparison. It seems possible that for Samira her failure to speak about intimate issues is a symbol of her 'failure' concerning 'collective issues'.

Samira is dissatisfied with herself because she thinks she does not take enough advantage of the opportunities open to her. She is not concerned about herself, but always about a collective, whether 'women' or 'the Palestinians'. She conceptualizes these collectives as 'oppressed' or 'suffering', while she is not suffering, or not suffering 'enough'; at the same time she locates herself as someone outside the grouping who has the resources to reduce the collective suffering. She thus voluntarily places herself in an individualized position, seeing herself as someone who could 'lead the way' but does not make sufficient use of this potential.

Here again, she compares her actions with those of her mother. She says that one of her earliest memories is of her mother sitting in front of the television during the $\rightarrow$ First Intifada, "either shouting or crying" in reaction to the news reports. Her mother takes a clear position in political matters and is not afraid to show it - and this, it must be recalled - in an unpolitical village. Her mother has the courage to use the few opportunities she has to express her political position. Samira perceives herself as having many more resources but not making enough use of them.

When Samira talks about her life today, she focuses on her art and her paid work. Her political activities are kept in the background. But she often gives the impression in the interview that she feels obliged to justify being so satisfied with her life. Thus, near the end of our second meeting she talks for a long time about visits to Ramallah, and emphasizes the way the people there suffer under the occupation, from their lack of freedom to travel, etc. She says she had not imagined that life there was so difficult, that she hadn't been able to imagine it, and that now she fears her political activity is not properly tailored to the needs of those she wants to help.

"Us for us as Palestinians in 48 actually yes we do care like, yes we live our lives, we have racism of course ya but we have like and some also faces house demolishing blah blah blah but bu- bu- but the end yes we are still thinking about the last solution the final solution to be but there in the West Bank like people there are getting bored of that, they just want to go to another city in the West Bank without the checkpoints ya that's it."

At the same time, she shows at various points of the interview that she is happy with her life, especially in the context of her art. She livens up when talking about the process of artistic creation. She tells me enthusiastically about her trips to Europe 
and how she once stayed in Germany for several weeks in connection with her political activities. This "international embeddedness", as she calls it, is very important to her. She says she liked it in Germany so much that she could imagine going to live there. But any 'individual' activity, especially if it gives her satisfaction, triggers self-criticism and makes her feel 'guilty' for not doing 'enough':

"I was involved in many things but now I'm trying more to concentrate on myself, but I guess I'm not successful in this, because, here in this country you are attached to your personal and to your collective issues and you can't you can't easily move between them, sometimes your personal issues are really pushing you towards them, they're trying to attract you, sometimes you are (pull) down and you're going to your collective issues, collective problems, and those things that have to do with others not only with you and it's my essential now my essential thought or my essential problem, you can say I make the balance I'm trying to make the balance, but balance is not a very easy thing ah, ah, what else [...] I can't deal with being schizophrenic like this."

Samira's ambivalences are particularly noticeable in connection with the topic of being Palestinian. There is no doubt that this is a very important issue in her life, but it is also clear that it is something that 'can be spoken about' and that it takes up so much space in the interview for this reason. After all, I am conducting the interview because Samira is Palestinian, I am doing research in this field, and she is therefore free to elaborate on her belonging, or the limitations of her belonging, and to thematize the challenges it brings for her. It is a 'safe' subject, and one that can serve to cover up 'unsafe' subjects.

She mentions in particular the 'contradictions' involved in being both Palestinian and Israeli at the same time. She emphasizes that her life would probably have taken a very different course without the existence of a State of Israel - with much less freedom, with much less scope of action, especially for her as a woman. But this idea bothers her because she thinks that without the existence of Israel, the people in Ramallah would also have had a different life, but in their case - or so she assumes a better and easier life. She is in a situation to be able to enjoy all the advantages of being in Israel to benefit her own life, she has advantages and opportunities which she ought to be able to exploit in order to do something for those who have never had these opportunities, to give something back to those who do not enjoy the same degree of freedom (because she does).

Thus, she is in a permanent field of tension between her own individual freedom and personal development, and a distinct feeling that she is enjoying this freedom at the expense of others who are Palestinians like herself, but who were not born on the right side of the border.

Samira gives the impression of being isolated, despite her many political and artistic interests and activities, her involvement in various groups and work teams, and the resulting extensive "human networks" of which she speaks. She is never alone, 
and certainly not lonely, and yet in the whole text of the interview there is no expression of unquestioned or unchallenged belonging. She has left her home village, her mother is more like a friend than a mother, her sister is "totally different", the party is a means to an end rather than a political home, her work is just work that she enjoys and no more than that. Art as 'home', as pointed out above, is not an activity that creates a concrete belonging. Rather, it serves Samira as a legitimate means of retreating into an individuality which exists 'naturally', something that by its very nature cannot and must not be shared with others.

Apart from the concrete groups mentioned above, the collectives to which she feels, or would like to feel, that she belongs - women and the Palestinians - are conceived by her in such a way that she cannot belong to them. The Palestinians are the people who suffer in Gaza and the West Bank. It almost seems as if she hesitates to include herself in the collective, for she does not suffer, or at least not enough.

The same applies to being a woman. She sees women as suffering, oppressed, unfree, everything which she feels she is not, or not enough. She thus excludes herself - perhaps in order to avoid the realization that the collective as she defines it does not exist.

Her own experiences of discrimination and suffering remain 'unspeakable' for her, perhaps because she regards them as innocuous in comparison to the collective suffering of the others. She presents herself as being in the more powerful position in all figurations - and thus hides her own weakness and uncertainty.

In sum we can say that Samira is caught up in a mesh of often very painful ambivalences. She wants to belong and doesn't want to belong. This is bound up with the fact that those collectives which could give her a sense of belonging are conceived by her in a way that means she cannot belong to them. She wants to be able to locate herself clearly, but finds this impossible. And so it is not surprising that she 'feels comfortable' in an urban environment in Haifa ('mixed', young, academic, artistic) in which no one expects her to locate herself or postulate belonging.

\subsection{Amber: "I never hold the Palestinian flag... I felt like being part of this country... an Israeli Arab"}

The second biographer I would like to present is Amber, whom I interviewed in English in 2013. She lives with her black US-American husband in a small flat in Haifa. I found the interview with Amber surprising and irritating in several respects. Amber divides her life story into two parts - before and after a severe experience of discrimination while she was at college. She says that before going to college she believed that all people were 'equal' and didn't notice any difference between Jewish Israelis and herself as a Palestinian, or between Christian and Muslim Palestinians, or thought the differences were unimportant, but that she completely changed her mind after going to college. She describes her experience of discrimination as a political awakening. And yet her sharp criticism is directed not against those who 
mobbed her - Muslim students - but against the Jewish Israelis, for instance when she says: "They want to delete our identity." She cannot blame the Muslim 'culprits', for this would be playing into the hands of the 'Jews' and what she sees as their strategy ("that's what the Jewish try to make this, they make groups"). She also attributes her youthful 'naivety' in respect of this 'knowledge' to the Jewish Israelis, when she says: "they make us feel like everything is good." These remarks are all made in the first six minutes of the interview. It seems as if Amber wants to present herself right from the beginning as politically 'aware', as someone who thinks about things and has a clear position. And it looks as if she is trying to defend herself against assumptions - which I did not make - that she is not such a person.

In this section I will show how this pattern of interpretation and presentation has been formed in biographical terms. An essential point is that for Amber postulating one or several collective belongings are a means of strengthening personal relations in her family and in her circle of friends, or of distancing herself from them. Amber, too, is unable to avoid dealing with 'collective issues', however much she would like to do so.

Like Samira, Amber was born in the mid 1980s, but in Haifa itself, to a Christian Palestinian family; at the time of the interview she is thus just under thirty years old. Her parents come from a village near Nazareth which used to have a Christian majority. They moved to Haifa, probably following a dispute between her father and his brothers over inheritance. It is safe to assume that her father broke off all contact with his family, because her paternal relatives are not mentioned again, in contrast to her maternal uncles and aunts. Not only was her father nearly cut off from his family, but her parents suffered another blow: her mother was pregnant with Amber (the couple's first child) when her parents died in a car crash. So Amber's parents lacked family support on both sides. They were alone. As will be shown, these shocks made the family draw close together, and the parents tried to shield themselves and their children from the 'outside'.

Amber was named after her dead grandmother. She was given her traditional Arabic name. It can be surmised that Amber's birth was regarded as the symbol not of a new beginning, but of the restoration of a happier status quo. Amber was delegated with the task to ensure the 'happiness' of her parents, and this tied her to the family system. She was responsible for upholding the memory of her grandmother, and, as the eldest daughter, she had to found a family.

A few years before the interview, Amber rejected her grandmother's name and replaced it by an international Anglo-American name. For this reason I have chosen to call her Amber. She says that the reason for her change of name was that she didn't like the old name. But there is more to it than this, and it can be assumed that the new name is her way of distancing herself from her family and the obligation delegated to her by her family. She has sent out a clear signal without quarrelling with, or even cutting herself off from, her family. And she has liberated herself symbolically from the narrowness of her family environment in favour of the openness of the ('Western') world. 
Amber presents herself in the interview as future-oriented and optimistic, full of energy and vitality. She says that although she is aware of negative issues - such as racism against her husband and against the Palestinian population - she is happy with her life and full of hope for the future. This presentation also creates a distance between herself and her family, for it is an almost unqualified rejection of their attempts to preserve a past status and their concentration on negative experiences in the past. Amber has thought about the 'negative past' and left it behind her. The following remark, although it refers to 'the Jews', can be read as characteristic of her whole presentation: "First you hate, then you start to understand, now I can see the difference and accept it."

Beyond her relationship with her family, her new name also had the advantage for Amber that she was not immediately recognizable as a Palestinian in the JewishIsraeli environment. She speaks Hebrew almost perfectly, and her physical appearance says nothing about her 'ethnic belonging': "I wanted to be like them, their freedom, their life, not their thoughts [...] I want them to accept me and I need to look like them."

With a mixture of pride and amusement, she says that she can easily pass herself off as a Jewish Israeli, and actually did so when she was young. She worked in a clothes shop where everyone thought at first that she was a 'Jewish Israeli'. She made friends with a girl who worked there and 'outed' herself to her as a Palestinian; they are still friends today. Not being recognizable as a Palestinian helps her to widen her horizon and escape from the narrowness of her family. It is clear that the element of pride in Amber's presentation comes from her experience that 'she can do it' maybe that she can do something her mother cannot, and that her mother cannot understand - and that 'she controls her environment'. Her amusement, on the other hand, seems to be a product of the main image she wants to present in the interview, for she is making fun here of the 'foolishness' of the 'Jews'. This corresponds to her hostile stance against the Jewish Israelis which she wants to explain as the result of her 'political awakening'.

What is meant by the narrowness of Amber's family? In the interview, Amber tells me that she grew up in an 'intact world'. Her parents, especially her mother, wanted to 'protect' her 'from the whole world'. Thus, Amber grew up in a very narrow cosmos consisting of her family and her Christian school. Her world was narrow in a literal sense, for the school was only a few hundred metres away from the house. Amber presents herself as being very naive during her childhood and adolescence; she says that she believed for a long time that all people in Haifa (and Israel) were 'like her' and her family, or at least that the differences seemed to her to be unimportant. The neighbourhood in which her family lives is almost exclusively ${ }^{12}$ inhabited by Palestinians who are relatively prosperous or at least comfortably off. This includes

\footnotetext{
${ }^{12}$ Many international Baha'i volunteers also live in this neighbourhood, because it is directly next to the Baha'i gardens, which are the landmark of Haifa and the second most important sanctuary of this religious community. The central administration or 'seat of government' of the Baha'i community
} 
her family of origin, which was not rich, but both her parents worked and they could easily support themselves and their four children.

Thus, Amber really did grow up in an 'intact world', but the question remains how much effort it cost her parents to hide from her both their personal misfortunes and the political situation in the country. According to Amber, politics meant nothing to her until she was twenty. She says that she did not even know what an Intifada was, let alone that the $\rightarrow$ Second Intifada was in progress. Consequently, she felt like an Israeli; Israel was 'her little world' in Haifa, in which 'everyone was equal'. And because she was living in such a homogeneous, petit-bourgeois, respectable environment, she didn't notice the racism in Israeli society. Haifa, with its comparatively open and secular atmosphere, was surely predestined to create such a 'small intact world' for Amber.

She tells me that when she was about thirteen she wanted to take part in the celebrations on Israel's Independence Day. She wanted to support her country and wave her flag. Her mother wouldn't allow her to go, saying "that is not for us", but, as she says, she couldn't understand this. However, she did not ask again and bowed to her mother's wishes, but without understanding why it was forbidden. The way she presents this story transports the enthusiasm she felt at the time, and even if she is critical of Israel later on in the interview, or refers to this criticism as a jump forward in her development, when telling this story there is no distance to what she experienced. Even today it is the fact that her mother would not allow her to attend the celebrations that annoys her. It can be assumed that at the time Amber only took notice of the restriction imposed on her by her mother, a restriction that had a realistic reason but one that she couldn't understand because she knew far too little about the political situation, or because her mother often used the same argument. This would mean that Amber became acquainted with a pattern of action that instrumentalizes the 'collective' as a means of achieving 'private' goals.

At college (when she was about eighteen), Amber learned to her cost that people are not all 'equal' and that those who are different are often rejected. Her clothes, her hair and the way she interacted with male students met with harsh criticism from female Muslim students ("they talk to me like I was a whore"). It is remarkable - and unusual for our interviews - that she clearly defines the other girls as Muslims and does not see them as part of a homogeneous group of Palestinians, just as she does not 'automatically' ascribe to the whole group the status of 'victims' (see chapters 2 and 3). At the same time, like Samira, she assumes that we share the same stereotype images of Muslims. For example she says that the other students didn't like it when she wore a short skirt and uses this as a metaphor for the situation she was in, without describing exactly what she did, or what the others did. She mentions her short skirt and thinks this is enough to make clear what happened without any need for further details. As in the case of Samira, I play along as interviewer and do not press

is also in Haifa. Voluntary service for the community is a religious duty among the Baha' $\mathrm{i}$, and so Baha'i from all over the world regularly come to stay for several months in Haifa. 
for more information, but in doing so I spoil my own chances of finding out more ("that was because of my clothes [...] I wear a skirt too short").

Amber describes this period of her life and the discrimination she suffered at college as a process of identity formation. Beyond the argument in her presentation (her discovery that all human beings are not equal), for the first time in her life she was mixing with people outside her home context for a long time, she had left her own narrow, but secure, world. Without wishing to relativize the way she suffered from discrimination and mobbing, it must be said that this was probably Amber's first experience of not being liked and accepted 'as she is'. And this in an environment that was explicitly for Palestinians only.

In the interview, she describes this as a 'political awakening', an awakening that gave her a clearer and more realistic view of Israel, the Jewish Israelis and the relationship between Palestinians and Jews. The irritating point here is that 'the Jews' had nothing to do with her college experiences, because there were no Jewish students there. Once again, there is a big discrepancy between the arguments presented and the experiences traceable in the interview text. The presentation from the present-day perspective, the statements that sound as if they are printed or rehearsed, like "they want to delete our identity", where 'they' is a reference to the Jewish Israelis, seem to come 'out of the blue' in the overall context of the interview because there is no reference anywhere to discrimination by Jews.

Without intending to deny the existence or minimize the importance of racism in all areas of Israeli society, it must be said here that when Amber speaks of 'deleting the Palestinian identity' this has no basis in her own experience. I would go even further and claim that being Palestinian is not a central component of her construction of belonging, or, as she would perhaps say herself, her identity. So why does she choose to make such a presentation?

On the one hand, it helps her to deal with the discrimination she suffered from at college. She does not have to think about these painful experiences because they are insignificant in comparison to the 'deletion' of whole collective identities. They opened her eyes to 'what the world is really like' and this was the first step in her personal development. But later on - and this seems to be much more important - she repeatedly heard friends discussing the Palestinian question and felt she was expected to join in. This group of Palestinian friends, some of whom were highly politicized, was formed in the context of her training and employment as a social worker. For Amber they were very important because they filled the emotional vacuum created by the increasing distance between herself and her family of origin. Inside this group, it was necessary for her to locate herself as a Palestinian, and it can be assumed that Amber first heard the arguments she presents in the interview during discussions in the group. It is probably also significant that Amber was suggested to us as a possible interviewee by one of these friends. This friend knew about our project and Amber also knew about it some time before the interview. It is probably not exaggerated to say that Amber was anxious to meet up to her friend's expectations by saying the 'right' things. In this sense she functioned as the 'extension of a megaphone'. 
Amber does not experience and construct herself as belonging to big collectives, but to small circles consisting of family and friends, or to less stable, short-term groups, such as work teams or a group of clients. But this tends to make her 'blind' to structural mechanisms of exclusion and inclusion.

Amber was confronted indirectly with these mechanisms over a long period of time after marrying a black US-American. In the interview she describes his experiences of discrimination vividly and with empathy ("if I meet racism is not what he met"). By contrast, her complaints about the position of the Palestinians in Israeli society seem stiff, like lines she has learned by heart. Her location of herself in the Palestinian collective is purely cognitive. But her marriage and resulting experience of mechanisms of racist discrimination have made it easier for her to grasp the racist action of Jewish Israelis that she presents on an argumentative level. It means that racism as such has now a basis in her experience.

But for Amber this marriage also meant being able to put a greater distance between herself and the obligations delegated to her by her mother. Her father had died of cancer a few years previously, so that her mother was probably even more anxious to bind Amber to herself. Among other things, her mother delegated to her the obligation to marry and thus help the family to grow. Amber tells me that she actually wanted to get to know 'black men', and that before marrying her present husband she had already had a love affair with a black man. She answers my question about her reasons for this by arguing that she 'likes' these men better. Although there is no reason to doubt this, the reasons for her choice of partner are probably more complex than just physical attraction. By manoeuvring herself into a racist motivated outsider position, Amber has again succeeded in creating a distance between herself and her family of origin, especially her mother, although in formal terms she has fulfilled her duty to marry. She has stayed in the narrow family cosmos (living in the same neighbourhood, even in the same building in which she lived as a child with her parents, only no longer in the same flat) and at the same time has extended its boundaries for herself as much as she can. She has preserved the security of close ties, and at the same time assured for herself her own freedom and independence.

Her husband is a practising member of an evangelical church and expects her to attend the services with him. Not surprisingly, she does this, and tells me in the interview that this is very important for her, that the Christian faith gives her security, and that she has rediscovered it. But this presentation of her belonging to a Christian community comes alive only in the parts where she talks about sharing this experience with her husband. Her declaration "I'm a Christian" to mark her collective belonging is strangely lifeless. Everything she says about Christianity again seems as if she is repeating lines she has learnt. We can conclude that she lays such emphasis on this collective belonging because it is important for her husband and for her relationship with him.

Amber's biography - at least since her late adolescence - is characterized by an ambivalent oscillation between the security and stability of her family and a desire to escape from its narrow limits. She is only able to distance herself from her family 
when she can fill the resulting vacuum with other close relationships, as with her friends and her husband. These webs of relationships and interdependencies oblige Amber to formulate her collective belongings. She can do this on a cognitive level, but the way she speaks about them shows that they are not anchored in her experience. She often sees how her husband suffers from discrimination, and she is able to connect these experiences with her belonging to the Palestinian community; this relieves her of the problem of not having experienced suffering herself at the hands of the Jewish Israelis. Her suffering at the side of her husband relieves her of criticism from her Palestinian friends and Western researchers. Being a Palestinian in Israel married to a Christian 'black man' in a way surpasses any other form of discrimination of Palestinians in Israel, and makes her inviolable. Moreover, she no longer needs to feel she belongs to a Palestinian collective, for she and her husband form their own little 'we'.

I also interviewed Amber's husband. He would like to move to western Europe, which in view of his profession is not an unrealistic ambition. But for Amber this would mean a permanent separation from her mother, quite different from the present arrangement in which the distance between them is overcome in many small everyday situations. I am not sure whether she would agree to such a move, for it seems to me that her ties to the family cosmos are still very strong.

\subsection{Conclusions from the cases}

What conclusions can be drawn from these cases? In this section the results of the study will be briefly discussed.

\section{Importance of the mothers}

It is striking how important the mothers are in both biographers' families of origin. This is in contrast to a surprising and irritating lethargy on the part of their fathers (cf. chapter 6 in this volume), who seem to have adopted a tolerant, perhaps even fatalistic, attitude. However, this lethargy is not marked as negative by the biographers, but is interpreted as liberality in respect of their own biographical drafts. For the daughters, the 'reserve' of their fathers makes it indeed possible for them to achieve a greater degree of freedom. This effect is not linear and causal, but systemic and processual, and for the mothers it means not only an extension of their own scope of action, but also a need to take over the function of guiding the family, their own children.

In the two cases presented here, the mothers interpret their (new) role differently, in respect of how they position themselves regarding different (ethno-) political locations and different constructions of collective belonging. Samira sees her mother as a model in her striving for emancipation and for collective and individual spaces of possibilities, while Amber's mother appears to want the exact opposite, she wants to 
preserve a stable status quo. No matter in which direction their delegated obligations point, it seems clear that both mothers try to compensate their own limitations in using the extended possibilities by expecting their daughters to use them in the way they themselves wish. Both mothers overburden their daughters with these delegated obligations, and both daughters are still grappling with them today. This is a problem that is not specific to this region, as shown for instance by Asiye Kaya (2009) or Ebru Tepecik (2010).

\section{Childhood and adolescence: No experience of Palestinian belonging}

Both biographers grew up in environments in which they had no (direct and conscious) experience of the ethno-political conflict between Jewish Israelis and Palestinians. Amber says this explicitly, while Samira implies it through her description of the atmosphere in a Muslim village. Thus, they have no experience of conflicts, and no experience of Jewish Israelis as the Others. ${ }^{13}$ For both women, the Others were those who did not belong to their family (of origin). Samira speaks of the Muslim village community from an outsider perspective as conservative and restrictive; in Amber's case - perhaps because she cannot homogenize her (social) environment so easily, or because Amber's family belongs to the established - the line of separation between her family and the Others is drawn more subtly. Of course belongings can unfold even in the absence of an Other, but this is certainly made easier by the presence of a different category, and indeed it is often this that makes self-location necessary. Without (the challenge of) a 'counterpart', the categories remain strangely empty. Thus, both biographers talk a lot about Palestinians, but always in distinction to the Jews. When asked what is 'Palestinian', what is typical of Palestinians, they both have to think for a long time and they both give the same answer: "hospitality". They add nothing else. Even assuming they could have mentioned two or three more things, but perhaps didn't want to because they would have sounded too negative, this is a friendly but very 'meagre' definition for a term that is used so often. Neither of the two biographers had any explicit experience of being Palestinian (as against being Jewish) during their childhood and adolescence. They therefore tend to think of Palestinians mainly as people who live in the West Bank or in Gaza. Hospitality, on the other hand, is something that is part of their experience. Because they lack other experiences, hospitality becomes, in their eyes, essential to being Palestinian.

\footnotetext{
${ }^{13}$ The only exception is Samira's mention of television news reports during the First Intifada. But Samira's experience is mainly of the emotional reactions of her mother ("shouting or crying"), and not of the ethno-political conflict they were related to.
} 


\section{Early adulthood: Growing importance of Palestinian belonging}

As they grew older, they both went on to higher education, and their experience of Jewish-Israelis as the Other changed in different ways. Amber went to a Palestinian college, but lived at home with her parents. Thus not a lot changed for her. Samira, on the other hand, moved to a 'mixed' neighbourhood in Haifa and went to a university where the majority of students were Jewish Israelis. Here she began her civic involvement, located herself in the political spectrum, but not because she had experienced racist discrimination (in the interview she describes only a few occasions on which she felt discriminated against by Jewish students on racist grounds). Rather, doing something 'for society' means fulfilling the task delegated to her by her mother. This is not to discredit Samira's fight for women's emancipation and against racism by making it sound as if it was random, but is an attempt to reconstruct the processes which led to her construction of herself as a 'Palestinian'. In the political environment of Israel, supporting the 'Palestinian cause', or fighting for women's rights, offered themselves to Samira as a great opportunity. By positioning herself politically on the 'Palestinian side', Samira is forced to construct her own belonging as 'I am a Palestinian'. It seems to me that her real self-ascription is 'I am a politically committed person'; but in Israel's discursive environment this is 'inadequate' as a location, for the common view is that 'whoever is not for us is against us', you have to choose one side or the other. For individuals to make differentiations, gradations or relativizations is extremely difficult, if not impossible. In Samira's case, her self-ascription as a Palestinian is like a coat that matches her other clothes in colour and style; it covers (and 'hides') her differentiated belongings, opens up spaces for her, makes certain activities possible. Thus, Samira's construction of belonging as a Palestinian is related to her experience, even if only in an indirect way.

Amber also wears this coat. She needs to locate herself as a Palestinian in order to strengthen her friendships. But her coat - to stick with the metaphor - does not match her other clothes, either in colour or in style. She is not interested in changing society, but in creating personal relationships, whether friends or family. Her undifferentiated condemnation of Israel and the Jewish Israelis is an essential part of Amber's construction of belonging as a Palestinian which has no basis in her experience. It fits the discourse and is presentable and hardly ever open to question - especially in the company of 'left-wing Westerners'.

\section{Today: What or who is the Palestinian community?}

Both biographers construct themselves as belonging to the Palestinian community, but the question remains: what do they understand by this community? Who belongs to it? What are the criteria?

Amber offers only a pale image of the community in the interview. This is not surprising if we remember that her belonging is constructed as a means to an end (not to be confused with 'deliberately'). Beyond her presentation, this belonging is 
seldom important for her on the level of experiences and practices. For this reason she conceives of the Palestinians mainly as a foil to the Jewish Israelis. But the sentence "they want to delete our identity" sounds strangely hollow, for Amber is unable to define this identity. For her, the two contrasted groupings are perpetrators and victims respectively. The Palestinians are the victims of the Jewish Israelis. She offers only one example of Palestinian suffering: on television she saw pictures of children from Gaza after a bombing. Thus, like Samira, she presents an image of Palestinians outside Israel, and this relieves her of having to define the community more clearly.

Samira faces much more difficult questions. She clearly marks the Palestinians in the West Bank as 'the' Palestinians. But this creates difficulties for her. Because she comes from Israel and still lives there today, it is impossible for her to belong to this community by her own definition. How does she arrive at this definition? For Samira the main criterion for belonging to the Palestinian community is suffering. In comparison to the Palestinians outside Israel, those inside Israel do not suffer (or do not suffer enough), ergo she does not belong to the community. One gains the impression that she does not want to 'water down' or trivialize the pure suffering of the Palestinians.

It seems that she cannot admit her own experiences of discrimination as suffering. On the one hand, this would contradict her (ideal) image of herself as a strong and educated woman, who because of her strength is in a position to relieve the suffering of others. On the other hand, the greater suffering of the 'Others' seems to 'cover up' her own and prevent her from perceiving the discrimination she faces. ${ }^{14}$

Thus she creates a homogenizing ascription of the Palestinians as a 'community of suffering', a community of 'victims'. She fails to see the potentials and resources offered by heterogeneity. This is a further reason why Samira, with all her potentials, 'cannot' belong to the community. Such a view also homogenizes the 'other side', the Jewish Israelis, seeing them as the superior 'perpetrators'. In her political activities, Samira works together with Jewish Israelis, and even regards some of them as friends. In her eyes they do not belong to this Jewish community which she conceptualizes as being one-dimensional. It seems as if a community sui generis has been formed- the community of those who 'do not belong', but who want to change and improve the co-existence of others.

Before this backdrop, Samira's statement that she cannot concentrate on herself because she is preoccupied with 'collective issues' gains a deeper meaning in the sense that the collective does not belong to her, or rather, she does not belong to the collective.

\footnotetext{
${ }^{14}$ Palestinians in Israel suffer discrimination in many ways, including unequal treatment in respect of family reunification, exclusion from the state benefits linked to military service, the difficulty of buying building land, the limitations placed on building land for Palestinian villages, the disadvantages of Palestinian parties when running for elections, etc. (see for example the Or Commission Report (Jewish Virtual Library 2003); Rouhana/Sultany 2003).
} 


\section{Loved and hated Israel - Haifa helps}

It is quite clear in the interviews that both biographers 'like' Israel and love (life in) Haifa. Amber says that she experienced being an 'Israeli Arab' in her childhood and youth. Little has changed for her in this respect today, despite the change of perspective that is explained in her presentation. In the interview with Samira, I ask her directly what she thinks about the country in which she lives. She talks of the opportunities open to her in this country, especially as a Muslim woman - opportunities which she presumes she would not have had in an Arab state, of whatever kind. She speaks of liberality, freedom, education, and 'Western' values.

But at the same time, for Samira, and also for Amber, Israel is the country which is responsible for the suffering of the Palestinians in Gaza (Amber) and in the West Bank (Samira). The suffering of the community which they cannot, yet must, belong to. Surely it can't be right to like such a country, for this implies showing a lack of solidarity with the community. Moreover, there are enough Jewish Israeli voices telling the Arabs they don't belong here, a message that finds expression in all the dispositifs designed to ensure their unequal treatment. Is it possible to feel good in such a country? For the biographers it obviously is.

In my opinion, this is possible in Haifa more than in other Israeli cities because of Haifa's specific secular atmosphere, and because of the argument which is repeatedly heard in the public discourse and in the presentations of those residents of Haifa whom we interviewed: respect can be earned here through education and work. Moreover, there is a neighbourhood in Haifa, the neighbourhood in which Samira lives, that is very mixed in respect of the ethnic and religious affiliation, educational and socio-economic status, age and biographical drafts of the residents. For Samira, living here means that her necessary and yet 'inadequate' belonging to the Palestinian community is not constantly questioned or challenged, despite her ambivalences, for the environment is not 'unambivalent'. On the contrary, it is possible that these very ambivalences are what give her a feeling of homogeneity. Many of her friends live in this neighbourhood, and she can be assured that those with a clear sense of belonging (which involves animosity against others) will not choose to live here permanently. It is even possible that for Samira this neighbourhood (or at least some streets in it) is like the realization of a utopian 'live and let live' (not in a neoliberal sense but in the sense of true solidarity). This is something that she did not experience in the Muslim Palestinian village where she grew up, nor is it something that she can assume in general for Israel. For Samira this neighbourhood is an 'ideal' place to live, because of its ambivalence and fuzziness, or, in more positive terms, because of its 'mixture', its multiple possibilities and opportunities for location, without any obligation to locate oneself at all. The development of such a neighbourhood was probably not only possible in Haifa with its specific conditions, but only in Haifa did such a neighbourhood develop. 


\title{
11 Being Palestinian in Jaffa: How Druze and Bedouin Israeli women talk about we-images and belonging
}

\author{
Rixta Wundrak
}

\subsection{Introduction}

In this chapter on Palestinian voices from Jaffa I will focus on two biographies. I have selected them from a 'collection' of biographical and other data ${ }^{1}$ because they show not only the ideological, political and symbolic significance of being Palestinian, but also its dilemmatic entanglement (Monterescu 2007) in ethnicizations and associated gender-specific and other discriminating practices and homogenizations. The Israeli-Palestinian women whose life stories are discussed here were interviewed by me and my colleague, Mariam Abdul Dayem, ${ }^{2}$ in the period from April to June 2013. They were both around fifty years old at the time of the interviews, in which they present ${ }^{3}$ and position themselves as part of an active Palestinian community in Jaffa. One thing that makes their biographies so interesting is seeing the differ-

\footnotetext{
${ }^{1}$ Besides participant observation and ethnographic interviews, the data collected in Jaffa include 26 biographical narrative interviews. See ch.1 for methodological details.

${ }^{2}$ My warm thanks go to Mariam Abdul Dayem for her professional help, without which these analyses would not have been possible.

${ }^{3}$ In this context the term present should not be misunderstood as a strategic presentation. It is an interactive approach to the interviewee's own history and a (spontaneous) communication of memories in the course of the interview. The presentation thus consists of memories that occur to the person, and how the person interprets and communicates them in the present. Naturally this includes con-
} 
ences and similarities in the way they were socialized as Palestinians when they were growing up. In their self-presentations they both use their linguistic talents, or nonHebrew languages, in order to give their life stories not only a political, but also a poetic flavour. Their biographical self-presentations are reasoned and differentiated, but the experiences they narrate are full of conflicts and tensions.

The biographical accounts of these women are preceded by short introductions that serve to show the background against which the analyses were made. On the one hand this is the common feature of their multiple outsider positioning in the State of Israel, and on the other hand it is the significance of Jaffa (Yafo) as the scene of the narrations - with the historiography, the image and the intrinsic logic ('Eigenlogik', see Löw 2012) of this city, or of this part of Tel Aviv-Yafo. The stories told by the two women will then be examined from two points of view: the way they present themselves in the interview situation, and our reconstruction of their experienced lives. The chapter closes with a discussion of the typology, taking the mentioned aspects into account: their outsider position and lived experience, their overall view of their personal biography and their we-image as Palestinians, their changing belonging in the context of multiply interdependent figurations with Jewish Israelis in the State of Israel, their presentations in the interviews and their life today in the city of Jaffa (with its intrinsic logic).

\section{A common difference}

The two women, who were introduced to me in Jaffa as socio-politically active Palestinian women in the city, have one difference in common: they both spent their childhood segregated and in poverty, in families that belonged to two marginalized groupings, the Druze and the Bedouins. Thus, two constructions of belonging come into play which serve to differentiate (or even throw doubt on) their Palestinian belonging. As Druze and Bedouin they belong to minorities within the Arab population in Israel, so that they are minorities within the minority, or double outsiders in the language of figurational sociology. ${ }^{4}$ Before contacting these women, I knew nothing about this 'belonging', which I put here in quotation marks because it does not correspond (either predominantly or exactly) to their self-definitions. We learned about it through the stories they told us, through their accounts of where and how they grew up. Their original socialization, and their processing (and abandonment) of the belonging into which they were born, were thematized only in their biographical self-presentations. And so we are in the middle of the dilemma faced by

scious intentions; but, as in any communicative setting, these are only a fraction of what is developed performatively by the actors in an interview (see Rosenthal 1995).

${ }^{4}$ As has been pointed out, or rather problematized, in ch. 9, in Israeli statistics "the people are divided into 'Jews', 'Arabs' and 'Others'. About 75 percent of the population are listed as 'Jews', and just over 20 percent as 'Arabs'”(p.156). In the official statistics, the Druze and the Bedouins each make up about 10 percent of Israel's Arab population (see Israel Central Bureau of Statistics 2014). 
researchers of finding a way to describe ethno-political ascriptions and hierarchies methodologically, without ontologizing or reproducing them. ${ }^{5}$ This problem, which is a general problem in 'research on ethnicity' (Müller/Zifonun 2010), is even more virulent in the field of Israel and Palestine, not least because of the ethnocratic nature of the political system (Yiftachel 2006) ${ }^{6}$ and the established-outsider figurations this leads to, in other words the way the distinction between Jewish and nonJewish penetrates all areas of life and action. As explained by Gabriele Rosenthal (chapter 1, p.11), the drawing of borders between categories of belonging is based on the principle of "discursive' separation into majority and minority groupings, with increasing division and fragmentation of the various minorities". The resulting figurations are thematized in the biographies of the two women from the beginning; both their dilemmatic entanglement and their resistance and autonomy, which they live (biographically), as will be shown below, are connected with this homogenization and division. For this reason, their Druze and Bedouin belongings will not be introduced at this point, but will be included in the biographical case reconstructions and our discussion of them. Their significance can be understood only in the context of the established and outsider figurations in the city of Jaffa and in the State of Israel. ${ }^{7}$

\section{Jaffa, an ideological dome}

The two interviewees live today with their families in old ${ }^{8}$ houses in Jaffa and feel that they belong to this city and have close ties to it. Thus, they both belong to the scene that is special to - and characteristic of - Jaffa, which its inhabitants like to call 'an ideological dome'. People with similar attitudes have chosen to live here: 'intellectuals' and 'left-wingers', social workers and volunteers from the US and Europe, people living temporarily in Jaffa, who join peace projects or take part in educational initiatives, theatre workshops or art happenings. These projects are initiated and organized by numerous NGOs, which also typically choose Jaffa as their headquarters (Payes 2005). Thus the city has the reputation of being a kind of oasis for people who are tired of the unending political and religious conflicts and who want to 'do something' about them, whether through art, law, politics or journalism. This image of the city, or rather its intrinsic logic, is to a considerable extent based on a

\footnotetext{
${ }^{5}$ See Bourdieu/Wacquant (1992) and Wacquant (2013: 274): “The constitutive power of symbolic structures".

${ }^{6}$ The political system in Israel, which is referred to by Yiftachel as an ethnocracy, is based essentially on three politico-historical developments (and their interaction): "(a) the formation of a (colonial) settler society; (b) the mobilizing power of ethnonationalism; and (c) the ethnic logic of capital." (Yiftachel 2006: 12)

${ }^{7}$ For a similar hegemonic structure, see the case study by Kaya (2009) of Sunni and Alevi families in Germany and their homogenization as Turkish immigrants in German immigration policies.

${ }^{8}$ Meaning houses that have been preserved in the old city which are very important for the Arab identity of the city.
} 
narrative about the city before 1948, in other words before the founding of the State of Israel and before the $\rightarrow$ Nakba, when most of the Arab population was driven out of the city. The way the Palestinian inhabitants (mostly old men) talk about the 'old days' plays an important role in this narrative. They talk about their grandparents and great-grandparents whose histories are interwoven with the historiography of Jaffa back into the 19th century. The narrative paints the city as a centre of trade, a cosmopolitan centre of the Middle East, which was of international, cultural and economic importance, and which was attractive for entrepreneurs, traders and workers, writers, actors and people of different origins. Thus, it is often presented as a secular counterpart to Jerusalem with its more religious connotation (see chapter 3). In order to preserve this narrative, 'long-time residents' who can 'bear witness' to the history of Jaffa from their own experience or that of their family are held in high esteem (see Wundrak 2012). LeVine refers to the former city as "non-colonial" and "cosmopolitan Levantine modernity" or "third space" (LeVine 2007: 282). No matter whether it is legend or historiography, the we-image of the people who live in Jaffa is shaped by this narrative, as shown by the interviews we conducted and our participant observation: the image of a community that is open-minded and to some extent cosmopolitan, a community to which the women who will be discussed below also feel that they belong.

\section{Image and social reality}

However, the imagined openness and special 'flair' of the city, which is reproduced by all voices in the discourse, hides (at least on the outside) the daily reality of discrimination and ethno-segregation. This imagination of the city, which is exploited for economic and touristic purposes, is a neo-orientalist simulacrum, to borrow the term used by Daniel Monterescu (2009). According to him, its logic is "to create an 'authentic' environment by fictive means" (2009: 405). His sociological studies of developments in Jaffa in recent decades show the interwoven contradictions: how this simulacrum, which has become real because it believes in itself, ${ }^{9}$ is crossed with the social reality of the Palestinian population. The Palestinians suffer from poverty, lack of rights, racist displacement and discrimination mechanisms, and segregation into small units. ${ }^{10}$ His book titles express these contradictions: Mixed Towns, Trapped Communities (Monterescu/Rabinowitz 2007) or Jaffa Shared and Shattered (Monterescu 2015). Multiculturality can very quickly be unmasked as irony; one only needs to look more closely when walking about the streets.

\footnotetext{
${ }^{9}$ Daniel Monterescu is referring here to the term simulacrum as used by Jean Baudrillard (in particular in media theory). Here, the medial image is so dominant that it replaces people's knowledge of 'reality', or rather what the image once referred to, and itself becomes reality (and thus without any reference) (Baudrillard/Glaser 2004).

${ }^{10}$ See ch. 9 for an explanation of the concept of 'mixed places' in our research.
} 
Some of what has been said here about Jaffa can be read in journals and books (or tourist brochures). This chapter is devoted to an examination of how the biographical experiences of the women are interwoven with the historiography of the city, and how their self-presentations fit into the narrative described above. ${ }^{11}$ The study is concerned not only with the more or less familiar factors of religious, national and (ethno-)political belonging, but also with shifts in established-outsider figurations in different biographical phases and in different phases of the collective history. These belongings are also linked to other categories, especially gender, education and other forms of capital (symbolic, social), or fiercely contested ideological and social values such as modernity, emancipation, legal freedom, economic equality or political participation. In accordance with theoretical approaches to biography, these factors will be analysed systemically and in their processuality in the context of generational and family relationships.

\subsection{The story of Doaa Jub}

Doaa Jub ${ }^{12}$ grew up in a Druze village in the mountains of Galilee under strict religious and social control. Today she lives in Jaffa with her family (her husband, who is suffering from a chronic disease, and three children), and works as a child minder. The story of her life from her childhood to the present is long and fascinating, and my interpreter and myself followed it with great interest in the interviews with her, each of which lasted several hours. She presents herself as someone who does not talk a lot. The interview then lasts for five hours and is continued at a second meeting. She attaches importance to speaking in Arabic and not Hebrew ${ }^{13}$ in order to demonstrate that she is (still) a Palestinian. But she says that she has not taught her children to speak Arabic, for which - as Ms. Jub tells us - she is admonished by her daughter, who, as a politically aware person in Israel, "is naturally interested in her Palestinian roots". The interviewee speaks Arabic with the interpreter, who is a native speaker, and shows how important this language is for her by often stopping to search for the right expression.

Doaa Jub frames her story as a love story within the stream of peace movements and political struggles in Israel that began in the 1970s. She speaks about her husband in terms of great respect. He comes from a well-known communist and Jewish family of Silesian (Polish-German) origin, many members of which were killed dur-

\footnotetext{
${ }^{11}$ A triangulation of biographical research, discourse analysis and ethnography (Wundrak 2010) shows how biographical courses can be studied in the urban context or in research in urban sociology, and concludes by proposing the concept of discourse ethnography (WDE) (Wundrak 2013), on the model of Reiner Keller's (2005) use of discourse analysis in the sociology of knowledge.

${ }^{12}$ The name and some biographical data have been changed in the interest of data protection.

${ }^{13}$ During the interview we chatted in English, Hebrew and Arabic. Mariam Abdul Dayem, my interpreter, also speaks all these languages, of which Arabic is her mother tongue.
} 
ing the Holocaust. While I was listening, I mentally saw scenes from Casablanca ${ }^{14}$ and Liza (Ingrid Bergmann) talking about her husband Victor (Paul Henreid), a renowned resistance leader, and her commitment to him. At our meeting Ms. Jub introduces her son, who is due to be drafted into the Israeli army in a few weeks, as someone who is "just like his father", for he is going to refuse to take up arms ${ }^{15}$ and will therefore be sent to prison for an indefinite length of time. Her second son is a wonderful violin player, who transformed our interview into a musical event, and who works as a volunteer at binational (music) meetings in Jaffa, just like her daughter, who works on a voluntary basis at a counselling centre for refugees in Jaffa. Her accounts of her present life are dominated by the deteriorating condition of her husband, and the financial difficulties this has caused. The Israeli social security system provides very little assistance for her husband, who lost his job a few years ago, shortly after his condition was diagnosed. This woman radiates vital energy as she tells her life story. She weeps a lot during the interview, and smiles at the same time. She presents the members of her family as politically active, courageous and strong, and I have to make an effort to prevent myself from saying that I see her as the strong personality. In the notes I wrote afterwards, I recorded this as my lasting impression of her.

Let us go back into Doaa Jub's past and look first at the structure of her experienced life in its social context. As mentioned above, Ms. Jub was born in 1962 in a Druze village. Her father was a dock worker in Haifa. Her 30-year-old mother was a housewife and her father was her mother's second husband. Her mother's first marriage had been to a much older man, who had died not long afterwards. Ms. Jub says very little about her childhood, although she repeatedly comes near to this time in the interview. It seems as if the memory of her childhood is hidden in a mist. She begins to weep, going on for several minutes, thus showing us with her body what she cannot express in words. Later, she begins to cry whenever the talk turns to her childhood. Our analysis suggests that the distress this subject causes her to this day is due to several (linked) factors which are related to conflicts within her family - and her separation from her family - as well as to ethno-political conflicts over inequality and power constellations within the Druze village when she was a child.

Since the social positioning of the Druze in Israel is important for an understanding of this case, this will be briefly discussed in the next section.

\footnotetext{
${ }^{14}$ A 1942 American film directed by Michael Curtiz.

${ }^{15}$ He intends to refuse not only to serve in the West Bank, as many opponents of the occupation do, but any kind of service involving the use of arms.
} 


\section{A short digression into the Druze}

The term Druze refers to the members of a religious community that has its roots in Ismailite Islam, ${ }^{16}$ but which has been greatly influenced by mysticism and Greek philosophy. The Druze spread over the Middle East from Egypt and sought shelter from persecution in mountainous areas of present-day Syria, Lebanon, Israel and Jordan. An important characteristic of this community is the secrecy of its doctrine and its use of the principle of taqiya. This principle means that they are allowed "to hide the true faith in times of crisis or persecution and to behave outwardly as if a different faith were practised" (Lang 2013: 19, transl. from the German). The lack of knowledge about this community has led to the creation of all kinds of myths among scholars. "The Druze literature, which unites parts of the Druze canon with the accounts of historians, reads in parts like a long attempt to explain the accusations and speculations against them" (Randa 2008: 33, transl. from the German). It is not hard to imagine that under these circumstances the Druze underwent very different political and historical developments in the different countries in which they lived. In Israel, Druze villages are mainly found in the north of the country, the Golan Heights (with their own special development in the context of the Israeli occupation), on the border with Jordan, and in the mountainous area around Haifa, Mount Carmel.

The inhabitants of the Druze villages, especially those on Mount Carmel, tried to persuade the $\rightarrow$ British mandatory government that they were a separate minority, and they did not always participate in the Arab uprisings (1929 and 1936). This can also be explained by the fact that the Arab uprisings had a Sunni connotation with which the Druze did not identify themselves. During the process of nation building and the founding of the State of Israel, they were said to have mastered "the adaptive mechanism of being whatever the situation required" (Klein 2001: 93, transl. from the German). This adaptive mechanism was also instrumentalized. They were isolated from their fellow Druze in Syria and Lebanon, which was aggravated by Israeli policy. In 1957 minority status was granted to the Druze community in Israel, and they were henceforth described in their passports as having 'Druze' and not 'Arab nationality' (Firro 1999); later they were permitted to run their own schools and their own courts. Those who refused to take on the new nationality because they regarded themselves as Arabs had to reckon with harassment by the state authorities (Lang 2013: 72; Firro 2001). Doing military service (compulsory since 1956) is a specific feature that distinguishes the Druze from the Muslims and Christians (and which has caused divisions among them). However, their increasing segregation from the Arab population has not led to equality with the Jews, but has reinforced their special status as multiple outsiders (see Elias / Scotson 2008). Because of this special status,

\footnotetext{
${ }^{16}$ The Ismailite community had separated from mainstream Shia Islam by the 9th century. The Fatimids (10-12th centuries) were an Ismailite dynasty that formed the historical root of the Druze (see Lang 2013).
} 
the Druze are not Arabs and certainly not Muslims (Lang 2013: 79). However, their culture and language is Arabic. And to this day the status of the Druze is not very different from that of the Christians and Muslims in respect of the way they are treated by Israeli institutions (ibid.: 112).

At the end of the 1960s, these developments led to divisions within the Druze community. Some cultivated their special status based on traditional religious leadership and loyality to the State of Israel. Others declared their solidarity with the Arab population out of frustration over their discrimination. The latter group split again into those who regarded themselves as being on the side of the Arab pro-Palestinian population in their struggle against the Israelis, and those who were intent on fighting for their minority rights as Arab Israelis.

Today, the Druze are recorded in the statistics as a sub-group of the Arab minority in Israel. They are represented in several parties and are not clearly classifiable. Traditionally many Druze were close to the trade unions and workers' parties, especially those living in the villages around Haifa. A Druze, Abba Hushi, was first the secretary of the Zionist trade union in Haifa, and later (1951-1969) he became the mayor of Haifa. He helped many Druze to find employment in the port, where Ms. Jub's father worked. At the same time, the political voice of the Arabs in Israel, represented by the Communist Party, became increasingly loud.

Druze belonging is connected to a life reality which has grown out of their history of persecution and their segregated way of life. "Druze settlements in isolated areas have forged a rural, conservative and close-knit community that preserves its esoteric religion and cultural values meticulously" (Abu-Rabia-Queder/ Weiner-Levy 2008: 668). This isolation and preservation of traditional patterns can be seen for instance in their rigid marriage practice, which frowns on marriage with non-Druze (Layish 1982), and patriarchal structures despite programmatic equality (Azzam 2007). The Druze have always had to find a way of reconciling state-regulated constructions of belonging and solidarity on the one hand, and their own distinct religious and traditional norms on the other. They faced this challenge in different ways in different historical periods. These dilemmatic situations could take the form of offers of solidarity or usurpative prescriptions (from outside and from inside). They could split villages and families, which had to decide which side to take.

Several things here are relevant to the reconstruction of Ms. Jub's biography: the multiple differentiations that contribute to making the Druze community an outsider grouping (see Elias/Scotson 2008), multiple fragmentation within the community, the impossibility of classifying the Druze, the invisibility of their otherness, and their dilemmatic intermediate position in the discursive and political binarism of Jewish-Israeli versus Arab-Palestinian. We can take it that these entanglements also caused splits within the family of Ms. Jub. 


\section{Biographical turning point and we-images}

Doaa was still very young when she became interested in the Communist Party in Haifa, the Rakah. ${ }^{17}$ She was sixteen when she left her village and "ran away" ${ }^{18}$ to Haifa. She associates this event with the parliamentary elections in Israel in 1977 and thus reveals a structural element of her presentation: she narrates her life story by referring to corresponding political events. ${ }^{19}$ In these elections, Menachem Begin and the Likud bloc, a conservative alliance, defeated the Labour Party which had governed for many years, and Begin became prime minister. But this was also the year in which the left-wing coalition Hadash ${ }^{20}$ was formed in preparation for the elections. For the Communist Party in Israel this was a turbulent time characterized by fusions and splits, chiefly concerning Zionist issues, the attitude of the Soviet Union and the split between Jewish and non-Jewish or Arab members. Ms. Jub presents her interest in the Communist Party as an essential part of her personal phase of identity formation at this time, and opposes it to the Druze tradition and doctrine. She explains to us: "My teacher at the khalwa couldn't answer the questions I had, the party had answers." As a girl, Doaa went to the khalwa, the Druze prayer house, ${ }^{21}$ and in the interview she tells us how it disappointed her. In the town where she went to school, and where she probably lived with friends or had no fixed address, she felt happier than she did at home. This was chiefly because of the Party, where she met like-minded people, she says. She became politically active at a very early age with great enthusiasm, and completely identified herself with the Communist Party. The communist ideas she heard about from a teacher in her village exercised a great fascination on Doaa:

\footnotetext{
${ }_{17}$ The Rakah grew out of the Communist party Ha-miflaga ha-komunistit ha-jisraelit, or Maki for short, which was founded in 1921 and was the only programmatically binational party in Israel (see Paukstat 2015). Its characteristic feature was the reconciliation of opposites, with many fusions (including cooperation between Jewish immigrants and the Arab population) but also splits, which began long before 1977. The first clear breaks happened in 1952, when the USSR changed its position on Israel and turned instead to the Arab states (see Seliger 1976: 251). In 1965 there was an important split, which was, however, a matter of mutual agreement: the Maki remained the party with a Jewish majority among its members, and the Rakah, to which Ms. Jub felt closer, was supported chiefly by Arabs.

${ }^{18}$ Expressions taken from the interviews have been translated and placed in inverted commas to mark them as quotations.

${ }^{19}$ Running away from the village is presented by her in the interview as a turning point in her life and thus forms a biographical interpretation point (Fischer 1978).

${ }^{20}$ The main party in this coalition was the Palestinian-Arab 'New Communist List'. Hadash stands for 'Democratic Front for Peace and Equality'. Besides pleading for the "realization of communism, it offered a broad political platform. Its demands ranged from a stable Israeli-Arab peace to recognition of workers' rights and equal rights for women to defending the interests of the poor" (Krakau 2005: 67, transl. from the German).

${ }^{21}$ The khalwa is a Druze prayer house, usually outside the village, where assemblies are held on Thursday night for prayer and counselling (Klein 2001: 47).
} 
"I read and I like the ideas, the equality and so, and then I get introduced to people from the communist party, their number was very small in our village and on the personal level they were so progressive in their thoughts and attitude towards their women daughters and sisters, their approach was different from the general approach in the village, I like these things very much and I was tempted to them."

It was not only the ideas and the writings that fascinated Doaa, such as those by Mahmud Darwish or Samih al-Qasim. As she says here, it was also the idea of gender equality, which was so different from the Druze rules of behaviour:22 "From early age I was so disturbed by how women are treated in our society I mean the Druze I was so revolutionary toward the society and from early age almost 16 years old I was outside the society in several areas (1) this thing led then to the communist party."

Ms. Jub says that it was also the courage of those who took up a position of resistance in the Druze village and the clarity of the values expressed. These splits (and instances of cooperation between Zionists and Druze on the one hand, and Druze and Muslims on the other) created rivalries between and within Druze families (Parsons 2008). Ms. Jub describes the break in her own family before the backdrop of this political oscillation of different groupings.

She explains that in Druze villages a teacher who has communist ideas risks being publicly denounced and removed from his post. This was done by subtle means. She quotes the example of a teacher in a neighbouring village who was denounced by "spies" and accused of child abuse. ${ }^{23}$ Doaa herself, and especially her parents, were placed under observation from the time she began to have contact with the Communist Party. Her parents were warned that something could happen to their daughter, and agents came to their house and spent hours questioning her parents. Due to these experiences, Ms. Jub learned very young what it was like to be an outsider and she perceived herself as an enemy of the state. She says, "I, as a child, was a danger to society, and I asked myself, what kind of world is this?"

"I remember that they came to our house, they said that they want to talk to us, as they threatened me if I didn't stop my relation with the communist party, they will spread rumours about me directly this what they told me (1) I remember I was very surprised that this thing existed and they could do such a thing to people (1) I told you I was very revolutionary, I told them you can

\footnotetext{
22 The Druze secret community was originally committed to gender equality. But because of their history of persecution and discrimination, their everyday practice continued to be patriarchal and incrusted, with a rigid set of (protective) regulations.

${ }^{23}$ It should be pointed out here that Druze villages (as against Bedouin villages) have an independent primary school system, while their secondary schools (mainly in the north of Israel) are combined with the Arab villages (see Abu-Rabia-Queder/ Weiner-Levy 2008: 668).
} 
do whatever you want I will not stop anything ((laughing)) you can do whatever you want (1) I didn't imagine that these things will affect my life, after they came to us they invited me for investigation to the offices in Haifa, there was an investigator who spoke Arabic and he talked to me, he told me Syrian sayings of how to take care of my tongue, not to talk and I don't know what, it was a threat but it wasn't worth because there wasn't anything [...] I was like 17 years old girl I didn't think to do something to threat the security of the state, I would not even have thought about these things ((laughing)) since then I became more active, I started to participate in every demonstration and in the activities, even this reason caused me to recognize that the Druze is part of the Palestinian nation."

It is not possible within the limits of our case reconstruction to find out exactly who visited Doaa's parents, but it is clear that the appearance in the family of religious leaders and Israeli institutions was a threatening event that had a decisive influence on Doaa's subsequent biography. The interview passage shows an entanglement of belongings in the context of her family of origin, social exclusion and political identity. Doaa did not complete her schooling, but began to work for the Arab-language newspaper of the Communist Party, Al-Ittihad (The Union). As a result, Doaa had to cut herself off from her family, could not return to her village, and was no longer accepted by her parents. The price of her adherence to a political party was the loss of her family and her childhood home.

\section{Belonging and love}

During her unusual work for the Party, Doaa met Mr. Jub, an Ashkenazi Jew whose family immigrated to Israel in 1965 . He was ten years older than her and also a committed activist.

"We were working in a building workshop in that period he was working out in khader kosher ((gym in Hebrew)) and he had muscles ((laughs)), he lifted a very big rock he was mashvits ((showing off in Hebrew)) in that period because of his muscles he was lifting things that he couldn't really lift but he was making effort that I can see it ((laughs)) so this is the situation that I remember ((laughs)) (1) we met several times, there was after a festival of communism culture also demonstrations things like that and activities in party's framework we met a lot of times (2) and next year I think we met again in the voluntary camp and since that day we became a couple." ${ }^{24}$

\footnotetext{
${ }^{24}$ In this memory framed with masculinity, Ms. Jub underlines her husband's muscular strength and constitutes it as part of the founding myth of her love story. It gains a special significance in the light of her present desperate situation: her husband is suffering from a serious neurological disease of which the symptoms are slow movements, tremor and rigid muscles.
} 
Ms. Jub's eyes shine as she tells us a love story that is a story of overcoming barriers and of common devotion to a political cause. They both continued to be politically active, and in the second half of the 1980s they attended a six-month training course in a special camp in the Soviet Union. This was an important time for Ms. Jub, as she says in the interview, full of hope for a better world and inspiring experiences of the common struggle for ideas and political goals. She and Mr. Jub had planned to marry in the Soviet Union. But, as Ms. Jub tells us, the Party opposed their marriage. It became a political issue within the Party, especially between the Druze and the Jewish members. The pressure came from the Druze comrades, who in turn were under pressure from the Druze religious community (or so Ms. Jub presumes).

The young couple were thus disappointed in their Party. They were unable to formally seal their relationship, which was not only a personal relationship but also a political one. A chasm opened up between the political ideals expressed in the party programme on the one hand and the political realities in everyday life on the other, a chasm which runs through their biographies. For two years they had kept their relationship secret. Neither their closest relatives nor their comrades in the Party knew about it. Ms. Jub continued her romantic love story and risked another step. When it was time to return to Israel from the Soviet Union, they set off with the group, but instead of completing the journey with the others, they made their way to Cyprus, where they secretly married. From there they travelled to Australia, where Mr. Jub's sister lived. In the following months they tried to get residence permits, but without success. So they had to return to Israel and lived there from then on, staying at first in Beer Sheva, the city in the Negev desert, with Mr. Jub's (communist) parents, and refraining from political activity.

For both Ms. Jub and her husband their position as outsiders, resulting from the political beliefs they hold while belonging to the Jewish 'establishment' (see Elias / Scotson 2008), is the binding element in their life and their marriage. These political convictions, as expressed in the programmes and activities of the Communist Party, are the binding element, the criterion defining their belonging and their we-image, as presented by Ms. Jub in her self-presentation. The self-presentation of her political views enables her to engage with, and overcome, ethno-religious inequalities, not only in respect of her own position, but in society in general. Like her, her husband also belongs to a grouping that is caught between two stools (as a Jew but an opponent of the Israeli regime).

They are bound together not only by their political convictions and their overcoming of differences, but also by their experience of persecution or knowing their life is in danger because of their political ideas. Mr. Jub was born in Breslau shortly before the Nazis seized power. Most of his family (maternal and paternal great-aunts, great-uncles and their children) were killed. ${ }^{25} \mathrm{He}$ fled to the Soviet Union with his

\footnotetext{
${ }^{25} \mathrm{Mr}$. Jub comes from the Silesian city of Breslau (then German, today the Polish city of Wrocław), which was dominated by the Nazis following the General Election in 1933, and soon gained administrative importance (as Parteigau). One of the first Nazi concentration camps, Breslau-Dürrgoy, was
} 
communist grandfather. When he was twelve his family emigrated with him to Israel, but he later returned to the Soviet Union for a few years to do a degree in physics. Ms. Jub met him during what were his first political activities in Israel. He was known within the Party because he took part in a conference abroad which was also attended by Yasser Arafat. "He met Arafat he was known his picture was published in the newspapers with Arafat and so (1) it was expected that he will be put in prison at the airport but nothing happened." However, he was put in prison several times, for example for refusing to serve in Lebanon (at the time of the 1982 Lebanon War) and in the occupied areas. Mr. Jub was not alone in his refusal, but as a communist who had met Arafat he was a public figure. What effect their marriage had on their work for the Party is an open question. But it is clear that it was detrimental to the career of Mr. Jub. He could not work in the field he was qualified for (he had studied physics in the Soviet Union) because no organization would have accepted him due to his political views; jobs for physicists, as she explains, were mainly in the area of security. Ms. Jub continues to narrate. She frames this phase thematically as a life spent constantly moving from place to place, and associates her memories with political events. She uses Rabin's death in 1995 to fix the time when they - by now a small family - moved back to Tel Aviv, where their second son was born. The interesting thing here is how long this phase lasted, as she comments herself during the process of remembering, for there were seven years between their return to Israel and Rabin's death. This corresponds to the gestalt of her self-presentation referred to above, which follows the political historiography. She mentions that she worked as a typist and gave birth to a daughter during the years in Beer Sheva. But the narrative thread is closely connected with the social embedment of Mr. Jub's family, a Jewish, Russian, communist and (in comparison to herself) established family, and with the main political events of these years. In the following years she gave birth to two sons and they moved to Jaffa (at the time of the Second Intifada). After living at several different addresses in Jaffa, they finally moved into their present house, where the interview took place.

Two other important events dominated this period. The first is her reunion with her family. After the death of her father, the family arranged a meeting with the daughter who had 'deserted' them so many years ago. As might be imagined, this part of the story triggers more emotional markers in the interview. No less emotional and distressful for Ms. Jub is the description of her life at the side of a broken man (because of his political struggle) following Yitzhak Rabin's death: first the dependence of her husband on an employer who had accepted him despite his political views and activities, the outbreak of epilepsy and how she perceived and experienced this illness, which was completely new to her at the time, the loss of his job immediately after his release from hospital, and finally the diagnosis of another serious

opened on 28th April 1933. Most of the inmates were political prisoners, especially socialist and communist resistance fighters, members of the SPD, KPD and SAPD (Socialist Workers' Party of Germany) (see Rudorff 2005: 39). 
condition: Parkinson's disease. In order to earn enough to support the family, Ms. Jub cares for thirty children on her own for ten hours on six days in the week. The children are from families to whom 'binational co-existence' is important, who are 'leftists', or who have moved to Jaffa from elsewhere, and who appreciate Ms. Jub's work with the children for this reason.

Accordingly, she is under great stress, which is visible and audible during the interview. Possibly, she sees the interview as a kind of therapy, as she puts it herself, or as an opportunity to talk about herself. She obviously trusts my interpreter, and so decides that she can confide in us.

What does this presentation of her family of origin have to do with biographical constructions of belonging in the context of ethno-political figurations in Israel / Palestine? Ms. Jub has no sense of belonging to the Druze grouping into which she was born, and whose religious representatives were unable to furnish answers to her questions. As a Druze she experienced a very paradoxical form of exclusion. Through her political activism, she began to position herself more clearly as a Palestinian, as she explains in the interview. At the same time she moved into the Jewish-Israeli majority society. Even if she felt she belonged to the active Palestinian communists, it meant at that time that she joined the majority society and abandoned her Druze origin. Thus, her being political neutralized the ethno-religious conflicts within her nuclear family, and she was able to separate herself from it. Being political removed her from her outsider position (as a Druze) and put her in a socially established position (in a Jewish family). She changed her original belonging not only by joining the Communist Party, but also by entering into a relationship with a Jewish Ashkenazi communist. Together with her partner, who later became her husband, she belongs to the established Jewish society and to the outsiders (communists) at the same time.

\subsection{Maha Masarwi's story}

The second biography which will now be presented as a contrast (and in less detail), is that of a woman who also grew up in a village in the north of Israel and who today lives in Jaffa. Maha Masarwi, as I will call her, is also fifty years old, and teaches English at a high school in Jaffa. She was born in a Bedouin village (which will not be named to preserve its anonymity) and has Israeli citizenship. She has four children, two of whom are adopted. In the interview she speaks Arabic and English. She belonged to a Bedouin family and, like Ms. Jub, she left the village and her family as a young girl to go to school in Haifa, and later to go to university. Bedouin belonging, women and education are a thematic complex that reflects her extreme discrimination in society: "Because of this stringent application of cultural prohibition and political-historical constraints, female education in Bedouin society began only in the late 1980s (in 1998 there were 12 female Bedouin students in academia as compared to almost 200 in 2002)" (Abu-Rabia-Queder 2008: 669; see also Pessate-Schubert 2003; Litvak Hirsch/Lazar 2014). As in the case of Ms. Jub, 
also in the case of Ms. Masarwi there is an interpretation point (Fischer 1978) in her youth, which she underlines in her self-presentation. At fifteen, she had her black, curly hair, which reached to her waist, cut to shoulder-length, with the consequence that her mother refused to be seen with her on the street. In addition, she wore an old Bedouin coat of her grandfather's, on which she printed a picture of Michael Jackson, and she went to town to get a piercing. Today Ms. Masarwi lives in the centre of Jaffa and works as a writer and teacher. She is a very active 'networker', as can be seen for instance in the social media. Besides her political activities she writes children's books in Arabic and at the time of the interview she was involved in founding a feminist reading group in Jaffa for Arab women. Her children are also known for their political activism in the city and in Israeli peace networks. She uses the presentation of her life story as an opportunity to practise her English, thus emphasizing her education and her linguistic talents - she plays with the language and shows how she not only masters the language, but is able to exploit it as a writer. Her story is full of anecdotes and metaphors; the tales she tells are graphic and poetical. She paints accurate pictures of the important people in her life: the 'wicked stepmother' who wanted to prevent her from going to university; the daughter who knew how to get her own way even when she was small, and who chose her adoptive mother, rather than the other way round; the son who transformed himself from a devout Muslim into a Marxist. She reduces her accounts of experiences and events to their essentials, and usually ends with a punch line that causes a smile or an expression of astonishment.

Ms. Masarwi also talks about her life very openly and emotionally in the interview, and lets her story telling and recollection stream freely. She begins to weep early on, while telling the story of her marriage in the Bedouin village at the age of nineteen, and how her husband was arrested soon afterwards; she was pregnant and she moved to Jaffa with the two children (from her husband's first marriage). For her, Jaffa was a place that offered opportunities, where she could continue her education and further distance herself from her family of origin.

The move to Jaffa was not the easiest way, but it was the most emancipated way. This path of emancipation began in her childhood and youth. She did not get on with her mother, who divorced her husband (when Maha was thirteen), which in the village was tantamount to complete social exclusion, but also meant abandoning the norms and escaping the control of her social environment. Later on, despite resistance, Maha undertook an hour's journey every day to go to school in Haifa, and completed her final exams with very good results. This makes it all the more surprising that she married early at nineteen (in the interview she gets emotional again at this point), but - as she says herself - it was a means of getting away from her family and of punishing her mother, who never agreed to the marriage. Her youth was thus shaped by a dilemmatic entanglement in processes of belonging and separation in respect of her ethno-religious, gender-specific and education- or milieu-specific belongings. Later, after her marriage, she was advised (urged) by a psychologist to leave her husband as soon as possible, but (partly as a way of resisting the life of her par- 
ents) she decided not to leave him and "emancipated herself", as she calls it, and as she illustrates in her subsequent narrations. Thus, she describes how she registered at the university in Tel Aviv carrying her baby in her arms (without telling her husband or her mother-in-law), and how she only slept for three hours each day. She says she can't understand to this day where she got the strength from, but she can remember that she woke up every day filled with new strength. After she had finished her bachelor's degree, her professor told her - on hearing her story - that she deserved a monument. Ms. Masarwi, in contrast to Ms. Jub, talks a lot about the conflicts within her family, the way her father beat his wife and his children, the daily suffering of her mother under the domination of her father, and finally her mother's courageous and fateful decision to leave him. Ms. Masarwi not only tells stories about the time when she had her hair cut off, in other words the time when she began to revolt, but also about the time before, when she ran away from her father and got lost in the forest, or how she would hear her mother whimpering at night in the bedroom.

\section{Anecdotes of belonging and discourses of exclusion}

Maha Masarwi uses anecdotes as a narrative form, as in as the following case: One day she invited her only friend to come and stay at her home in the village. In the morning this friend needed to use the toilet and asked where it was. Maha indicated where it was by spreading out her arms. At first her friend did not understand, so she had to explain that she could just go anywhere in the fields outside the house. But this example, in which Ms. Masarwi describes the conditions in which she lived, must be treated with care, because she packs experiences in anecdotes which, as pointed out above, are always intended to cause a smile at the end. In other words, we can also speak of discursive idealization in the story.

In her self-presentation, she contrasts her life as a Bedouin with her life today. In her retrospect, she presents the two worlds not in ethnic, religious or political terms, but as different lifestyles: a traditional, simple world and a modern, emancipated world in which she feels free. Thematically, she connects this latter world, the world in which she lives today, and what she has become, with the we-image of an Arab Israeli. Jaffa is the symbolical place where this attitude can be lived. "I am a Bedouin you can say in my roots about 2526 years living in town I couldn't say I am a Bedouin now because-because Bedouins not just, it is kind of a tradition the way of life, I live in the city but my roots are Bedouin, this is not a lifestory of a Bedouin."

Any scholarly attempt to describe the Bedouin as a grouping faces the same basic problem as in the case of the Druze, namely the discrepancy between their historical specificity and social ignorance in current discourses, combined with their extreme political, social and economic marginalization. ${ }^{26}$ In dictionaries, the word Bedouin

\footnotetext{
26 There is a big difference between official and estimated figures in respect of the numbers of Bedouin living in Israel. It has already been pointed out that the official statistics distinguish only 'Jewish' and 'Arab'. In the annual statistical data for 2014 (Israel Central Bureau of Statistics 2014), the figure
} 
is defined as a traditional name for nomads in the Arab peninsula and bordering areas in Sinai, Iran and Palestine. From a historical persepective, typical features of the Bedouin are said to be their tribal structure, their linguistic and ethnic characterization as Arabs, and frequent armed conflicts in the past. They are also said to see themselves as being distinct from the sedentary population, and as being an elite with an aristocratic ethos (see Werner 2001). The reality they face today is characterized by structural factors such as extreme poverty, exclusion from education, and ethnicizing, stereotypical discrimination in all social spheres (Abu-Rabia-Queder 2008). They are a marginalized grouping with a high rate of illiteracy and unemployment, together with a high child mortality rate and a high rate of disease, especially among children. Their ownership of land is often not legally recognized, because they refuse to be registered or cannot pay taxes; in many areas they are denied electricity supply or other amenities. Their discrimination finds its most visible and most draconian expression in the pulling down of their houses (Amara/ Yiftachel 2014). Marginalization and poverty are the dominant features of their they-image and of their current reality. The largest number of Bedouins in Israel live in the Negev, but there are also Bedouin villages in the north of the country, which is where Maha Masarwi was born.

During our first meeting, Ms. Masarwi's biographical self-presentation is thematically framed by her childhood and youth in her family of origin, but in the second meeting she devotes more time to her present family life. She talks about emancipation in her marriage, as she says at the beginning of the interview, instead of getting a divorce, which is what her psychologist had advised her to do. This narration of an emancipatory marriage is illustrated by an account of her present activities in Jaffa, such as the feminist reading club for Arab women which she initiated. The second topic she devotes much time to is her children, especially one son. On the one hand this is because she is currently - at the time of the interview - worried about him and the life he is leading. On the other hand, it is a topic that fits into the presentation pattern of a changing and emancipating family history, which is a colourful story of transforming belongings and biographical changes. At the time of the interview, her son is 24 years old. As a schoolboy he was very religious like his father, and even surpassed his father. He went to Mecca (Ms. Masarwi relates this with an amused smile), wore a long beard and prayed several times a day. But then - as Ms. Masarwi tells in another anecdote - he fell in love with a girl and abandoned religion completely; he changed his ideas because he "saw the limits". After this he went to the "other extreme". Today he is politically active, often takes part in demonstrations,

220,220 is given for Arabs living in the district of Negev. This gives a good idea because the majority of Arabs living there are Bedouins. The Arab-Jewish Center for Equality, Empowerment and Cooperation (AJEEC-NISPED) also assumes that there are at least 200,000 Arab Bedouin in the Negev, see http://en.ajeec-nisped.org.il/the-facts/unrecognized-villages-in-brief, 08.06.2015. The Association for Civil Rights in Israel (ACRI) estimates the number of Bedouin living in the Negev at 160,000 (http://www.acri.org.il/en/category/arab-citizens-of-israel/negev-bedouins-and-unrecognized-villages, 08.06.2015). 
and works in a bar which is well known in Jaffa as a place for artistic and politicized events. He keeps in regular contact with his mother, and often comes to see her or sends her text messages. She says that people talk about him and ask whether he has gone out of his mind, saying that he takes drugs, which she thinks is probably harmless, but nevertheless she is worried about him. Listening to her talking about her son, I get the impression that Ms. Masarwi is proud of him. In the context of the thematic field of the interview, this part should be understood in the overall context as striving for emancipation from traditional and authoritarian patterns. It is a line that is continued by her son, and fits into the city's intrinsic logic. Being Palestinian is linked to a gender-related, family-related and generation-related striving for emancipation. The we-image is bound up with a delegated obligation to maintain or restore the image of an open, cosmopolitan community - on the model of the non-colonial past described by LeVine (2007). However, she does not tell her life story as a Palestinian, but as an Arab woman who lives in Israel, in other words an 'Arab Israeli', as she would be called in the official discourse in Israel. The Palestinian we-image is present, but on the whole only when she is talking about political issues, and in her self-presentation in the social media. Ms. Masarwi and her son stand for this we-image in two ways: on the one hand through their biographies, and on the other hand through their commitment and their presence at the different events and political or cultural meeting places in this scene, the ideological dome of Jaffa.

\subsection{Summary}

The analysis of these two biographies shows how the self-presentations of the two women are related to the we-image in the city and its intrinsic logic, with discourses in Israeli society, and with the theme of the Middle East conflict. They describe how in the course of their lives they have oscillated between belongings, and yet remained bound to their belonging. These women see themselves as Palestinians, but not by birth and incontrovertibly. Rather, they both underline the importance of discourses and social ascriptions for their awareness of their belonging. They illustrate the cracks in the Palestinian we-image we have been able to observe everywhere (see chapter 1), by showing how they have been confronted with them in the course of their lives. They do not try to cover them up, but talk about the tensions and the complexity of the lines of conflict. They show the significance not only of ethno-political (ethnic), national (civil) or religious belongings, but also of belongings relating to other inequalities, their discursive stigmatizations and dispositive effects, along rural or urban societies, divisions referring to educational capital, or hierarchies of gender relations.

The type represented in the we-image of their biographical self-presentations is thus both homogenizing and diversifying, harmonizing and militant, and the presentation is 'educative' in respect of the different, and sometimes insurmountable, lines of conflict. The women do not deny their origins or describe them in over- 
simplified terms, but tell differentiated stories in which their becoming Palestinian needs no further explanation. These two Israeli women living in Jaffa, one a Druze and the other a Bedouin, show that they self-evidently belong to the grouping of Palestinian Israelis by laying emphasis on the obstacles they have had to overcome. To Jewish Israelis, or to a Western audience, they present a we-image of belonging to a global, educated Arab-Palestinian community.

The characteristic of this type can thus be seen in the differentiation and divergence of the stories told by its representatives, in which they become Palestinians but without regarding it as apodictic. Rather, this belonging has 'grown' out of an individual history and a collective history. In the one case the biographer presents herself as a Palestinian of Druze origin who chose to become a Palestinian in the political sense because of her political socialization. In the other case the biographer presents herself as an Arab Israeli, as a person who shares the Arab culture and who belongs to the Arab minority, who is fighting for her political rights as an Arabic-speaking woman and a Palestinian. In her biographical presentation she does not explain how she defines herself as a Palestinian, because she does not fit herself into the homogenizing we-image, but devotes herself to a differentiated self-description. However, the connotations of her political activity and her political statements are similar to those in the first case.

In contrast to another type of presentation represented by political activists whom I have referred to as megaphones (Wundrak 2012), this form of politicization is 'thrown back' on the interviewee's own entangled and changing biography. In our sample, the megaphone type is usually represented by older male activists who try to present a biography that reveals what is typical of the community, including collective discriminations where possible, or they play the role of speakers and experts whose job is to present a homogenizing account of the truth of the conflict and the discrimination suffered by the Palestinian people to the (female) interviewer and thus to 'the West'. If necessary, especially when there are Jews among the interviewers, the interview setting is used as an arena for knowledge struggles. However, in the case of the two women described in this chapter, the significance of their narrations, biographies and political activism is different. They are not concerned with convincing people from the outside, but on showing their complex struggles in the context of individual, group-specific and social constraints. This understanding could perhaps be paraphrased as follows: 'Politics is part of my life, and an integral part of my identity. Politics is not my field of action, politics is not something I do, but politics plays a role when I tell the story of my life'.

On the level of experienced life, there are similarities in the two life stories. In both cases the family of origin belongs to an outsider grouping that occupies a special position within Israeli society. Both women left their families in order to achieve their very emancipated goals, whether political activism or education, activities which their families did not approve of, or which were incompatible with staying at home. In their youth both women acted in similar ways by breaking out of their family and their disadvantaged situation which was the result of being in a multiple 
outsider position (female, poor, living in a rural and traditional setting, belonging to an excluded grouping). At the same time, they abandoned the values of the previous generation, adopted political ideologies, became politically active, and later passed this on to their children, or have children who are also politically active. They both 'landed' (via different routes) in Jaffa as the city of their choice (see Herzog 2007). They both have children (one three, the other four), and live today with their husbands but are the main breadwinners in the family. As mothers, they both struggle with the problem of encouraging their children's political commitment while worrying about them at the same time. They are both politically committed and very active in Jaffa's social network, and they both contribute to continuing the narrative of Jaffa and maintaining its image as an ideological dome.

As regards their constructions of belonging, they can both be characterized as representatives of a type, which I will call formation of belonging through political activism, that has strong personal, biographical and familial meaning. ${ }^{27}$ It is related not only to their political-ideological activities, but also to their family life and love life and their educational and professional achievements. They succeed in combining the different, overlapping areas of their lives, and in working through the dilemmatic lines of tension and conflict in respect of their belongings and those of their husbands and children. They do not homogenize differences but work towards connecting them. This concerns firstly the connections / ties to their families of origin, a traditional Bedouin family and a Druze family. Secondly, both women marry as part of the process of working through conflicts and differences. In one case (Ms. Jub), the communist ideology provides a common ground and she marries into a Jewish communist family. In the other case, following a process of conflict and divorce in her parents' generation, the woman succeeds in overcoming accepted gender images within her marriage by reversing the classical gender roles of 'breadwinner' and 'homemaker'. Thirdly, conflicts and dialogues are continued with the children, who may change their belongings and ideologies but always live according to them, in most cases actively and rigorously. This work of conflict and dialogue is connected with rural-urban issues, with educational or social capital, and with gender inequalities. $^{28}$

Not least, this type is connected with the intrinsic logic of the city of Jaffa and its historical narrative. Despite these women's ethnicization (and resulting gender

\footnotetext{
${ }^{27}$ This answers the criticism, often faced by biographical research, that we are suggesting the women use their political activism as a form of compensation for something in their childhood. Rather, it is the decisions they made that are important here. As in any biographical case reconstruction, the question is what options were available to them at that particular time and in their particular circumstances, and how they then acted. We are not talking here about decisions in the sense of a rationally acting person who weighs up the arguments for and against each possible choice. We are talking about socially meaningful actions in their interconnection with personal experiences and social structures, or, as in this article, their constructions of belonging.

${ }^{28}$ By finding their own way, they open up paths that are not fixed but pursue similar ideals. In political practice this can be referred to as "transversal politics" (Yuval-Davis 1994).
} 
inequalities), their situation, lifeworlds and social conditions in Jaffa, with its image as an ideological dome, is different from that of women in the West Bank or the Gaza Strip (see chapter 9). Especially for women like these two biographers, the city offers spaces and opportunities to change or to choose one's own way of life (Herzog 2007). But this must be relativized in the light of the following facts: first and foremost, those who move to the city from a traditional context (as many people do) suffer great disadvantages as a result of turning their back on their origins. Secondly, following the expulsion of the Palestinian population in 1948 and subsequent urban developments, parts of Jaffa have retained a village-like structure; they are impoverished, divided into small segregated ethno-political areas, and marginalized within the city. Thirdly, the people in Jaffa also suffer from racism and oppression (even if to a lesser degree). The lifeworld of these Palestinian women is embedded, as the sociologist Hanna Herzog puts it, in "an urban space where dialectic processes of hope and despair, inclusion and exclusion, identification and alienation allows women to expand and sometimes redefine their multiple social identities" (Herzog 2007: 244). Jaffa as a lifeworld (Schutz/Luckmann 1973) thus creates tense and complex webs of interdependencies between people (Elias 1978), in which divisions and solidarities, distance and closeness, oppression and empowerment are constantly 'engaged in combat'.

The narratives of Jaffa are carried and retold by people with different belongings in the city. As in the biographies of the two women described here, they tell of, and also create, paradoxical, entangled figurations in terms of the relationships between different groupings. 



\section{Glossary}

\section{Administrative Detention}

Administrative detention is based on a military regulation introduced in 1945 under the $\rightarrow$ British Mandate which makes it possible to detain suspects without charge or trial for up to six months (with the possibility of renewing the detention order after this time) (see Rosenfeld 2004: 237). De facto there is no maximum period for administrative detention. Because of its extensive use of administrative detention in the occupied territories, Israel has often been accused of breaching international law and refusing to let prisoners defend themselves properly. The highest number of Palestinians held under an administrative detention order was 1,794 in November 1989; the lowest number, twelve, was in December 2000. There were 473 administrative detainees at the end of August 2014 (see http://www.btselem.org/ administrative_detention, 08.06.2015; http://www.btselem.org/administrative_detention/20141007_spike_in_number_of_administrative_detainees, 08.06.2015).

\section{al-Aqsa Mosque}

See $\rightarrow$ al-Haram ash-Sharif - Temple Mount

\section{Arab Nationalism}

See $\rightarrow$ Pan-Arabism

\section{British Mandate (League of Nations Mandate for Palestine)}

The (British) Mandate means the period in which Palestine was under British administration between the end of the First World War (1914-1918) and the founding of the State of Israel in 1948. Great Britain conquered the region situated on the periphery of the Ottoman Empire in 1917, and was formally granted a mandate for the civil administration of Palestine in 1922 by the League of Nations. This had been agreed on by the Allied Supreme Council at the San Remo conference in 
1920. During the British Mandate, in 1923, the area was divided into Transjordan (which later became the kingdom of Jordan) and Cisjordan (present-day Israel and Palestine). Under the terms of the mandate, Great Britain undertook to support the establishment of a Jewish national home in Palestine, without prejudice to the (civil and religious) rights of the non-Jewish population. Because of this 'double obligation', which was formulated as British policy in the pre-mandate phase in the form of promises of support for Jewish-Zionist and Arab independence aspirations (Balfour Declaration of 1917; McMahon-Hussein correspondence 1915-16), the Mandate at first gave both Jews and Arabs hopes of independence (Segev 2000: 5; see also Krämer 2008). However, the rapidly increasing immigration of Zionist Jews into the Mandate territory led to growing tensions and even violent clashes between British troops, paramilitary Jewish-Zionist organizations and the Arab population. The British Mandate ended on 14th May 1948 with the withdrawal of the British, the declaration of Israeli independence, and the beginning of the First Arab-Israeli War (see $\rightarrow$ al-Nakba).

\section{Fatah}

Fatah (Arabic: 'conquest', 'victory'; also an acronym for 'Palestinian National Liberation Movement') is a Palestinian nationalist party that was founded at the end of the 1950s. In the mid 1960s, under the leadership of Yasser Arafat (1929-2004) and Khalil al-Wazir (1935-1988), it began to call for an armed struggle for the liberation of Palestine. With Arafat as its chairman, Fatah rose to become the leading political fraction within the $\rightarrow$ PLO, the Palestinian umbrella organization, following the defeat of the Arab states in the $\rightarrow$ war of 1967 (see Baumgarten 2005: 31ff.; Kimmerling/Migdal 2003: 252ff.). Since 1964, various Fatah members and groups (including the al-Aqsa Martyrs' Brigades) had been involved in attacks on civil and military Israeli targets. After the $\rightarrow$ Oslo negotiations which were led by Fatah on the Palestinian side, the leader of Fatah, first Yasser Arafat and later Mahmoud Abbas, was also the chairman of the PLO and president of the new $\rightarrow$ Palestinian National Authority. Following serious disputes with $\rightarrow$ Hamas, the strongest competing party, and the expulsion of Hamas leaders from the West Bank and of Fatah from the Gaza Strip after the parliamentary elections in 2006, Fatah is today the dominant political party in the West Bank.

\section{First Intifada}

The uprising in the West Bank and the Gaza Strip that began in 1987 and ended around 1993 is referred to as the First Intifada (Arabic: 'rise up', 'shake off'). It was directed against the Israeli occupation and settlement policy, and the lack of perspectives for a political solution to the Middle East conflict. Because of its broad social support, the First Intifada is frequently interpreted as a 'popular uprising'. It began at the end of 1987, and is usually considered to have ended with the beginning of the $\rightarrow$ Oslo negotiations (from 1993). It was a time of demonstrations, strikes, boycotts and violent clashes between Palestinians on the one hand, and the 
Israeli army and Jewish settlers in the West Bank and the Gaza Strip on the other. According to Neslen (2011: 122), 120,000 Palestinians were arrested and 1,409 were killed during this time. In the same period, 271 Israelis were killed by Palestinians. The First Intifada was largely organized by local committees through party, family and neighbourhood networks, while the $\rightarrow$ PLO leaders had to operate from exile (Lybarger 2005: 146; cf. Ghanem 2002: 16ff. and Kimmerling/ Migdal 2003: 367ff.). During the First Intifada, political Islamic groupings $(\rightarrow$ Hamas, $\rightarrow$ Palestinian Islamic Jihad) became increasingly anchored in the Palestinian areas and were able to expand their influence within society (Hilal 2010: 25). The First Intifada led to far-reaching changes in inner-Palestinian power relations (especially gender and generational relations), to the advantage of the Intifada activists, so that the Intifada is considered not only as a "political" but also as a "social revolution" (a revolution of "children against fathers and women against husbands", Giacaman/ Johnson 1989: 160; cf. Robinson 1997).

\section{Hamas}

Hamas (Arabic: 'zeal', 'enthusiasm'; also an acronym for 'Islamic Resistance Movement') is a Palestinian party in the tradition of political Islam, which was founded by members of the Muslim Brotherhood in Gaza in 1987, in the context of the $\rightarrow$ First Intifada. In addition to the militant political struggle against Israel (through its military wing, the Izz ad-Din al-Qassam Brigades), Hamas is anchored in society because of its local provision of social services. While Hamas denies Israel's right to exist, it is today prepared to accept a de facto two-state solution under certain conditions. From the beginning of the 1990s, Hamas, or its military wing, has been responsible for many suicide attacks on civil and military targets in Israel, and, since 2001, also for rocket attacks. Many of its leaders and members have been killed as a result of attacks by the Israeli army. Following the victory of Hamas in the parliamentary elections in 2006, there have been violent clashes between $\rightarrow$ Fatah and Hamas (see Hilal 2010). In the 'Battle of Gaza' in June 2007, Hamas took over Gaza, while the West Bank remained under the control of Fatah. In 2008/2009 and in 2014, there were military conflicts between Hamas and the Israeli army, during which up to 3,500 Palestinians and up to 86 Israelis were killed.

\section{al-Haram ash-Sharif - Temple Mount}

The Haram ash-Sharif, or Temple Mount, is a hill in the Old City of Jerusalem that is renowned for its importance in Judaism and in Islam. On it is the al-Aqsa Mosque which is considered to be the third most holy site in Islam; tradition has it that Muhammad began his Night Journey to heaven from here. The al-Aqsa Mosque and the nearby Dome of the Rock were built in the 7th century. In the Jewish religion, the Temple Mount is considered as the holiest site because the first two temples are supposed to have stood here. However, most religious authorities forbid Jews to enter the Temple Mount, because it is unclear where the Holy of Holies was located, which may only be entered by the High Priest. For this reason, for many Jews, the Western 
Wall is the holiest place accessible today. Since the Old City was seized from Jordan in 1967, the Israeli government has forbidden Jews to pray on the Temple Mount. Some Jewish groups lobby against this, while others demand the building of the third temple prophesied in the religious traditions. Today, the Haram ash-Sharif is under the custodianship of Jordan, and its daily affairs are managed by the Jerusalem Islamic Waqf (foundation). The status of the Temple Mount has repeatedly been a cause of political unrest, for example in connection with the visit of Ariel Sharon on the eve of the $\rightarrow$ Second Intifada in 2000 (see Dumper 2002).

\section{IDF (Israel Defence Forces)}

The IDF (also known by the Hebrew acronym 'Tzahal') were set up at the end of May 1948 following the founding of the State of Israel. They were formed from the existing group 'Haganah' and the militant groups 'Irgun' and 'Lehi'. Most Israeli citizens have to do military service, men for three years, women for two years. The complex legal situation excludes Israeli Palestinians from this obligation (but not Druze); however, they can volunteer to serve. The so-called Tal law, which exempts ultra-orthodox Jews from military service, has given rise to many political and legislative controversies.

\section{Israeli barriers}

In June 2002, in the context of the $\rightarrow$ Second Intifada, Israel began to build a barrier to separate the West Bank. It mainly consists of an electronic fence, frequently together with a security strip, roads and ditches, so that the average width is 60 metres. At some points, the barrier was constructed as a wall with a height of six to eight metres. The planned length of the barrier, which in 2015 was not yet completed, is 709 kilometres. That is twice as long as the 1949 border or armistice line (the socalled 'Green Line'). As a result of court rulings, the route of the barrier has had to be changed several times. 85 percent of the present route is inside the West Bank and does not follow the 'Green Line'. When the barrier is complete, 9.5 percent of the West Bank and 60 settlements will be on the 'Israeli side'. The barriers restrict the freedom of movement of many Palestinians who live in the villages close to them, especially in the agricultural sector, and in towns which are 'surrounded' by the wall (see http://www.btselem.org/separation_barrier/map, 07.05.2015). Access to the area 'on the Israeli side' of the barriers is strictly regulated for Palestinians by different types of IDs (Israeli ID, Jerusalem ID or West Bank ID), and for inhabitants of the West Bank additionally by a complex system of 'entry permits'. These fix the purpose and the duration of the permitted visit.

\section{Jordanian rule over the West Bank and East Jerusalem}

The Hashemite Kingdom of Jordan ruled over the West Bank and East Jerusalem from 1948 to the beginning of the Israeli occupation following the $\rightarrow$ war of 1967. Jordan's formal annexation of the West Bank in 1950 was not internationally recognized. The inhabitants were issued with Jordanian passports. In 1988 Jordan 
surrendered its claim to sovereignty over these areas to the $\rightarrow$ PLO, retaining only its custodianship of the $\rightarrow$ Haram ash-Sharif. In 1994 Jordan and Israel concluded a peace agreement.

\section{al-Nakba}

The term Nakba (Arabic: 'catastrophe') is used to refer to the flight or expulsion of 700,000 - 750,000 Palestinians from their homes in the period between the adoption of the UN Partition Plan for Palestine on 29th November 1947 and the end of the First Arab-Israeli War with the armistice agreements between Israel and the Arab states of Egypt, Jordan, Syria and Lebanon (February to July 1949). The Palestinians were either driven out by Jewish military and paramilitary organizations (Haganah, $\rightarrow \mathrm{IDF}$ ), or they fled following military confrontations, for fear of such confrontations, or for fear of expulsion. This 'fear' was fostered by 'whispering campaigns' (see Morris 2008). Most of the approximately four hundred abandoned Palestinian villages (see Khalidi 1992) were wholly or partly destroyed. In the course of the Nakba, Palestinian civilians, too, were killed by Jewish-Israeli forces, as in the case of the 'massacre of Deir Yassin' in April 1948, in which more than one hundred people were killed. The term Nakba is also used to refer to the consequences of this exodus and the founding of the State of Israel from the Palestinian perspective, especially the loss of land and other possessions in the newly created Israeli national territory, and the refusal to let the refugees return (see $\rightarrow$ Right of return and $\rightarrow$ Palestinian refugee camps).

\section{Oslo process}

The Oslo process is a term used to refer to the negotiations on a permanent status between the Israeli government and $\rightarrow$ PLO leaders, which took place between 1993 and 2001. Important events in the Oslo peace process were the signing of the 'Declaration of Principles on Interim Self-Government Arrangements' (Oslo I) in September 1993, the 'Gaza-Jericho Agreement' in May 1994, and the 'Interim Agreement on the West Bank and the Gaza Strip' (Oslo II) in September 1995. The Oslo Accords led to the founding of the $\rightarrow$ Palestinian National Authority, and the withdrawal of the Israeli army from parts of the West Bank and the Gaza Strip. At the same time there were power struggles between the 'old' PLO leaders, who returned to the West Bank and the Gaza Strip for the first time, and the locally established power elites (see Hilal 2010: 25; Lybarger 2005: 146). The lack of binding statements in the Oslo Accords with regard to the refugee question (for example their $\rightarrow$ Right of return) led to a massive rejection of the Accords among the refugees, or among the political parties that had become firmly established in the refugee camps, and to doubt whether the interests of the refugees were adequately represented by the $\rightarrow$ PLO. For these and other reasons, various political groupings (such as the $\rightarrow$ PFLP and $\rightarrow$ Hamas) rejected the line followed by the PLO (or by $\rightarrow$ Fatah which dominated the PLO) in the peace negotiations, and boycotted the $\rightarrow$ PA elections in 1996. In the 'Oslo phase', despite the so-called peace negotiations, 
the construction of Israeli $\rightarrow$ settlements (Kimmerling/Migdal 2003: 360), clashes between Palestinians and the IDF, and attacks by Palestinian groupings on JewishIsraeli targets (ibid.: 372f.) all continued.

\section{Palestinian Islamic Jihad (PIJ)}

The PIJ was founded in 1981/1982 by members of the Muslim Brotherhood in Gaza as a group belonging to political Islam. Although its members are Sunni, the PIJ was inspired by the theocratic ideas of the Iranian Revolution of 1979 and was supported by Iran. The PIJ rejects a two-state solution and Israel's right to exist as a state. It has been responsible for many attacks on Israeli civil and military targets. Even before the $\rightarrow$ First Intifada, the PIJ began attacking Israeli targets in Gaza, and in the 1990s it carried out numerous suicide attacks in Israel. With the beginning of the $\rightarrow$ Second Intifada, there was an increase in the number of bomb attacks on civil targets or civilians in Israel by the PIJ.

\section{Palestine Liberation Organization (PLO)}

The PLO was founded in 1964 as an umbrella organization for different Palestinian fractions. Yasser Arafat was Chairman of the PLO from 1969 up to his death in 2004; his successor is Mahmoud Abbas. In the beginning, the PLO was strongly influenced by Gamal Abdel Nasser (see $\rightarrow$ Pan-Arabism). At first it propagated the goal of liberating Palestine through armed resistance. In the period from 1967 to 1970 there were many violent clashes between PLO groups in Jordan and the Israeli army, including the 'Battle of Karameh'. By the end of July 1971, all PLO groups had been driven out of Jordan in the Jordanian civil war known as 'Black September', and after this they operated from Beirut. In the course of the Israeli occupation of parts of Lebanon in 1982, the PLO had to leave Beirut and set up its headquarters in Tunis. In 1974 the PLO was granted observer status by the UN and was recognized by many countries as the official representative of the Palestinian people, while Israel declared it to be a terrorist organization up to 1991. In 1988 the PLO agreed to a two-state solution; in 1993 it recognized the State of Israel (see Kimmerling/Migdal 2003).

\section{Palestinian National Authority (PA)}

The Palestinian National Authority was set up in 1994 as part of the Oslo process to give the Palestinians limited powers of self-governance in the West Bank and the Gaza Strip. Gaza and the West Bank were divided into zones which define the PA's area of sovereignty, as agreed in the $\rightarrow$ Oslo Accords. In Zone A the PA has control over civilian and security-related issues, and in Zone B over civilian issues only ( $\rightarrow$ Zone A - Zone B - Zone C). The institutions of the Palestinian Authority include various ministries and security forces, besides the Palestinian Legislative Council (parliament) which has been legitimized by general elections only twice, in 1996 and 2006 (see $\rightarrow$ Fatah, $\rightarrow$ Hamas). 


\section{Palestinian refugee camps}

Most of the 19 refugee camps in the West Bank for Palestinians who fled from the future national territory of Israel in the course of the First Arab-Israeli War (194849) were set up in the years immediately following the war. Besides the camps in the West Bank, there are 39 other camps in the region (in the Gaza Strip, in Lebanon, in Syria and in Jordan). From the 1950s onwards, emergency relief in the camps in the West Bank was provided by the newly created $\rightarrow$ UNRWA. Although originally intended as a temporary arrangement, its services have become increasingly institutionalized (first food and health care, later also schools). For a long time, the camps were places with very poor living conditions, little infrastructure (see Rosenfeld 2002: 522) and high unemployment. They were also poorly integrated in their local environment. Today, the refugee camps in the West Bank are inhabited almost exclusively by Muslim Palestinians and can be seen as neighbourhoods of the nearby cities. The establishment of the UNRWA also led to institutionalization of the status of the refugees, who had to show that they met certain criteria in order to be able to benefit from the relief services. UNRWA refugee status can be passed on only to descendants of registered (male) refugees (see Cervenak 1994). It is difficult to find reliable figures regarding the total number of people living in refugee camps in the West Bank, but we can assume that the inhabitants of the camps form nearly 10 percent of the total population, and that around $20-25$ percent of Palestinians with a refugee background registered with UNRWA live in camps (PCBS Census 2007; UNRWA 2011). On the basis of data published by the Palestinian Central Bureau of Statistics (PCBS) for 2007, UNRWA assumes that there are a total of 125,252 refugees living in camps in the West Bank (UNRWA 2011: 14). The history of the refugee camps is also a history of conflict and struggle for dominant positions between different groupings and actors inside the camps, and of conflicts with the $\rightarrow$ IDF and (later) the $\rightarrow$ PA. During the $\rightarrow$ First Intifada, many refugee camps were the starting point for civil and militant resistance, and they were severely affected by the repressive measures taken by the Israeli army. During the $\rightarrow$ Oslo negotiations, the parties established in the refugee camps $(\rightarrow$ PFLP, $\rightarrow$ Hamas) criticized a tendency on the part of the $\rightarrow$ PLO leaders to neglect the interests of the refugees (especially the $\rightarrow$ right of return; see Sayigh 2006). To this day, violent clashes with the Israeli army (for example arrest operations, searching and destroying houses), but also with the security forces of the PA, constantly occur in and around the camps.

\section{Pan-Arabism}

Pan-Arabism (or Arab Nationalism) is the political idea of uniting all Arab states or regions in a single nation state. Pan-Arab ideas spread in the West Bank and all over the Middle East under the influence of Gamal Abdel Nasser, who took over the government of Egypt in 1952. Palestinian intellectuals had been influenced by Arab ideas of unity in the context of anti-colonial, anti-imperialist and anti-Zionist debates in the 1920s and 1930s (see Böhme/Sterzing 2012: 22). The Arab lack of unity in opposing the founding of the State of Israel was seen as one of the reasons 
for their defeat in the war of 1948 (see Kimmerling/Migdal 2003: 225-227). In the Palestinian territories, interest in Pan-Arabism waned after the defeat of the Arab states in the $\rightarrow$ war of 1967 , to be replaced by genuine Palestinian nationalism (under $\rightarrow$ Fatah).

\section{PFLP (and DFLP)}

The 'Popular Front for the Liberation of Palestine' is a Palestinian political party. Its predecessor, the 'Arab Nationalists' Movement', had been set up at the American University of Beirut. In 1967 it was united with other groups to form the PFLP, which was led for many years by George Habash. The PFLP became a member of the $\rightarrow$ PLO in 1970. At first it pursued a Nasserist course (see $\rightarrow$ Pan-Arabism), but then adopted a more Marxist position with greater emphasis on national Palestinian interests. There were several splinter groups, one of which later became the 'Democratic Front for the Liberation of Palestine' (DFLP), which was a driving force behind the separation of Palestine into the areas conquered in 1948 and 1967 (Kimmerling/Migdal 2003: 255-258).

\section{Right of return}

Claims to a 'right of return' for Palestinian refugees (see $\rightarrow$ Palestinian refugee camps) are usually based on Article 11 of Resolution 194 passed by the UN General Assembly on 11th December 1948 (and repeated in Resolution 3236 of 22nd November 1974). It is deduced from the text of the resolution that first-generation Palestinian refugees and their descendants should be permitted to return to their former homes inside Israeli territory. Despite disagreement over the interpretation of Resolution 194, which is not legally binding, it has been used by the $\rightarrow$ PLO and other Palestinian parties and organizations as an important resource of symbolic recognition, and interpreted as an expression of international recognition of the right of return.

\section{Second Intifada}

The Second Intifada (also known as the 'Al-Aqsa Intifada') lasted from the end of September 2000 to around 2005 and consisted of frequent and mostly violent confrontations between Palestinians and the $\rightarrow$ IDF, long Israeli military campaigns in Palestinian cities, and Palestinian attacks on Jewish military and civil targets. The outbreak of the Second Intifada is often said to have been caused by Ariel Sharon's visit to the $\rightarrow$ al-Haram ash-Sharif, or Temple Mount, in Jerusalem on 28th September 2000, but it must be interpreted in the context of hesitant implementation of the $\rightarrow$ Oslo Accords, inner-Palestinian tensions (in connection with the establishment of the $\rightarrow$ PA), and the continued (and in many ways more repressive) Israeli occupation. In comparison to the $\rightarrow$ First Intifada, the Second Intifada was more violent and was more strongly dominated by militant groupings (such as the Izz ad-Din alQassam Brigades, see $\rightarrow$ Hamas, the Al-Aqsa Brigades, or the $\rightarrow$ Palestinian Islamic Jihad). Palestinian resistance became more militarized (suicide attacks on civilians, 
firing on settlements and military bases), while the Israeli army deployed 'lethal' weapons, tanks, helicopters and snipers. Houses were destroyed; there were curfews and roadblocks, and targeted killings (see Norman 2010: 31; Hammami/Tamari 2001: 12). The ordinary people were much less actively involved in 'resistance activities' during the Al-Aqsa Intifada in comparison to the First Intifada. The reasons for this include the repressive measures imposed by Israel, the intensification of innerPalestinian conflicts (Norman 2010: 32), the political and institutional weakness of the PA, Israel's de facto control over large parts of the West Bank and the Gaza Strip, and a generally "weakened civil society" (Hammami/ Tamari 2001; Norman 2010).

\section{Settlements in the West Bank and in East Jerusalem}

The construction and expansion of Israeli settlements in the West Bank and East Jerusalem, which began after the Israeli occupation of 1967, became intensified after the end of the 1970s (and was thus one of the causes of the $\rightarrow$ First Intifada). In addition to 2,100,000 Palestinians, there are around 530,000 settlers living in the territories that were controlled by Jordan up to 1967. Around 340,000 settlers live in the West Bank and around 190,000 in East Jerusalem (statistics of 2011 and 2012). In addition to the 125 settlements in the West Bank and the 12 Jewish neighbourhoods in East Jerusalem that are officially recognized by the Israeli Ministry of the Interior, there are settlers living in 100 unofficial 'outposts' in the West Bank, and in scattered small settlements in the Old City of Jerusalem and other Palestinian neighbourhoods. Settlers are Israeli citizens, not persons with a West Bank ID or Jerusalem ID. Even if some of the present-day settlements were originally set up as military bases, the building of settlements is a breach of international law, which says that occupying powers may not make any permanent changes in occupied areas and may not create settlements there for their own people. In the West Bank and in East Jerusalem, violent clashes between the Jewish settlers and the Palestinian population are common.

\section{UNRWA}

United Nations Relief and Works Agency for Palestine Refugees in the Near East, founded in 1949. See $\rightarrow$ Palestinian refugee camps

\section{War of 1948 - First Israeli-Arab War - War of Independence See $\rightarrow$ al-Nakba}

\section{War of 1967 - al-Naksa - Six-Day War}

The war of 1967 was a war between Israel on the one hand, and Egypt, Jordan and Syria on the other. Egypt took on a leading role in the war under Gamal Abdel Nasser. Several minor border clashes (including the mobilization of Egyptian troops in the Sinai) preceded the Israeli air strike against the Egyptian and Syrian air forces which marked the beginning of the war (see Segev 2007: 13f.). The war 
lasted from 5th to 10th June 1967. In its course, Israel captured the Sinai Peninsula and the Gaza Strip from Egypt, the West Bank and East Jerusalem from Jordan, and the Golan Heights from Syria. In the years following 1967, fighting between Israel and Egypt continued during the 'War of Attrition'. Around 250,000 Palestinians (Kimmerling/ Migdal 2003: 41; cf. Bowker 2003: 81) were expelled or fled from the West Bank, East Jerusalem and the Gaza Strip. Many of them had been forced to leave their homes during the $\rightarrow \mathrm{Nakba}$, in other words they were already refugees, although estimates of numbers in this respect differ (see Tolan 2007: 507f. on the different sources for numbers of refugees in 1967). The defeat of the Arab states in the war of 1967 was one of the reasons for the decline of $\rightarrow$ Pan-Arab groupings in Palestine and the rise of $\rightarrow$ Fatah, which focused on the Palestinian national liberation struggle (Ghanem 2002: 13). The term Naksa (Arabic: 'setback') is also used in Palestinian discourses to refer to the war of 1967, which is often referred to as the Six-Day War.

\section{Zone A - Zone B - Zone C}

In 1995, the West Bank was divided into three - supposedly temporary - administrative regions during the $\rightarrow$ Oslo process under the terms of the Oslo II Accords (Interim Agreement) between the Israeli government and the $\rightarrow$ PLO. Zone A, in which the $\rightarrow$ Palestinian National Authority has many governmental powers, comprises about 18 percent of the land in the West Bank and contains all the Palestinian urban areas and most of the Palestinian population. Zone B covers about 22 percent of the West Bank (around 440 villages, chiefly rural areas). In this zone Israel is in charge of security, but the PA is responsible for civil matters. Zones A and B are divided into 165 units. About 60 percent of the West Bank belongs to Zone C. In this area, the PA is only responsible for providing health and education services for the Palestinian population, while all other matters are in the hands of the Israeli occupation authorities: infrastructure, security and, in particular, access to land and building permits, which are almost completely restricted. Over 99 percent of Zone $\mathrm{C}$ consists of $\rightarrow$ settlements, military zones or areas defined by Israel as nature reserves. Between 200,000 and 300,000 Palestinians and all the 340,000 settlers in the West Bank live in Zone C (see http://www.btselem.org/area_c/what_is_area_c, 09.06.2015). 


\section{Transcription symbols}

\begin{tabular}{|c|c|}
\hline $\begin{array}{l}\text { Speaker 1: and so \#we went\# } \\
\text { Speaker 2: \#hmhm yes\# }\end{array}$ & simultaneous utterances \\
\hline (says he) & approximate transcription \\
\hline ) & $\begin{array}{l}\text { incomprehensible (space between brackets } \\
\text { approximately corresponding to length / duration } \\
\text { of passage) }\end{array}$ \\
\hline$(($ slowly $)) \quad(($ coughs $))$ & $\begin{array}{l}\text { transcriber's comments, also descriptions of } \\
\text { moods \& non-verbal utterances or sounds }\end{array}$ \\
\hline \... ((slowly))\ & $I$ marks beginning and end of phenomenon \\
\hline$(($ vividly $)) \ldots$ & general change of mood, probably continuing \\
\hline , & brief pause \\
\hline (5) & pause in full seconds \\
\hline many mo-, more & sudden halt / faltering / (self-)interruption \\
\hline ye=yes & rapid speech, words closely linked \\
\hline ye:s & sound lengthened \\
\hline 'yes' & softly, in a low voice \\
\hline never & syllable (sound) stressed \\
\hline NO & loudly \\
\hline NEVER & $\begin{array}{l}\text { stress (emphasis) during passage spoken in a loud } \\
\text { voice }\end{array}$ \\
\hline
\end{tabular}





\section{About the authors}

Ahmed Albaba is a PhD student at the Center of Methods in Social Sciences, University of Göttingen. Between 2012 and 2015 he worked in the trilateral research project Belonging to the Outsider and Established Groupings: Palestinians and Israelis in Various Figurations. Additionally, in 2015 and 2016 he worked for the research project The Social Construction of Border Zones. A Comparison of two geopolitical cases. Both projects were funded by the German Research Foundation. Currently he is working as legal guardian for unaccompanied minor refugees in Lower Saxony (Niedersachsen). His PhD project deals with the history of the Israeli-Palestinian conflict, collective memory, biographies, and generational figurations of Palestinian refugees in the West Bank.

Johannes Becker has recently completed his $\mathrm{PhD}$ thesis on biographical processes of 'emplacement' in Jerusalem's Old City. From 2010 to 2015 he was part of the trilateral research project Belonging to the Outsider and Established Groupings: Palestinians and Israelis in Various Figurations at the University of Göttingen. This project was funded by the German Research Foundation. His research interests include biographical research, historical sociology, ethnography, spatial and urban sociology, Middle East studies.

Hendrik Hinrichsen is currently lecturer and researcher at the Center of Methods in Social Sciences, University of Göttingen. He is working on a PhD tackling the intersection of historical generations and familial belonging in the Palestinian territories in the post-Oslo-period. From 2012 to 2015 he was a research assistant in the trilateral project Belonging to the Outsider and Established Groupings: Palestinians and Israelis in Various Figurations, funded by the German Research Foundation. His research interests include biographical research, figurational sociology, generational research, Middle East studies and qualitative methods in social sciences. 
Gabriele Rosenthal is a sociologist and professor of Qualitative Methodology at the Center of Methods in Social Sciences, University of Göttingen. Her major research focus is the intergenerational impact of collective and familial history on biographical structures and actional patterns of individuals and family systems. Her current research deals with ethnicity, ethno-political conflicts and the social construction of borders. She is the author and editor of numerous books, including The Holocaust in Three Generations (2009), Interpretative Sozialforschung (2011) and, together with Artur Bogner, Ethnicity, Belonging and Biography (2009).

Nicole Witte is a lecturer and researcher at the Center of Methods in Social Sciences, University of Göttingen. She holds a PhD in social sciences and a degree in economics. She teaches qualitative methods, biographical research and sociology. Her research topics are ethnicity and belonging, as well as urban sociology.

Arne Worm is a lecturer and researcher at the Center of Methods in Social Sciences, University of Göttingen (since 2012). Between 2010 and 2015 he worked in the trilateral research project Belonging to the Outsider and Established Groupings: Palestinians and Israelis in Various Figurations. Since October 2014 he has worked in the research project The Social Construction of Border Zones. A Comparison of two geopolitical cases. Both projects were funded by the German Research Foundation. His $\mathrm{PhD}$ project deals with the biographies and migration processes of Syrian refugees migrating to the European Union and the meaning of constructions of belonging within these processes. His research interests include interpretative research methods, biographical research, migration and ethnicity, and figurational sociology.

Rixta Wundrak is a sociologist and is writing a post-doc thesis on Practices of narration. Praxeological and discourse-analytical approaches in biographical research at the University of Göttingen, Germany. Her research areas are migration and cultural studies, globalization, sociology of knowledge, and interpretative and qualitative methodology (ethnography, discourse analysis and biographical research). Her current publications examine the methodology of discourse ethnography. She is engaged in field research in South Eastern Europe and the Middle East. 


\section{Bibliography}

Abu-Rabia-Queder, Sarab (2008), Does education necessarily mean enlightenment? The case of higher education among Palestinians-Bedouin women in Israel, Anthropology \& Education Quarterly, vol. 39, no. 4, pp. 381-400.

Abu-Rabia-Queder, Sarab/Weiner-Levy, Naomi (2008), Identity and gender in cultural transitions: Returning home from higher education as 'internal immigration' among Bedouin and Druze women in Israel, Social Identities, vol. 14, no. 6, pp. 665-682.

Ahmed, Hamoud Yahya / Hashim, Ruzy Suliza / Lazim, Zalina Mohd / Vengadasamy, Ravichandran (2012), Identity and land in Mahmoud Darwish's selected poems: An ecopostcolonial reading, International Journal of Applied Linguistics \& English Literature, vol. 1, no. 6, pp. 7-19.

Al Jazeera (2007), The Palestine papers: NSU memo re: Palestinian refugees absorbed into Israel since 1948, 25.05.2015, http://transparency.aljazeera.net/ en/projects/thepalestinepapers/20121823144781654.html

Amara, Ahmad/ Yiftachel, Oren (2014), Konfrontation im Negev, in: STUDIEN, 08.04.2015, http://www.rosalux.de/fileadmin/rls_uploads/pdfs/Studien/Studien_Konfrontation_dt_eng_web.pdf

Amireh, Amal (2003), Between complicity and subversion: Body politics in Palestinian national narrative. South Atlantic Quarterly, vol. 102, no. 4, pp. 747-772.

Amireh, Amal (2010), Afterword, GLQ: A Journal of Lesbian and Gay Studies, vol. 16, no. 4, pp. 635-647.

Antonius, Soraya (1980), Prisoners for Palestine: A list of women political prisoners, Journal of Palestine Studies, vol. 9, no. 3, pp. 29-80.

Arnon, Adar (1992), The quarters of Jerusalem in the Ottoman Period, Middle Eastern Studies, vol. 28, no. 1, pp. 1-65. 
Assmann, Aleida (2016), Shadows of trauma: Memory and politics of postwar identity (transl. by Sarah Clift), New York.

Azzam, Intisar J. (2007), Gender and religion: Druze women, London.

Baudrillard, Jean / Glaser, Sheila Faria (2004), Simulacra and simulation, Ann Arbor.

Baumgarten, Helga (2005), The three phases of Palestinian nationalism, 1948-2005, Journal of Palestine Studies, vol. 34, no. 4, pp. 25-48.

Becker, Johannes (2013), Old men's truth: The 'poverty generation' of neighborhood men talk about life in Jerusalem's Old City, Middle East Journal of Culture and Communication, vol. 6, no. 3, pp. 264-285.

Benvenisti, Meron (1996), City of stone: The hidden history of Jerusalem, Berkeley/Los Angeles.

Böhme, Jörn / Sterzing, Christian (2012), Kleine Geschichte des israelisch-palästinensischen Konflikts, Schwalbach.

Bogner, Artur (2003), Macht und die Genese sozialer Gruppen, Sociologus, vol. 53, no. 2, pp. 167-181.

Bogner, Artur/ Rosenthal, Gabriele (2012), Die ,unerzählten` Geschichten von Außenseitern und deren Relevanz für die Analyse von (Post-)Konfliktfigurationen: Interviews mit Opfern kollektiver Gewalt in Norduganda (West Nile), Sociologus, vol. 62, no. 2, pp. 115-141.

Bogner, Artur / Rosenthal, Gabriele (in print), Biographien - Diskurse - Figurationen: Methodologische Überlegungen aus einer sozialkonstruktivistischen und figurationssoziologischen Perspektive, in: Tina Spies / Elisabeth Tuider (eds), Biographie und Diskurs: Methodisches Vorgehen und Methodologische Verbindungen von Biographie- und Diskursforschung, Wiesbaden.

Bolliger, Monika (2015), Israels gemischte Stadt Jaffa: Echo einer arabischen

Metropole, in: Neue Zürcher Zeitung, 07.02.2015, http://www.nzz.

ch/international/naher-osten-und-nordafrika/echo-einer-arabischenmetropole-1.18477584

Bornstein, Avram (2001), Ethnography and the politics of prisoners in PalestineIsrael, Journal of Contemporary Ethnography, vol. 30, no. 5, pp. 546-574.

Bourdieu, Pierre (1998), Practical reason: On the theory of action, Stanford.

Bourdieu, Pierre / Wacquant, Loïc J. D. (1992), An invitation to reflexive sociology, Chicago.

Bowker, Robert (2003), Palestinian refugees: Mythology, identity and the search for peace, Boulder.

Braverman, Irus (2007), Powers of illegality: House demolitions and resistance in East Jerusalem, Law \& Social Inquiry, vol. 32, no. 2, pp. 333-372.

Brenner, Michael (2010), A short history of the Jews (transl. by Jeremiah Riemer), Princeton.

Cervenak, Christine M. (1994), Promoting inequality: Gender-based discrimination in UNRWA's approach to Palestine, Human Rights Quarterly, vol. 16, no. 2, pp. 300-374. 
Cheshin, Amir S./ Hutman, Bill / Melamed, Avi (1999), Separate and unequal: The inside story of Israeli rule in East Jerusalem, Cambridge.

Cohen, Hillel (2009), Army of shadows: Palestinian collaboration with Zionism, 1917-1948, Berkeley.

Cohen, Hillel (2011a), Good Arabs: The Israeli security agencies and the Israeli Arabs, 1948-1967, Berkeley.

Cohen, Hillel (2011b), The rise and fall of Arab Jerusalem: Palestinian politics and the city since 1967, London / New York.

Connell, Raewyn (1995), Masculinities, Cambridge.

Coston, Bethany M./ Kimmel, Michael (2012), Seeing privilege where it isn't: Marginalized masculinities and the intersectionality of privilege, Journal of Social Issues, vol. 68, no. 1, pp. 97-111.

Dhillon, Navtej/ Yousef, Tarik (2009), Generation in waiting: The unfulfilled promise of young people in the Middle East, Washington.

Die Welt (2014), Applaus für Ablehnung Israels als jüdischer Staat, in: Welt, 24.05.2015, http://www.welt.de/politik/ausland/article125657136/Applausfuer-Ablehnung-Israels-als-juedischer-Staat.html

Dumper, Michael (2002), The Old City of Jerusalem in the Middle East conflict, Boulder / London.

Dumper, Michael (2008), The multiple borders of Jerusalem: Policy implications for the future of the city, Divided Cities / Contested States Working Paper No.4, Cambridge, 30.08.2016, http://www.conflictincities.org/pdfs/workingpaper4_4.9.08.pdf

Dumper, Michael (2014), Jerusalem unbound: Geography, history, and the future of the Holy City, New York / Chichester.

Eickelman, Dale F. (1998), The Middle East and Central Asia: An anthropological approach, 3rd edition, Upper Saddle River.

Eitan, Uri / Tatarsky, Aviv / Maimon, Oshrat/ Sela, Ronit / Alyan, Nisreen / Tzafrir, Keren (2013), Annual status report: The failing East Jerusalem education system, The Association for Civil Rights in Israel, 10.09.2013, http://www. acri.org.il/en/wp-content/uploads/2013/09/EJ-edu-report-2013.pdf

Elias, Norbert (1956), Problems of involvement and detachment, British Journal of Sociology, vol. 7, no. 3, pp. 226-252.

Elias, Norbert (1978), What is sociology? (transl. by Stephen Mennell and Grace Morrissey), London.

Elias, Norbert/Scotson, John L. (2008), The established and the outsiders, Revised edition, Collected Works, vol. 4 (Ed. by Cas Wouters), Dublin.

Elias, Norbert (2010), Mozart: The sociology of a genius, in: Norbert Elias, Mozart and other essays on courtly art, Collected Works, vol. 12 (Ed. by Eric Baker and Stephen Mennell), Dublin, pp. 56-179.

Escher, Anton (2009), Rehabilitation of the mediterranean medina in Morocco, in: Ludovico Micara / Attilio Petrucciolo/ Ettore Vadini (eds), The mediterranean medina: An international seminar, Rom, pp. 345-350. 
Faitelson, Yakov (2011), Demographic trends in the land of Israel, 25.05.2015, http:/www.theettingerreport.com/Demographic-Scare/DemographicTrends-in-the-Land-of-Israel.aspx

Firro, Kais (1999), The Druzes in the Jewish state: A brief history, Leiden / Boston.

Firro, Kais (2001), Reshaping Druzes in the Jewish particularism in Israel, Journal of Palestine Studies, vol. 30, no. 3, pp. 40-53.

Fischer, Wolfram (1978), Struktur und Funktion erzählter Lebensgeschichten, in: Martin Kohli (ed.), Soziologie des Lebenslaufs, Darmstadt / Neuwied, pp. 311-336.

Freitag, Ulrike (2003), Politische Religion im Nahen Osten: Nationalistische und islamistische Modelle, in: Klaus Hildebrand (ed.), Zwischen Politik und Religion: Studien zur Entstehung, Existenz und Wirkung des Totalitarismus, München, pp. 139-155.

Gellner, Ernest (1983), Nations and nationalism, New York.

Ghanem, As'ad (2002), The Palestinian regime: A “partial democracy”, Brighton / Portland.

Giacaman, Rita/Johnson, Penny (1989), Palestinian women: Building barricades and breaking barriers, in: Zachary Lockman/Joel Beinin (eds), Intifada: The Palestinian uprising against Israeli occupation, Boston, pp. 155-169.

Glass, Joseph B./ Khamaisi, Rassem (2005), Report on the socio-economic conditions in the Old City of Jerusalem. The Jerusalem Project, Munk Centre for International Studies, University of Toronto.

Goffman, Erving (1986), Stigma: Notes on the management of spoiled identity, New York.

Gordon, Neve (2008), Israel's occupation, Berkeley/Los Angeles.

Gurr, Ted R. / Pitsch, Anne (2002), Ethnopolitische Konflikte und separatistische Gewalt, in: Wilhelm Heitmeyer/ John Hagan (eds), Internationales Handbuch der Gewaltforschung, Wiesbaden, pp. 287-312.

Gurwitsch, Aron (1964), The field of consciousness, Pittsburgh.

Hahn, Alois (2010), Körper und Gedächtnis, Wiesbaden.

Halbwachs, Maurice (1992/1925), On collective memory (Ed. and transl. by Lewis A. Coser), Chicago/London.

Halevi, Yossi Klein (2002), Refugee status, in: The New Republic, 30.08.2016, http://www.glapn.org/sodomylaws/world/palestine/psnews008.htm

Hammami, Rema/Tamari, Salim (2001), The second uprising: End or new beginning?, Journal of Palestine Studies, vol. 30, no. 2, pp. 5-25.

Hanafi, Sari (2009), Palestinian refugee camps in the Palestinian territory: Territory of exception and locus of resistance, in: Adi Ophir/Michal Giovanni / Sari Hanafi (eds), The power of inclusive exclusion: Anatomy of Israeli rule in the occupied Palestinian territories, New York, pp. 495-517.

Hanaf, Sari (2010), Governing Palestinian refugee camps in the Arab East: Governmentalities in search of legitimacy, Working Paper Series Nr. 1, Issam Fares Institute for Public Policy and International Affairs, Beirut. 
Herzog, Hanna (2007), Mixed cities as a place of choice: The Palestinian women's perspective, in: Daniel Monterescu/ Dan Rabinowitz (eds), Mixed towns, trapped communities. Historical narratives, spatial dynamics, gender relations and cultural encounters in Palestinian-Israeli towns, Aldershot, pp. 243-257.

Hilal, Jamil (2010), The polarization of the Palestinian political field, Journal of Palestine Studies, vol. 39, no. 3, pp. 24-39.

Hinrichsen, Hendrik / Worm, Arne (2012), Das harmonisierende und homogenisierende Wir-Bild der Palästinenser, unveröffentlichte Magisterarbeit, GeorgAugust-Universität Göttingen.

Hochberg, Gil Z. (2010), Introduction: Israelis, Palestinians, queers: Points of departure, GLQ: A Journal of Lesbian and Gay Studies, vol. 16, no. 4, pp. 493-516.

Hudson, Leila (1994), Coming of age in occupied Palestine: Engendering the Intifada, in: Fatma Müge Göçek/Shiva Balaghi (eds), Reconstructing gender in the Middle East: Tradition, identity and power, New York, pp. 123-136.

Independent Media Review Analysis (2001), Egyptian dream: Israel will disappear "thanks to demographics", 15.05.2015, http://www.imra.org.il/story. php3?id $=8828$

International Peace and Cooperation Center (IPCC) (2009), Jerusalem: The Old City: The urban fabric and geopolitical implications, Jerusalem, 22.05.2015, http://www.ochaopt.org/documents/opt_prot_ipcc_old_city_urban_fabric_geopo_implications_2009.pdf

International Peace and Cooperation Center (IPCC) (2013), East Jerusalem housing review, 21.05.2015, www.fespal.org/wp-content/uploads/2013/10/EastJerusalem-Housing-Review.pdf

Israel Central Bureau of Statistics (2014), Annual Report, 05.06.2015, http://www. cbs.gov.il/reader/newhodaot/hodaa_template_eng.html?hodaa $=201411257$

Jewish Virtual Library (2003), Israeli Arabs: The official summation of the Or Commission report, 16.05.2015, http://www.jewishvirtuallibrary.org/ jsource/Society_\&_Culture/OrCommissionReport.html

Jewish Virtual Library [o. Jahr], Israel lands - Privatization or national ownership?, 16.05.2015, http://www.jewishvirtuallibrary.org/jsource/Society_\&_Culture/land.html

Johnson, Penny (2006), Living together in a nation in fragments: Dynamics of kin, place, and nation, in: Lisa Taraki (ed.), Living Palestine. Family survival, resistance, and mobility under occupation, New York, pp. 51-102.

Kagan, Michael / Ben-Dor, Anat (2008), Nowhere to run: Gay Palestinian asylumseekers in Israel, Tel Aviv University / Faculty of Law: Public Interest, 28.08.2012, http://www.law.tau.ac.il/Heb/_Uploads/dbsAttachedFiles/Nowhere.pdf 
Kårtveit, Bård (2012), Land, law, and family protection in the West Bank, in: Anh Nga Longva / Anne Sofie Roald (eds), Religious minorities in the Middle East: Domination, self-empowerment, accommodation, Leiden / Boston, pp. $97-122$.

Kaschl, Elke (2003), Dance and authenticity in Israel and Palestine: Performing the nation, Leiden / Boston.

Kaya, Asiye (2009), Mutter-Tochter-Beziehungen in der Migration: Biographische Erfahrungen im alevitischen und sunnitischen Kontext, Wiesbaden.

Keller, Reiner (2005), Wissenssoziologische Diskursanalyse: Grundlegung eines Forschungsprogramms, Wiesbaden.

Kessl, Fabian / Reutlinger, Christian (2007), Sozialraum: Eine Einführung, Wiesbaden.

Khalidi, Walid (1987), From haven to conquest: Readings in Zionism and the Palestine problem until 1948, 2nd edition, Washington.

Khalidi, Walid (1992), All that remains: The palestinian villages occupied and depopulated by Israel in 1948, Washington.

Khalidi, Rashid (1997), Palestinian identity: The construction of modern national consciousness, New York.

Kimmerling, Baruch/Migdal, Joel S. (2003), The Palestinian people: A history, Cambridge.

Klein, Peggy (2001), Die Drusen in Israel, Marburg.

Konrad-Adenauer-Stiftung (2014), Die gemeinsamen israelisch-palästinensischen Umfragen, 25.05.2015, http://www.kas.de/israel/de/pages/11244/

Kook, Rebecca B. (2002), The logic of democratic exclusion: African Americans in the United States and Palestinian citizens in Israel, Oxford.

Krämer, Gudrun (2008), A history of Palestine: From the Ottoman conquest to the founding of the state of Israel, Princeton.

Krakau, Constanze (2005), Die Rolle der palästinensischen Minderheit im politischen Leben Israels 1976-1996, Münster.

Kuttab, Daoud (1988), A profile of the stonethrowers, Journal of Palestine Studies, vol. 17, no. 3, pp. 14-23.

Lang, Tobias (2013), Die Drusen in Libanon und Israel: Geschichte, Konflikte und Loyalitäten einer religiösen Gemeinschaft in zwei Staaten, Berlin.

Layish, Aharon (1982), Marriage, divorce, and succession in the Druze family: A study based on decisions of Druze arbitrators and religious courts in Israel and the Golan Heights, Leiden.

LeVine, Mark (2007), Nationalism, religion and urban politics in Israel: Struggles over modernity and identity in 'global' Jaffa, in: Daniel Monterescu / Dan Rabinowitz (eds), Mixed towns, trapped communities. Historical narratives, spatial dynamics, gender relations and cultural encounters in PalestinianIsraeli towns, Aldershot, pp. 181-301. 
Litvak Hirsch, Tal / Lazar, Alon (2014), Cultural distance from the internal other: Education and relations with the other as discussed in life stories, in: Forum Qualitative Sozialforschung / Forum: Qualitative Social Research, vol. 15, no. 2, 09.06.2015, http://nbn-resolving.de/urn:nbn:de:0114-fqs140230

Löw, Martina (2012), The intrinsic logic of cities: Towards a new theory on urbanism, Urban Research \& Practice, vol. 5, no. 3, pp. 303-315.

Lustick, Ian S. (1997), Has Israel annexed East Jerusalem?, Middle East Policy, vol. 5, no. 1, pp. 34-45.

Lybarger, Loren D. (2005), Palestinian political identities during the post-Oslo period: A case study of generation effects in a West Bank refugee camp, Social Compass, vol. 52, no. 2, pp. 143-156.

Lybarger, Loren D. (2007a), For church or nation? Islamism, secular-nationalism, and the transformation of Christian identities in Palestine, Journal of the American Academy of Religion, vol. 75, no. 4, pp. 777-813.

Lybarger, Loren D. (2007b), Identity and religion in Palestine: The struggle between Islamism and Secularism in the occupied territories, Princeton / New Jersey.

Mana, Adi / Sagy, Shifra / Srour, Anan / Mjally-Knani, Serene (2012), Perceptions of collective narratives and identity strategies: The case of Palestinian Muslims and Christians in Israel, Mind \& Society, vol. 11, no. 2, pp. 165-182.

Mana, Adi / Sagy, Shifra / Srour, Anan / Mjally-Knani, Serene (2014), On both sides of the fence: Perceptions of collective narratives and identity strategies among Palestinians in Israel and in the West Bank, Mind \& Society, vol. 14 , no. 1 , pp. 57-83.

Mannheim, Karl (1952/ 1928), The Problem of generations, reprinted in: Paul Kecsemeti (ed.), Karl Mannheim: Essays, London, pp. 276-322.

Massad, Joseph (1995), Conceiving the masculine: Gender and Palestinian nationalism, Middle East Journal, vol. 49, no. 3, pp. 467-483.

McGahern, Una (2011), Palestinian Christians in Israel: State attitudes towards non-Muslims in a Jewish State, Abingdon / Oxon / New York.

Mennell, Stephen (1989), Norbert Elias: Civilization and the human self-image, Oxford.

Middle East Monitor (2014), Lieberman renews plan for land swaps and 'transfer' of Palestinians, 15.05.2015, https://www.middleeastmonitor.com/news/ middle-east/15525-lieberman-renews-plan-for-land-swaps-and-transfer-ofpalestinians

Migdal, Joel S. (1980), Palestinian society and politics, Princeton.

Mills, Amy (2007), Gender and mahalle (neighbourhood) space in Istanbul, Gender, Place, and Culture, vol. 14, no. 3, pp. 335-354.

Minority Rights Group International (2009), Palestinians, 20.08.2016, http://minorityrights.org/minorities/palestinians/ 
Monterescu, Daniel (2007), Heteronomy: The cultural logic of urban space and sociality in Jaffa, in: Daniel Monterescu/Dan Rabinowitz (eds), Mixed towns, trapped communities: Historical narratives, spatial dynamics, gender relations and cultural encounters in Palestinian-Israeli towns, Aldershot, pp. 157-178.

Monterescu, Daniel (2009), To buy or not to be: Trespassing the gated community, Public Culture, vol. 21, no. 2, pp. 403-430.

Monterescu, Daniel (2015), Jaffa shared and shattered: Contrived coexistence in Israel / Palestine, Bloomington.

Monterescu, Daniel/ Rabinowitz, Dan (eds) (2007), Mixed towns, trapped communities: Historical narratives, spatial dynamics, gender relations and cultural encounters in Palestinian-Israeli towns, Aldershot.

Morris, Benny (1987), The birth of the Palestinian refugee problem 1947-1949, Cambridge.

Morris, Benny (2004), The birth of the Palestinian refugee problem revisited, Cambridge.

Morris, Benny (2008), 1948: A history the first Arab-Israeli war, New Haven / London.

Müller, Marion/Zifonun, Dariuš (eds) (2010), Ethnowissen, Wiesbaden.

Neslen, Arthur (2011), In your eyes a sandstorm: Ways of being Palestinian, Berkeley.

Newman, Marissa (2014), In first, Christian Arabs recognized as own minority, in: The Times of Israel, 26.05.2014, http://www.timesofisrael.com/in-firstchristian-arabs-recognized-as-own-minority/

Norman, Julie M. (2010), The second Palestinian Intifada: Civil resistance, London / New York.

Palestine Royal Commission (1937), Report: Presented by the Secretary of State for the Colonies to parliament by command of His Majesty, July, 1937, London.

Palestinian Central Bureau of Statistics (PCBS) (1997), Palestinian population in the Palestinian territory by locality and religion, unpublished report.

Palestinian Central Bureau of Statistics (PCBS) (2007), Palestinian population in the Palestinian territory by locality and religion, unpublished report.

Palestinian Central Bureau of Statistics (PCBS) (2011), On the eve of the international day of refugees, 13.06.2014, http://www.pcbs.gov.ps/Portals/_pcbs/ PressRelease/Refugee2011E.pdf

Palestinian Central Bureau of Statistics (PCBS) (2012), Census final results population Report, 13.06.2014, http://pcbs.gov.ps/Portals/_PCBS/Downloads/book1853.pdf

Parsons, Laila (2008), The Druze and the birth of Israel, in: Eugene L. Rogan/ Avi Shlaim (eds), The war for Palestine: Rewriting the history of 1948, pp. 60-78. 
Paukstat, Adrian (2015), Israels Kommunisten, der Konflikt in Syrien und die Frage des Internationalismus - Vergangenheit und Gegenwart, in: Alsharq, 10.04.2015, http://www.alsharq.de/2013/mashreq/syrien/israels-kommunisten-der-konflikt-in-syrien-und-die-frage-des-internationalismus-vergangenheit-und-gegenwart/

Payes, Shany (2005), Palestinian NGOs in Israel: The politics of civil society, London/New York.

Pearlman, Wendy (2011), Violence, nonviolence, and the Palestinian national movement, Cambridge.

Peled, Yoav (2007), Citizenship betrayed: Israel's emerging immigration and citizenship regime, Theoretical Inquiries in Law, vol. 8, no. 2, pp. 603-628.

Pessate-Schubert, Anat (2003), Changing from the margins: Bedouin women and higher education in Israel, Women's Studies International Forum, vol. 26, no. 4, pp. 285-298.

Peteet, Julie (1994), Male gender and rituals of resistance in the Palestinian Intifada: A cultural politics of violence, American Ethnologist, vol. 21, no. 1, pp. 31-49.

Qleibo, Ali (2011), The Hebronite spirit of enterprise, This Week in Palestine, vol. 164, pp. 12-18.

Radenbach, Niklas / Rosenthal, Gabriele (2012), Das Vergangene ist auch Gegenwart, das Gesellschaftliche ist auch individuell: Zur Notwendigkeit der Analyse biographischer und historischer ,Rahmendaten', Sozialer Sinn, vol. 13, no. 1, pp. 3-37.

Randa, Mahmut (2008), Die Drusen: Geschichte und Identität einer Minderheit im Zeitalter des Internets, Tübingen.

Riemann, Gerhard/ Schütze, Fritz (1991), "Trajectory" as a basic theoretical concept for analyzing suffering and disorderly social process, in: David R. Maines (ed.), Social organization and social process. Essays in honor of Anselm Strauss, New York, pp. 333-357.

Robinson, Glenn (1997), Building a Palestinian state: The incomplete revolution, Bloomington and Indianapolis.

Romann, Michael/ Weingrod, Alex (1991), Living together separately: Arabs and Jews in contemporary Jerusalem, Princeton.

Rosenfeld, Maya (2002), Power structure, agency, and family in a Palestinian refugee camp, International Journal of Middle East Studies, vol. 34, no. 3, pp. 519-551.

Rosenfeld, Maya (2004), Confronting the occupation: Work, education and political acitivism of Palestinian families in a refugee camp, Stanford.

Rosenthal, Gabriele (1995), Erlebte und erzählte Lebensgeschichte: Gestalt und Struktur biographischer Selbstbeschreibungen, Frankfurt/M. 
Rosenthal, Gabriele (1997), Zur interaktionellen Konstitution von Generationen: Generationenabfolgen in Familien von 1890-1970 in Deutschland, in: Jürgen Mansel / Gabriele Rosenthal/ Angelika Tölke (eds), GenerationenBeziehungen, Austausch und Tradierung, Opladen, pp. 57-73.

Rosenthal, Gabriele (2000), Historische und familiale Generationsabfolgen, in: Martin Kohli / Marc Szydlic (eds), Generationen in Familie und Gesellschaft, Opladen, pp. 162-279.

Rosenthal, Gabriele (2010), Zur Interdependenz von kollektivem Gedächtnis und Erinnerungspraxis: Kultursoziologie aus biographietheoretischer Perspektive, in: Monika Wohlrab-Sahr (ed.), Kultursoziologie: Paradigmen, Methoden, Fragestellungen, Wiesbaden, pp. 151-175

Rosenthal, Gabriele (2011), Interpretative Sozialforschung, updated and expanded edition, Weinheim/München.

Rosenthal, Gabriele (2012), Methodische Herausforderungen interkultureller Studien: Mehrfach verschränkte Figurationen von Etablierten und Außenseitern im Westjordanland, ZQF Schwerpunktheft ,Kulturvergleichende qualitative Forschung', vol. 13, no. 1-2, pp. 125-150.

Rosenthal, Gabriele (2016), The social construction of individual and collective memory, in: Gerd Sebald / Jatin Wagle (eds), Theorizing social memories: Concepts, temporality, functions, London, pp. 32-55.

Rouhana, Nadim N. (1991), Palestinians in Israel: Responses to the uprising, in: Rex Brynen (ed.), Echoes of the Intifada: Regional repercussions of the Palestinian-Israeli conflict, Boulder, p. 98 and pp. 103-105.

Rouhana, Nadim N. / Sultany, Nimer (2003), Redrawing the boundaries of citizenship: Israel's new hegemony, Journal of Palestine Studies, vol. 33, no. 1, pp. 5-22.

Rudorff, Andrea (2005), Breslau-Dürrgoy, in: Wolfgang Benz / Barbara Distel / Angelika Königseder (eds), Der Ort des Terrors: Geschichte der nationalsozialistischen Konzentrationslager, München.

Ruhne, Renate (2010), Etablierte und Außenseiter: (Räumliche) Potentiale eines figurationssoziologischen Modells zur Analyse sozialer Exklusionen, in: Heike Herrmann (ed.), RaumErleben: Zur Wahrnehmung des Raumes in Wissenschaft und Praxis, Opladen / Farmington Hills, pp. 123-146.

Sabella, Bernard (1994), Socio-economic characteristics and the challenges to Palestinian Christians in the Holy Land, in: Michael Prior/William Taylor (eds), Christians in the Holy Land, London, pp. 31-44.

Sabra, George (2006), Two ways of being a Christian in the Muslim context of the Middle East, Islam and Christian-Muslim Relations, vol. 17, no. 1, pp. 43-53.

Sagy, Shifra / Ayalon, Ariel / Diab, Khansaa (2011), Perceptions of narrative of the 'other' among Arab and Jewish adolescents in Israel: Between peace talks and violent events, Intercultural Education, vol. 22, no. 2, pp. 191-206. 
Salamanca, Christa (2004), A new old Damascus: Authenticity and distinction in urban Syria, Bloomington / Indianapolis.

Sayigh, Rosemary (2006), Back to the center: Post-Oslo revival of the refugee issue, in: Joel Beinin / Rebecca Stein (eds), The struggle for sovereignty. Palestine and Israel 1993-2005, Standford, pp. 130-139.

Schnur, Olaf (ed.) (2008), Quartiersforschung: Zwischen Theorie und Praxis, Wiesbaden.

Schutz, Alfred/Luckmann, Thomas (1973), The structures of the life-world, Vol. 1, (translated by Richard M. Zaner and Tristam Engelhardt), Evanston.

Schütze, Fritz (1983), Biographieforschung und narratives Interview, Neue Praxis, vol. 13, no. 3, pp. 283-293.

Schütze, Fritz (2006), Verlaufskurven des Erleidens als Forschungsgegenstand der interpretativen Soziologie, in: Heinz-Hermann Krüger/Winfried Marotzki (eds), Handbuch erziehungswissenschaftliche Biographieforschung, Wiesbaden, pp. 205-237.

Schütze, Fritz (2007), Biography analysis on the empirical base of autobiographical narratives: How to analyse autobiographical narrative interviews, Part II, in: INVITE_Biographical counselling in rehabilitative vocational training: Further education curriculum, Module B.2.2, 31.07.2016, http://www.unimagdeburg.de/zsm/projekt/biographical/1/B2.2.pdf

Schütze, Fritz (2014), Autobiographical accounts of war experiences: An outline for the analysis of topically focused autobiographical texts. Using the example of the "Robert Rasmus" account in Studs Terkel's book "The good war", Qualitative Sociology Review, vol. 10, no. 1, pp. 224-283.

Segev, Tom (2000), One Palestine, complete: Jews and Arabs under the British Mandate (transl. by Haim Watzman), New York.

Segev, Tom (2007), 1967. Israel, the war, and the year that transformed the Middle East (transl. by Jessica Cohen), New York.

Seliger, Kurt (1976), Rakach und Maki: Die zwei kommunistischen Parteien Israels, Osteuropa, vol. 26, no. 4, pp. 251-253.

Šenkyr, Jan (1998), Die Situation der israelischen Araber: Eine Herausforderung für den jüdischen Staat?, in: KAS-Auslandsinformationen, 16.05.2015, http://www.kas.de/wf/doc/kas_10548-544-1-30.pdf

Shaheen, Naseeb (2005), A pictorial history of Ramallah, part II, Beirut.

Shehadeh, Haseeb (1993), Christian Arabs in the Middle East, in: Heikki Palva/Knut S. Vikør (eds), The Middle East: Unity and diversity. Papers from the second Nordic conference on Middle Eastern Studies, Copenhagen, 22.-25. October 1992, Kopenhagen, pp. 71-83.

Shenhav, Yehouda (2006), The Arab Jews: A postcolonial reading of nationalism, religion and ethnicity, Stanford.

Shibli, Adania (2006), Al-Manara Square: Monumental architecture and power, Jerusalem Quarterly, vol. 26, pp. 52-64. 
Shohat, Ella (1999), The Invention of the Mizrahim, Journal of Palestine Studies, vol. 29, no. 1, pp. 5-20.

Singerman, Diane (2011), The negotiation of waithood: The political economy of delayed marriage in Egypt, in: Samir Khalaf/Roseanne Khalaf (eds), Arab youth: Social mobilisation in times of risk, London, pp. 67-78.

Smooha, Sammy (1998), Arabs and Jews in Israel, Boulder.

Süddeutsche Zeitung (2010), Mahmud Abbas: Palästinenser-Regierung erkennt Israel an, 24.05.2015, http://sz.de/1.843163

Tamari, Salim (2000), Jerusalem's Ottoman modernity: The times and lives of Wasif Jawhariyyeh, Jerusalem Quarterly, vol. 9, pp. 5-27.

Tamari, Salim (2011), Palestinian refugees, displaced persons, and the negotiating strategy, Forced Migration and Refugee Unit, Ibrahim Abu-Lughod Institute of International Studies, Birzeit University, 30.08.2016, http://dx.doi. org/10.2139/ssrn.1794762

Tamcke, Martin (2008), Christen in der islamischen Welt: Von Mohammed bis zur Gegenwart, München.

Taraki, Lisa (2008), Urban modernity on the periphery: A new middle class reinvents the Palestinian city, Social Text, vol. 26, no. 2, pp. 61-81.

Tepecik, Ebru (2010), Bildungserfolge mit Migrationshintergrund: Biographien bildungserfolgreicher MigrantInnen türkischer Herkunft, Wiesbaden.

Tessler, Mark/ Grant, Audra (1998), Israel's Arab Citizens: The continuing struggle, The ANNALS of the American Academy of Political and Social Science, vol. 555, no. 1, pp. 97-113.

Tolan, Sandy (2007), The lemon tree: The true story of a friendship that survives four decades of the world's bitterest conflict, London.

Treibel, Annette (1993), Transformationen des Wir-Gefühls, in: Reinhard Blomert / Helmut Kuzmics / Annette Treibel (eds), Transformationen des WirGefühls, Frankfurt/M., pp. 313-345.

Tsimhoni, Daphne (1993), Christian communities in Jerusalem and the West Bank since 1948, London.

Turki, Fawaz (1988), Soul in exile, New York.

UN (United Nations-Report; Office for the Coordination of Humanitarian Affairs occupied Palestinian territory) (2011), East Jerusalem, key humanitarian affairs, 30.04.2015, http://www.ochaopt.org/documents/ocha_opt_jerusalem_report_2011_03_23_web_english.pdf

UNRWA (2011), Palestine refugees in the West Bank: Socio-economic trends and long-term opportunities, 21.05.2015, www.unrwa.org/ userfiles/2011110145541.pdf

Usher, Graham (1996), The politics of internal security: The PA's new intelligence services, Journal of Palestine Studies, vol. 25, no. 2, pp. 21-34.

Wacquant, Loïc J. D. (2013), Symbolic power and group-making: On Pierre Bourdieu's reframing of class, Journal of Classical Sociology, vol. 13, no. 2, pp. 274-291. 
Werner, Christoph (2001), Beduinen, in: Ralf Elger / Friederike Stolleis (eds), Kleines Islam-Lexikon: Geschichte - Alltag - Kultur. München, 22.05.2015, http://www.bpb.de/nachschlagen/lexika/islam-lexikon/21350/ beduinen

Whitaker, Brian (2006), 'People think it's a mental illness', in: The Guardian, 12.10.2012, http://www.guardian.co.uk/world/2006/jun/13/gayrights. lifeandhealth

Witte, Nicole (2014), Zum Fall des Falles: Fallrekonstruktionen in der interpretativen Sozialforschung: Dialogarbeit als biographische Arbeit: Der Fall der jüdischen Israeli Ella, in: Düwell, Susanne/ Pethes, Nicolas (eds), Fall - Fallgeschichte - Fallstudie: Theorie und Geschichte einer Wissensform. Frankfurt / M. / New York, pp. 195-213.

Worm, Arne / Hinrichsen, Hendrik (2014), How does participation in resistance interact with the construction of family relations? West Bank Palestinians between the First Intifada and the 'post-Oslo' period, unpublished paper, ISA World Congress of Sociology, Yokohama, 18.07.2014.

Wundrak, Rixta (2010), Die chinesische Community in Bukarest: Eine rekonstruktive, diskursanalytische Fallstudie über Immigration und Transnationalismus, Wiesbaden.

Wundrak, Rixta (2012), Erzählungen aus Jaffa: Narrationstheorie und Triangulation in kulturvergleichenden Analysen, Zeitschrift für qualitative Forschung (ZQF), vol. 13, no. 1-2, pp. 151-172.

Wundrak, Rixta (2013), Geschichten über versus Geschichten von?! Eine triangulierende Diskursanalyse am Beispiel der chinesischen Community in Bukarest, in: Reiner Keller/Inga Truschkat (eds), Methodologie und Praxis der wissenssoziologischen Diskursanalyse, Wiesbaden, pp. 249-279.

Yiftachel, Oren (2006), Ethnocracy: Land and identity politics in Israel/ Palestine, Philadelphia.

Yiftachel, Oren (2011), Ghetto citizenship: Palestinian Arabs in Israel, in: Nadim N. Rouhana/Areej Sabbagh-Khoury (eds), Palestine and Israel: Key terms, Mada Center for Applied Research, Haifa, pp. 177-208.

Yuval-Davis, Nira (1994), Women, ethnicity and empowerment, Feminism \& Psychology, vol. 4, no. 1, pp. 179-197. 
alestinians frequently present a harmonizing and homogenizing we-image of their own national we-group, as a way of counteracting Israeli attempts to sow divisions among them, whether through Israeli politics or through the dominant public discourse in Israel. However, a closer look reveals the fragility of this homogenizing we-image which masks a variety of internal tensions and conflicts.

By applying methods and concepts from biographical research and figurational sociology, the articles in this volume offer an analysis of the Middle East conflict that goes beyond the polar opposition between "Israelis" and "Palestinians". On the basis of case studies from five urban regions in Palestine and Israel (Bethlehem, Ramallah, East Jerusalem, Haifa and Jaffa), the authors explore the importance of belonging, collective self-images and different forms of social differentiation within Palestinian communities. For each region this is bound up with an analysis of the relevant social and socio-political contexts, and family and life histories. The analysis of (locally) different figurations means focusing on the perspective of Palestinians as members of different religious, socio-economic, political or generational groupings and local group constellations - for instance between Christians and Muslims or between long-time residents and refugees.

The following scholars have contributed to this volume: Ahmed Albaba, Johannes Becker, Hendrik Hinrichsen, Gabriele Rosenthal, Nicole Witte, Arne Worm and Rixta Wundrak.

Gabriele Rosenthal is a sociologist and professor of Qualitative Methodology at the Center of Methods in Social Sciences, University of Göttingen. Her major research focus is the intergenerational impact of collective and familial history on biographical structures and actional patterns of individuals and family systems. Her current research deals with ethnicity, ethno-political conflicts and the social construction of borders. She is the author and editor of numerous books, including The Holocaust in Three Generations (2009), Interpretative Sozialforschung (2011) and, together with Artur Bogner, Ethnicity, Belonging and Biography (2009). 